JOHN FERNEY ALVAREZ ROSARIO

ESTUDO DA INTEGRIDADE SUPERFICIAL E SEU EFEITO NA FADIGA DE CONTATO DE UM AÇO FERRAMENTA

Tese apresentada à Escola Politécnica
da Universidade de São Paulo para
obtenção do título de Doutor em
Engenharia Mecânica
Área de concentração: Engenharia
Mecânica de Projeto de Fabricação

São Paulo 
JOHN FERNEY ALVAREZ ROSARIO

\section{ESTUDO DA INTEGRIDADE SUPERFICIAL E SEU EFEITO NA FADIGA DE CONTATO DE UM AÇO FERRAMENTA}

Tese apresentada à Escola Politécnica da Universidade de São Paulo para obtenção do título de Doutor em Engenharia Mecânica

Área de concentração: Engenharia Mecânica de Projeto de Fabricação

Orientadora: Professora Dra. Izabel Fernanda Machado

São Paulo 
Este exemplar foi revisado e alterado em relação à versão original, sob responsabilidade única do autor e com a anuência de seu orientador.

São Paulo, de novembro de 2011.

Assinatura do autor

Assinatura do orientador

FICHA CATALOGRÁFICA

Alvarez Rosário, John Ferney

Estudo da integridade superficial e seu efeito na fadiga de contato de um aço ferramenta / J.F. Alvarez Rosario. -- ed.rev. -São Paulo, 2011.

$154 \mathrm{p}$.

Tese (Doutorado) - Escola Politécnica da Universidade de São Paulo. Departamento de Engenharia Mecânica.

1. Integridade estrutural 2. Fadiga de contato 3 . Torneamento 4. Retificação I. Universidade de São Paulo. Escola Politécnica. Departamento de Engenharia Mecânica II. t. 
A mis sobrinos.

“...Son la prolongación de la existencia”

A mis hermamos.

Por el apoyo incondicional

A mi madre, Jiorman.

Por su amor y ejemplo de vida

A mi padre, Gonzalo.

Porque aún está presente en mi vida, en mis logros y derrotas 


\section{AGRADECIMENTOS}

À senhora orientadora, Profa. Dra. Izabel Fernanda Machado, pela sua amizade, apoio, confiança e pelas contribuições durante a realização deste trabalho.

Ao senhor, Prof. Dr. Amilton Sinatora, pelo apoio e confiança depositada em mim, ao me permitir fazer parte da equipe do Laboratório de Fenômenos de Superficies - LFS.

Ao senhor, Prof. Dr. Roberto Martins de Souza, pelo seu apoio e amizade.

Ao Conselho Nacional de Desenvolvimento Científico e Tecnológico - CNPq, pela concessão da bolsa e pelo apoio financeiro, o que possibilitou a minha manutenção no Brasil e a realização dos meus estudos de Doutorado.

Ao Laboratório de Dinâmica e Instrumentação - Ladin, na figura do senhor, Prof. Dr. Linilson Padovese Rodrigues, pela disponibilização da sua equipe de trabalho e instalações para realizar a caracterização magnética das amostras.

Ao Departamento de Caracterização de Materiais do Instituto de Pesquisas Energéticas e Nucleares - IPEN, na figura do senhor, Prof. Dr. Nelson Batista de Lima, pela disponibilização da sua equipe de trabalho e instalações para realizar as medições de tensão residual.

Ao laboratório de microscopia eletrônica e de força atômica - LabMicro, na figura do senhor, Prof. Dr. André P. Tschiptschin, pela disponibilização da sua equipe de trabalho e instalações para realizar a caracterização das amostras no microscópio eletrônico de varredura.

À empresa BODYCOTE BRASIMET, na figura do senhor, M.Sc. Eng. Carlos Humberto Sartori, pela realização dos tratamentos térmicos dos corpos de prova.

Ao senhor, Prof. Dr. Rodrigo Lima Stoeterau, pela colaboração na realização dos ensaios de torneamento duro. 
Ao senhor, Prof. Dr. Freddy Armando Franco Grijalba, pela colaboração na realização da caracterização magnética das amostras.

À senhora Silene Carneiro e ao senhor Sidney Carneiro, pela colaboração e amizade.

Aos amigos do Laboratório de Fenômenos de Superficies, pela amizade. Especialmente ao Leandro e ao Francisco, pela colaboração na caracterização microestrutural e avaliação das propriedades mecânicas.

À minha namorada, Ana Maria Zetty, pela sua colaboração, amor, apoio e compreensão especialmente durante esta reta final de doutorado.

Aos amigos com os quais partilhei muitos momentos aqui no Brasil, pela alegria e pela força nos momentos dificeis: Fernanda N., Carol N., Laura A., Tania Y., Adriana S., Martinha, Montserrat N., Viviana V., Anderson A., Lina R, Lenin V, Rubén S.

Aos amigos da Maloka, especialmente ao Felipe Bernardes e ao Eduardo Fontes. Obrigado por todos esses momentos de alegria inesquecíveis, que tanto bem fizeram quando a saudade da minha casa apertava.

Aos amigos da Universidade de Ibagué que vieram para o Brasil estudar ou trabalhar, e com os quais partilhei a experiência de viver longe de casa durante estes anos todos: Leonardo V., Eduardo P., John Alexander C., Wilfredo M., Ediguer F., Carlos A., Ricardo S., Freddy F., Adriana G., Mario G., Alexander A., Germán R., Yovanni A. e John Carlos Q. 


\section{RESUMO}

Os processos de manufatura, bem como os parâmetros de processamento utilizados produzem diferentes resultados com relação à integridade de uma superficie. Estas alterações se refletem em mudança das propriedades da superficie, as quais podem influenciar o desempenho dos componentes. $O$ presente trabalho estuda o efeito da integridade superficial gerada pelos processos de torneamento e retificação na resistência à fadiga de contato do aço ferramenta AISI H13. A influência do processo de usinagem e dos parâmetros de corte no estado da superficie e subsuperficie, e como estas características afetam o desempenho são determinados. Foram geradas quatro condições diferentes para as superficies torneadas mediante a combinação de parâmetros de corte. As superficies retificadas foram produzidas empregando as mesmas condições de retificação, com isso, obteve-se a mesma condição para todos os corpos de prova ensaiados. As características medidas da integridade superficial foram: os parâmetros de rugosidade, tensões residuais, microdureza Vickers da seção transversal e ruído magnético de Barkhausen. Foi determinado o desempenho das superficies por fadiga de contato de rolamento, num equipamento na configuração esfera-plano. Os corpos de prova foram anéis de AISI H13 temperados e revenidos. A totalidade dos ensaios foi realizada até a ocorrência de lascamento ("Spalling”). Os ensaios foram realizados com lubrificação e com uma máxima pressão de contato de Hertz de 3,6 GPa. Foi observado que dependendo do nível de integridade superficial induzido pelo processo de usinagem e dos parâmetros selecionados, o desempenho da superficie em fadiga de contato de rolamento foi afetado. Contudo, as melhores condições de desempenho foram dos materiais retificados, e para os materiais torneados o melhor desempenho foi obtido com maiores velocidades de corte.

Palavras-chave: Integridade superficial. Fadiga de contato de rolamento. Torneamento. Retificação. 


\begin{abstract}
The manufacturing process and the machining parameters selected lead to different integrity of the surface, and these characteristics will influence the functional performance of the components. This study evaluated and analyzed the effect of surface integrity on the contact fatigue resistance of the $\mathrm{H} 13$ hot work tool steel. The surfaces were manufactured by hard turning and grinding process. Therefore, the influences of the machining process and the cutting parameters on the surface and on the subsurface layer were studied. Four different turned surfaces were obtained as a combination of cutting parameters selected for the tests. On the other hand, grinding surfaces were generated using the same machining conditions. The characteristics of surface integrity evaluated were: surface roughness parameters, residual stresses, Barkhausen noise, and microhardness of surface and sub-layers in transverse section. It was also evaluated the performance of the samples by rolling contact fatigue tests conducted in a ball on washer machine. The specimens were rings made of AISI H13 steel, which were quenched and tempered. All tests were performed until the occurrence of spalling. The tests were carried out under lubrication and with a maximum Hertz contact pressure of $3.6 \mathrm{GPa}$. Monitoring and failure detection were carried out by analyzing the changes in the vibration signal of the test machine sensors. It was observed that the performance of the surface in rolling contact fatigue resistance was affected by the level of the surface integrity, related to the machining process and the machining parameters.
\end{abstract}

Keywords: Surface integrity. Rolling contact fatigue. Turning. Grinding. 


\section{LISTA DE FIGURAS}

Figura 1.1 - Representação esquemática dos elementos superficiais e subsuperficiais que definem a tecnologia das superficies

Figura 1.2 - Representação esquemática das direções dos movimentos que geram a remoção do cavaco para o processo de torneamento

27

Figura 1.3 - Representação esquemática da seção transversal de uma peça usinada. Ilustram-se as camadas geradas como resultado do processo de usinagem (GRIFFITHS, 2001)

28

Figura 1.4. Mudanças da camada superficial observadas na seção transversal de um ferro fundido mesclado após torneamento ( $\mathrm{Vc}=60 \mathrm{~m} / \mathrm{min} ; \mathrm{f}=0,1 \mathrm{~mm} / \mathrm{rot}$ ). Aumento de 6500X. Análise de elétrons retro-espalhados. Ataque com Nital 3\%

Figura 1.5 - Representação esquemática das regiões geradoras de calor durante o processo de corte

Figura 1.6 - Variação da distribuição de energia de corte com a velocidade de corte e distribuição da temperatura para uma ferramenta de metal duro.

Figura 1.7 - Parcela de geração de calor e distribuição de temperaturas no processo de torneamento de um aço (vc $=60 \mathrm{~m} / \mathrm{min}$ ).

32

Figura 1.8 - Representação esquemática do mecanismo de geração de tensão residual trativa em matérias dúcteis.

Figura 1.9 - Avaliação da tensão residual após o torneamento de um ferro fundido nodular, a dois níveis diferentes de intensidade após torneamento: a) $\mathrm{V}=4 \mathrm{~m} / \mathrm{min}$; b) $10 \mathrm{~m} / \mathrm{min}$. VB é o desgaste de flanco da ferramenta, f é o avanço, a tensão residual paralela à superfície é $\sigma\left(\mathrm{N} / \mathrm{mm}^{2}\right)$.

Figura 1.10 - Vida da superfície em função do Índice de Desempenho da Superfície (IDS) de amostras de aço AISI H13 geradas mediante fresamento HSM e submetidas a desgaste por deslizamento. $\left(\mathrm{v}_{\mathrm{c}}=\right.$ velocidade de corte $(\mathrm{mm} / \mathrm{min}) ; \mathrm{a}_{\mathrm{p}}=$ profundidade de corte $(\mathrm{mm}) ; a_{e}=$ penetração de trabalho $(\mathrm{mm}) ; \mathrm{f}_{\mathrm{z}}=$ avanço por dente $\left.(\mathrm{mm})\right)$.

36

Figura 1.11 - Esquema representativo das três (3) etapas para a formação do cavaco no processo de retificação

Figura 1.12 - Efeito da intensidade no processo de retificação na resistência à fadiga de alto ciclo de um aço AISI 4140.

Figura 1.13 - Efeito de diferentes processos de acabamento superficial no limite de resistência à fadiga de um ferro fundido.

Figura 1.14 - Representação esquemática da distribuição de tensões de cisalhamento abaixo do contato nas situações de rolamento puro, deslizamento e rolamento com deslizamento.

Figura 1.15 - Fatores que afetam a vida em fadiga de contato de rolamento.

Figura 1.16 - Imagens da seção transversal da superfície do aço AISI 52100 a) retificado; b) torneado. Imagens obtidas com microscópio óptico e microestrutura revelada com nital ao $2 \%$

Figura 1.17 - Imagens da seção transversal mostrando o defeito e o padrão de trinca para a condição a) retificado; b) torneado. Imagens obtidas com microscópio eletrônico de varredura revelada com nital ao $2 \%$

Figura 1.18 - Comparação do desempenho em fadiga de contato de rolamento para superficies obtidas por torneamento duro (TD) e retificação (R) 
Figura 1.19 - Representação esquemática das caracteristicas de uma superficie onde são ilustradas as diferentes ordens de grandeza ao se avaliar a topografia.

Figura 1.20 - Representação esquemática da: a) superficie geométrica; b) superficie real; c) superficie efetiva.

50

Figura 1.21-Princípio de funcionamento do perfilômetro mecânico com apalpador.

Figura 1.22 - Símbolos usados para representar as marcas da ferramenta na designação da textura da superficie segundo as normas ANSI Y14.36 de 1978 [ANSI, 1978], e ISO 1302 de 2001 [ISO, 2001].

Figura 1.23 - Imperfeições da superficie definidas pela norma ISO 8785 (1998) em superficies manufaturadas relevantes durante o estudo da integridade superficial.

Figura 1.24 - Imagens da camada branca em superficies manufaturadas obtidas da seção transversal mediante o emprego das técnicas de: a) microscopia; b) microscopia eletrônica de varredura.

55

Figura 1.25 - Perfil de dureza na escala microscópica avaliada na secção transversal de um componente de aço AISI 4340, submetido ao processo de retificação mediante seleção de condições de corte severas e leves (moderadas)

Figura 1.26 - Ruído de Barkhausen e curva de histerese associada

Figura 1.27 - Sistema de medição: a) Sonda para medição do RMB; b) representação do sinal do RMB no domino do tempo.

60

Figura 2.1 - Esquema representativo dos pontos de contato entre superficies a) sem contato com o carregamento inicial P; b) contato após a aplicação de carregamento.

Figura 2.2 - Esquema representativo de contatos conformes e não-conformes.

Figura 2.3 - Geometria de contato de dois corpos elásticos com superficies: a) convexas. b) convexa e côncava. c) convexa e plana. $R_{(\mathbf{a}, \mathbf{b}) \mathbf{x}}$ é o raio de curvatura do corpo ( $\mathrm{a}$ ou b) com respeito ao eixo $\mathrm{x}, \mathrm{R}_{(\mathrm{a}, \mathbf{b}) \mathrm{y}}$ é o raio de curvatura do corpo (a ou b) com respeito ao eixo y, w é a carga aplicada, a é o raio de elipse no eixo $\mathrm{x}$, b é o raio da elipse no eixo y.

66

Figura 2.4 - Curva de Stribeck em função do parâmetro $\lambda$. Onde $\mu$ é ocoeficiente de atrito, HD é lubrificação hidrodinâmica, EHL é lubrificação elastohidrodinâmica.

Figura 2.5 - Exemplos de contatos não conformes: a) Dente de uma engrenagem, b) Conjunto came - seguidor, c) esfera na pista de rolamento.

Figura 2.6 - (a) Distribuição esquemática de pressão num contato elastohidrodinâmico; (b) perfil de deformação mostrando a espessura de filme central $\left(h_{c}\right)$ e a espessura mínima de filme $\left(\mathrm{h}_{\mathrm{o}}\right)$.

73

Figura 3.1 - Representação esquemática das etapas que compõem o procedimento experimental para a realização de ensaios de fadiga de contato em superfícies usinadas.

Figura 3.2 - Torno CNC de precisão da marca "Schaublin Machines S.A", modelo 225TM-CNC utilizado para a geração das superficies torneadas.

Figura 3.3 - Difratômetro de raios -X Rint 2000 do fabricante "Rigaku" utilizado para a medição da tensão residual.

Figura 3.4 - Sistema para medição de propriedades magnéticas desenvolvido no Laboratório de Dinâmica e Instrumentação (LADIN) da Universidade de São Paulo. 
Figura 3.5 - Principais componentes do equipamento de fadiga de contato de rolamento desenvolvido no Laboratório de Fenômenos de Superficies (LFS) da Universidade de São Paulo.

Figura 3.6 - Esquema representativo dos detalhes construtivos do equipamento de fadiga de contato de rolamento

80

Figura 4.1 - Representação esquemática do corpo de prova de fadiga de contato (todas as dimensões em $\mathrm{mm}$ ).

82

Figura 4.2 - Representação esquemática dos pontos (P1, P2) e do sentido de medição (m1, m2) da tensão residual na superficie das amostras.

Figura 4.3 Representação esquemática dos pontos de medição (P1, P2, P3, P4) e do sentido de medição do ruído magnético de Barkhausen paralelo às marcas da ferramenta $(\mathrm{m} 1)$.

Figura 4.4 - Representação esquemática do diagrama eletro-eletrônico dos componentes do quadro de controle instalado no sistema instrumentado do equipamento de fadiga de contato de rolamento.

88

Figura 5.1 - Imagem da microestrutura do corpo de prova (anéis de aço AISI H13) onde se mostra a matriz martensítica fina. Imagem obtida em microscópio óptico (MO). Ataque com Vilella e aumento de 1000 vezes.

Figura 5.2 - Imagem da microestrutura do corpo de prova (anéis de aço AISI H13) onde se mostra a presença de carbonetos refinados dispersos na matriz metálica. Imagem obtida em microscópio eletrônico de varredura (MEV). Ataque com Vilella e aumento de 3500 vezes. Análise de elétrons secundários.

90

Figura 5.3 - Imagem da microestrutura do contra-corpo (esferas de aço ABNT 52100) onde se mostra a presença de carbonetos espalhados na matriz martensítica. Imagem obtida em microscópio óptico (MO). Ataque com vilella e aumento de 1000 vezes.

90

Figura 5.4 - Perfil de rugosidade da superficie do corpo de prova na condição S1 após torneamento com velocidade de corte $(\mathrm{Vc})$ de $60 \mathrm{~m} / \mathrm{min}$, e avanço (f) de 0,05 $\mathrm{mm} /$ rot.

Figura 5.5 - Perfil de rugosidade da superficie do corpo de prova na condição S2 após torneamento com velocidade de corte (Vc) de $60 \mathrm{~m} / \mathrm{min}$, e avanço (f) de 0,1 $\mathrm{mm} /$ rot.

Figura 5.6 - Perfil de rugosidade da superficie do corpo de prova S3 após torneamento com velocidade de corte (Vc) de $120 \mathrm{~m} / \mathrm{min}$, e avanço (f) de 0,05 mm/rot.

Figura 5.7 - Perfil de rugosidade da superficie do corpo de prova na condição S4 após torneamento com velocidade de corte (Vc) de $120 \mathrm{~m} / \mathrm{min}$, e avanço (f) de 0,1 $\mathrm{mm} /$ rot.

Figura 5.8 - Perfil de rugosidade da superficie do corpo de prova na condição SR após retificação com velocidade de corte $\left(\mathrm{v}_{\mathrm{c}}\right)$ de $54 \mathrm{~m} / \mathrm{s}$, avanço $\left(\mathrm{v}_{\mathrm{p}}\right) 4 \mathrm{~m} / \mathrm{min}$ e profundidade de corte $\left(a_{e}\right)$ 0,03 $\mathrm{mm}$.

93

Figura 5.9 - Influencia dos parâmetros de corte no valor médio dos parâmetros de rugosidade ( $\mathrm{Ra}, \mathrm{Rq}, \mathrm{Rsm})$ para as superficies geradas.

Figura 5.10 - Imagem da superficie do corpo de prova na condição $\mathrm{S} 1$ após torneamento com velocidade de corte (Vc) de $60 \mathrm{~m} / \mathrm{min}$, e avanço (f) de $0,05 \mathrm{~mm} / \mathrm{rot}$. Imagens obtidas em MEV com aumento de: a) 100x; b) 1000x.

Figura 5.11-Imagem da superficie do corpo de prova na condição S2 após torneamento com velocidade de corte (Vc) de $60 \mathrm{~m} / \mathrm{min}$, e avanço (f) de $0,1 \mathrm{~mm} / \mathrm{rot}$. Imagens obtidas em MEV com aumento de: a) 100x; b) 1000x. 
Figura 5.12 - Imagem da superficie do corpo de prova na condição S3 após torneamento com velocidade de corte (Vc) de $120 \mathrm{~m} / \mathrm{min}$, e avanço (f) de 0,05 $\mathrm{mm} / \mathrm{rot}$. Imagens obtidas em MEV com aumento de: a) 100x; b) 1000x.

98

Figura 5.13 - Imagem da superficie do corpo de prova S4 após torneamento com velocidade de corte (Vc) de $120 \mathrm{~m} / \mathrm{min}$, e avanço (f) de 0,1 $\mathrm{mm} /$ rot. Imagens obtidas em MEV com aumento de: a) 100x; b) 1000x.

99

Figura 5.14 - Imagem da superficie do corpo de prova SR após retificação com velocidade de corte ( $\mathrm{Vc}$ ) de $\mathrm{m} / \mathrm{min}$, e avanço (f) de $0,1 \mathrm{~mm} /$ rot. Imagens obtidas em MO com aumento de: a) 50x; b) 1000x.

100

Figura 5.15 - Esquema representativo do corte das amostras para a análise da camada da superficie: a) num plano paralelo ao sentido de avanço da ferramenta; b) num plano perpendicular ao sentido de avanço da ferramenta.

101

Figura 5.16 - Imagem da subsuperfície do corpo de prova na condição S1. Corte transversal no plano a) perpendicular ao sentido de avanço da ferramenta; b) paralelo ao sentido de avanço da ferramenta. Após torneamento com velocidade de corte (Vc) de $60 \mathrm{~m} / \mathrm{min}$, e avanço (f) de $0,05 \mathrm{~mm} /$ rot. Imagens obtidas em MO com aumento de 1000x. Ataque com Villela.

102

Figura 5.17 - Imagem da subsuperfície do corpo de prova na condição S1. Corte transversal no plano a) perpendicular ao sentido de avanço da ferramenta; b) paralelo ao sentido de avanço da ferramenta. Após torneamento com velocidade de corte (Vc) de $60 \mathrm{~m} / \mathrm{min}$, e avanço (f) de 0,05 mm/rot. Imagens obtidas em MEV com aumento de 10000x. Ataque com Villela.

103

Figura 5.18 - Imagem da subsuperfície do corpo de prova na condição S2. Corte transversal no plano a) perpendicular ao sentido de avanço da ferramenta; b) paralelo ao sentido de avanço da ferramenta. Após torneamento com velocidade de corte (Vc) de $60 \mathrm{~m} / \mathrm{min}$, e avanço (f) de $0,1 \mathrm{~mm} /$ rot. Imagens obtidas em $\mathrm{MO}$ com aumento de 1000x. Ataque com Villela.

104

Figura 5.19 - Imagem da subsuperfície do corpo de prova na condição S3. Corte transversal no plano a) perpendicular ao sentido de avanço da ferramenta; b) paralelo ao sentido de avanço da ferramenta. Após torneamento com velocidade de corte (Vc) de $120 \mathrm{~m} / \mathrm{min}$, e avanço (f) de 0,05 mm/rot. Imagens obtidas em MO com aumento de 1000x. Ataque com Villela.

106

Figura 5.20 - Imagem da subsuperfície do corpo de prova na condição S3. Corte transversal no plano a) perpendicular ao sentido de avanço da ferramenta; b) paralelo ao sentido de avanço da ferramenta. Após torneamento com velocidade de corte (Vc) de $120 \mathrm{~m} / \mathrm{min}$, e avanço (f) de $0,05 \mathrm{~mm} /$ rot. Imagens obtidas em MEV com aumento de 10000x. Ataque com Villela.

107

Figura 5.21 - Imagem da subsuperfície do corpo de prova na condição S4. Corte transversal no plano a) perpendicular ao sentido de avanço da ferramenta; b) paralelo ao sentido de avanço da ferramenta. Após torneamento com velocidade de corte (Vc) de $120 \mathrm{~m} / \mathrm{min}$, e avanço (f) de 0,1 mm/rot. Imagens obtidas em $\mathrm{MO}$ com aumento de 1000x. Ataque com Villela.

108

Figura 5.22 - Imagem da subsuperfície do corpo de prova na condição S4. Corte transversal no plano a) perpendicular ao sentido de avanço da ferramenta; b) paralelo ao sentido de avanço da ferramenta. Após torneamento com velocidade de corte (Vc) de $120 \mathrm{~m} / \mathrm{min}$, e avanço (f) de $0,1 \mathrm{~mm} /$ rot. Imagens obtidas em MEV com aumento de 10000x. Ataque com Villela.

109

Figura 5.23 - Imagem da subsuperfície do corpo de prova na condição SR. Corte transversal no plano a) perpendicular ao sentido de avanço; b) paralelo ao sentido de avanço. Após retificação com velocidade de corte $\left(\mathrm{v}_{\mathrm{c}}\right)$ de $54 \mathrm{~m} / \mathrm{s}$, avanço $\left(\mathrm{v}_{\mathrm{p}}\right) 4 \mathrm{~m} / \mathrm{min}$ e profundidade de corte $\left(\mathrm{a}_{\mathrm{e}}\right)$ 0,03 $\mathrm{mm}$. Imagens obtidas em MO com aumento de 1000x. Ataque com Villela. 
Figura 5.24 - Imagem da subsuperficie do corpo de prova na condição SR. Corte transversal no plano a) perpendicular ao sentido de avanço; b) paralelo ao sentido de avanço. Após retificação com velocidade de corte $\left(\mathrm{v}_{\mathrm{c}}\right)$ de $54 \mathrm{~m} / \mathrm{s}$, avanço $\left(\mathrm{v}_{\mathrm{p}}\right) 4 \mathrm{~m} / \mathrm{min}$ e profundidade de corte $\left(\mathrm{a}_{\mathrm{e}}\right)$ 0,03 $\mathrm{mm}$. Imagens obtidas em $\mathrm{MEV}$ com aumento de 10000x. Ataque com Villela.

Figura 5.25 - Indentações realizadas em microdurômetro Vickers, onde se observa que o tamanho da diagonal das marcas de dureza para as cargas utilizadas de 50 e $10 \mathrm{gf}$.

Figura 5.26 - Medidas de dureza feitas com microdurometro com indentador Vickers e carga de 50gf, avaliada na seção transversal de uma das amostras torneadas na condição S2. O plano de corte da amostra é perpendicular ao sentido de avanço (na direção de corte).

113

Figura 5.27 - Marcas de dureza instrumentada com carga de 10gf, avaliada na seção transversal de uma das amostras torneadas na condição S2. Mostra-se o plano perpendicular ao sentido de avanço (na direção de corte). Imagens obtidas em MO com aumento de 1000x.

115

Figura 5.28 - Medidas de nanodureza feitas com indentador Vickers e carga de 10gf, avaliada na seção transversal na condição S2. O plano de corte da amostra é perpendicular ao sentido de avanço (na direção de corte).

115

Figura 5.29 - Medidas de tensão residual das superficies ensaiadas adquiridas no sentido de avanço da ferramenta (Radial) e de corte (Tangencial).

117

Figura 5.30 - Valor médio das medidas de tensão residual das superficies ensaiadas avaliada no sentido de avanço: radial nas superficies torneadas e tangencial nas superficies retificadas.

118

Figura 5.31 - Sinal de RMB no domínio do tempo obtido nas superficies no estado inicial utilizadas como referência.

120

Figura $5.32-$ RMB $_{\text {RMS }}$ do RMB para as superficies retificadas e no estado inicial. $\mathbf{1 2 0}$

Figura 5.33 - RMB $_{\text {RMS }}$ do RMB para as diversas superficies testadas agrupadas de acordo com a condição de geração da superficie. São indicados apenas os corpos de prova torneados. Os corpos de prova retificados e na condição inicial são apresentados como dados de referência para todas as amostras.

121

Figura 5.34 - Comparativo da vida em fadiga de contato de rolamento para as superficies torneadas e retificadas.

124

Figura 5.35 - Comparativo da vida em fadiga de contato de rolamento e o RMB $\mathrm{RMS}_{\text {do }}$ RMB para as superficies torneadas na condição S1. As superficies no estado inicial são apresentadas como ponto de referência. As amostras indicadas de 1 a 5 correspondem às 10, 12, 13, 17 e 11 torneadas, respectivamente (Figura 5.31). 126

Figura 5.36 - Comparativo da vida em fadiga de contato de rolamento e o RMB $\mathrm{R}_{\mathrm{RMS}}$ do RMB para as superficies torneadas na condição S2. . As superficies no estado inicial são apresentadas como ponto de referência. As amostras indicadas de 1 a 5 correspondem às 1, 3, 15, 20 e 8 torneadas, respectivamente (Figura 5.31).

126

Figura 5.37 - Comparativo da vida em fadiga de contato de rolamento e o RMB $\mathrm{RMS}_{\text {do }}$ RMB para as superficies torneadas na condição S3. . As superficies no estado inicial são apresentadas como ponto de referência. As amostras indicadas de 1 a 5 correspondem às 5, 7, 9, 14 e 16 torneadas, respectivamente (Figura 5.31).

127

Figura 5.38 - Comparativo da vida em fadiga de contato de rolamento e o RMB RMS $_{\text {do }}$ RMB para as superficies torneadas na condição S4. As superfícies no estado inicial são apresentadas como ponto de referência. As amostras indicadas de 1 a 5 correspondem às 2, 4, 6, 18 e 19 torneadas, respectivamente (Figura 5.31). 
Figura 5.39 - Comparativo da vida em fadiga de contato de rolamento e o RMB $B_{\text {RMS }}$ do RMB para as superficies retificadas na condição SR. As superficies no estado inicial são apresentadas como ponto de referência.

128

Figura 5.40 - Comparativo da vida média em fadiga de contato de rolamento contra o valor médio do RMB RMS $_{\text {do }}$ RMB para as superficies torneadas e retificadas.

129

Figura 5.41 - Comparação do comportamento do parâmetro $\lambda$ e da inclinação de Weibull $(\beta)$ para as superficies ensaiadas.

133

Figura 5.42 - Imagem da superfície do corpo de prova No 15 (condição S1) (Vc 60 $\mathrm{m} / \mathrm{min}$, f 0,05 mm/rev). Imagem obtida em MEV com aumento de 350x. Análise de elétrons secundários

133

Figura 5.43 - Imagem da superficie do corpo de prova No 15 (S1) (Vc 60 m/min, f 0,05 $\mathrm{mm} / \mathrm{rev}$ ), ampliando um detalhe da Fig. 5.42 onde se mostra o padrão de fratura do defeito seguindo a direção das marcas da ferramenta. Imagem obtida em MEV com aumento de 800x. Análise de elétrons secundários

134

Figura 5.44 - Imagem da superficie do corpo de prova No 11 (S1) (Vc 60 m/min, f 0,05 $\mathrm{mm} / \mathrm{rev}$ ). Imagem obtida em MO com aumento de 100x.

135

Figura 5.45 - Imagem da superfície do corpo de prova No 8 (S3) (Vc 120 m/min, f 0,05 $\mathrm{mm} / \mathrm{rev}$ ). Imagem obtida em MO com aumento de 100x.

136

Figura 5.46 - Imagem da superficie do corpo de prova No 14 (S3) (Vc $120 \mathrm{~m} / \mathrm{min}$, f $0,05 \mathrm{~mm} / \mathrm{rev}$ ). Imagem obtida em MEV com aumento de 350x. Análise de elétrons secundários.

137

Figura 5.47 - Imagem da superfície do corpo de prova No 15, (Condição SR) ( $\mathrm{v}_{\mathrm{c}} 54$ $\mathrm{m} / \mathrm{s}, v_{p} 4 \mathrm{~m} / \mathrm{min}, a_{e} 0,03 \mathrm{~mm}$ ). Imagem obtida em MEV com aumento de 250x. Análise de elétrons secundários

137

Figura 5.48 - Imagem da superficie do corpo de prova No 15 (SR), ampliando um detalhe da Fig. 5.48. Imagem obtida em MEV com aumento de 1000x. Análise de elétrons secundários

138

Figura 5.49 - Imagem da superficie do corpo de prova No 15 (S2), ampliando um detalhe da Fig. 5.47. Imagem obtida em MEV com aumento de 500x. Análise de elétrons secundários

138

Figura 5.50 - Imagem da superficie do corpo de prova No 15 (S2), ampliando um detalhe da Fig. 5.47. Imagem obtida em MEV com aumento de 500x. Análise de elétrons secundários

Figura 5.51 - Imagem da superficie do corpo de prova No 2 (SR) $\mathrm{v}_{\mathrm{c}} 54 \mathrm{~m} / \mathrm{s}, \mathrm{v}_{\mathrm{p}} 4$ $\mathrm{m} / \mathrm{min}, \mathrm{a}_{\mathrm{e}}$ 0,03 $\mathrm{mm}$ ). Imagem obtida em MO com aumento de 100x.

140

Figura 5.52 - Imagem da superficie do corpo de prova No 6 (SR) $\mathrm{v}_{\mathrm{c}} 54 \mathrm{~m} / \mathrm{s}, \mathrm{v}_{\mathrm{p}} 4$ $\mathrm{m} / \mathrm{min}, \mathrm{a}_{\mathrm{e}}$ 0,03 $\mathrm{mm}$ ). Imagem obtida em MO com aumento de $100 \mathrm{x}$.

140

Figura 5.53 - Imagem da seção transversal do corpo de prova No 19 , onde se mostra a seção transversal do Lascamento. Imagem obtida em MEV com aumento de 500x. Análise de elétrons secundários

141

Figura 5.54 - Imagem da superficie do corpo de prova No 19T, ampliando um detalhe da Fig. 5.51 onde se mostra nucleação da trinca passando por uma segunda fase. Imagem obtida em MEV com aumento de 5000x. Análise de elétrons secundários 141

Figura 5.55 - Imagem da superficie do corpo de prova No 19 onde se mostra nucleação de duas trincas na seção transversal. Imagem obtida em MEV com aumento de 5000x. Análise de elétrons secundários 


\section{LISTA DE TABELAS}

Tabela 1.1. Profundidades aproximadas dos sinais do RMB, em dependência de suas frequências de emissão.

Tabela 3.1. Sequência de tratamento térmico dos corpos de prova (AISI H13).

Tabela 3.2. Composição química do aço AISI H13.

Tabela 3.3. Máquinas ferramenta e ferramental de corte utilizados.

Tabela 4.1. Parâmetros de corte para a condição de torneamento de acabamento.

Tabela 4.2. Matriz de ensaios para a condição de torneamento de acabamento.

Tabela 4.3. Parâmetros de corte para as superficies obtidas pelo processo de retificação.

Tabela 4.4. Comprimento de amostragem (“cut-off”).para superficies periódicas .

Tabela 4.5. Variáveis de processo empregadas durante o os ensaios de fadiga de contato de rolamento.

Tabela 5.1. Valor médio dos parâmetros de rugosidade (Ra, Rq, Rsm) avaliados em todas as repetições para cada condição.

Tabela 5.2. Valores de vida em ciclos de FC das superficies testadas

Tabela 5.3. Inclinação de Weibull (b) e durabilidade característica ( $\theta$ ) da distribuição de falha das superficies ensaiadas nas diferentes condições.

Tabela 5.4. Valores médios da rugosidade quadrática média Rq antes do ensaio de FCR nos corpos de prova e no contra corpo (esfera de aço AISI 52100).

130

Tabela 5.5. Valores do parâmetro $\lambda$ nas diferentes superfícies ensaiadas.

Tabela 5.6. Valores do parâmetro $\lambda$ e da inclinação de Weibull ( $\beta$ ) das superficies ensaiadas nas diferentes condições. 


\section{LISTA DE ABREVIATURAS E SIGLAS}

ABNT Associação Brasileira de Normas Técnicas

AISI American Iron and Steel Institute

EHL Lubrificação elastohidrodinâmica

FC Fadiga de contato

FCR Fadiga de contato de rolamento

HL Lubrificação hidrodinâmica

HSM High speed machining

I.S. Integridade da superficie

IDS Índice de Desempenho da Superficie

MEV Microscópio eletrônico de varredura

MO Microscópio óptico

RMB Ruído magnético de Barkhausen

$\mathrm{RMB}_{\mathrm{RMS}} \quad$ Raiz média quadrática do ruído magnético de Barkhausen

S1 Superficie obtida por torneamento na condição 1

S2 Superficie obtida por torneamento na condição 2

S3 Superficie obtida por torneamento na condição 3

S4 Superficie obtida por torneamento na condição 4

SAE $\quad$ Society of Automotive Engineers

SR Superficie obtida por retificação

TD Torneamento duro 


\section{LISTA DE SÍMBOLOS}

a

$a_{p}$

$\beta$

$\alpha$

$\delta$

E

$E^{*}$

$\mathrm{E}^{\prime}$

f

hc

ho

$\mathrm{k}$

$\mu$

$\lambda$

$\eta_{0}$

$\theta$

$\mathrm{p}_{0}$

$\mathrm{p}$

$\mathrm{R}$

$\mathrm{R}^{\prime}$
Raio da circunferência de contato

Profundidade de corte

Parâmetro de forma da distribuição de Weibull

Coeficiente de variação da viscosidade com a pressão

Aproximação entre os centros de dois corpos postos em contato

Módulo de elasticidade

Módulo de elasticidade combinado

Módulo elástico reduzido

Avanço

Espessura central do filme lubrificante

Espessura minima do filme lubrificante

fator de elipsidade

Coeficiente de atrito

Parâmetro lambda

Viscosidade do lubrificante à pressão atmosférica

Parâmetro de escala da distribuição de Weibull

Pressão normal máxima de contato

Pressão (variável) dentro da circunferência de contato

Raio da esfera

Raio de curvatura reduzido 
$\mathrm{Rq} \quad$ Desvio quadrático médio do perfil

Rsm Largura média de um elemento do perfil

$\mathrm{Rx} \quad$ Raio de curvatura reduzido na direção $\mathrm{x}$

Ry Raio de curvatura reduzido na direção y

Rax Raio de curvatura do corpo A na direção $\mathrm{x}$

Ray Raio de curvatura do corpo A na direção y

$\mathrm{Rbx} \quad$ Raio de curvatura do corpo B na direção $\mathrm{x}$

Rby Raio de curvatura do corpo B na direção y

Rt Altura total do perfil

$\mathrm{Rv} \quad$ Altura de vale mais profundo do perfil

$\tau_{\max } \quad$ Tensão máxima de cisalhamento

U Velocidade de entrada da superficie

$\mathrm{U}_{\mathrm{A}} \quad$ Velocidade tangencial do corpo A

$\mathrm{U}_{\mathrm{B}} \quad$ Velocidade tangencial do corpo B

$v \quad$ Coeficiente de Poisson

$\mathrm{v}_{\mathrm{c}} \quad$ Velocidade de corte

W Carga aplicada no contato 


\section{SUMÁRIO}

INTRODUÇÃO E OBJETIVOS

1. REVISÃO BIBLIOGRÁFICA 23

1.1. DEFINIÇÃO DE INTEGRIDADE SUPERFICIAL - “I.S.”................................................................23

1.2. A INTEGRIDADE SUPERFICIAL NOS PROCESSOS DE MANUFATURA ..........................................26

1.2.1. INTEGRIDADE SUPERFICIAL NOS PROCESSOS DE USINAGEM COM FERRAMENTAS DE GEOMETRIA DEFINIDA .........30

1.2.2. INTEGRIDADE SUPERFICIAL NOS PROCESSOS DE USINAGEM COM FERRAMENTAS DE GEOMETRIA NÃO-DEFINIDA . 36

1.2.3. OS PROCESSOS DE ACABAMENTO E A SUA RELAÇÃO COM A INTEGRIDADE SUPERFICIAL ..............................39

1.3. O PAPEL DA INTEGRIDADE SUPERFICIAL NA FADIGA DE CONTATO DE ROLAMENTO .................40

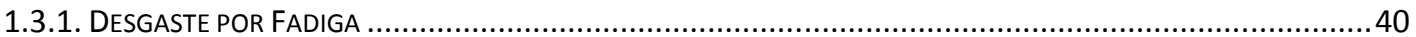

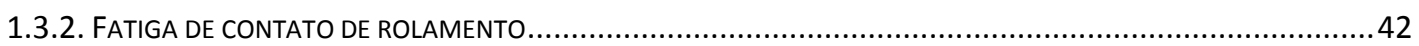

1.3.3. FADIGA DE CONTATO DE ROLAMENTO E INTEGRIDADE SUPERFICIAL EM SUPERFÍCIES TORNEADAS E RETIFICADAS 44

1.4. MÉTODOS DE MEDIÇÃO DA INTEGRIDADE SUPERFICIAL....................................................48

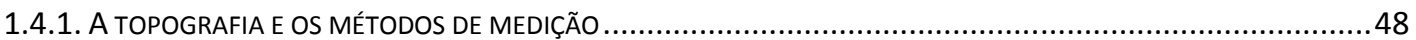

1.4.2. CARACTERÍSTICAS SUBSUPERFICIAIS E TECNICAS DE MEDICÃO ..................................................5

2. FUNDAMENTOS COMPLEMENTARES DE DESGASTE POR ROLAMENTO 62

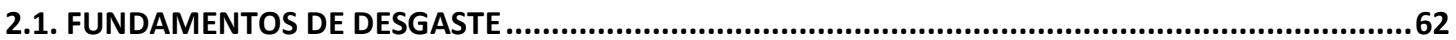

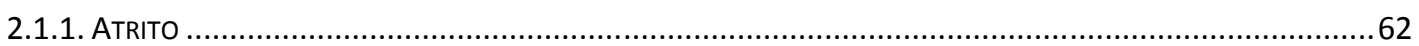

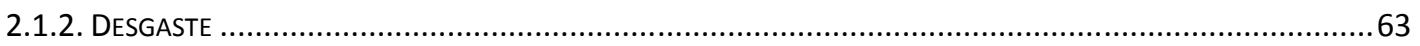

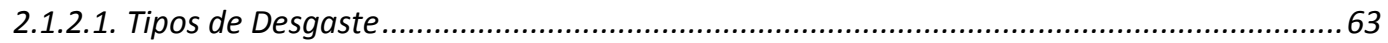

2.2. CONTATO

2.2.1. GEOMETRIA DE CONTATO ENTRE DOIS CORPOS ELÁSTICOS .........................................................6 65

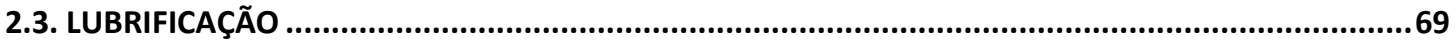

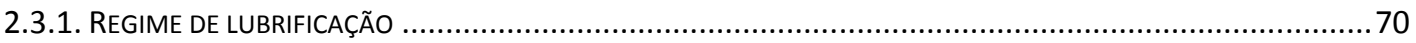

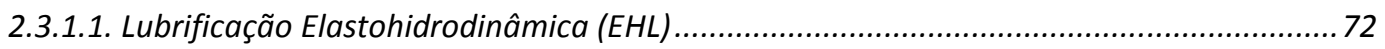

3. MATERIAS E MÉTODOS

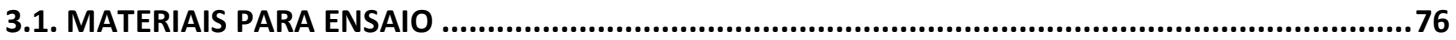

3.2. MÁQUINA-FERRAMENTA E FERRAMENTAL DE CORTE ........................................................76 
3.3. EQUIPAMENTOS PARA A CARACTERIZAÇÃO DA INTEGRIDADE SUPERFICIAL E DAS

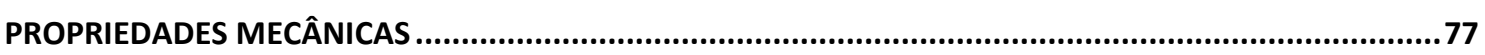

3.4. EQUIPAMENTO PARA A AVALIAÇÃO DO DESEMPENHO TRIBOLÓGICO .....................................79

4. PROCEDIMENTO EXPERIMENTAL 81

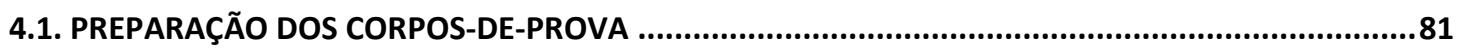

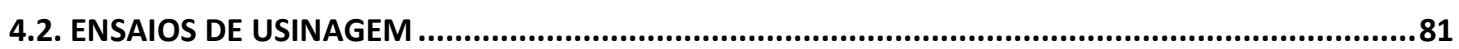

4.2. PROCEDIMENTO PARA A CARACTERIZAÇÃO DA INTEGRIDADE SUPERFICIAL ...........................83

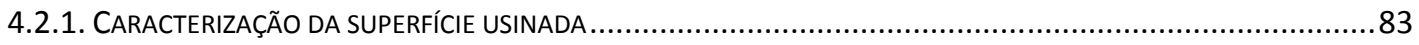

4.2.1.1. Preparação de amostras para caracterização da IS .....................................................83

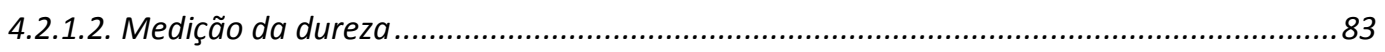

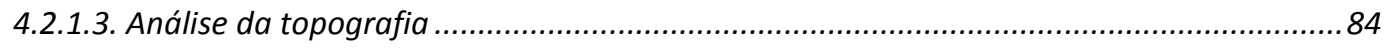

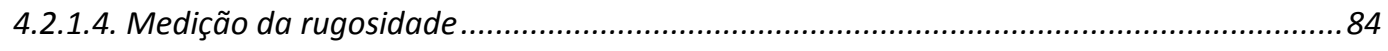

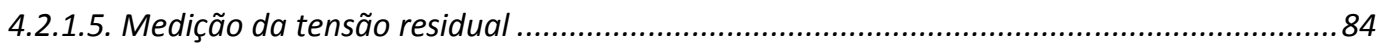

4.2.1.6. Medição das propriedades magnéticas - Ruído magnético de Barkhausen (RMB)..........85

4.3. PROCEDIMENTO EXPERIMENTAL PARA ENSAIOS DE DESGASTE............................................8.

5. RESULTADOS E DISCUSSÃO

5.1. CARACTERIZAÇÃO MICROESTRUTURAL DOS AÇOS UTILIZADOS.............................................89

5.2. INFLUÊNCIA DOS PARÂMETROS DE CORTE NA INTEGRIDADE DE SUPERFÍCIE. ..........................91

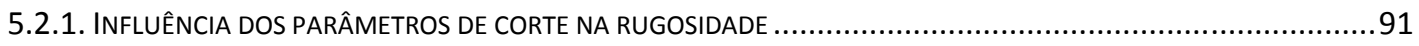

5.2.2. INFLUENCIA DOS PARÂMETROS DE CORTE NO ASPECTO DA SUPERFÍCIE ..........................................95

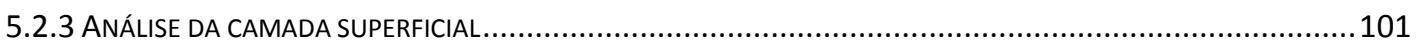

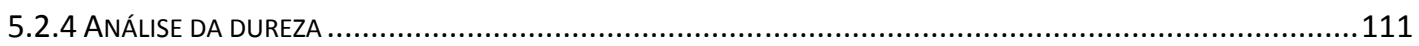

5.2.5. CARACTERIZAÇÃO DA SUPERFÍCIE MEDIANTE MEDIÇÃO DE TENSÃO RESIDUAL.......................................116

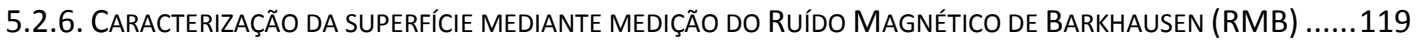

5.3. EFEITOS DA INTEGRIDADE NO DESEMPENHO FUNCIONAL..................................................122

5.3.1. DESEMPENHO EM FADIGA DE CONTATO ............................................................................... 122

5.3.1.1. Desempenho da superfície em fadiga de contato e ruído magnético de Barkhausen ....125

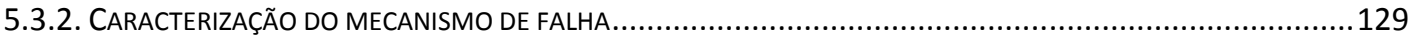

$\begin{array}{lr}\text { 6. CONCLUSÕES } & 143\end{array}$

7. SUGESTÕES PARA NOVOS TRABALHOS 146

$\begin{array}{lr}\text { REFERÊNCIAS BIBLIOGRÁFICAS } & 147\end{array}$ 


\section{INTRODUÇÃO E OBJETIVOS}

O torneamento duro é um termo usado para expressar a usinagem de materiais endurecidos com ferramentas monocortantes, e que possuem uma dureza superior a 55 HRc (MATSUMOTO, 1998). Este valor de dureza varia nos trabalhos apresentados por diferentes autores (MATSUMOTO, 1998). O torneamento duro e a retificação são processos de acabamento concorrentes durante a usinagem de elementos mecânicos, onde a precisão é um aspecto fundamental. Contudo, as características próprias de cada processo de fabricação geram efeitos diferentes na superficie usinada, que podem acarretar diferenças no desempenho funcional. Em função disso, a avaliação da superficie é importante.

Lonardo e Colaboradores (2002) analisaram as tendências emergentes da metrologia da superfície. Dentro desta tendência está a melhoria do processo de manufatura para gerar uma variação na geometria e/ou nas propriedades da superficie para obter uma função específica. Tais superficies são classificadas como superfícies engenheradas. Dentro deste conceito o desenvolvimento do processo de geração de uma superfície visando a sua função pode ser tratado dentro do campo da engenharia como "Projeto de uma Superficie". A demanda por uma superficie funcional é uma realidade dentro da prática da engenharia de superfícies, mas a dificuldade está na determinação de parâmetros que caracterizem propriamente esta superficie. A função da superficie deve ser o primeiro dado de entrada no planejamento do processo de fabricação. Ou seja, a partir dela deve-se definir o equipamento de usinagem. Com isso, o projeto do componente e a correta seleção do processo de acabamento somente são possiveis mediante o conhecimento do processo de fabricação.

As pesquisas iniciais neste tema focaram-se na definição dos fatores no processo de usinagem que afetam o acabamento superficial (MACHINABILITY DATA CENTER, 1980), sendo que, o acabamento superficial não é o único parâmetro que determina as características de uma superfície usinada. O acabamento superficial está associado com um melhor aspecto superficial, e é um conceito geralmente ligado a uma baixa rugosidade. Contudo, as mudanças que ocorrem na subsuperficie como resultado do processo de 
usinagem do material podem afetar de maneira significativa o desempenho do componente.

A integridade superficial é uma área de estudos inserida dentro da ciência de engenharia das superficies que foi criada no início da década de 1970, para o estudo da relação existente entre a metalurgia, a usinabilidade e os ensaios mecânicos; e tem sido utilizada em diversas aplicações, dadas as crescentes exigências para a fabricação de componentes com superficies que requerem um alto nivel de qualidade e desempenho funcional (MACHINABILITY DATA CENTER, 1980; GRIFFITHS, 2001). Durante os últimos 40 anos, diversos trabalhos têm sido realizados para entender a integridade das superficies obtidas mediante os diferentes processos de fabricação. No Laboratório de Fenômenos de Superficies do Departamento de Engenharia Mecânica da Universidade de São Paulo (LFS - USP) têm sido realizadas diversas pesquisas a partir de testes em escala laboratorial que permitem avaliar o desempenho tribológico de diferentes superficies e a sua relação com mudanças no processo de fabricação (ALVAREZ, 2006; HIOKI, 2006; NEVES, 2006; UEAHARA, 2005). Hioki (2006) mostrou no caso de fresamento de acabamento de moldes e matrizes de uma superficie, que o processo de usinagem pode influenciar o desempenho tribológico, o qual justificaria a dispersão na vida dos componentes. Uehara (2005) estudou a influência do acabamento superficial e a textura da superficie no desempenho tribológico de bronzinas. O processo de usinagem pode modificar a textura da superficie e a integridade da mesma, sendo que o desempenho tribológico é muito importante em aplicações onde se tem contato entre as superficies. Neves (2006) estudou o comportamento em fadiga de contato de rolamento em ferros fundidos e aços, mas a topografia decorrente do processo de usinagem não foi objeto de estudo, sendo removida antes dos ensaios mediante técnicas de preparação metalográfica de superficies. Contudo, os trabalhos desenvolvidos ainda não abordam o tópico em sua totalidade, por exemplo, em termos do efeito que as mudanças na microestrutura do material podem ter sobre a qualidade das superfícies e no desempenho tribológico do componente.

Ao longo do projeto de doutorado, objetivou-se estudar o efeito que a integridade superficial de um aço ferramenta exerce sobre a resistência à fadiga de contato de rolamento, como consequência dos processos de torneamento e retificação sob condições de usinagem convencionais. 
Finalmente, o objetivo do trabalho pode ser resumido em termos de um objetivo principal e objetivos secundários.

Objetivo Principal: Estudar o efeito que a integridade superficial possui na resistência à fadiga de contato em aços ferramenta após o processo de usinagem de acabamento.

\section{Objetivos Secundários:}

i. Analisar os efeitos dos parâmetros de corte sobre as características da integridade da superficie (parâmetros de rugosidade, espessura da camada branca, dureza superficial, tensão residual e métodos magnéticos baseados no ruído magnético de Barkhausen).

ii. Analisar os efeitos das características da integridade sobre o desempenho da superficie usinada por meio da avaliação da resistência à fadiga de contato de rolamento. 


\section{REVISÃO BIBLIOGRÁFICA}

\subsection{Definição de Integridade Superficial - "I.S."}

A ciência das superficies pode ser definida como a área do conhecimento encarregada de estudar todos os tipos de superficies em todos os niveis, e as interações das interfaces entre dois ou mais corpos. Estas interações podem ser de natureza física, química, elétrica, mecânica, térmica, biológica, geológica e astronômica (ASTHANA, 2006; apud ASTAKHOV, 2009).

Astakhov (2009) fez uma definição de engenharia para a integridade superficial (I.S.), descrevendo-a como o conjunto de propriedades de uma superficie de engenharia (superficiais e subsuperficiais) que afetam o seu desempenho em serviço. Contudo, um fato que tem dificultado o entendimento e disseminação da abordagem em I.S. na engenharia é que, na literatura predominam divergências, tanto nos conceitos fundamentais como nas informações geradas a partir de aplicações mais específicas (FIELD E KHALES 1971; FIELD et al., 1972; MACHINABILITY DATA CENTER, 1978; ANSI B.46.1, 1980; ANS B211.1, 1986; MORTON, 1994; TRICARD, 1994; WHITEHOUSE, 1994; GRIFFITHS, 2001; ASTAKHOV, 2009). Ao anterior se soma a ausência de uma metodologia sistemática estabelecida para a determinação da I.S., o qual é devido a dois fatos básicos ao realizar uma abordagem em I.S.:

i. O papel e importância que a I.S. desempenha no projeto depende das características próprias do sistema ou elemento de máquina;

ii. Necessidade da existência de um conjunto específico de dados para cada um dos diferentes processos de usinagem.

O aprimoramento da definição de "integridade da superficie" tem acompanhado a evolução das técnicas de caracterização de superfícies, sendo que o conceito tem sido aperfeiçoado na medida em que são realizados avanços nas tecnologias e métodos para a avaliação do estado das superfícies. A consequente disseminação dessas novas tecnologias permite que a abordagem em "integridade da superficie" seja incorporada cada vez mais nas linhas de produção de componentes, especialmente daqueles que precisam de altos padrões de desempenho (BRINKSMEIER, 1989; GOCH et al, 1999). 
Trabalhos realizados nas décadas de 1960 e 1970 onde foram feitos estudos importantes sobre a integridade superficial foram publicados por Field e Kahles $(1964,1971)$. Estes pesquisadores além de cunhar o termo "integridade superficial" durante o estudo de operações de retificação de superficies e outros procedimentos de acabamento (1964), fizeram uma primeira revisão sobre a integridade superficial em componentes usinados, descrevendo os diferentes tipos de alterações que podem ocorrer numa superficie usinada (1971). Field e Kahles (1971) definiram a integridade da superficie como " $a$ relação existente entre as propriedades de uma superfície e o seu comportamento funcional, a qual foi obtida por um processo de usinagem ou mediante outro processo de geração de superfícies”. A integridade superficial tornou-se oficialmente um campo de estudos durante a 21a Assembléia Geral do CIRP em 1971.

Em outro trabalho, Field e Kahles (1972) propuseram as técnicas disponiveis na época para avaliar os danos e os conjuntos de informações mínimas, padrão e estendida para caracterizar a integridade da superficie. Foi feita uma primeira definição para os fatores que compõem uma superficie, e foram enunciados como "a) rugosidade da superficie ou topografia da superficie; b) metalurgia da superficie”. Contudo, Field e Kahles não conseguiram uma definição clara para o uso do termo I.S., e, por exemplo, como citado por Hioki (2006), utilizou-se o mesmo termo "integridade da superficie" para fazer referência ao estado da superficie em dois contextos diferentes. Num deles o termo foi usado para expressar a característica da superficie gerada, enquanto no outro, foi utilizado para descrever a atividade que permite caracterizar e controlar o estado da superficie.

O Machinability Data Center (1980), baseado nos trabalhos de Field e Khales $(1971 ; 1972)$, publicou um dos primeiros textos com ampla informação sobre os resultados experimentais relacionados com o estudo da integridade superficial. No mesmo documento definiu-se o termo "tecnologia das superficies", fazendo referência à atividade que descreve a superfície e subsuperficie de um componente manufaturado, ficando assim mais claro o conceito de integridade da superficie, exposto inicialmente por Field e Kahles $(1971,1972)$. A tecnologia das superficies foi definida como " $a$ atividade que descreve, detalha e avalia a condição do conjunto superfície e camada superficial dos elementos manufaturados”. A tecnologia das superficies 
como apresentado no Machinability Data Center (1980), incluía a descrição do conjunto de efeitos internos e externos à superficie, compostos pela "textura superficial" e "integridade da superficie". Na Figura 1.1, apresenta-se uma representação esquemática dos elementos que compunham a tecnologia das superficies segundo o Machinability Data Center (1980)

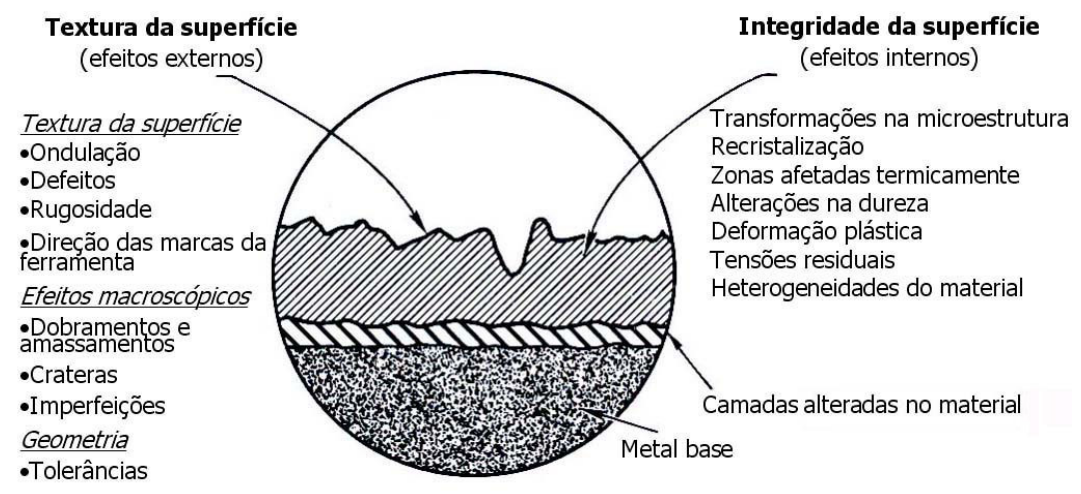

Figura 1.1 - Representação esquemática dos elementos superficiais e subsuperficiais que definem a tecnologia das superficies, segundo o Machinability Data Center (1980)

Como observado na Figura 1.1, a definição de textura superficial feita pelo Machinability Data Center (1980) considerou os seguintes elementos: a textura da superficie, os efeitos macroscópicos e a geometria. As definições apresentadas no Machinability Data Center (1980) basearam-se no conceito de textura superficial proposto pela norma ANSI B.46.1-1978 (1978), a qual considerava a rugosidade, a ondulação, a orientação das marcas da ferramenta, e os defeitos superficiais como elementos que compunham a textura da superficie; fato que pode explicar as inconveniências na terminologia empregada. Por outro lado, a integridade da superficie foi considerada como os efeitos internos na subsuperficie dos elementos manufaturados.

É importante observar que, embora a tecnologia de superficies esteja baseada no estudo dos elementos que compõem a integridade da superfície e da textura da superficie, o critério mais tradicionalmente adotado para avaliar a qualidade de uma superficie usinada é somente a textura superficial (WHITEHOUSE, 1994). Whitehouse (1994) definiu integridade superficial como "o conjunto de propriedades utilizadas para descrever as características físicas e geométricas das superfícies usinadas”. Griffiths (2001) descreve a integridade da superficie como "as caracteristicas topográficas, quimicas, mecânicas e 
metalúrgicas de uma superficie usinada e a sua relação com o desempenho funcional”, definição que será adotada neste trabalho.

Para avaliar a integridade superficial, Griffiths (2001) definiu duas categorias de elementos: "topografia da superficie tridimensional e características subsuperficiais". Ao unir a definição realizada por Griffiths (2001) com as definições realizadas por Field e Khales(1971), Field et al. (1972), Whitehouse (1994) e Morton (1994), é possivel classificar os elementos que permitem descrever a integridade da superficie de um componente manufaturado como composto de: topografia (acabamento superficial, textura da superficie, orientação das marcas da ferramenta, erros de forma e imperfeições), características da subsuperfície e avaliação do desempenho funcional (ALVAREZ, 2006).

\subsection{A integridade superficial nos processos de manufatura}

A usinagem pode ser entendida como o conjunto de processos de fabricação que envolve a remoção de cavacos, mas, uma definição mais abrangente foi feita por Ferarresi (1970): “operação que ao conferir à peça a forma, ou as dimensões ou acabamento, ou ainda uma combinação qualquer destes três itens, que produzem cavaco". De um modo geral toda máquina ferramenta está baseada num princípio fundamental, que é o de providenciar um movimento relativo entre a peça e a ferramenta de corte para gerar a superficie desejada. Os movimentos relativos entre a peça e a aresta de corte que causam diretamente a saída do cavaco são chamados de movimentos ativos, e são (DINIZ et al., 2008):

i. Movimento de corte: movimento entre a peça e a ferramenta, a qual sem o movimento de avanço origina somente uma única retirada de cavaco durante uma rotação;

ii. Movimento de avanço: movimento entre a peça e a ferramenta, o qual juntamente como o movimento de corte origina a retirada contínua de cavaco;

iii. Movimento efetivo: movimento resultante dos movimentos de corte e avanço, realizados ao mesmo tempo. As direções dos movimentos que causam diretamente a retirada do cavaco são as direções de corte, de avanço e efetiva, o qual é ilustrado esquematicamente na Figura 1.2 para o processo de torneamento. 
Tradicionalmente os processos de usinagem têm procurado cumprir dois objetivos principais: garantir melhores acabamentos superficiais e, ao mesmo tempo, reduzir os tempos totais das operações de acabamento (GRIFFITHS, 2001). A superfície gerada sofre efeitos mecânicos e térmicos inerentes ao processo, envolvendo principalmente transformações de natureza mecânica, metalúrgica e química.

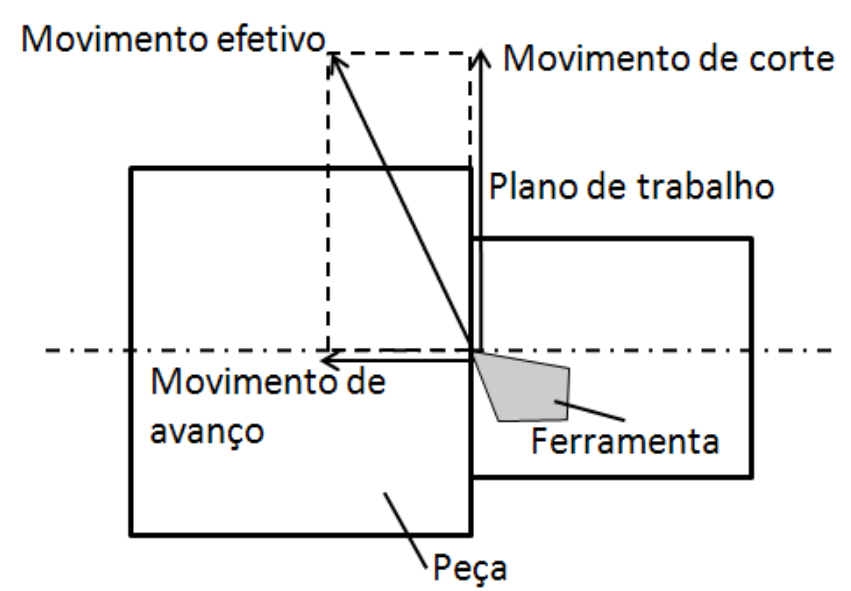

Figura 1.2 - Representação esquemática das direções dos movimentos que geram a remoção do cavaco para o processo de torneamento.

Dentro do conjunto de alterações que podem ser geradas na peça usinada durante o processo de usinagem podem ser citadas: deformações plásticas, ruptura, recuperação elástica, transformações de fase, tensões residuais, reações químicas, entre outras (GRIFFITHS, 2001). Estas mudanças antes mencionadas ocorrem numa camada superficial e geralmente acompanham os padrões de textura da topografia na superficie (GRIFFITHS, 2001). Ao longo do presente trabalho é considerada como camada superficial a porção de material logo abaixo da superficie, porém, a se fazer referência a este termo exclui-se os elementos que compõem a sua topografia (acabamento superficial, textura da superficie, orientação das marcas da ferramenta, erros de forma e imperfeições).

As mudanças nas propriedades do material se atribuem aos diferentes fatores envolvidos no processo de corte, e que compõem os eventos de natureza térmica, mecânica ou química. O tipo de camada gerada dependerá do balanço dos níveis de energia térmica, mecânica e química existentes durante o evento da manufatura e, consequentemente, estão relacionadas com os fatores próprios do processo de usinagem tais como tipo de tensão (trativas ou compressivas), nivel de tensão, taxa de aquecimento, taxa de resfriamento 
e das condições ambientais do local (GRIFFITHS, 2001). Na Figura 1.3 são apresentadas esquematicamente as diferentes camadas afetadas como resultado do processo de remoção de material.

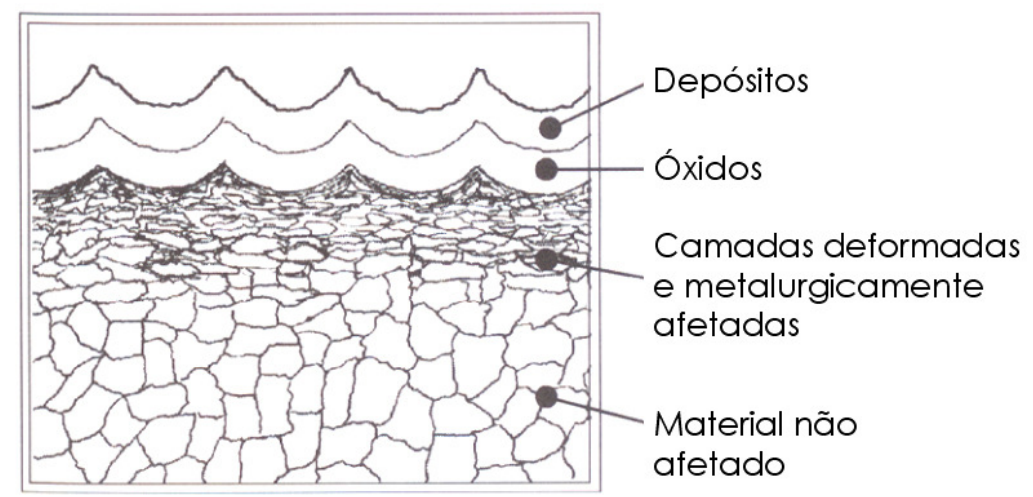

Figura 1.3 - Representação esquemática da seção transversal de uma peça usinada. Ilustram-se as camadas geradas como resultado do processo de usinagem (GRIFFITHS, 2001)

Em função do tipo e da intensidade da energia empregada no processo de usinagem, as propriedades do material da peça de trabalho ficam afetadas e é produzida uma ampla variedade de efeitos na subsuperficie (GRIFFITHS, 2001). Para ilustrar melhor as mudanças que podem ocorrer na subsuperficie, apresenta-se na Figura 1.4 uma adaptação de uma imagem obtida por Alvarez (2006) da seção transversal de um ferro fundido mesclado submetido ao processo de torneamento. Na Figura 1.4 se observa que devido à intensidade do processo de remoção de material gerou-se uma primeira camada mais superficial denominada camada branca, e que acompanha os padrões da topografia. Numa camada mais profunda predomina a deformação plástica. Observa-se a orientação dos grãos da matriz metálica e de partículas da segunda fase na direção de corte (como ressaltado pelas linhas vermelhas pontilhadas) a uma profundidade de aproximadamente $10 \mu \mathrm{m}$. Abaixo de certa profundidade $(10 \mu \mathrm{m})$ é possivel observar uma camada de material não afetado, o qual é isento de alterações na microestrutura que possam ser associadas ao processo de remoção de material. A rebarba que é observada na Figura 1.4 é uma alteração superficial (imperfeição), porém, é objeto de análise da topografia. 


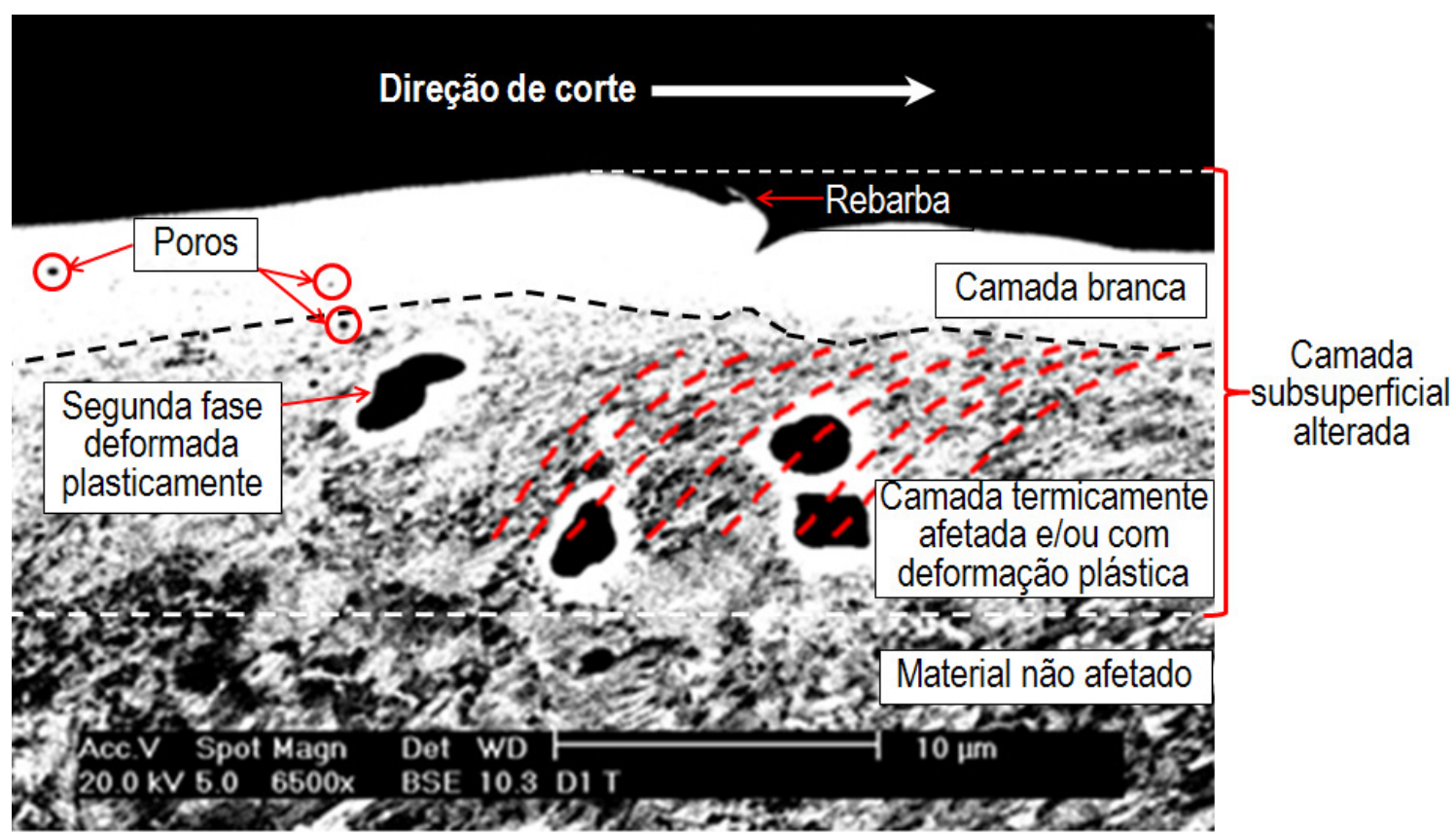

Figura 1.4 - Mudanças da camada superficial observadas na seção transversal de um ferro fundido mesclado após torneamento ( $\mathrm{Vc}=60 \mathrm{~m} / \mathrm{min} ; \mathrm{f}=0,1 \mathrm{~mm} / \mathrm{rot}$ ). Aumento de 6500X. Análise de elétrons retro-espalhados. Ataque com Nital 3\% (ALVAREZ, 2006)

As linhas de estudo em I.S. têm sido direcionadas ao atendimento de três dos aspectos característicos mais importantes nos processos de manufatura:

- Geração de propriedades específicas nos componentes mediante diferentes processos de manufatura;

- Descrição das propriedades geradas na superfície e subsuperficie do componente

- Correlação entre estas propriedades e o desempenho funcional da superficie

Os trabalhos que predominam na literatura sobre I.S. se baseiam no conceito exposto nos dois primeiros itens, e focam-se no estudo das propriedades geradas na superficie e os métodos de caracterização próprios da tecnologia de superfícies (FIELD e KAHLES, 1971; FIELD et al., 1972; PANASYUK et al., 1995; LESKOVAR e KOVAC, 1988; GUO E WARREN, 2008; GUO et al., 2010). Em um trabalho clássico realizado por Field et al. (1972), apresentou-se um resumo completo dos métodos de medição para a I.S. existentes na época da sua publicação, no qual se descreveram em detalhe as principais técnicas de caracterização de superficies e apresentou-se uma primeira metodologia sistemática para classificar a I.S. em níveis de complexidade de informação. 
A contribuição mais importante que uma abordagem em I.S. oferece durante a concepção de elementos de máquinas está direcionada ao seu impacto no aperfeiçoamento do projeto, permitindo nesta fase a escolha do processo de fabricação e a definição dos parâmetros de processo em termos de especificações de desempenho da superficie. Diversos trabalhos apresentaram exemplos de aplicações onde foram estabelecidos parâmetros de processo em função de critérios de desempenho para superfícies geradas por meio de diferentes processos de fabricação (GRIFFITHS, 2001; KALPAKJIAN e SCHMID, 2001; HIOKI, 2005; HASHIMOTO et al., 2006).

\subsubsection{Integridade superficial nos processos de usinagem com ferramentas de geometria definida}

Nos processos de usinagem com ferramentas de geometria definida quase todo o trabalho mecânico associado à geração de cavaco é convertido em calor (TRENT e WRIGHT, 2000; SHAW, 2005; DINIZ et al., 2008). As fontes geradoras de calor são a deformação e o cisalhamento do cavaco no plano de cisalhamento, o atrito do cavaco com a ferramenta, e o atrito da ferramenta com a peça, gerando três regiões bem definidas e denominadas como: zona primária, secundária e terciária (ALTINTAS, 2000; TOENSHOFF et al., 2000; TRENT e WRIGHT, 2000; GRIFFITHS, 2001; SHAW, 2005, DINIZ et al., 2008), sendo apresentadas na Figura 1.5.

$\mathrm{Na}$ zona primária ocorre a deformação e a separação do cavaco, sendo a principal fonte geradora de calor, seguida pela zona secundária devido ao atrito do cavaco com a superficie de saída na ferramenta e, por último, a zona terciária devido às deformações da peça e atrito com a superficie de folga da ferramenta (SHAW, 2005). As porcentagens de calor total e as respectivas temperaturas presentes em cada uma das regiões apresentadas na Figura 1.5 são específicas para cada condição de processo, variando com o tipo de usinagem, o material da peça e da ferramenta, as condições de usinagem e a forma da ferramenta (DINIZ et al., 2008). 


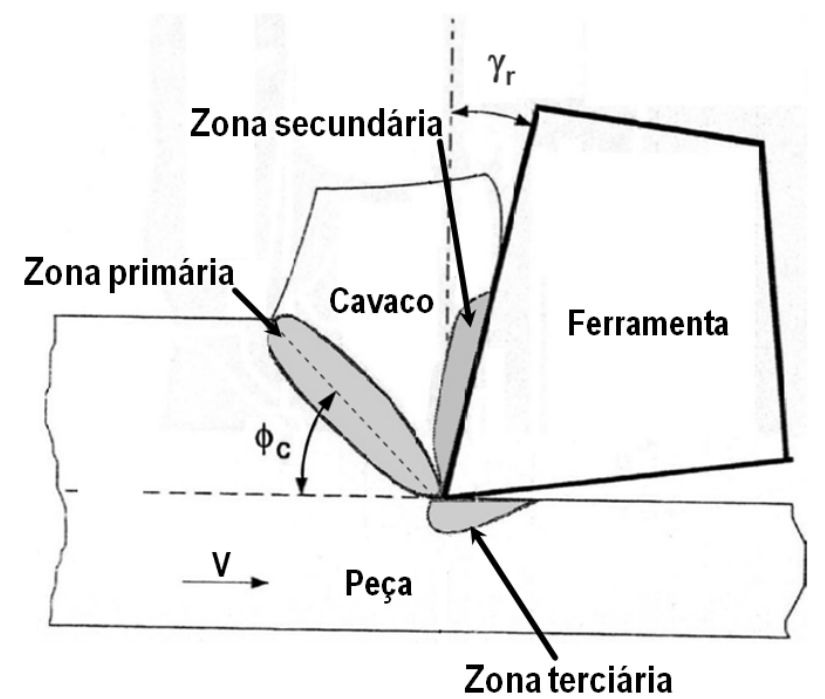

Figura 1.5 - Representação esquemática das regiões geradoras de calor durante o processo de corte (ALTINTAS, 2000; GRIFFITHS, 2001).

Na Figura 1.6 apresenta-se uma curva que informa sobre a variação da parcela de energia de corte empregada no processo de torneamento em função da velocidade de corte; igualmente é mostrada a distribuição de temperaturas nas diferentes regiões geradoras de calor durante o torneamento utilizando uma ferramenta de metal duro.
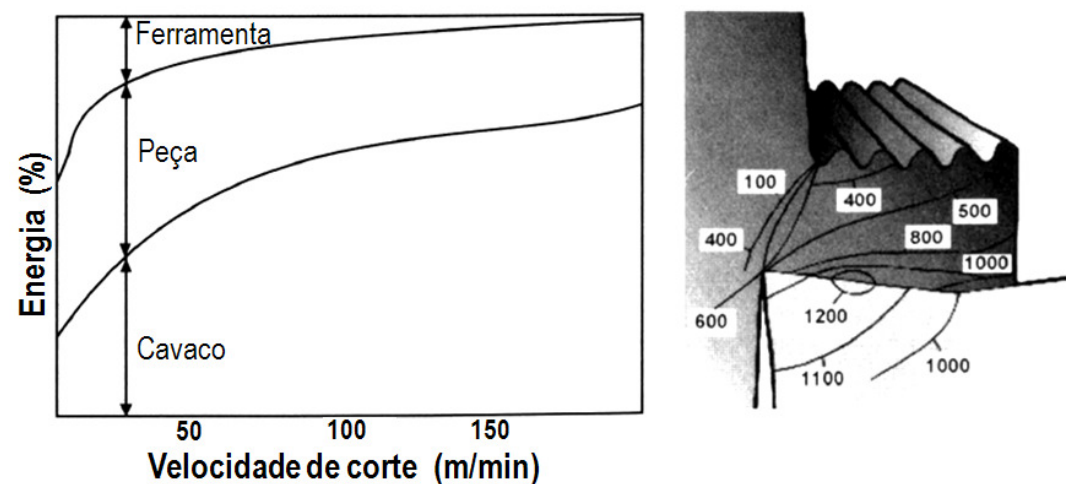

Figura 1.6 - Variação da distribuição de energia de corte com a velocidade de corte e distribuição da temperatura para uma ferramenta de metal duro (KOENIG, 1981; MACHADO e DA SILVA, 2004; DINIZ et al, 2008).

Outros autores (KEONIG e CLOCKE, 1997 apud OLIVEIRA, 2006) também apresentam informações sobre as parcelas de geração de calor e a distribuição de temperaturas durante o torneamento de um aço, como mostrado na Figura 1.7. Observa-se que estas informações coincidem com o apresentado por Diniz e colaboradores (2008), donde a deformação e o cisalhamento do cavaco na região primária ficam como as principais fontes geradoras de calor. 
Os efeitos térmicos e mecânicos que ocorrem na região primária e terciária (Figura 1.5) são os principais responsáveis pelas alterações na peça usinada, as quais podem ocorrer na superficie e na subsuperficie. Outro fato importante a ser comentado é que a maior parte do calor gerado é dissipado pelo cavaco. A outra parcela significativa de calor fica na ferramenta de corte. Embora a parcela de calor gerada seja dissipada, em sua maior parte, entre o cavaco e a ferramenta, é importante comentar que em função das velocidades de corte, o calor que flui pela peça fica concentrado em regiões pequenas. A velocidade com que ocorrem as mudanças e o fluxo de calor está relacionada com as propriedades físicas dos materiais usinados (MACHADO, 2009).

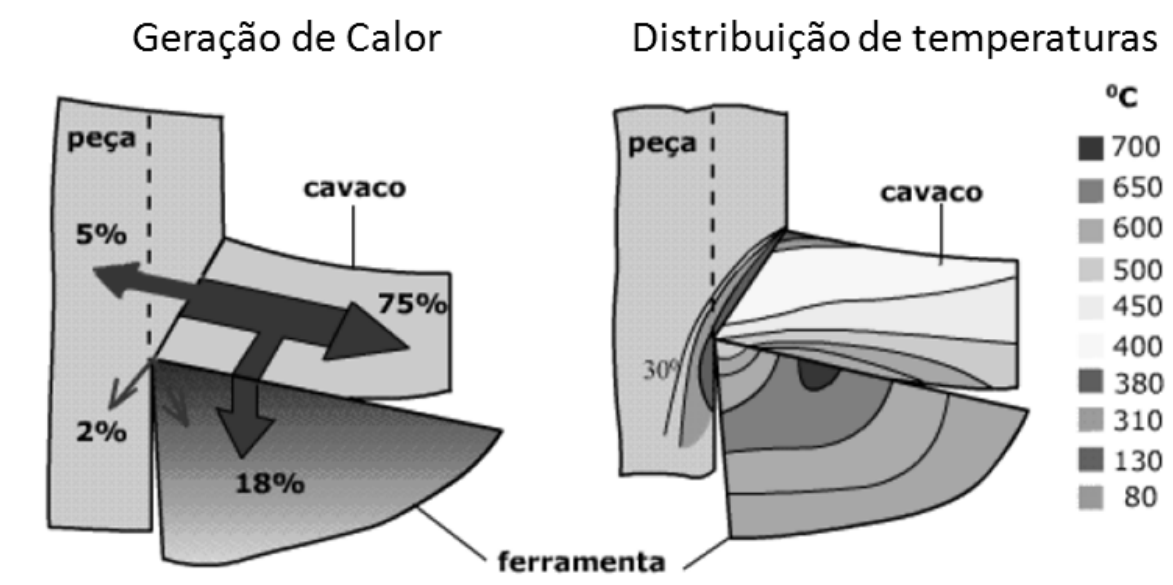

Figura 1.7 - Parcela de geração de calor e distribuição de temperaturas no processo de torneamento de um aço (vc $=60 \mathrm{~m} / \mathrm{min}$ ) (KOENIG e CLOCKE, 1997 apud OLIVEIRA, 2006).

Um fator que caracteriza os processos de usinagem com ferramentas com geometria definida ocorrem na zona primária, onde é gerada grande deformação plástica com altas taxas de deformação pelo cisalhamento de material, motivo pelo qual o torneamento pode ser considerado como um processo "mecâno-térmico" em função da natureza dos mecanismos que governam a remoção do cavaco (GRIFFITHS, 2001). Ao se analisar o efeito na superficie e subsuperficie das peças torneadas devido aos eventos de origem mecânica, podem-se observar a presença de depósitos de material, fluxo lateral de material, sulcos, dobras, abertura de cavidades e deformação plástica a frio, entre outros (ALVAREZ, 2006; GRIFFITHS, 2001). Dentre os efeitos mais comuns ocasionados na camada termicamente afetada podem ser mencionados: as transformações de fase, a presença de trincas a nível macroscópico e microscópico de origem térmica e a deformação plástica a quente (GRIFFITHS, 2001). 
A tensão residual pode ser definida como a tensão existente num corpo elástico depois de serem removidas as cargas externas (JANG et al; 1996). A combinação das alterações que ocorrem na superficie e subsuperficie como resultado dos esforços mecânicos podem gerar tensões residuais trativas ou compressivas, sempre em função das variáveis de processo empregadas (FIELD et al, 1972; LIU e BARASH, 1976; LESKOVAR e KOVAC, 1988; CAPELLO et al, 1999; MATSUMOTO et al; 1999; GRIFFITHS, 2001). A origem das tensões residuais nos processos que empregam ferramentas com geometria definida é predominantemente mecânica; e numa menor proporção como resultado da ação das elevadas temperaturas de corte (LIU e BARASH, 1976; GRIFFITHS, 2001), causando tensões residuais. Durante o torneamento as forças de corte são elevadas, gerando deformação plástica localizada ou deformação elástica não homogênea em algumas regiões da camada superficial, podendo induzir tensões residuais compressivas ou trativas. Shaw (2005) apresenta o mecanismo de geração de tensão residual trativa num material dúctil durante a usinagem (Figura 1.8).

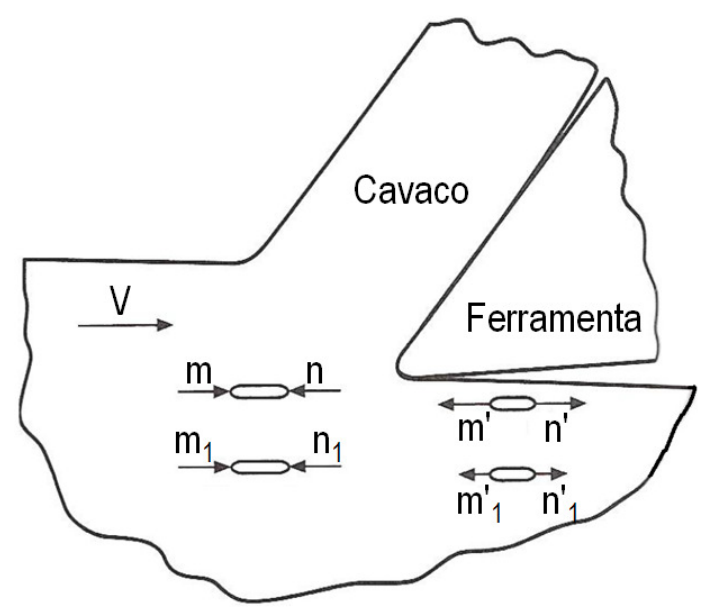

Figura 1.8 - Representação esquemática do mecanismo de geração de tensão residual trativa em matérias dúcteis (SHAW, 2005).

Observa-se na Figura 1.8 que a porção de material representado pelo segmento "mn" é submetido a tensões de compressão antes de ser atingido pela aresta de corte da ferramenta. Assim que a ferramenta ultrapassar o segmento "mn", a maior parte da energia de deformação acumulada nesta região será liberada. Se a energia de deformação for muito elevada (produzindo cavacos com grandes regiões de material não deformado e originando alto desgaste na ferramenta) e rapidamente liberada (sob ação de altas velocidades de corte), a recuperação do material (m'n') é potencializada com a passagem da 
ferramenta, decorrendo em tensões residuais de tração. A magnitude da tensão residual de tração diminui com o aumento da profundidade (segmento m' ${ }_{1}{ }^{\prime}{ }_{1}$ ), aumentando com o emprego de ferramentas desgastadas e ângulos de folga menores (SHAW, 2005).

Já a temperatura elevada produz alterações volumétricas da estrutura, distorcendo o material localizado na zona afetada termicamente, porém, gerando tensões residuais trativas (se ocorrer contração do volume) ou compressivas (se ocorrer dilatação do volume) na subsuperficie (GRIFFITHS, 2001). De uma forma geral, a presença de tensão residual de tração na superficie reduz a resistência à fadiga como resultado do favorecimento da ocorrência de fissura do material (MEYERS, 2000). O comportamento oposto ocorre sob a presença de tensões residuais compressivas, levando ao respectivo aumento da resistência à fadiga.

Leskovar e Kovac (1988) aplicaram o conceito da I.S. como critério da qualidade na fabricação de componentes. O trabalho consistiu na avaliação da tensão residual devida aos efeitos dos parâmetros de processo em operações de torneamento, fresamento, retificação e soldagem. Em todos os casos foi feita a medição de tensão residual mediante a remoção de camadas e o uso de extensômetros durante o alivio da deformação do corpo de prova (método do furo cego incremental). Na Figura 1.9 apresenta-se o estado de tensões para a condição de torneamento de ferro fundido nodular, cuja usinagem foi realizada com dois niveis de intensidade: moderada e severa. Estes autores determinaram o efeito dos parâmetros de corte (velocidade de corte e avanço) e o desgaste da ferramenta (desgaste de flanco) no estado de tensão residual. Observa-se da Figura 1.9 que a velocidade de corte influenciou no estado de tensão residual tornando-a trativa ou compressiva, enquanto o avanço só modificou a magnitude da tensão residual. Um maior desgaste de flanco acarretou aumento na tensão residual trativa.

O levantamento das informações obtidas por Leskovar e Kovac (1998) possibilita o aperfeiçoamento do projeto e fabricação de componentes, já que em função dos parâmetros de processo é possível gerar um estado de tensões residuais que favoreçam o desempenho da superficie. Contudo, para conhecer o impacto do estado das tensões geradas pelos diferentes parâmetros de processo, testes adicionais de desempenho seriam necessários. 


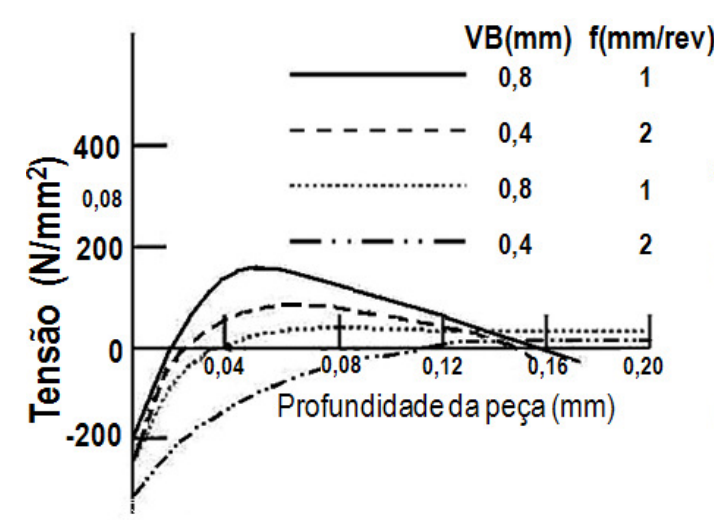

(a)

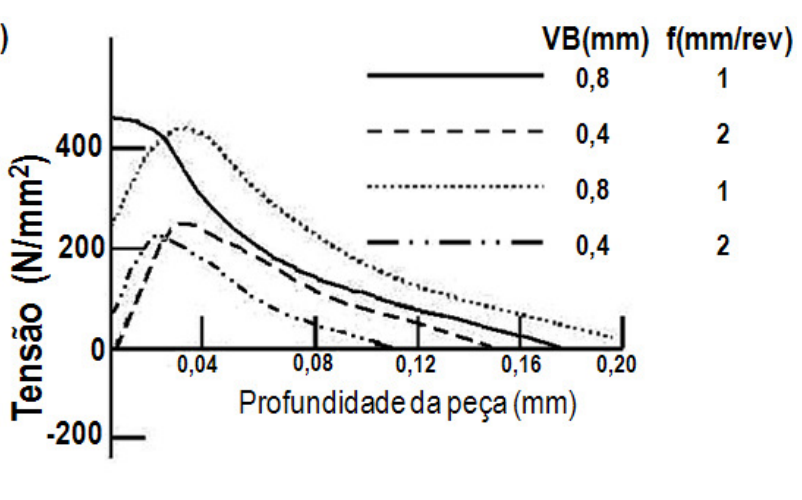

(b)

Figura 1.9 - Avaliação da tensão residual após o torneamento de um ferro fundido nodular, a dois níveis diferentes de intensidade após torneamento: a) $\mathrm{V}=4 \mathrm{~m} / \mathrm{min}$; b) $10 \mathrm{~m} / \mathrm{min}$. VB é o desgaste de flanco da ferramenta, f é o avanço, a tensão residual paralela à superficie é $\sigma\left(\mathrm{N} / \mathrm{mm}^{2}\right.$. (LESKOVAR e KOVAC, 1988).

Hioki (2005) a partir ensaios de desgaste realizados em superficies fresadas com usinagem à alta velocidade "High speed machining (HSM)" mostrou os efeitos que os parâmetros de corte exercem sobre o desempenho tribológico de um aço ferramenta. Na metodologia de análise adotada por Hioki (2005) foi feita uma descrição detalhada da relação entre os efeitos dos parâmetros de processo da I.S. e do desempenho funcional. A superficie e a camada superficial foram avaliadas usando técnicas próprias da tecnologia de superficies (metalografia da seção transversal, análise de tensão residual, medição perfil de dureza na seção transversal e avaliação da rugosidade 3D) para logo ser testado o desempenho tribológico mediante a determinação da vida da superficie com ensaios de desgaste por deslizamento.

Destaca-se do trabalho apresentado por Hioki (2005) a criação de um índice baseado em dados experimentais obtidos a partir da topografia e da I.S., contribuição que permitiu estabelecer uma relação quantitativa entre os parâmetros do processo de fabricação e a vida da superficie. Este índice adimensional chamado pelo autor de "Índice de Desempenho da Superfície (IDS)", está composto pelas características da superficie e subsuperfície que tiveram maior efeito (maior significância estatística) sobre o desempenho tribológico. Estas características foram: a razão de textura superficial (topografia), o índice de formação de cavidades (topografia - direcionalidade, assimetria e curtose), a rugosidade média quadrática (topografia), e a tensão residual medida no sentido longitudinal e transversal à direção de avanço (subsuperficie). A seguir é apresentada na Figura 1.9 a curva que relaciona a vida da superficie contra o IDS. 


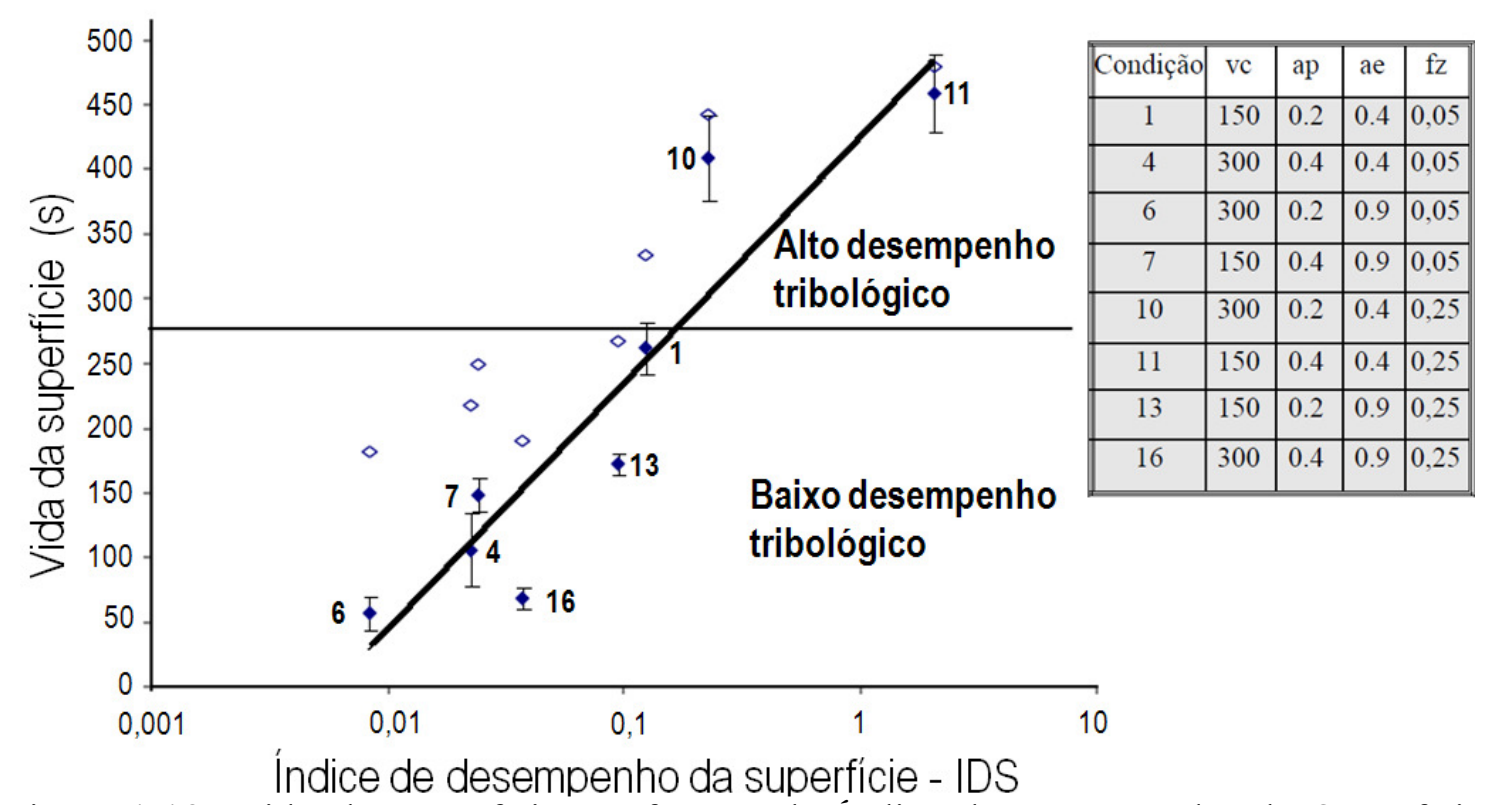

Figura 1.10 - Vida da superficie em função do Îndice de Desempenho da Superfície (IDS) de amostras de aço AISI H13 geradas mediante fresamento HSM e submetidas a desgaste por deslizamento (HIOKI, 2005). $\left(\mathrm{v}_{\mathrm{c}}=\right.$ velocidade de corte $(\mathrm{mm} / \mathrm{min}) ; \mathrm{a}_{\mathrm{p}}=$ profundidade de corte $(\mathrm{mm}) ; a_{\mathrm{e}}=$ penetração de trabalho $(\mathrm{mm}) ; \mathrm{f}_{\mathrm{z}}=$ avanço por dente $(\mathrm{mm}))$.

Observa-se da Figura 1.10 que as superficies testadas por Hioki apresentaram proporcionalidade entre o valor do IDS e a vida da superficie, e consequentemente, foi possivel classificar os diferentes grupos de superficies em niveis de alto e baixo desempenho tribológico em função de parâmetros de processo.

\subsubsection{Integridade superficial nos processos de usinagem com ferramentas de geometria não-definida}

Nos processos de corte de geometria não definida a remoção de material é realizada pela ação de grãos de materiais duros, os quais são colocados em interferência com o material da peça. No processo de retificação a ferramenta possui geometria não definida, porém, é uma técnica fundamentada na ação de um abrasivo, onde o rebolo pode ser considerado como uma ferramenta de corte que possui uma quantidade muito grande de arestas de corte distribuídas de forma aleatória (SHAW, 2005; DINIZ et al., 2008). Na Figura 1.11 apresenta-se uma representação esquemática das três fases principais no processo de remoção do cavaco na retificação, onde se mostra a ação de corte de material de um grão abrasivo. 


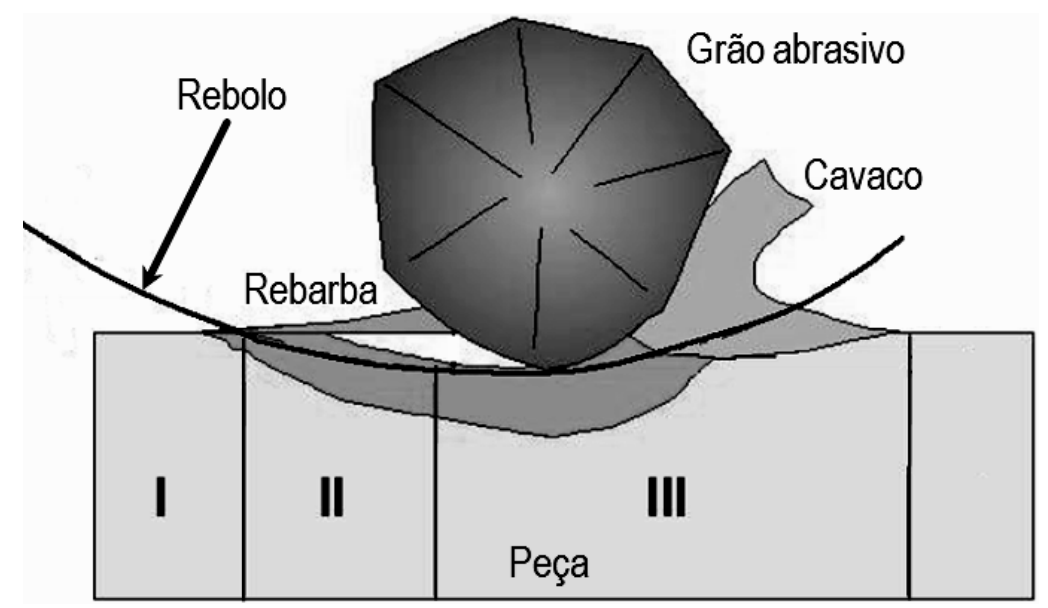

Figura 1.11 - Esquema representativo das três (3) etapas para a formação do cavaco no processo de retificação (DINIZ et al, 2008)

Num primeiro estágio (I), o grão abrasivo ao começar a entrar em contato com a peça escorrega na superfície da mesma e como consequência do atrito, gera deformação elástica na pequena região de material atingida. O segundo estagio (II) está comandado pelo mecanismo de riscamento, o qual acontece como resultado do aumento das tensões na interface grão-material, causando principalmente deformação plástica em outra pequena porção de material na forma de rebarbas. Finalmente, num terceiro estagio (III), é atingida a tensão de ruptura do material e acontece a remoção de uma pequena porção de material em forma de cavaco, sendo que nesta região de saída do grão abrasivo tem-se também uma parcela de deformação plástica e elástica (DINIZ et al., 2008).

Ao se comparar a retificação com os processos de geometria definida uma das principais diferenças que surge tem a ver com a velocidade de remoção do cavaco, sendo que, a velocidade do grão abrasivo pode chegar a ser até 10 vezes maior, quando comparada com a velocidade utilizada no processo de torneamento. Igualmente, a energia total requerida para o processo de retificação é da ordem de 2 a 20 vezes maior que para outros processos de usinagem, para o mesmo volume de cavaco removido na unidade de tempo (DINIZ et al, 2008). Este fato aliado às altas forças normais (radiais) empregadas gera altas temperaturas de corte $\left(1000\right.$ a $\left.1600^{\circ} \mathrm{C}\right)$, podendo atingir e superar sua temperatura de fusão, porém sem se fundir, pois o tempo de exposição a essa temperatura é curto.

Segundo Diniz e colaboradores (2008), a maior parcela do calor gerado no processo de retificação vai para a peça (85\%). O rebolo é pouco afetado pelo 
calor, já que geralmente é feito de material refratário e possui uma área grande para dissipação do calor gerado (10\%). A parcela de calor restante $(5 \%)$ é transmitida para o cavaco. Diante disso, a alta parcela de calor recebida pela peça pode gerar mudanças microestruturais numa camada superficial, erros de forma e dimensão, o qual se soma o estado do material que geralmente já foi tratado termicamente antes da retificação. Para minimizar os efeitos prejudiciais devidos ao calor gerado na peça é utilizado fluído de corte de maneira abundante e contínuo durante a remoção de material.

Koster et al. (1976 apud KALPAKJIAN e SCHMID, 2001) estudaram o efeito da retificação no desempenho de um aço. Na Figura 1.12 é apresentada a resistência à fadiga de alto ciclo para um aço AISI 4140 retificado, empregando dois niveis de intensidade de processo (suave e severa).

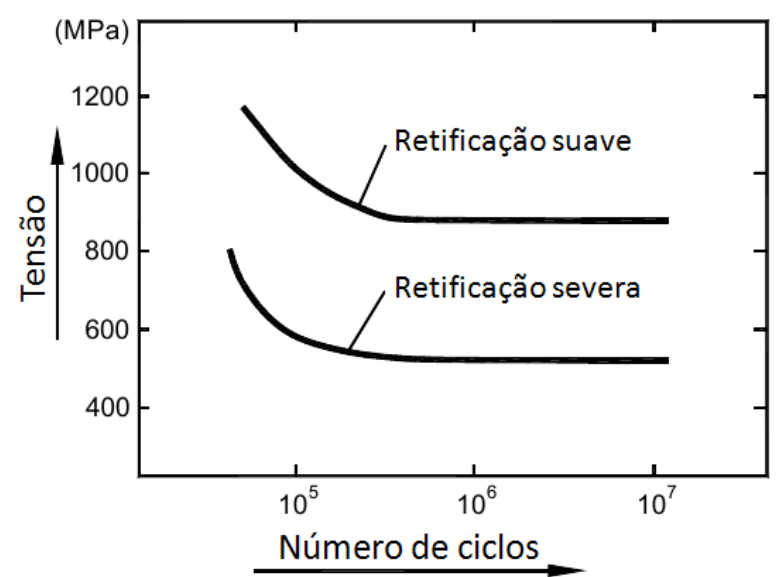

Figura 1.12 - Efeito da intensidade no processo de retificação na resistência à fadiga de alto ciclo de um aço AISI 4140. (KOSTER et al., 1976 apud KALPAKJIAN e SCHMID, 2001).

Observa-se na Figura 1.12 que o desempenho é afetado pela intensidade com que o processo de remoção de material é realizado na retificação. Com a mudança na intensidade do processo de retificação suave até severa apresenta-se a diminuição na resistência à fadiga (KOSTER et al., 1976 apud KALPAKJIAN e SCHMID, 2001). De uma maneira geral, segundo a intensidade do processo de retificação da superficie, são induzidas no componente diferentes características e propriedades físicas, mecânicas, metalúrgicas e químicas que podem levar a alterações no desempenho funcional (GRIFFITHS, 2001). 


\subsubsection{Os processos de acabamento e a sua relação com a integridade superficial}

O acabamento superficial influencia amplamente o comportamento dos componentes, afetando a maneira como estes irão interagir com o meio e com a superficie com as quais entrarão em contato. Ao se realizar o acabamento de uma superficie procura-se satisfazer diferentes necessidades, que vão desde a diminuição do desgaste, até a redução do atrito e da corrosão, melhoria na aparência, resistência à fadiga, transferência de calor, propriedades ópticas, escoamento de fluidos, entre outros (GRIFFITHS, 2001). Igualmente, as operações de acabamento em particular são as responsáveis por garantir não só a precisão dimensional dos componentes, mas também as características superficiais (topografia) e subsuperficiais (deformação plástica, trincas, tensões residuais, transformações de fase, entre outras) presentes no componente antes da sua aplicação em serviço.

As operações de acabamento em resumo são as responsáveis por definir na superficie acabada a topografia, o estado metalúrgico e as propriedades mecânicas do componente. Estes elementos caracterizam o estado de uma superficie acabada e a modificação de qualquer um deles, possui um peso fundamental sobre o desempenho funcional dos componentes usinados; o qual é objeto de estudo da integridade superficial (SHAW, 1984; GRIFFITHS, 2001). Em geral, como apresentado durante o presente capitulo, as operações de usinagem induzem tensões de natureza mecânica e térmica. Com isso, o entendimento básico das relações existentes entre os principais elementos que compõem os processos de fabricação convencionais (peça de trabalho, ferramenta, máquina ferramenta, ambiente de trabalho e variáveis de processo) e os seus efeitos nos aspectos mecânicos e térmicos durante processo de remoção de material, é de fundamental importância no aperfeiçoamento dos processos de acabamento de superficies (DEGARMO et al., 2003).

O efeito que os processos de usinagem exercem sobre o desempenho em fadiga de alto ciclo também tem sido objeto de estudo da I.S. Kalpakjian e Schmid (2001) apresentaram a influência do acabamento das superficies geradas por diferentes processos de fabricação sobre o limite de resistência à fadiga rotativa. Observa-se da Figura 1.13 que a redução no limite de 
resistência à fadiga do ferro fundido em questão, depende tanto do tipo de processo de acabamento escolhido como do limite de resistência do material.

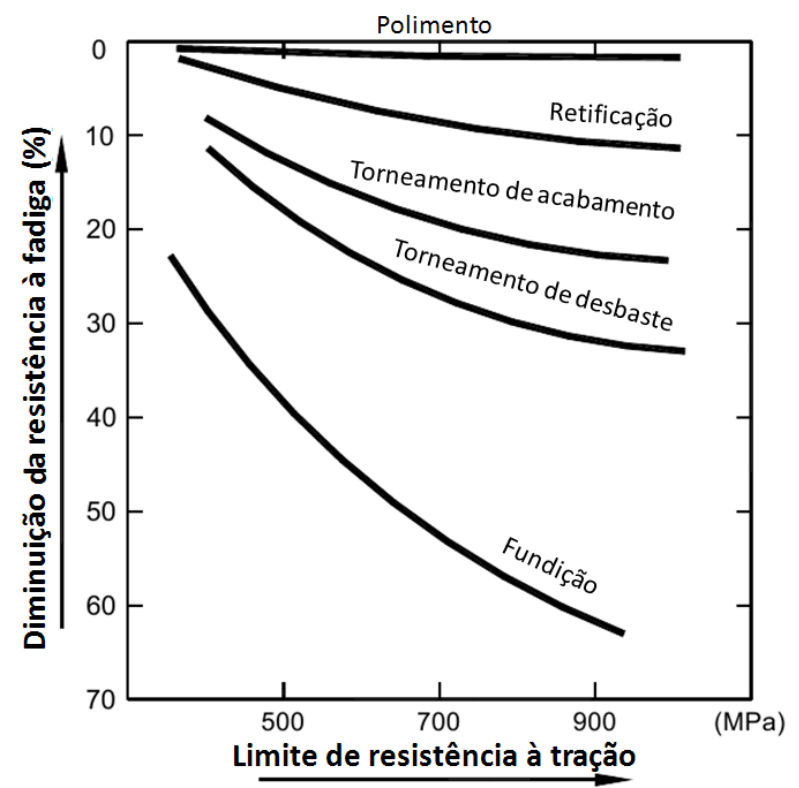

Figura 1.13 - Efeito de diferentes processos de acabamento superficial no limite de resistência à fadiga de um ferro fundido (KALPAKJIAN e SCHMID; 2001)

Os diferentes processos de acabamento empregados não geram somente a diminuição do acabamento superficial e consequente aumento na rugosidade, mas também, acarretaram alterações na integridade das superficies. A peça que não foi submetida a nenhum processo de acabamento e foi ensaiada com a superficie decorrente do processo de fundição apresentou o menor desempenho, enquanto a superficie polida não teve redução no limite de resistência à fadiga. Lembrando como apresentado anteriormente (Figura 1.13), o desempenho de uma superficie não depende só do tipo de processo de manufatura utilizado, mas também do nível de intensidade das variáveis empregadas durante processo de remoção.

\subsection{O papel da Integridade Superficial na Fadiga de contato de rolamento}

\subsubsection{Desgaste por Fadiga}

O desgaste por fadiga pode ocorrer em contatos por rolamento e por deslizamento. Quando corpos em movimento apresentam ciclos de deslizamento e rolamento, pode ser observada fadiga superficial e subsuperficial após um determinado número de ciclos. Os ciclos de carregamento e descarregamento aos quais está submetido o material podem levar à nucleação de trincas na superfície ou na subsuperficie, que após um 
tempo de operação fazem com que a superfície falhe pelo lascamento do material, dando origem ao termo "desgaste por fadiga". No estudo do desgaste por fadiga é mais relevante a determinação da vida do componente em função do número de ciclos ou tempo de operação antes de ocorrer a falha por fadiga (BHUSHAN, 2002).

Contudo, antes desta falha crítica acontecer (o qual pode chegar a ocorrer após milhões de ciclos de carregamento), o desgaste geralmente é considerado como desprezivel, embora ele exista. Em um grande número de contatos bem lubrificados a adesão entre as duas superficies é desprezivel, entretanto, há ainda uma taxa de desgaste. Este desgaste é produzido pelas deformações sofridas pelas asperezas e as camadas superficiais, e pela interação das asperezas nas superficies opostas em contato. Igualmente, o contato entre asperezas acompanhado por altas tensões localizadas se repete sucessivamente durante o deslizamento e o rolamento, e partículas de desgaste são geradas a partir de trincas propagadas por fadiga. A consideração de desgaste desprezivel contrasta com a abordagem adotada para avaliar o desgaste devido a mecanismos de adesão e abrasão onde a degradação ocorre de maneira gradativa desde o começo até o final do evento. Nesses casos, a taxa de material removido é considerada como parâmetro de avaliação da severidade do desgaste.

A origem do desgaste por fadiga está no campo de tensões formado no processo de rolamento/deslizamento. Nas situações onde se tem contato por rolamento o movimento de rolamento nem sempre é puro, e está frequentemente acompanhado de escorregamento ou deslizamento das superficies. O movimento complexo nas mais diversas situações onde predomina o contato por rolamento inclui no mínimo uma pequena parcela de escorregamento ou deslizamento (na faixa de 1 a 10\%), e ocorrem em diversos componentes mecânicos como rolamentos, engrenagens, cames e trilhos de trem (BHUSHAN, 2002). As tensões associadas ao movimento de deslizamento fazem com que a máxima tensão de cisalhamento fique próxima da superfície, e a falha por fadiga seja superficial. Em regimes mistos de rolamento/deslizamento a posição da máxima tensão cisalhante dependerá da magnitude do atrito de deslizamento. Na Figura 1.14 é apresentado o campo de tensões para as condições onde se tem rolamento puro, deslizamento puro, e combinação de rolamento/deslizamento. A curva pontilhada mostra que o 
atrito entre os corpos é suficiente para aproximar a máxima tensão cisalhante da superfície. Já o escorregamento pode levar a dano por desgaste adesivo severo ("scuffing") das superficies em contato.

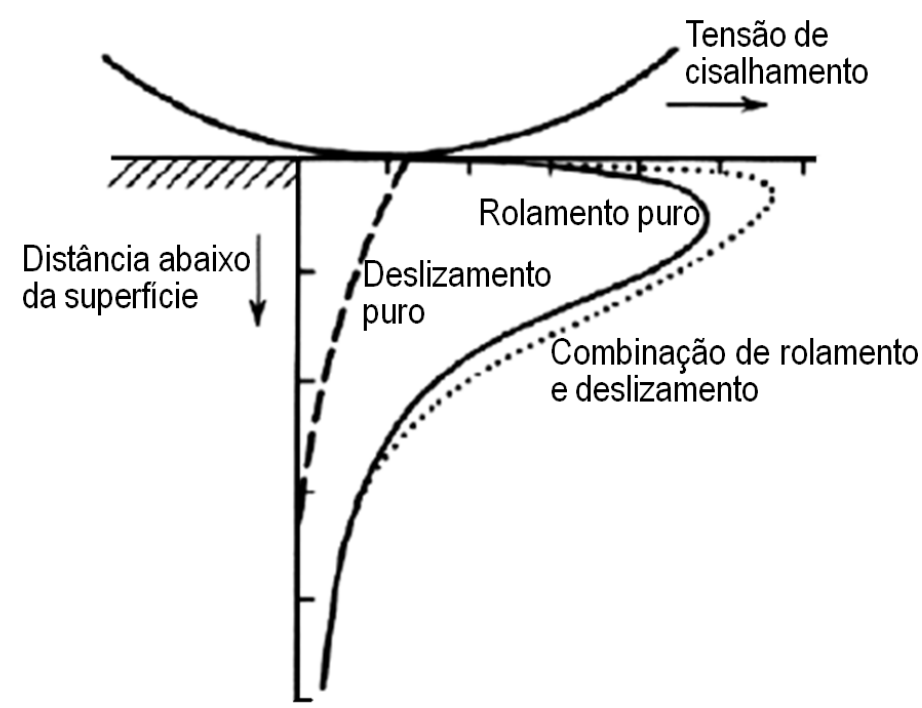

Figura 1.14 - Representação esquemática da distribuição de tensões de cisalhamento abaixo do contato nas situações de rolamento puro, deslizamento e rolamento com deslizamento (BHUSHAN, 2002).

\subsubsection{Fadiga de contato de rolamento}

O termo fadiga de contato ou fadiga superficial usada comumente na literatura é um jargão utilizado para denotar o dano superficial causado pelo contato de rolamento cíclico (STACHOWIAK e BATCHELOR, 2001). A fadiga de contato (FC) faz referência ao dano inicial numa superficie lisa e é usada mais frequentemente no contexto dos rolamentos. Quando é aplicada lubrificação em metais e uma película elastohidrodinâmica é formada adequadamente, o contato metal-metal é prevenido e a destruição repetitiva dos filmes de óxido na superficie é impedida ou limitada. Qualquer desgaste ou destruição da superfície ocorrerá completamente como resultado da variação nas tensões cíclicas imprimidas pelo contato por rolamento cíclico. Desgaste ou fadiga de contato origina-se pela formação de trincas superficiais que eventualmente permitem a separação de partículas de desgaste da superficie.

Na Figura 1.15 está sumarizado uma série de fatores envolvidos nesse sistema e que potencialmente podem contribuir para a formação e/ou propagação de uma trinca de fadiga de contato (ASM, 1996). Como colocado por Neves (2006), devido à quantidade de fatores que afetam à vida em fadiga de contato durante o funcionamento de um sistema de contato de rolamento 
ao menos um dos fatores apresentados causará em uma microrregião o acúmulo de sucessivas deformações plásticas.

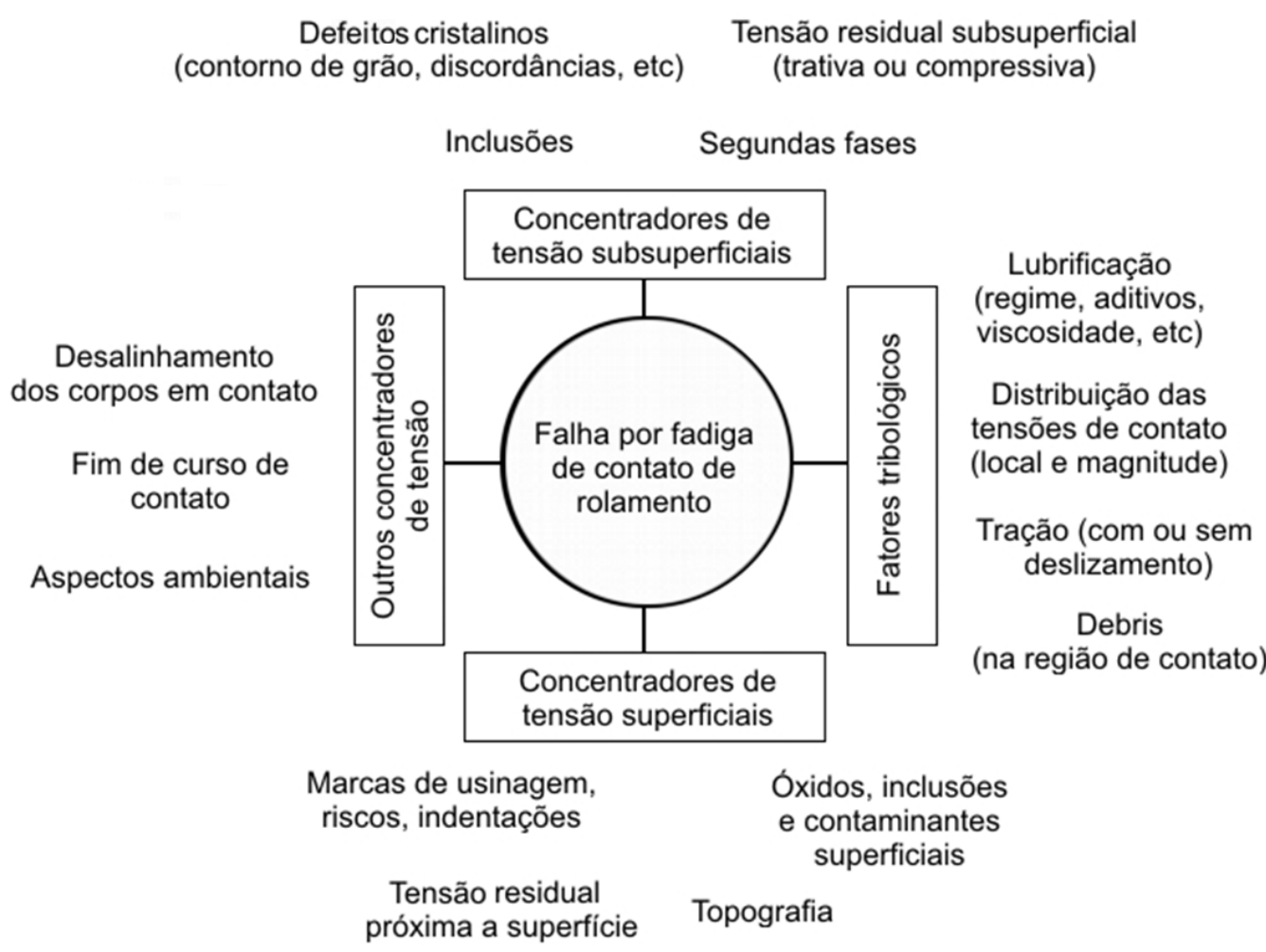

Figura 1.15 - Fatores que afetam a vida em fadiga de contato de rolamento (NEVES, 2006; ASM, 1996).

Como observado na Figura 1.15, a falha por fadiga de contato de rolamento (FCR) pode ocorrer devido a uma série fatores tribológicos e de concentradores de tensão que atuam na superficie e na subsuperficie do material, os quais incidem na nucleação e/ou a propagação do defeito (NEVES, 2005). Igualmente, os diferentes tipos de processos de usinagem ou de remoção de material têm um grande impacto nas características superficiais $\mathrm{e}$ subsuperficiais, os quais são gerados pela combinação de diversos fatores que estão diretamente relacionados ao processo de fabricação ou ao material da peça acabada (MORTON, 1994). Popinceanu et al. (1981) durante o estudo do efeito das tensões residuais na vida em fadiga de contato, determinaram que o estado de tensão residual pode ser ótimo somente para uma dada geometria de contato e condições de carregamento específicas. Esta observação se baseia no fato que a vida em fadiga é determinada pela ação de uma tensão crítica, que age dependendo da combinação das tensões de contato e das tensões residuais no material. 
As tensões desenvolvidas abaixo da superficie podem então interagir, por exemplo, com alguma inclusão posicionada em seu campo de ação e este se tornar o ponto inicial de deformação localizada a partir de onde uma trinca será nucleada e se propagará pelo material até o desprendimento de uma lasca da superficie. Se após a propagação da trinca for gerada fratura no material, decorrendo no desprendimento de pequenas partículas da superfície, o fenômeno é conhecido como "pitting". Geralmente, o "pitting" é seguido da perda de grandes quantidades de material na superficie, o qual é conhecido como "spalling".

\subsubsection{Fadiga de contato de rolamento e Integridade superficial em superfícies torneadas e retificadas}

Existe uma estreita relação entre a I.S. e a FC das superficies usinadas e inclusive, a metodologia de análise para o estudo destes dois conceitos está fundamentada no entendimento de propriedades e características semelhantes. Por exemplo, a determinação do estado de tensões residuais, do grau de deformação plástica, da topografia, e do dano superficial (entre outros fatores externos e internos) é objeto de interesse quando é feita uma abordagem tanto em I.S. como para FC.

A I.S. das superficies torneadas e retificadas influi na vida em FCR (AGHA e LIU, 2000; CHOI e LIU, 2006; HASHIMOTO et al., 2006; GUO e WARREN, 2008; GUO et al., 2010), sendo objeto de interesse durante o acabamento de superficies de componentes que devem possuir precisão dimensional e alto desempenho funcional, características próprias das superfícies submetidas a solicitações que requerem contato e altos cíclicos de carregamento.

Mediante o emprego do torneamento duro (TD), é induzida uma ampla faixa de tensões residuais compressivas na camada superficial das superficies usinadas, as quais são função dos parâmetros de usinagem (FARIAS, 2009). No TD, mesmo se tratando de um processo de remoção de material de geometria definida é possivel gerar os mesmos níveis de acabamento superficial que aqueles obtidos mediante o emprego de processos baseados em abrasão, e sem produzir dano térmico na superficie (LIU e MITTAL, 1996). Este processo permite realizar o acabamento de componentes em uma única etapa, levando a significantes ganhos de tempo e custo durante o processo de fabricação do componente. Liu e Mittal (1998) apresentaram uma metodologia 
para a escolha dos parâmetros de TD durante o acabamento da superficie de pistas de rolamento, visando o aumento da vida em FCR. Agha e Liu (2000) estudaram experimentalmente o efeito dos parâmetros de corte do TD no desempenho de superficies submetidas a FCR. Os resultados apresentados nesse trabalho mostraram que os parâmetros de corte selecionados no TD afetam significativamente os aspectos da integridade da superficie das peças fabricadas e consequentemente, a vida em fadiga.

Hashimoto et al. (2006) compararam a I.S. de superficies geradas pelos processos de TD e retificação, empregando corpos de prova de aço AISI 52100 temperados e revenidos, e com uma dureza na faixa de 61 a 62 HRc. A avaliação da I.S. foi realizada mediante a consideração do acabamento superficial, caracterização da microestrutura ao longo da seção transversal e medições de dureza instrumentada nas escalas micro e nano. Imagens da seção transversal dos corpos de prova são apresentadas na Figura 1.16, onde é possivel observar as alterações na subsuperficie decorrentes do processo de fabricação, ressaltando nas áreas demarcadas as regiões que ficaram endurecidas pela usinagem (com espessura entre 4 e $6 \mu \mathrm{m}$ ), e também, nas áreas de maior espessura $(8$ até $14 \mu \mathrm{m})$ as regiões que foram afetadas termicamente.
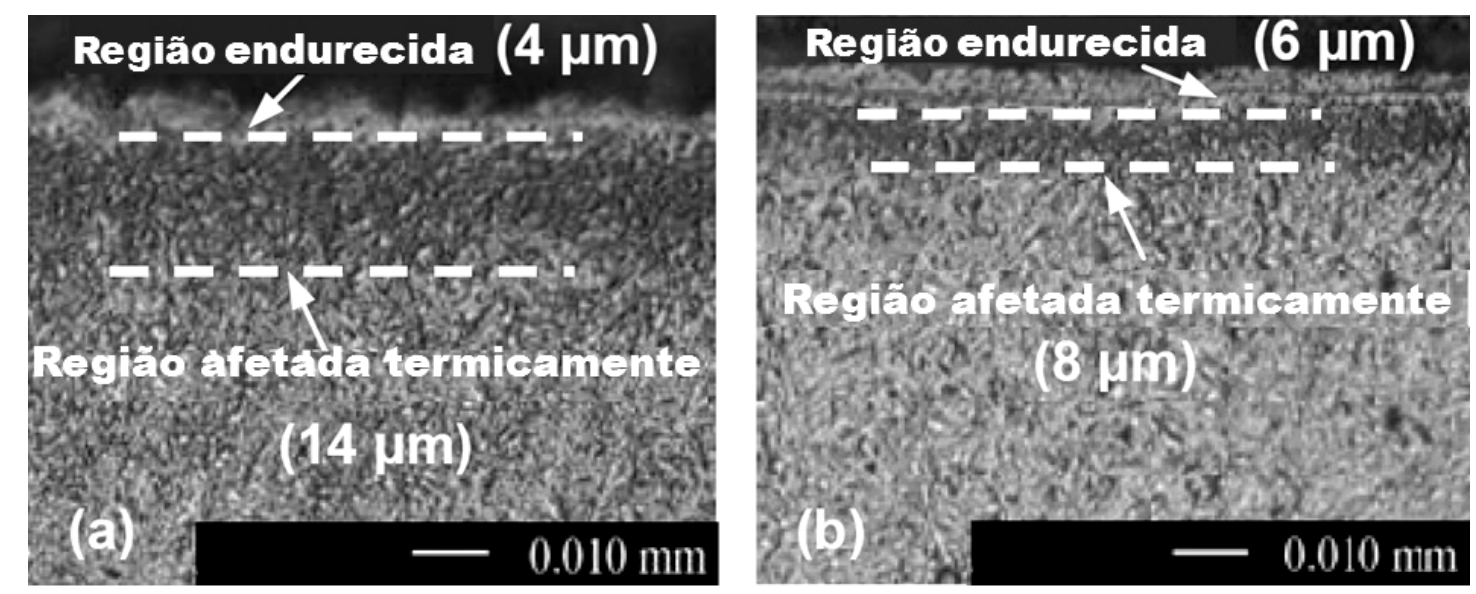

Figura 1.16 - Imagens da seção transversal da superfície do aço AISI 52100 a) retificado; b) torneado. Imagens obtidas com microscópio óptico e microestrutura revelada com nital ao $2 \%$ (HASHIMOTO et al., 2006)

Mesmo com evidências de regiões na subsuperficie que sofreram alterações devidas à temperatura, esta não foi suficientemente elevada para gerar dano na superficie associada a efeitos térmicos. As diferenças nas regiões apresentadas nas micrografias correspondem ao efeito dos diferentes gradientes de deformação e do tamanho de grão presentes na microestrutura 
como resultado do processo de manufatura. Contudo, foi a amostra torneada quem ficou menos afetada ao se comparar a profundidade e espessura das camadas afetadas com as observadas na amostra retificada.

O desempenho das superficies descritas anteriormente foi avaliado mediante ensaios de fadiga de contato por rolamento (FCR) (HASHIMOTO et al., 2006) num equipamento com a configuração esfera sobre plano, empregando uma tensão de contato de Hertz de $4.5 \mathrm{GPa}$ a uma velocidade de rotação do eixo de $2600 \mathrm{rpm}$. O carregamento na superficie dos corpos de prova foi aplicada mediante o emprego de 9 esferas de aço para rolamento com diâmetro de 5,56 $\mathrm{mm}$. As trincas por fatiga subsuperficiais se propagaram a $35^{\circ}$ e $40^{\circ} \mathrm{com}$ relação à direção de rolamento, como apresentado na Figura 1.17. Estes pesquisadores não apresentaram informação suficiente que permita aprofundar na análise das trincas e conhecer o local de nucleação das mesmas, e assim inferir sobre se a origem da trinca foi na superficie ou na subsuperficie, informação importante para o entendimento dos mecanismos de desgaste e da I.S.
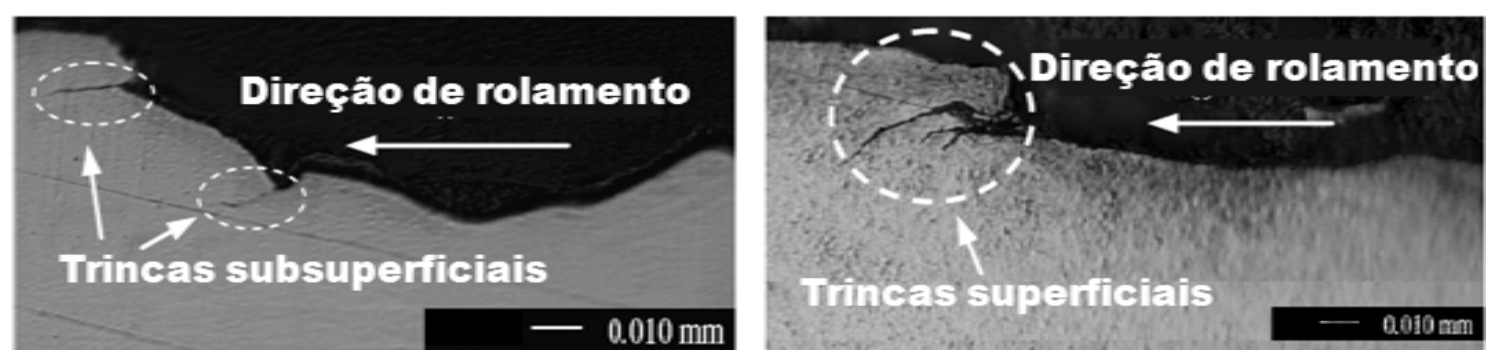

Figura 1.17 - Imagens da seção transversal mostrando o defeito e o padrão de trinca para a condição a) retificado; b) torneado. Imagens obtidas com microscópio eletrônico de varredura revelada com nital ao $2 \%$ (HASHIMOTO et al., 2006)

Guo e Warrem (2008) compararam as diferenças da I.S. gerada pelo processo de torneamento duro (TD) e retificação sobre os mecanismos de dano em contato por rolamento. Estes pesquisadores identificaram que dependendo do processo utilizado para gerar as superficies existem diferenças no padrão de propagação das trincas subsuperficiais. A partir de imagens obtidas em MEV, determinaram que a sequência de formação de trincas por fadiga (superficiais, principais e ramificadas) é diferente para as superficies torneadas e retificadas. O desempenho das superficies testadas é sumarizado na Figura 1.18. 


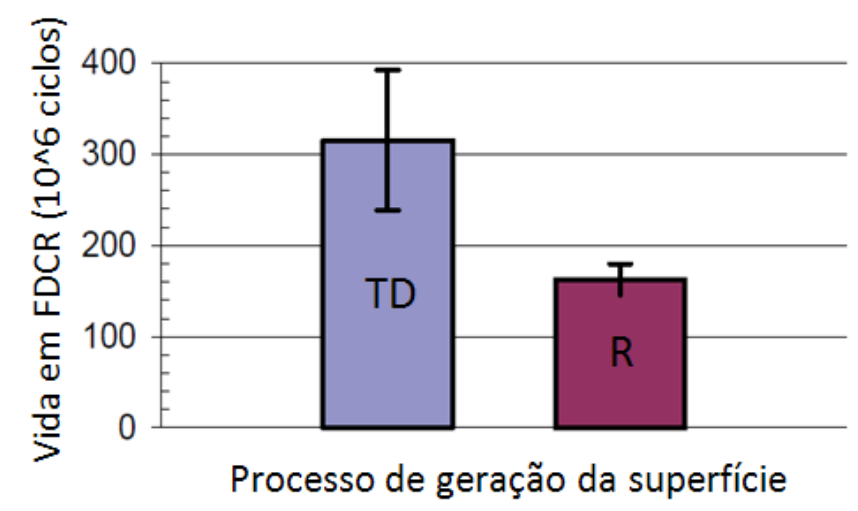

Figura 1.18 - Comparação do desempenho em fadiga de contato de rolamento para superficies obtidas por torneamento duro (TD) e retificação (R) (HASHIMOTO et al., 2006)

A vida em fadiga de contato foi obtida ao tirar o valor médio da vida de três corpos de prova para cada condição. A superficie torneada apresentou uma vida em FCR 100\% maior quando comparada com a condição retificada. Esta diferença é devida às características próprias de cada processo de fabricação, que fazem com que a I.S. possua um papel fundamental no desempenho destas superfícies em FCR (HASHIMOTO et al., 2006). Contudo, esta diferença considerável de desempenho atribuída por Hashimoto et al. (2006) à I.S. pode estar afetada por um erro de natureza estatística, já que como é apresentado na literatura o fenômeno de FC está descrito por uma distribuição de Weibull (ou Lognormal), e não, pela distribuição Normal (VANEGAS et al., 2009). Foi realizado polimento metalográfico das superficies torneadas e retificadas antes de realizar os ensaios de FCR. Este procedimento foi realizado com o intuito de minimizar o efeito que as diferenças em rugosidade das duas superficies podem acarretar na vida em FC. Ao realizar o polimento na superficie das amostras, não é retirada somente a topografia decorrente da usinagem, mas também, a camada subsuperficial de material mais próximo da superfície é removida. Este procedimento não permite conhecer o desempenho da I.S. da superficie gerada pelo processo de fabricação, em função da camada superficial retirada durante o polimento, eliminando a camada de material que sofreu deformação plástica e que foi afetada termicamente pelo processo, o qual como apresentado nos capítulos anteriores pode gerar transformações microestruturais, alterações na dureza e/ou na tensão residual.

Schwach e Guo (2005) a partir de amostras de aço AISI 52100 mostraram que a presença de camadas de material termicamente afetado podem comprometer o desempenho em FCR, e que mediante a mudança nos 
parâmetros de corte é possivel encontrar diferenças de até 50\% na vida em FC. Outro aspecto que deve ser levado em consideração ao remover a superfície própria da usinagem, é que não é possivel comparar os processos em termos das diferenças no desempenho funcional que são atribuídas à topografia. Por exemplo, fazendo polimento se elimina a propriedade da topografia das superficies torneadas e retificadas de apresentar rugosidade com "Skewness" negativa, o qual favorece a capacidade de retenção de lubrificante (KUNDRAK E BANA, 2003).

\subsection{Métodos de medição da integridade superficial}

A integridade superficial é avaliada mediante o emprego de diversas técnicas que fazem parte da tecnologia de superfícies. Segundo a definição de integridade superficial adotada no presente trabalho, a topografia é um dos três conjuntos de elementos que permitem avaliar a integridade superficial junto com as características subsuperficiais e o desempenho funcional. A seguir serão definidas as características da IS que serão avaliadas durante o presente trabalho e as técnicas de caracterização utilizadas.

\subsubsection{A topografia e os métodos de medição}

O termo "topografia de uma superficie" é utilizado para descrever as características da superficie de um componente usinado. Estas características são apresentadas esquematicamente na Figura 1.19, na qual se ilustra alguns dos elementos que compõem a topografia e as diferenças nas ordens de grandeza durante o seu processo de avaliação.

Segundo a American Society of Mechanical Engineering (ASME B46.1, 2002), uma superficie quando representada idealmente em desenhos de projeto ("superficie geométrica ou nominal") difere da "superficie real"; isto é devido a esta última possuir irregularidades de diversas ordens de grandeza resultantes do método como foi gerada. 


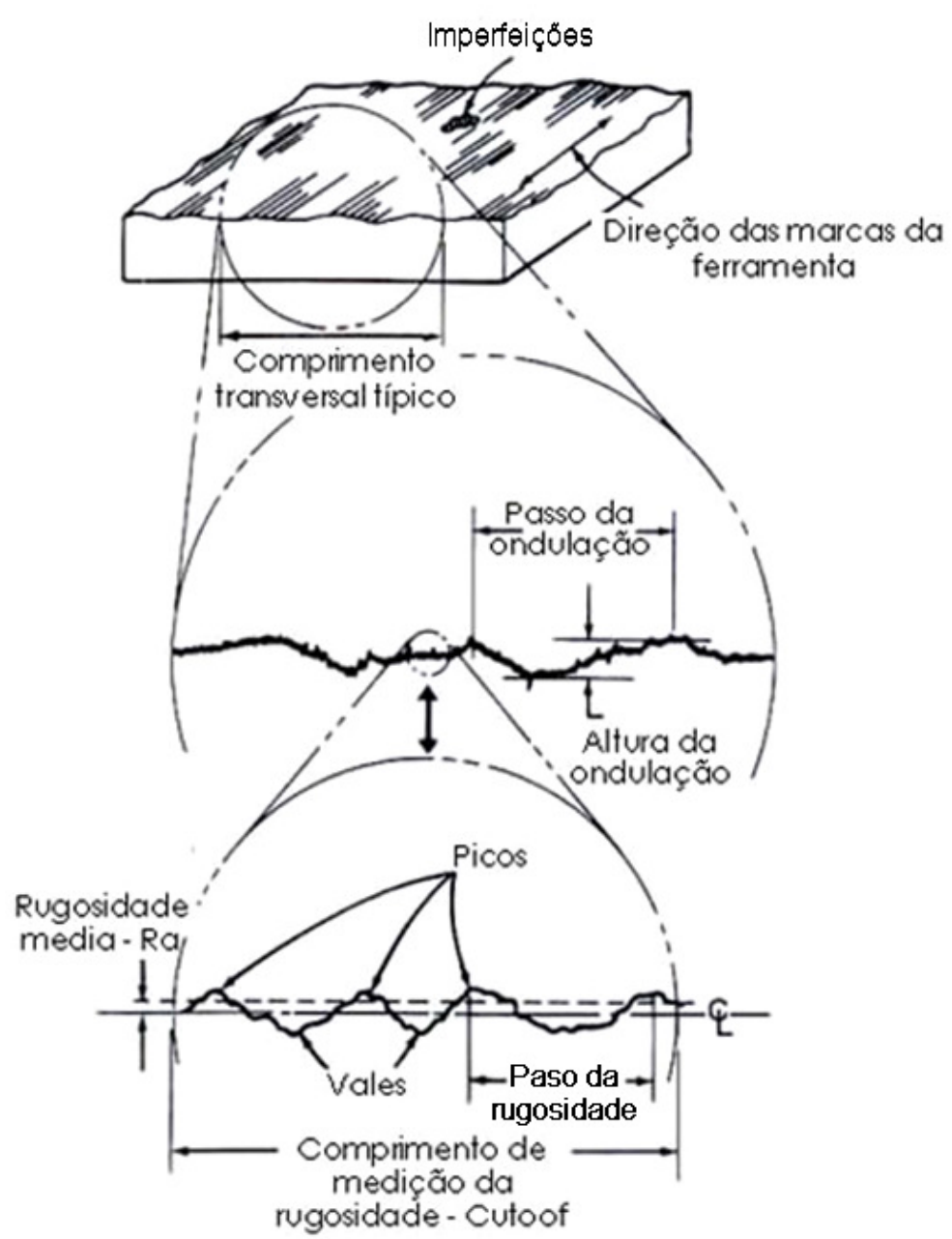

Figura 1.19 - Representação esquemática das caracteristicas de uma superficie onde são ilustradas as diferentes ordens de grandeza ao se avaliar a topografia (ANSI Standard B46.1, 1978 apud MACHINABILITY DATA CENTER, 1980).

Estas diferenças da superficie real em relação à superficie nominal são em termos da sua textura, imperfeições e erros de forma. Contudo, quando a superfície real é representada mediante o auxílio de instrumentos de medição é chamada de "superficie efetiva ou medida" (ASME B46.1, 2002). Na Figura 1.20 ilustram-se esquematicamente as definições anteriormente apresentadas.

A topografia de uma superficie real pode ser descrita mediante a avaliação da textura da superficie, acabamento superficial, orientação das marcas da ferramenta, erros de forma e imperfeições. 
Superfície Geométrica

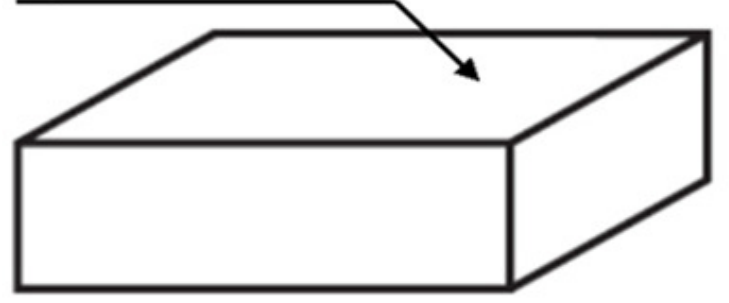

a)

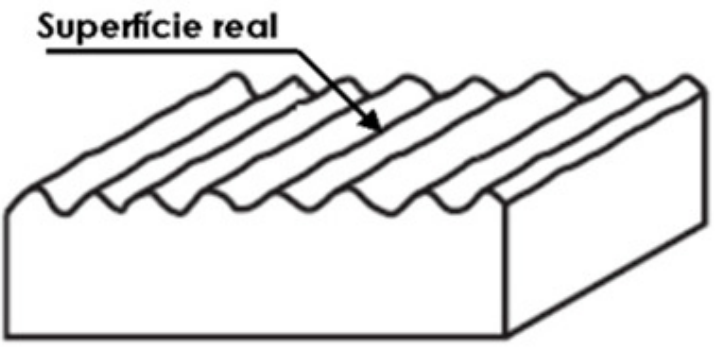

b)

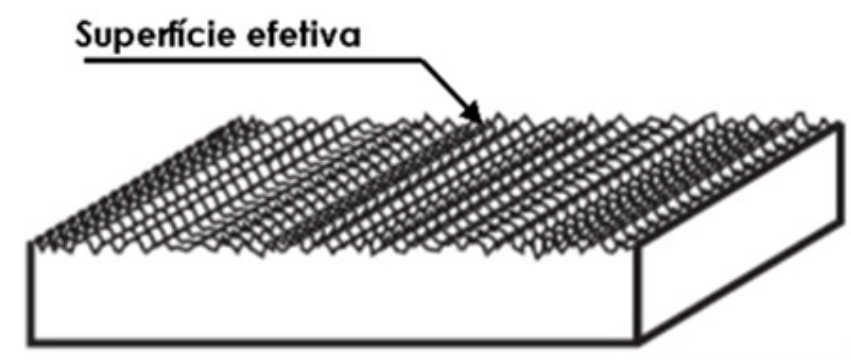

c)

Figura 1.20 - Representação esquemática da: a) superficie geométrica; b) superficie real; c) superficie efetiva (ASME B46.1, 2002).

A textura da superficie é a composição de certos desvios que são típicos de uma superficie real, a qual inclui a rugosidade e a ondulação (ASME B46.1 1995). Fundamentalmente existem dois tipos de instrumentos para medir a textura de um componente, os que possibilitam realizar a medição com ou sem contato do instrumento com a superficie. Assim, têm-se os seguintes métodos e instrumentos que se baseiam em diferentes princípios de funcionamento: mecânicos por apalpador ("Stylus"), ópticos (perfilômetro óptico) e de varredura (microscópio eletrônico de varredura, microscópio de força atômica).

O instrumento utilizado mais amplamente é o perfilômetro mecânico do tipo apalpador (GRIFFITHS, 2001). Durante a medição, o apalpador desliza horizontalmente sobre a superficie que está sendo medida. Na medição em 2D o perfil é a base de toda informação que se deseja extrair da superfície, e o principio de funcionamento do perfilômetro mecânico com apalpador é apresentado na Figura 1.21. Devido às diferenças de altura (picos e vales) da superficie real, o apalpador se desloca verticalmente, movimentos que são convertidos em sinais elétricos por um transdutor piezelétrico. 


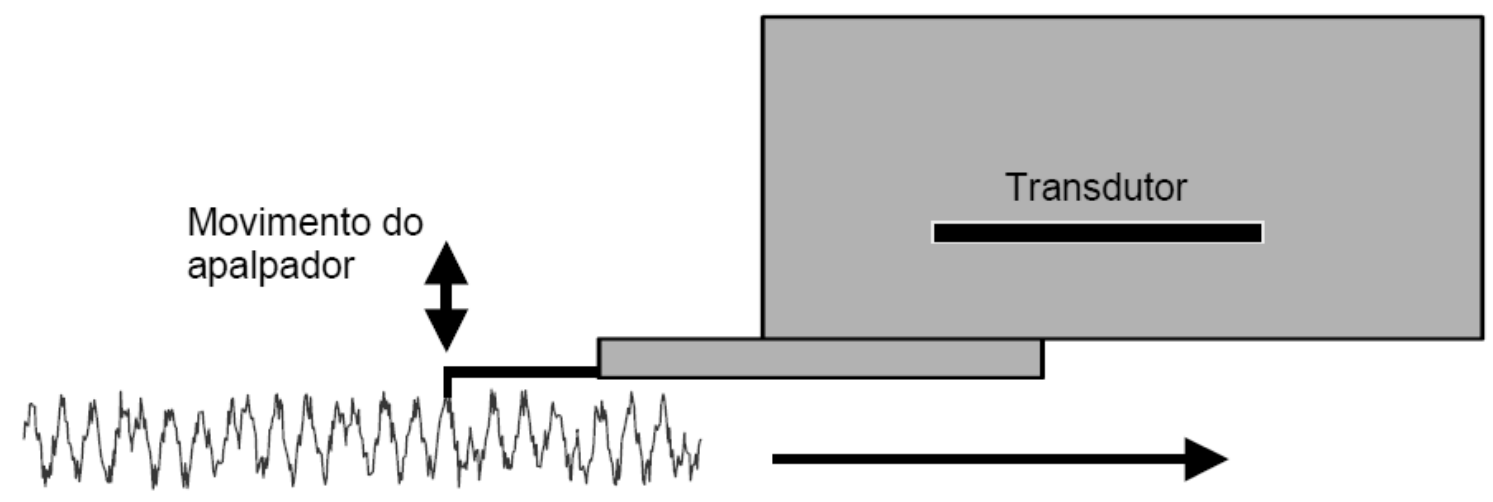

Figura 1.21 - Princípio de funcionamento do perfilômetro mecânico com apalpador

A rugosidade caracteriza-se pelas micro-irregularidades geométricas na superfície do material decorrentes do processo de fabricação. A ondulação é o componente de maior espaçamento da textura da superficie, sendo normalmente atribuída à rigidez do sistema (deflexão da máquina ou da peça, vibração e trepidação). Os parâmetros de rugosidade para os métodos de medição baseados no uso de perfilômetros (parâmetros de rugosidade bidimensionais) são classificados como: parâmetros de altura, parâmetros de espaçamento, parâmetros de forma e funções e, finalmente, parâmetros híbridos (ASME, 1996). Como reportado em algumas das principais fontes consultadas (MORTON, 1994; ASME, 1996; GRIFFITHS, 2001; WHITEHOUSE, 2004), os parâmetros de rugosidade comumente utilizados para estudar a IS das superficies geradas mediante processos de usinagem se restringem ao uso de parâmetros de altura, sendo os mais utilizados: Ra, Rz, Rt e Rq. Um dos parâmetros que definem a ondulação é a altura da ondulação (Wt). A altura da ondulação é a altura do pico mais alto ao vale mais profundo do perfil modificado; modificações que consistem em remover do perfil a rugosidade e parte da forma mediante filtragem, alisamento, ou outros meios.

A orientação das marcas da ferramenta é a característica que diferencia a direção dos padrões gerados numa superfície usinada para cada processo de fabricação (MORTON, 1994). Por exemplo, no torneamento de faceamento e na retificação com retífica plana (processos utilizados no presente trabalho), o padrão de orientação das marcas da ferramenta é paralelo. Na Figura 1.22, apresentam-se os símbolos utilizados para representar a direção das marcas da ferramenta relativas à superficie nominal; simbologia que é apresentada pelo Machinability Data Center (1980) e Griffiths (2001), baseados nas normas 
ANSI Y14.36 de 1978 (ANSI, 1978) e ISO 1302 de 2001 (ISO, 2001), respectivamente.

\begin{tabular}{|c|c|c|}
\hline $\begin{array}{c}\text { Símbolo } \\
\text { Gráfico }\end{array}$ & Interpretação & $\begin{array}{l}\text { Padrão dle } \\
\text { Orientação }\end{array}$ \\
\hline & $\begin{array}{l}\text { Paralelo ao plano de vista no qual o } \\
\text { simbolo empregado. }\end{array}$ & \\
\hline & $\begin{array}{l}\text { Perpendicular ao plano de vista no qual } \\
\text { o simbolo é empregado. }\end{array}$ & \\
\hline & $\begin{array}{l}\text { Cruzado em duas direçós obliquas } \\
\text { relativas ao plano no qual o simbolo ta } \\
\text { empregado. }\end{array}$ & \\
\hline & Múltiplas direçōes. & \\
\hline & $\begin{array}{l}\text { Aproximadamente circular relativo ao } \\
\text { centro da superficie onde o simbolo é } \\
\text { empregado. }\end{array}$ & \\
\hline R & $\begin{array}{l}\text { Aproximadamente radial relativo ao } \\
\text { centro da superficie onde o simbolo ef } \\
\text { empregado. }\end{array}$ & \\
\hline P & $\begin{array}{l}\text { Marcas com orientaça particular, nào } \\
\text { direcionada ou em relevo. }\end{array}$ & 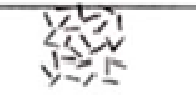 \\
\hline
\end{tabular}

Figura 1.22 - Símbolos usados para representar as marcas da ferramenta na designação da textura da superficie segundo as normas ANSI Y14.36 de 1978 [ANSI, 1978], e ISO 1302 de 2001 [ISO, 2001]

As imperfeições são as interrupções não intencionais, inesperadas, e não desejadas que ocorrem esporadicamente em uma determinada região da superficie. Segundo a norma ISO 8785 (1998), "uma imperfeição é um elemento, irregularidade ou grupo de elementos e irregularidades da superfície real intencional ou acidentalmente causado durante a usinagem, armazenamento ou uso". As imperfeições da superficie mais comuns nas superficies manufaturadas incluem trincas, crateras, inclusões, sulcos, riscos, entre outras. As principais imperfeições definidas pela norma ISSO 8785 (1998) relevantes durante o estudo da IS são sumarizadas na Figura 1.23 (GRIFFITHS, 2001). A quantidade, tamanho e distribuição de imperfeições que são consideradas como prejudiciais para a IS devem ser definidas durante as diferentes etapas de projeto do componente. 

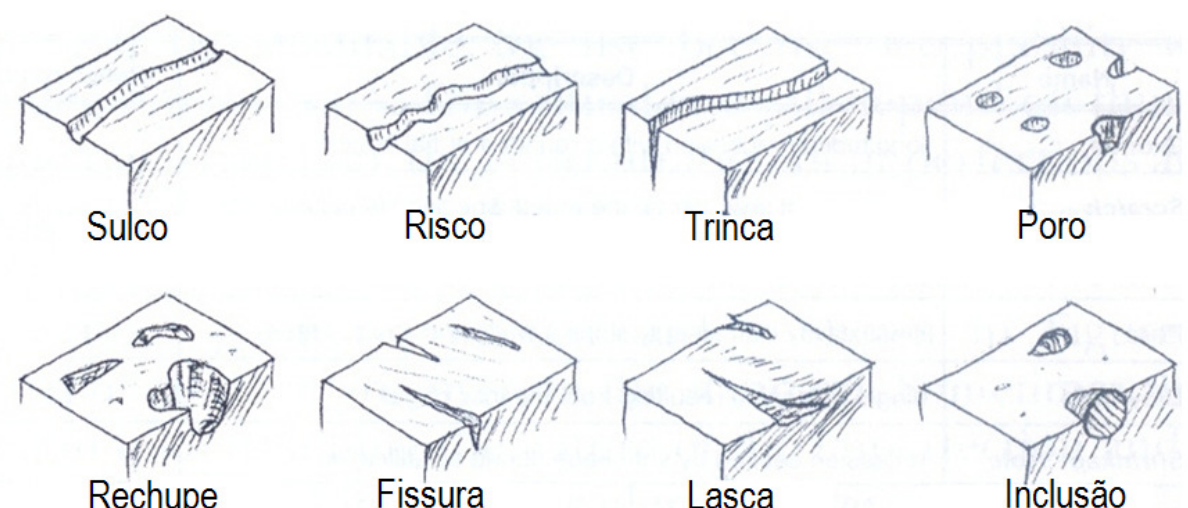

Fissura
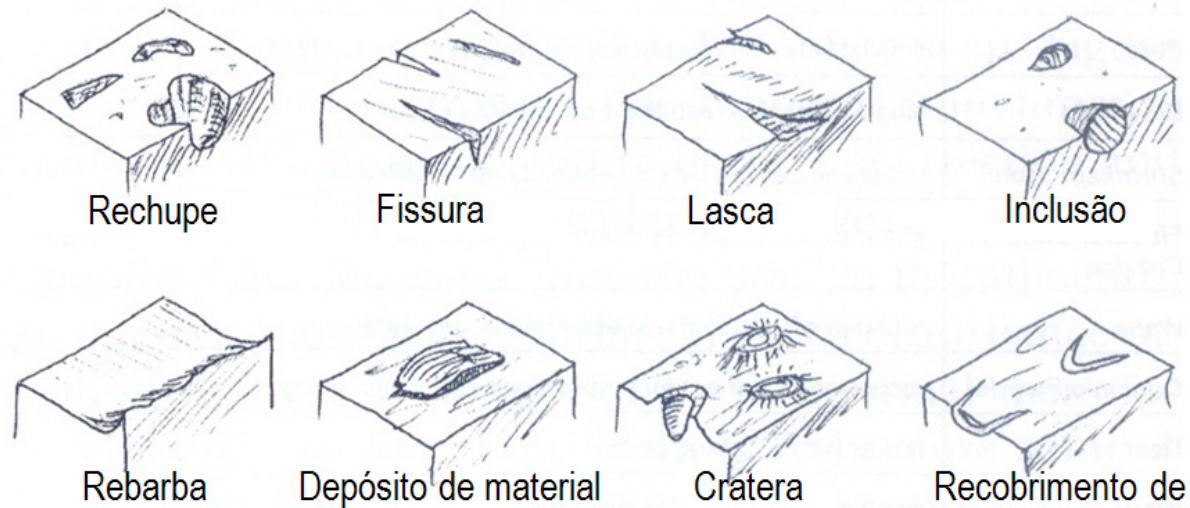

Recobrimento de crateras/inclusões ("Lap")

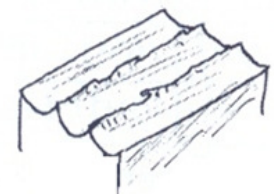

Resíduos de cavaco
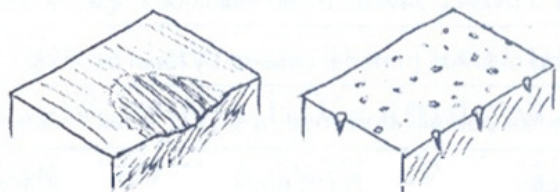

Erosão

Picadas ("Pitting")

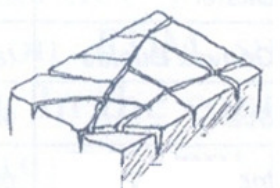

Rachadura

Figura 1.23 - Imperfeições da superfície definidas pela norma ISO 8785 (1998) em superficies manufaturadas relevantes durante o estudo da integridade superficial (GRIFFITHS, 2001).

O acabamento superficial é um termo comumente usado para indicar a qualidade geral de uma superfície e não está ligado necessariamente à textura ou à orientação das marcas da ferramenta, nem aos valores específicos de rugosidade. Não obstante, o acabamento superficial é expresso como uma característica qualitativa do acabamento relativa a uma determinada aplicação, e, em termos gerais, um bom acabamento sugere a ausência de defeitos, imperfeições e valores reduzidos na rugosidade (MORTON, 1994).

No presente trabalho a avaliação das outras características da topografia (marcas da ferramenta, imperfeições e acabamento superficial) diferentes da textura superficial será feita mediante a utilização de métodos ópticos, para o qual será utilizada microscopia óptica, microscopia eletrônica de varredura e microscopia estereoscópica. Estas técnicas permitem observar detalhes específicos das características da superficie real (destacando aspectos na ordem de alguns micrometros), as quais são registradas digitalmente no formato de imagens com alta resolução para a sua posterior análise. 


\subsubsection{Características subsuperficiais e técnicas de medição}

Em função do tipo e da intensidade da energia empregada no processo de usinagem pode ocorrer transformações na camada superficial pela ação de esforços mecânicos e das elevadas temperaturas em consequência da ação da ferramenta de corte (GRIFFITHS, 2001). As propriedades do material da peça de trabalho ficam afetadas e é produzida uma ampla variedade de efeitos na subsuperficie, sendo os mais comuns a deformação plástica (resultante de deformação a quente ou a frio), microtrincas e macrotrincas, transformações de fase, tensão residual, entre outros (ver item 1.2). Geralmente estas alterações são frequentes e possuem pouca profundidade $(2,5 \mu \mathrm{m})$ quando utilizadas condições de trabalho convencionais. Sob condições de trabalho muito severas, a profundidade das alterações podem oscilar na faixa de 127 $\mu \mathrm{m}$ a $380 \mu \mathrm{m}$ (MACHINABILITY DATA CENTER, 1980). A literatura reporta amplamente a presença deste tipo de alterações durante a usinagem de aços endurecidos, aços inoxidáveis e ligas de titânio e níquel. Uma alteração particular que surge durante a usinagem de materiais endurecidos é a formação da camada branca.

No âmbito das superficies manufaturadas, o termo "camada branca" expressa o tipo de dano que se apresenta em materiais ferrosos como uma camada dura e frágil, a qual é gerada sob determinadas condições de processo (FIELD e KHALES, 1964; TORRANC, 1978; SHAW e VIAS, 1994; GRIFFITHS, 1995; KRUTH et al., 1995; CHOU e EVANS, 1999). Esta camada de material apresenta cor branca sob a ação de reagentes metalográficos quando observada em microscópio óptico, e aparece definida contrastando com a cor do material não alterado quando observada em microscópio eletrônico de varredura (GRIFFITHS, 1987). Na Figura 1.24 são apresentadas duas imagens da camada branca obtidas por microscopia óptica e microscopia eletrônica de varredura. É possível observar nas duas imagens a diferença de escala dos detalhes que são possíveis de serem observados nas duas micrografias apresentadas.

A espessura típica desta camada pode chegar aos $10 \mu \mathrm{m}$, variando a sua dimensão em função das condições de corte empregadas (BOSHEH e MANTINVEGA, 2005). A microestrutura da camada branca é reconhecida 
como uma "martensita anormal" composta de nanocristais e material parcialmente transformado com alta densidade de discordância.

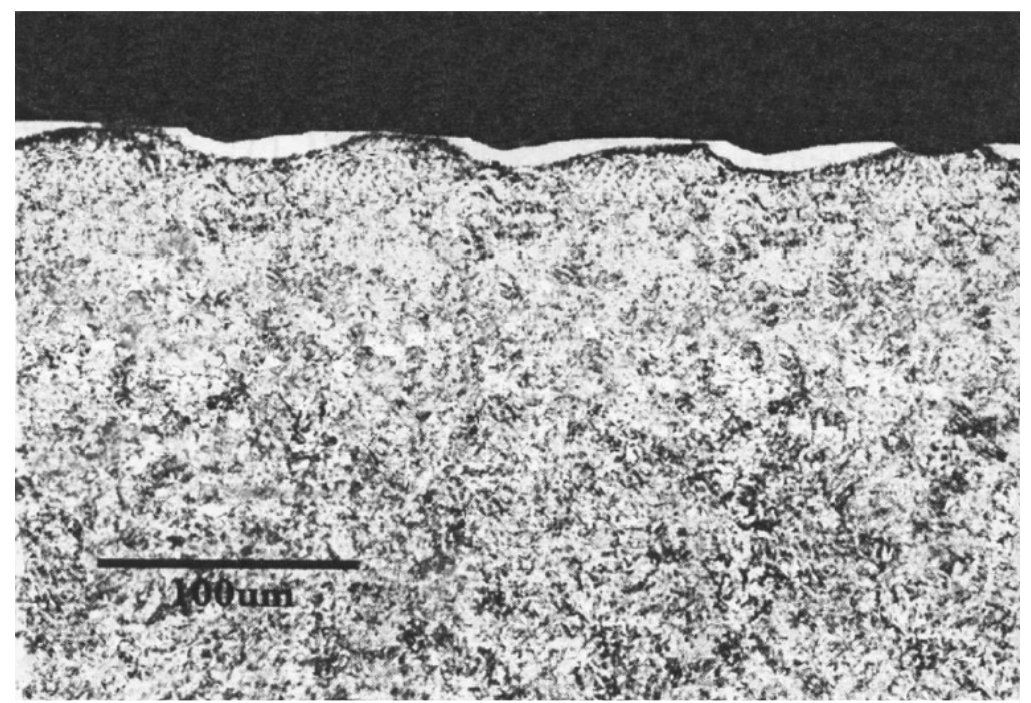

a)
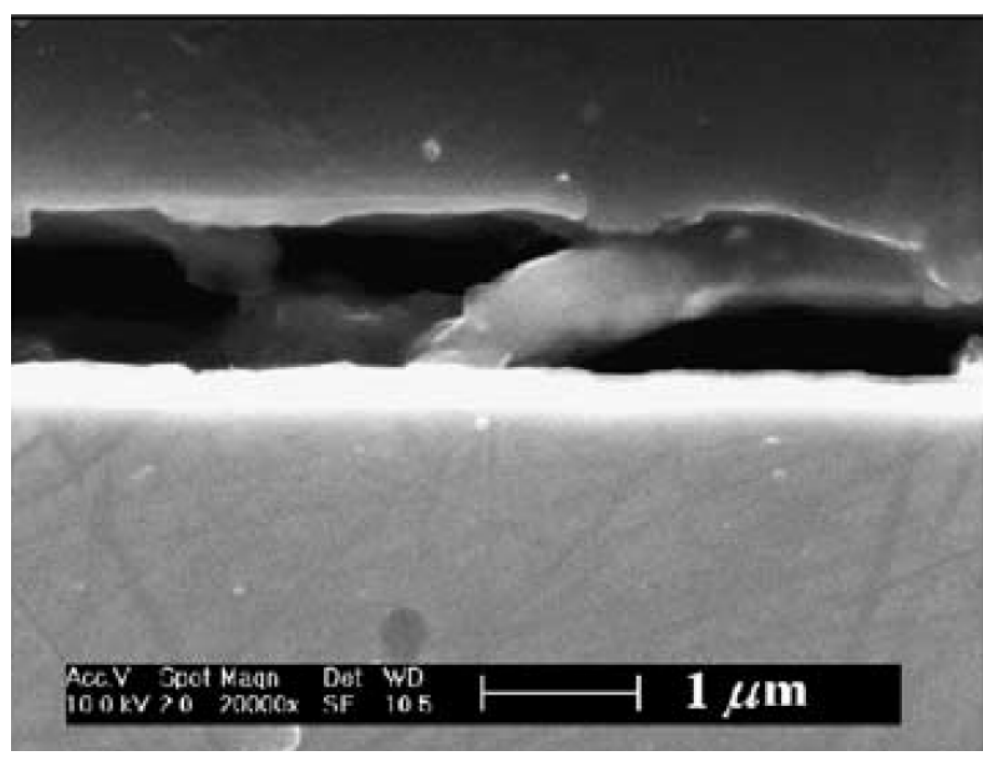

b)

Figura 1.24 - Imagens da camada branca em superficies manufaturadas obtidas da seção transversal mediante o emprego das técnicas de: a) microscopia óptica (FIELD e KHALES, 1971); b) microscopia eletrônica de varredura (BOSHEH e MANTINVEGA, 2005).

Segundo Poulachon et al. (2004), a camada branca é composta de linhas de martensita muito fina (entre 30 a $100 \mathrm{~nm}$ ) com carbonetos finamente dispersos e altos teores de austenita retida. O mecanismo de formação da camada branca é explicado a partir de três teorias existentes na literatura (HIOKI, 2006). Na primeira delas, atribui-se ao mecanismo de escoamento plástico a geração de uma estrutura homogênea ou uma estrutura refinada. Outra teoria relaciona a camada branca com o mecanismo de aquecimento e revenimento 
da superficie durante a usinagem. Finalmente, a terceira teoria relaciona a camada branca com o mecanismo de reação da superficie com o meio ambiente (nitretação, carbonetação e sulcamento por oxidação). Com relação aos efeitos que os parâmetros de processo exercem sobre o mecanismo de formação da camada branca não existe consenso geral na literatura (CHOU e EVANS, 1999; BRAGHINI, 2002; BOSHEH e MATIVENGA, 2005; HIOKI, 2006). Igualmente, é controverso o efeito que a camada branca exerce sobre o desempenho dos componentes manufaturados (YANG et al., 1996; BOSHEH e MATIVENGA, 2005). Esses fatos justificam a realização de ensaios específicos para estudar o efeito deste fenômeno e o seu impacto na integridade superficial do componente.

As técnicas de análise metalográfica permitem a partir de imagens, estudar a topografia ou as características microestruturais quando a superficie é preparada metalograficamente (polida e atacada quimicamente). Dependendo do aumento utilizado, é possivel analisar desde as dimensões da amostra, imperfeições da superficie, acabamento superficial, fases estruturais até os grãos da microestrutura (HORNBOGEN, 1984). A partir do conjunto de informações obtidas da análise das imagens geradas é possivel inferir sobre o método como o componente foi fabricado, o estado do tratamento térmico, características de interesse para a avaliação da IS, análise de falhas, e em geral, caracterizar os efeitos do processamento do componente que são refletidos nas propriedades da microestrutura.

Em resumo, a análise mediante o uso das técnicas de metalografia convencional e da microscopia óptica é um meio importante e econômico para fazer uma rápida avaliação da microestrutura dos componentes usinados, na tentativa de caracterizar as mudanças que ocorrem na região alterada no material (HORNBOGEN, 1984). Não obstante, além da microscopia óptica, o emprego de outras técnicas especiais é necessário para estudar alguns dos fenômenos que acontecem numa camada subsuperficial em escalas menores (aumentos acima de 1500 vezes), dentro das quais podem ser mencionadas a microscopia eletrônica de varredura (MEV) e a microscopia por força atômica (GRIFFITHS, 2001). Esta última técnica é empregada na avaliação das mudanças que acontecem a alguns nanômetros abaixo da superficie. 
A dureza das camadas logo abaixo da superficie pode ser alterada como resultado das mudanças microestruturais induzidas pelos processos de manufatura (FIELD et al., 1972; KOSTER et al., 1976; MACHINABILITY DATA CENTER, 1980; SALAH e LIU, 2000; GRIFFITHS, 2001; RECH e MOISAN, 2002; BOSHEH e MATIVENGA, 2005; HASHIMOTO et al., 2006; HIOKI, 2006). TABOR (1954) definiu a dureza como a propriedade do material que exprime a capacidade de resistir à ação de um penetrador duro. Pode-se afirmar que o valor de dureza depende fundamentalmente de três variáveis: o material ensaiado, a geometria do penetrador e a força aplicada. A medição da microdureza pode ser feita mediante o uso de microdurômetros, nos quais podem ser usados diferentes tipos de penetradores (Knoop ou Vickers), e com forças de ensaio que variam entre 1 e 1000 gf (0,098 e 9,8 N). Com isso, o levantamento do perfil de dureza pode ser utilizado para identificar as mudanças que ocorrem na microestrutura da camada superficial.

Koster et al. (1976 apud MACHINABILITY DATA CENTER, 1980) apresentaram o efeito do processo de retificação de um aço AISI 4340 (temperado e revenido) considerando a severidade das condições de corte utilizadas no perfil de dureza na escala microscópica como apresentado na Figura 1.25.

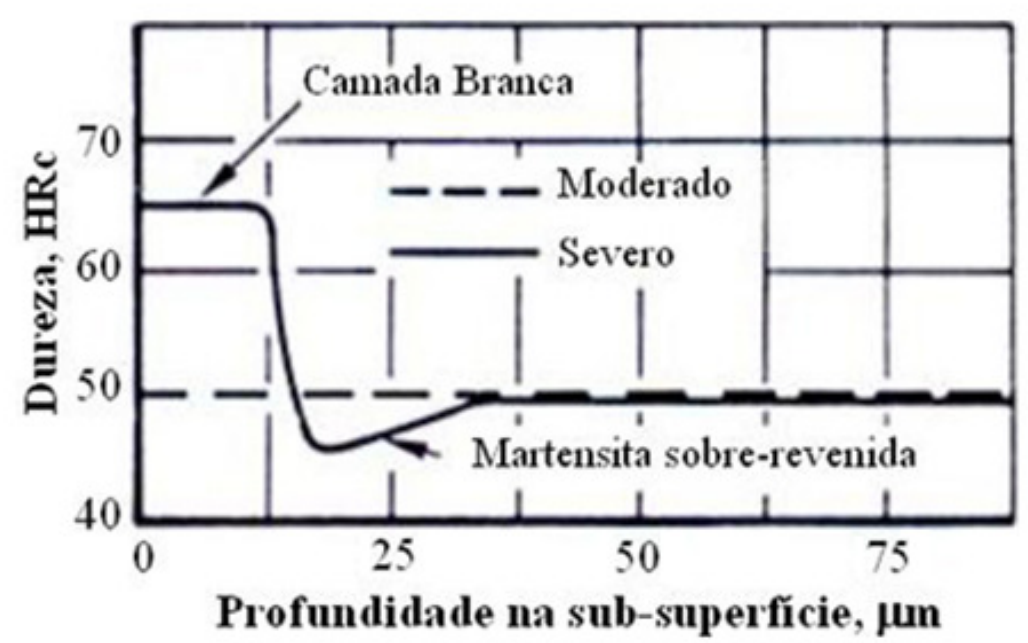

Figura 1.25 - Perfil de dureza na escala microscópica avaliada na secção transversal de um componente de aço AISI 4340, submetido ao processo de retificação mediante seleção de condições de corte severas e leves (moderadas) (KOSTER et al., 1976 apud MACHINABILITY DATA CENTER, 1980)

Observa-se da Figura 1.25, que a variação nos valores de dureza acompanha as alterações nas características microestruturais da superficie retificada sob 
condições severas de ensaio, características que foram observadas pelos autores a partir da análise de imagens da seção transversal obtidas por microscopia óptica (KOSTER et al., 1976 apud MACHINABILITY DATA CENTER, 1980). Observa-se o aumento da dureza quando avaliada na camada branca com respeito ao resto do material. Igualmente, tem-se uma queda no valor de dureza quando avaliada na camada onde a martensita foi sobrerevenida como resultado calor absorvido e os respectivos efeitos térmicos. Já a superficie que foi gerada sob condições leves de corte não sofreu alterações, não apresentando variação no valor da dureza.

Durante o processo de usinagem de um componente, ou depois de um tratamento térmico, ocorrem deformações inerentes ao processo e se induzem tensões residuais no material. A tensão residual é definida como aquela tensão que permanece no componente após a solicitação à qual foi submetido (MATSUMOTO et al., 1986). A maior parte das tensões residuais induzidas pelos processos de usinagem ocorre nos primeiros 12,7 $\mu \mathrm{m}$ a $254 \mu \mathrm{m}$ abaixo da superficie (MACHINABILITY DATA CENTER, 1980). As principais técnicas para estimar a tensão residual estão fundamentas em diferentes principios, podendo ser enumeradas: deflexão por remoção eletrolítica (EL-KHABERRY e FATTOUH, 1989), difração de raios X (FIELD e KHALES, 1971), por indentação (SURESH e GIANNAKOPOULOS, 1998). Um dos métodos mais usados para medir tensões residuais está baseado nas técnicas de extensometria através do método do furo cego, isto por se tratar de uma técnica relativamente simples, accessivel tecnologicamente e de baixo custo (LINDGREN e LEPISTO, 2003 apud FARIAS, 2009). Outra técnica bastante difundida nos meios acadêmicos e industriais é a difração de raios $\mathrm{X}$, em função do alto grau de desenvolvimento tecnológico atingido (DELIJAICOV, 2004).

A técnica de difração de raios $\mathrm{X}$ está fundamentada no princípio do fenômeno da difração, sendo definido como um fenômeno de espalhamento de radiação eletromagnética por um arranjo periódico de centros de espalhamento, com espaçamento da mesma ordem de magnitude do comprimento de onda da radiação incidente (LIMA, 2007). A profundidade de penetração dos raios $\mathrm{X}$ utilizados nas técnicas para medição da tensão residual é comumente inferior aos $10 \mu \mathrm{m}$ nos aços (MARTINS et al., 2004). Segundo TRICARD (1994), as áreas críticas encontram-se localizadas geralmente numa região mais abaixo na camada superficial $(150 \mu \mathrm{m}$ a 
$200 \mu \mathrm{m})$, motivo pelo qual é necessário monitorar cuidadosamente as tensões residuais ao longo da profundidade. Uma opção que possibilita este procedimento é a utilização da técnica de polimento eletrolítico para remoção gradual das camadas superficiais (MACHINABILITY DATA CENTER, 1980).

Segundo Grijalba (2010), o Ruído Magnético de Barkhausen (RMB) pode ser aplicado no monitoramento de alterações microestruturais decorrentes de processos mecânicos ou térmicos, controle de qualidade de tratamentos superficiais, acompanhamento do processo de envelhecimento de componentes, de fadiga, avaliação de textura microestrutural e de alteração da microestrutura em superficies geradas mecanicamente (usinagem e conformação). Esta técnica é um ensaio não destrutivo baseado no princípio do Ruído Magnético de Barkhausen (RMB), o qual é afetado pelas alterações microestruturais, tensões residuais e as deformações plásticas presentes em materiais ferromagnéticos. O RMB é produzido quando ao submeter materiais ferromagnéticos a campos magnéticos variáveis são gerados pulsos magnéticos em resposta da movimentação das paredes de domínios magnéticos, que à sua vez, são originados por saltos discretos durante a indução (GRIJALBA, 2010).

Durante o processo de magnetização, o movimento de paredes de $90^{\circ}$, a rotação de domínios, e a aniquilação de paredes também contribuem ao RMB. Assim que o processo se aproxima da saturação magnética, o movimento de paredes desaparece. Na Figura 1.26 é apresentada a evolução do RMB durante um ciclo de histerese (GRIJALBA, 2010). A maior parte dos eventos Barkhausen é produzida pelo movimento irreversivel de paredes de domínio magnético de $180^{\circ}$, que estão localizados na região da curva de magnetização onde existe a maior inclinação.

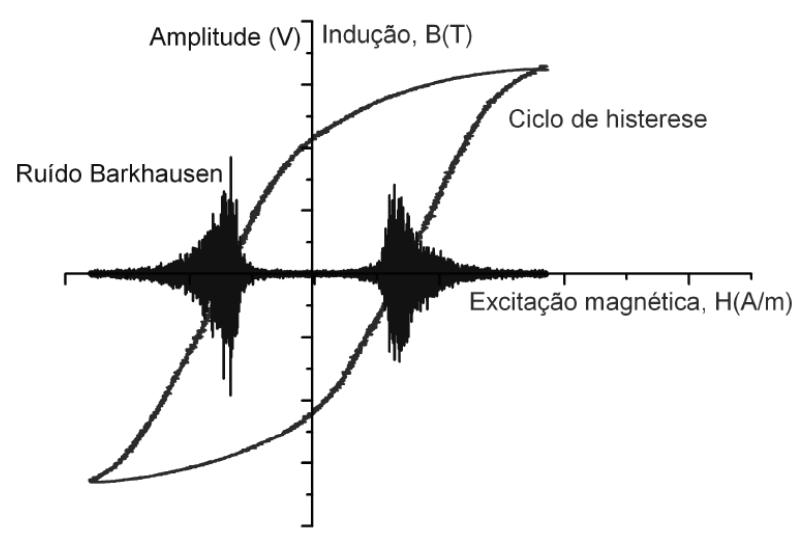

Figura 1.26- Ruído de Barkhausen e curva de histerese associada (GRIJALBA, F.A.F, 2010) 
A base do sistema de medição de RMB é uma sonda que possui um yoke eletromagnético (que produz o campo magnético alternado) e uma bobina leitora (que detecta o sinal de RMB) (GRIJALBA, 2010) (Figura 1.27a). A bobina leitora é colocada próxima da superficie durante a movimentação das paredes de domínio, e devido à mudança gerada na magnetização são induzidos pulsos elétricos na bobina. Após uma etapa processamento e análise do sinal, o RMB pode ser representado graficamente no domínio do tempo (Figura 1.27b)

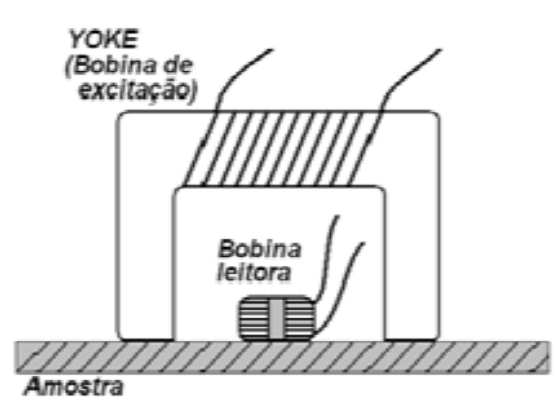

a)

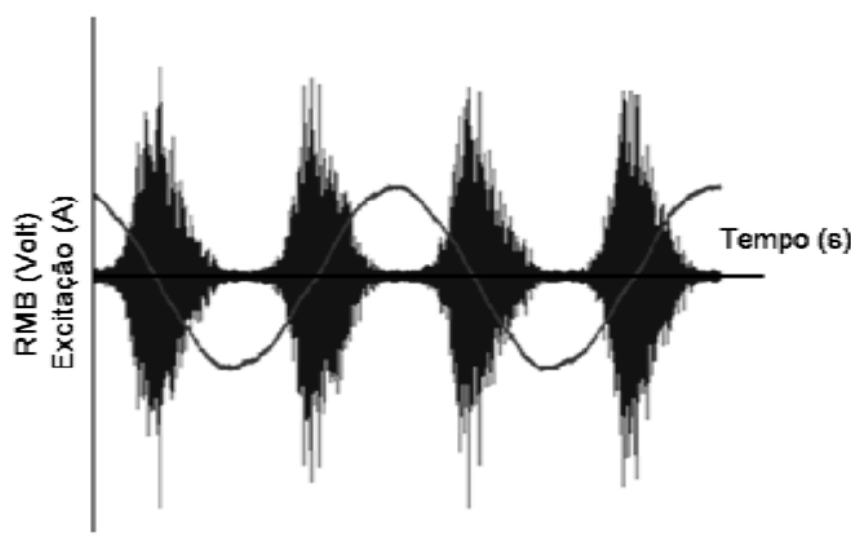

b)

Figura 1.27- Sistema de medição: a) Sonda para medição do RMB; b) representação do sinal do RMB no domino do tempo (GRIJALBA, 2010)

Grijalba (2010) a partir de estudos realizados para determinar o efeito da tensão uniaxial mecânica no RMB em materiais ferromagnéticos (JILES, 1989; ANGLADE e RIVERA, 2001; CAPO e SANCHEZ, 2007; PEREZ e BENITEZ, 2007), observou que, de um modo geral, as tensões de tração favorecem o aumento dos sinais de RMB. O oposto ocorre com as tensões de compressão, que geram niveis menores de RMB.

Com relação ao efeito da deformação plástica no RMB (HWANG, 1988; MOORTHY et al, 1999; STEFANITA et al., 2000; DHAR, 2001; CAMPOS et al., 2008), a amplitude do sinal de RMB aumenta conforme aumenta a deformação plástica, atingindo um valor máximo em certo nível de deformação. Se continuar aumentando o nível de deformação do material, a amplitude de RMB diminuirá até chegar a um ponto de saturação com baixa amplitude do RMB. Outra série de estudos foi realizada para determinar a sensibilidade da técnica para detectar as alterações microestruturais em diferentes aços tratados termicamente (tempera e revenido) (KLEBER, 2004; GUR, 2007; DAVUT; 2007; KAPLAN, 2007). Os resultados mostraram boa correlação na 
detecção das fases e na avaliação da fração dos microconstituintes (ferrita e martensita) empregando RMB. Igualmente, a dureza sendo uma resposta das características microestruturais do material, apresentou uma boa correlação linear com o RMB. Em termos gerais, a amplitude do RMB teve um comportamento inversamente proporcional à dureza do material.

A profundidade dos sinais do RMB varia em função da sua frequência de emissão (Na faixa de $1-200 \mathrm{KHz}$ ) (GRIJALBA, 2010). Os sinais de RMB são atenuados em maior ou menor grau pelas correntes parasitas ao passar pelo material, em função da frequência em que são geradas e devido à sua natureza eletromagnética. Desta forma, as faixas de alta frequência do RMB são atribuídas a seções do material próximas da superficie, enquanto as de baixa frequência provêem tanto de menores como de maiores profundidades (GRIJALBA, 2010). Na tabela 1.1 é apresentada a profundidade aproximada de emissão dos sinais do RMB com diferentes frequências para um aço com permeabilidade relativa de 50 até 5.000 , e condutividade de 5 a $10\left(10^{6} \Omega^{-1} \mathrm{~m}^{-1}\right)$.

Tabela 1.1. Profundidades aproximadas dos sinais do RMB, em dependência de suas frequências de emissão (JILES, 2000 apud GRIJALBA, 2010). 


\section{FUNDAMENTOS COMPLEMENTARES DE DESGASTE POR ROLAMENTO}

Embora neste capítulo não sejam apresentados elementos diretamente relacionados com a integridade da superficie, este é o fundamento para o entendimento dos conceitos que complementam a abordagem dada neste trabalho.

\subsection{Fundamentos de desgaste}

A tribologia é um campo da ciência ${ }^{1}$ que estuda a interação das superfícies em movimento relativo, visando o estudo do atrito, o desgaste e a lubrificação. O desgaste e o atrito não são propriedades intrínsecas do material, mas são características próprias do tribosistema (GAHR, 1987). O desgaste é a maior causa de perdas de material e diminuição do desempenho mecânico, qualquer redução do desgaste pode decorrer em consideráveis ganhos no sistema. $O$ atrito é a principal causa do desgaste e a dissipação de energia. A lubrificação é um meio efetivo de controlar o desgaste e reduzir o atrito. Como foi apresentando, os elementos que compõem a tribologia estão ligados entre si, e serão apresentados a seguir na mesma ordem que foi enunciada na definição.

\subsubsection{Atrito}

Quando duas superficies se tocam, o contato geralmente ocorre sob partes isoladas da área de contato nominal. É através destas regiões de contato localizadas que as forças são transmitidas entre corpo e contra corpo, e ao mesmo tempo estas forças são as responsáveis pelo atrito. $\mathrm{O}$ atrito é definido como a resistência oferecida ao movimento relativo entre duas superfícies que estão em contato devido a uma carga normal (HUCTCHINGS, 1992; BAYER, 1994) e está associado com a perda de energia total em um sistema que tenha algum movimento relativo.

1 A tribologia foi reconhecida como área da ciência em 1967 por um comitê da Organização para a Cooperação Econômica e o Desenvolvimento (STACHOWIAK e BATCHELOR, 2001). 


\subsubsection{Desgaste}

O desgaste se manifesta como alteração dimensional e/ou mudanças na superficie dos componentes, o qual geralmente acarreta em problemas secundários como vibração e desalinhamentos. A geração de "debris" ou partículas de desgaste, particularmente em tribosistemas com tolerâncias estreitas, pode danificar mais o componente do que as mudanças dimensionais. De maneira geral, pode-se afirmar que o desgaste é causado pela degradação decorrente da interação dos elementos de máquina, o qual ocorre como resultado do sobrecarregamento do material na borda da superficie (SCHMALTZ, 1936 apud GAHR, 1987).

\subsubsection{Tipos de Desgaste}

Segundo Rabinowicz (1995), diversas pesquisas têm estabelecido quatro tipos principias de desgaste e outros processos menores, os quais são referenciados também como tipos de desgaste. Está classificação está baseada de acordo aos mecanismos físicos de desgaste predominantes, e será detalhada a seguir:

- Desgaste Adesivo: Apresenta-se quando dois corpos em contato deslizam um sobre o outro, e partículas de uma superficie são desprendidas de um corpo é se aderem à outra. Este tipo de desgaste surge devido a grandes forças de adesão quando as asperezas se encontram em contato intimo.

- Desgaste Abrasivo: Ocorre quando sobre uma superfície atuam partículas duras que ao entrarem na interface de contato, deslizam removendo material deixando marcas sobre a superficie, como trilhas ou sulcos na direção do movimento.

- Desgaste Corrosivo: Acontece quando o deslizamento toma lugar num meio oxidante. Na ausência de deslizamento, gera-se uma camada sobre a superficie que tende a deter a corrosão. Na presença de movimento relativo entre as superfícies, esta camada protetora se remove dando continuidade ao ataque corrosivo.

- Desgaste por Fadiga Superficial: É observado durante o deslizamento ou rolamento sobre uma trilha ou sulco. Devido aos ciclos de carregamento e descarregamento são nucleadas trincas superficiais e subsuperficiais que se propagam, produzindo a separação de grandes fragmentos de material da superficie. Este tipo de desgaste será objeto de estudo no presente 
trabalho, e foi feita uma revisão mais extensa ao longo do primeiro capítulo desta tese.

Outros tipos de desgaste menores são:

- Fretting: Este tipo de desgaste ocorre quando superficies em contato sofrem deslocamentos oscilatórios tangenciais de pequena amplitude.

- Erosão: É um processo onde partículas duras são transportadas num meio fluido, o qual atinge uma superficie sólida gerando a remoção de material.

- Cavitação: Este tipo de desgaste ocorre quando um líquido sofre um ciclo de compressão e tração; onde a remoção do material se produz pelo colapso de bolhas que impactam sobre a superficie.

Outras classificações do desgaste podem ser realizadas, considerando as marcas de desgaste (sulcos, estrias, trincas, etc.) ou, pela condição circunstancial do desgaste (por deslizamento, desgaste a seco, lubrificado, metal-polimero, por rolamento, etc.) (HIOKI, 2006; BAYER, 1994). O desgaste pode ser percebido nas seguintes formas: sem perda de massa (deformações plásticas provocando alterações nas tolerâncias dimensionais e geométricas), e com perda de massa (formação de trincas superficiais) (HIOKI, 2006; BAYER, 1994).

\subsection{Contato}

A rugosidade de uma superficie limita o contato entre duas superficies sólidas a uma pequena parte da área aparente de contato. A área real de contato é o resultado da deformação elástica dos picos mais altos localizados no perfil das superficies em contato (asperezas). Ao aumentar o carregamento entre os corpos, a área real de contato aumenta como resultado do incremento na deformação elástica das asperezas em contato (ver Figura 2.1), sendo que se as tensões de contato entre as asperezas forem muito elevadas, em alguns os casos pode ocorrer deformação plástica localizada. (STACHOWIAK e BATCHELOR, 2001; JOHNSON, 1985). 


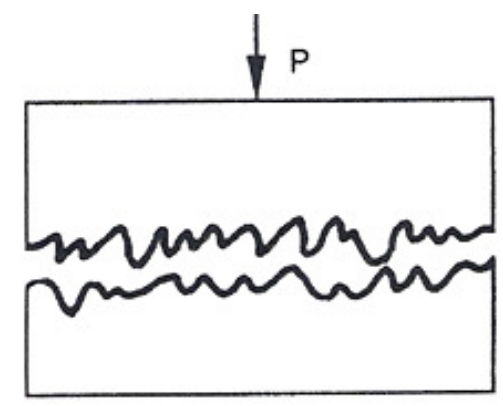

a)

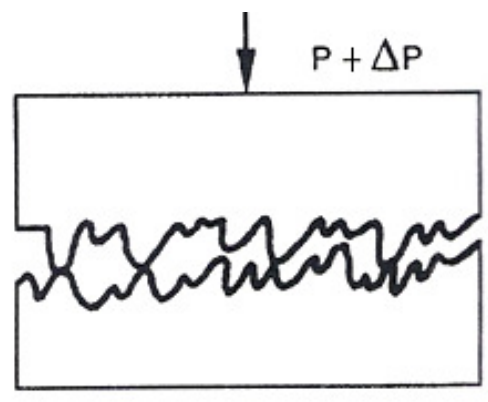

b)

Figura 2.1 - Esquema representativo dos pontos de contato entre superficies a) sem contato com o carregamento inicial P; b) contato após a aplicação de carregamento.

Em função da geometria da área aparente das superfícies em contato, o contato pode ser classificado como: conforme e não conforme. Contato conforme é aquele que ocorre quando as superficies dos dois corpos ajustamse perfeitamente em temos macroscópicos. Quando os perfis são dissimilares, então o contato entre as superficies é dito não-conforme (JOHNSON, 1985). Na Figura 2.2 são ilustradas essas duas situações. Quando dois sólidos de geometria não-conforme são colocados em contato eles se tocam inicialmente em um único ponto, ou ao longo de uma linha.
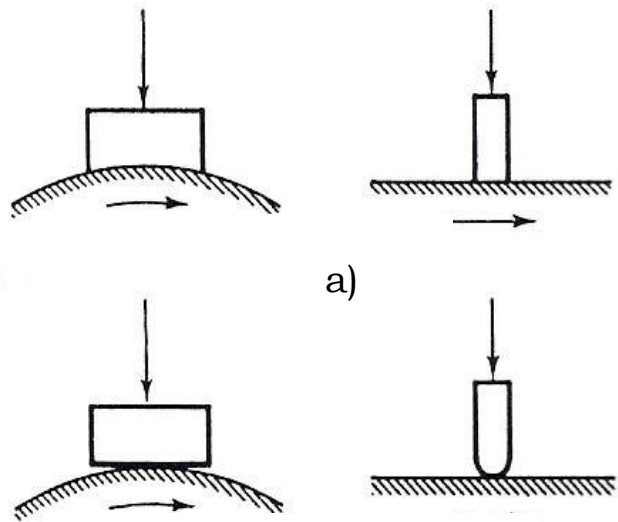

a)

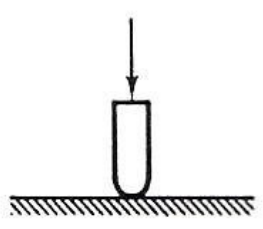

b)

Figura 2.2 - Esquema representativo de contatos: (a) conformes; (b) não-conformes (HUTCHINGS, 1992).

\subsubsection{Geometria de contato entre dois corpos elásticos}

Corpos elásticos em contato se deformam e a geometria do contato, o carregamento e as propriedades do material determinam a área e as tensões de contato. O formato da área de contato depende da forma geométrica (curvatura) dos corpos, podendo ser um ponto (para esferas em contato) ou uma linha de contato (para cilindros paralelos em contato). Sendo que ao longo deste trabalho a área de contato corresponde à configuração esfera 
sobre plano, o caso da linha de contato típica de cilindros não será abordado. A configuração de dois corpos elásticos com superficies convexas em contato foi originalmente considerada por Hertz em 1881. Na Figura 2.3 ilustram-se três (3) possíveis combinações para a configuração do contato com as diversas curvaturas da superfície (plana, côncava e convexa).

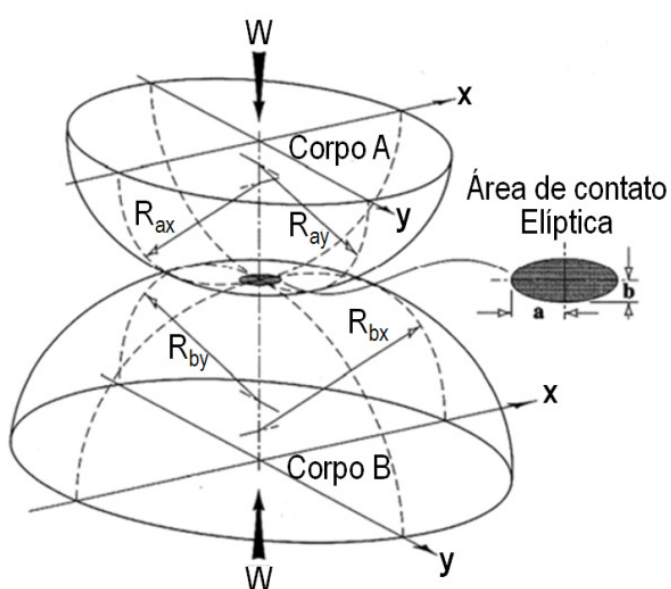

a)

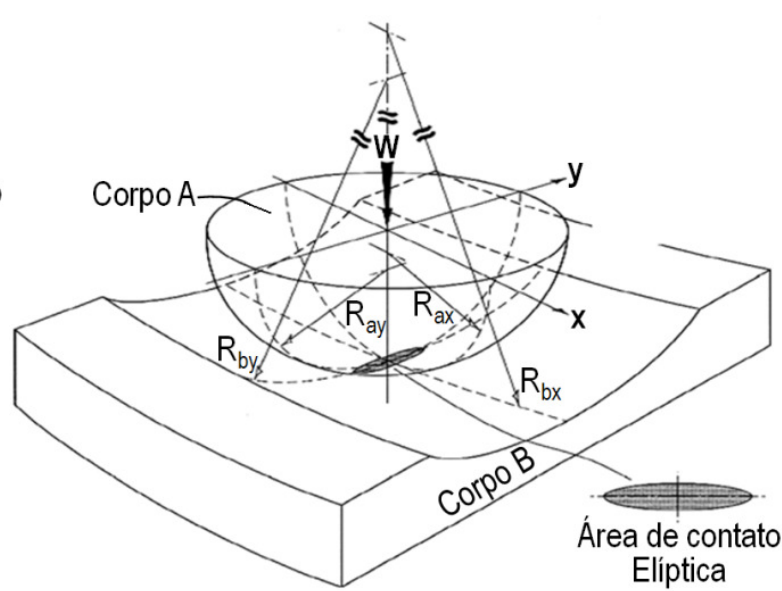

b)

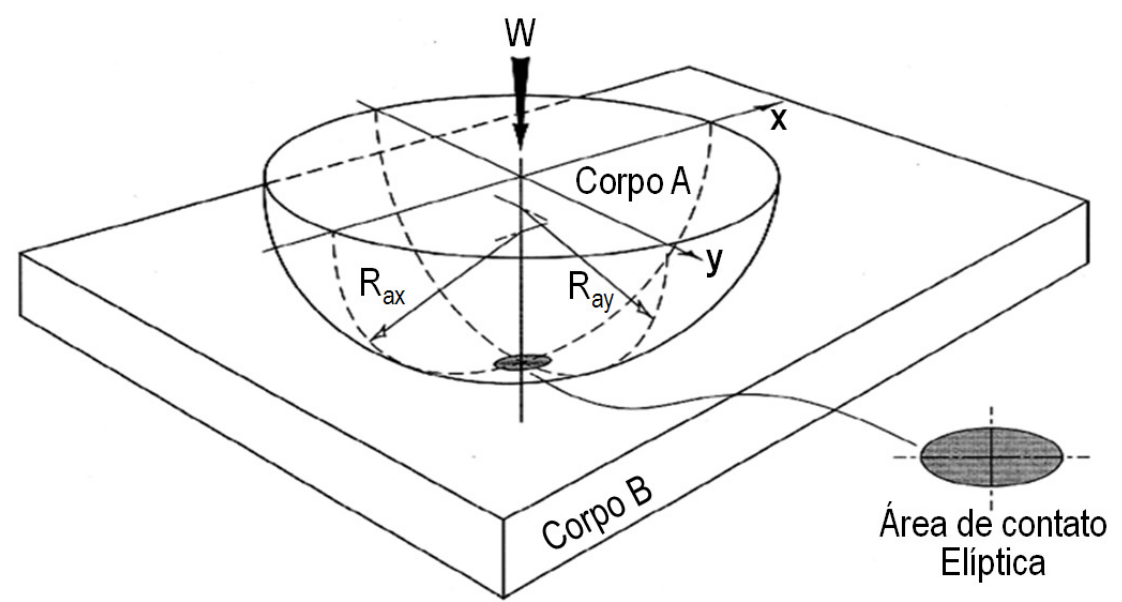

c)

Figura 2.3 - Geometria de contato de dois corpos elásticos com superficies: a) convexas. b) convexa e côncava. c) convexa e plana (STACHOWIAK e BATCHELOR, 2001). $R_{(\mathbf{a}, \mathbf{b}) \mathbf{x}}$ é o raio de curvatura do corpo (a ou b) com respeito ao eixo $x, R_{(\mathbf{a}, \mathbf{b}) \mathbf{y}}$ é o raio de curvatura do corpo (a ou b) com respeito ao eixo y, w é a carga aplicada, a é o raio de elipse no eixo $\mathrm{x}, \mathrm{b}$ é o raio da elipse no eixo $\mathrm{y}$.

Um parâmetro utilizado para caracterizar a geometria de contato é conhecido como "radio reduzido de curvatura", e está baseado em relações entre o raio de curvatura das superficies em contato. O raio reduzido de curvatura ( $R$ ) para cada condição apresentada na Figura 2.3 fica definido como (STACHOWIAK e BATCHELOR; 2001): 
Superficies convexas:

$\frac{1}{\mathrm{R}^{\prime}}=\frac{1}{\mathrm{Rx}}+\frac{1}{\mathrm{Ry}}=\frac{1}{\mathrm{Rax}}+\frac{1}{\mathrm{Rbx}}+\frac{1}{\mathrm{Ray}}+\frac{1}{\mathrm{Rby}}$

Superficie convexa e plana:

$$
\frac{1}{\mathrm{R}^{\prime}}=\frac{1}{\mathrm{Rax}}+\frac{1}{\mathrm{Rbx}}
$$

Nas equações anteriores o termo " $\mathrm{R}(\mathrm{a}, \mathrm{b}) \mathrm{x}$ " é o raio de curvatura do corpo (a ou b) com respeito ao eixo $\mathrm{x}$, " $\mathrm{R}(\mathrm{a}, \mathrm{b}) \mathrm{y}$ " é o raio de curvatura do corpo ( $\mathrm{a}$ ou b) com respeito ao eixo y, "W" é a carga aplicada, "a" é o raio de elipse no eixo x e "b" é o raio da elipse no eixo y.

Para o caso de uma esfera, pode ser assumido que o raio de curvatura ( $\mathrm{Ra}$ ) possui o mesmo valor $(\operatorname{Rax}=$ Ray), e a equação 2 pode ser simplificada da seguinte maneira:

$$
\frac{1}{\mathrm{R}^{\prime}}=\frac{2}{\mathrm{Ra}}
$$

Superficie convexa e côncava:

$$
\frac{1}{\mathrm{R}^{\prime}}=\left(\frac{1}{\mathrm{Rax}}+\frac{1}{\mathrm{Ray}}\right)-\left(\frac{1}{\mathrm{Rbx}}+\frac{1}{\mathrm{Rby}}\right)
$$

Antes de definir os parâmetros de contato, é necessário determinar um módulo composto que considera os módulos de elasticidade de cada uma das superficies em contato. Como apresentado por Neves (2006) existem duas expressões para exprimir o valor desse módulo composto, fato que não costuma ser apresentado nas fontes de consulta de fundamento, o qual gera certa confusão no leitor. Uma das expressões permite obter o "módulo combinado - $\mathrm{E}^{* \prime}$ e é apresentada na equação 5 (JOHNSON, 1985), enquanto a outra informa o “ módulo reduzido - E' " é mostrada na equação 6 (STACHOWIAK e BATCHELOR; 2001). Para as duas expressões os termos va, $E_{a}$ e $v_{b}, E_{b}$ corresponderão aos coeficientes de Poisson e os módulos de elasticidade respectivamente, dos materiais dos corpos em contato: "A" e "B". 


$$
\begin{aligned}
& \frac{1}{\mathrm{E}^{*}}=\frac{1-v_{\mathrm{a}}^{2}}{\mathrm{E}_{\mathrm{a}}}+\frac{1-v_{\mathrm{b}}^{2}}{\mathrm{E}_{\mathrm{b}}} \\
& \frac{1}{\mathrm{E}^{\prime}}=\frac{1}{2}\left(\frac{1-v_{\mathrm{a}}^{2}}{\mathrm{E}_{\mathrm{a}}}+\frac{1-v_{\mathrm{b}}^{2}}{\mathrm{E}_{\mathrm{b}}}\right)
\end{aligned}
$$

A determinação dos parâmetros de contato é fundamental em muitas aplicações práticas de engenharia (STACHOWIAK e BATCHELOR; 2001), sendo que os parâmetros de contato mais empregados são:

- As dimensões da área de contato,

- A máxima pressão de contato (também conhecida como tensão de Hertz),

- A deflexão máxima no centro das superfícies em contato,

- A localização da máxima tensão de cisalhamento abaixo da superfície.

As expressões para obter os parâmetros de contato para a configuração esfera plano apresentada na Figura 2.3(b) serão apresentadas a seguir (STACHOWIAK e BATCHELOR; 2001):

Raio da circunferência de contato (a):

$$
a=\left(\frac{3 W R^{\prime}}{E^{\prime}}\right)^{\frac{1}{3}}
$$

Deflexão máxima no centro dos dois corpos $(\delta)$ :

$$
\delta=1,0397\left(\frac{\mathrm{W}^{2}}{\mathrm{R}^{\prime} \mathrm{E}^{\prime}}\right)^{\frac{1}{3}}
$$

Pressão máxima de contato $\left(\mathrm{P}_{\max }\right)$ :

$$
\mathrm{P}_{\max }=\frac{3 \mathrm{~W}}{2 \pi \mathrm{a}^{3}}
$$

Pressão média de contato ( $\mathrm{P}_{\text {média }}$ ):

$$
\mathrm{P}_{\text {média }}=\frac{\mathrm{W}}{\pi \mathrm{a}^{2}}
$$


Nas séries de equações 7 à $10 \mathrm{~W}$ é a carga aplicada, R' é o raio da esfera e E' é módulo elástico reduzido dos materiais.

Finalmente, o último parâmetro de contato a ser apresentado é a máxima tensão de cisalhamento $\left(\tau_{\max }\right)$ que está expressada pela equação 11 , e ocorre a uma profundidade $(z)$ de 0,48 vezes o raio da circunferência de contato (a).

$$
\tau_{\max }=\frac{1}{3} \mathrm{P}_{\max }
$$

Para o caso de uma esfera que está rolando sobre um plano, a condição de contato mais adequada é a representada pela configuração das superfícies convexa e plana apresentada na Figura 2.3(b). Não obstante, quando a pista de rolamento começa a se degradar com o tempo devido ao desgaste adesivo e ao desgaste por fadiga, inerentes ao movimento de rolamento, deslizamento e do escorregamento, ocorrem mudanças na geometria do contato (STACHOWIAK e BATCHELOR; 2001). Isto faz com que após um número de ciclos o desgaste evolua com o tempo até se aproximar à configuração do contato apresentada na Figura 2.3(c).

\subsection{Lubrificação}

Hioki (2006) definiu a lubrificação como: "o conjunto de técnicas utilizadas para reduzir o atrito, reduzir o desgaste ou ambos". Durante a lubrificação podem ser utilizadas sustâncias com baixa resistência ao cisalhamento em estado líquido, sólido ou gasoso, com a finalidade de suavizar o movimento relativo entre duas superficies e evitar o dano; e qualquer elemento que na interface das superficies desempenhe estes papéis poderá ser considerado um lubrificante (STACHOWIAK e BATCHELOR, 2001). Bayer (1994) apresentou os mecanismos mediante os quais um lubrificante age no contato como fator redutor da adesão, diminuindo consequentemente o desgaste e o atrito. Estes mecanismos são: a adsorção, modificação química da superficie e a separação da superficie. Os dois primeiros mecanismos tendem a reduzir a resistência das ligações das junções. O terceiro reduz o número de junções (BAYER, 1994). Hioki (2006) apontou que estas definições ampliam a abordagem dos conceitos tradicionais da lubrificação, permitindo a sua aplicação na área da usinagem, na tentativa de minimizar os efeitos do atrito nas variáveis de resposta do sistema. Igualmente, dentro da área da integridade superficial e 
da tribologia, permite explorar alternativas de procurar uma condição de lubrificação (Ex. utilização de lubrificantes sólidos em matrizes para forjamento a frio), que afete diretamente o desempenho tribológico de superficies usinadas.

\subsubsection{Regime de lubrificação}

Num sistema lubrificado o lubrificante pode não evitar por completo o contato entre as asperezas, não obstante, pode diminuir o contato e reduzir a resistência das junções formadas. Por outro lado, o lubrificante pode separar completamente as superficies, impedindo a junção entre as asperezas. Contudo, seja qual for a situação de lubrificação do sistema, o uso de lubrificante sempre levará à redução do desgaste por deslizamento, sendo este um dos principais ganhos da lubrificação (HUTCHINGS, 1992). Uma classificação dos tipos de lubrificação pode ser feita considerando o grau de interação entre as superficies em contato como efeito da separação pelo lubrificante, sendo possivel diferenciar os seguintes regimes: lubrificação com película completa, lubrificação mista e lubrificação limítrofe (HUTCHINGS, 1992; STACHOWIAK e BATCHELOR, 2001). A lubrificação de película completa pode ser dividida em lubrificação elastohidrodinâmica (EHL) e lubrificação hidrodinâmica (HD); a primeira ocorre em contatos não conformes com altas pressões; enquanto que a segunda se apresenta geralmente em contatos conformes com pressões baixas (HUTCHINGS, 1992).

No regime de lubrificação limítrofe, o atrito é relativamente alto, existindo uma elevada interação mecânica entre as superfícies, dando lugar a uma grande probabilidade de desgaste. Para regimes de lubrificação de película completa, as superficies são separadas completamente por uma película de lubrificante, existindo um baixo coeficiente de atrito e desgaste mínimo. A transição entre a lubrificação HD/EHL e limítrofe corresponde ao regime de lubrificação mista, onde os dois regimes de lubrificação podem coexistir. O regime misto é também referenciado como quasi-hidrodinâmico, fluido parcial, ou lubrificação de película fina (geralmente na faixa de 0,025 -2,5 $\mu \mathrm{m}$ ) (BHUSHAN, 2002). Os regimes de lubrificação podem ser ilustrados por meio da curva de Stribeck (Figura 2.4), onde o coeficiente de atrito é traçado em função de um parâmetro que inclui velocidade de deslizamento, a viscosidade do óleo e a carga de trabalho. Outro parâmetro usado frequentemente para 
determinar a condição de lubrificação é o parâmetro $\lambda$, o qual é a relação entre a espessura mínima da película lubrificante e a rugosidade superficial composta (HUTCHINGS, 1992):

$$
\lambda=\frac{\mathrm{h}_{0}}{\sqrt{\mathrm{R}_{\mathrm{q} 1}^{2}+\mathrm{R}_{\mathrm{q} 2}^{2}}}
$$

Onde $R_{\mathrm{q} 1}$ e $R_{\mathrm{q} 2}$ são as rugosidades media quadrática (ou RMS) da superficie dos dois corpos em contato, e $h_{0}$ é a espessura mínima da película lubrificante, a qual depende entre outros fatores, entre eles a geometria do contato e será tratada num capítulo posterior. Valores do parâmetro $\lambda$ maiores que 3 indicam lubrificação EHL ou HD, valores de $\lambda$ entre 3 e 1 indicam lubrificação mista, e valores menores que 1 significam lubrificação limítrofe. Na Figura 2.4 é mostrada a curva de Stribeck em função do parâmetro $\lambda$, onde é possivel observar dois tipos de comportamento dos valores do coeficiente de atrito $(\mu)$ para valores de $\lambda$ entre 1 e 3 , e maiores que 3 , dependendo da condição de lubrificação (EHL ou HD).

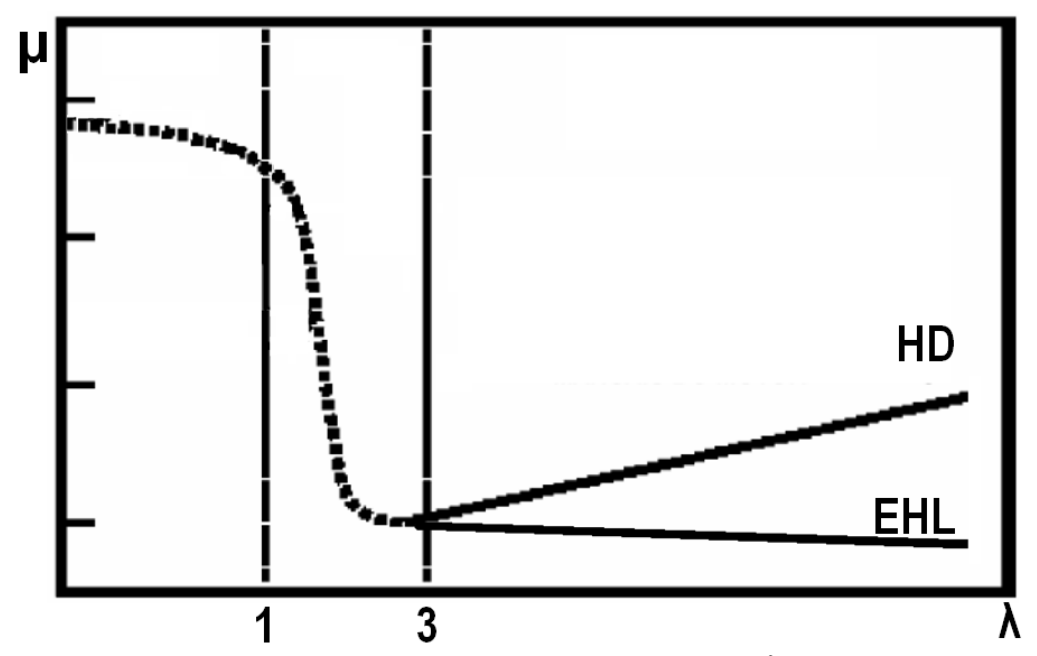

Figura 2.4 - Curva de Stribeck em função do parâmetro $\lambda$. Onde $\mu$ é o coeficiente de atrito, HD é lubrificação hidrodinâmica, EHL é lubrificação elastohidrodinâmica.

Um exemplo típico da aplicação dos diferentes regimes de lubrificação em componentes mecânicos é encontrado em mancais, onde ocorrem dois tipos de regime de lubrificação dependendo da configuração dos componentes do mancal. Para mancais de deslizamento, onde o tipo de contato é conforme, existe uma condição de lubrificação hidrodinâmica (HD). Por outro lado, os mancais de rolamentos geralmente apresentam uma condição de lubrificação elastohidrodinâmica (EHL), onde o tipo de contato é não conforme, seja 
contato pontual, caso dos rolamentos de esferas, ou contato linear, caso dos rolamentos de rolos. (HUTCHINGS, 1992).

\subsubsection{Lubrificação Elastohidrodinâmica (EHL)}

Se as superficies de contato são não conformes, envolvendo uma linha o um ponto de contato, as pressões locais na região de contato podem ser geralmente muito maiores do que as existentes na lubrificação hidrodinâmica. Alguns exemplos deste tipo de contato são apresentados na Figura 2.5. Os dentes das engrenagens, o conjunto came - seguidor, e a esfera na pista de um rolamento são exemplos onde o contato se encontra concentrado sobre uma área muito pequena, onde as tensões de contato entre componentes de aço geralmente atingem a faixa dos gigapascais $(\mathrm{GPa})$. Sob estas condições, a dependência da viscosidade da lubrificação na pressão tem um papel muito importante, por que é o responsável da deformação elástica das superficies (HUTCHINGS, 1992).

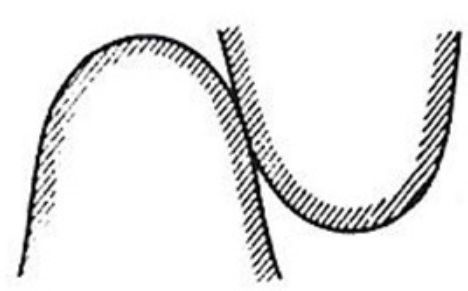

a)

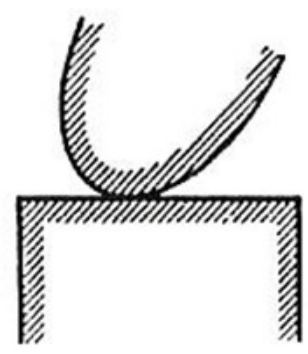

b)

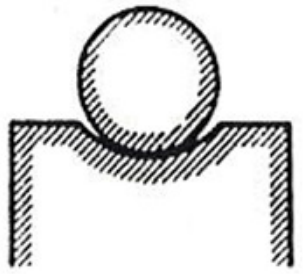

c)

Figura 2.5 - Exemplos de contatos não conformes: a) Dente de uma engrenagem, b) Conjunto came - seguidor, c) esfera na pista de rolamento.

A espessura da película lubrificante nos sistemas que possuem lubrificação EHL é da ordem dos nanômetros (nm), mas como citado por Neves (2006), este fato só foi possível de se explicar em 1949 por Grubin e Vinogradova (1949 apud DOWSON; HIGGINSON, 1977). Estes pesquisadores inseriram no seu modelo o fenômeno da piezo-viscosidade do óleo, o qual não tinha sido considerado até então na teoria hidrodinâmica. A piezo-viscosidade é o incremento drástico na viscosidade de um lubrificante como consequência do aumento da pressão no contato (STACHOWIAK e BATCHELOR, 2001).

Num contato estático o perfil de distribuição de pressão é hemisférico ou elipsoidal, de acordo com o descrito pela teoria clássica de Hertz. Não obstante, para superficies com movimento relativo separadas por um lubrificante com propriedades piezo-viscosas, o campo de pressão difere do 
exposto pelo modelo de Hertz. A piezo-viscosidade muda o perfil de distribuição de pressão na entrada e na saída da região de contato, devido ao aumento drástico da viscosidade no lubrificante que assume um caráter sólido. Os efeitos combinados do movimento de rolamento e da película do lubrificante geram uma deformação da superficie, fazendo com que a área de contato fique levemente alongada e curvada. O lubrificante apresenta um acelerado aumento da viscosidade na entrada do contato, e de maneira idem, segue uma queda repentina de viscosidade na saída do contato. Na entrada do contato existe uma região onde as superficies são paralelas e planas, e a separação das mesmas é realizada por uma película de lubrificante chamada "espessura de filme central" ( $\left.h_{c}\right)$. Para se manter a continuidade do fluxo e compensar a perda de viscosidade, as superficies experimentam uma constrição na saída do contato como ilustrado na Figura 2.6. Nesta região a separação das superfícies é descrita pela "espessura mínima de filme" ( $\left.h_{\circ}\right)$.

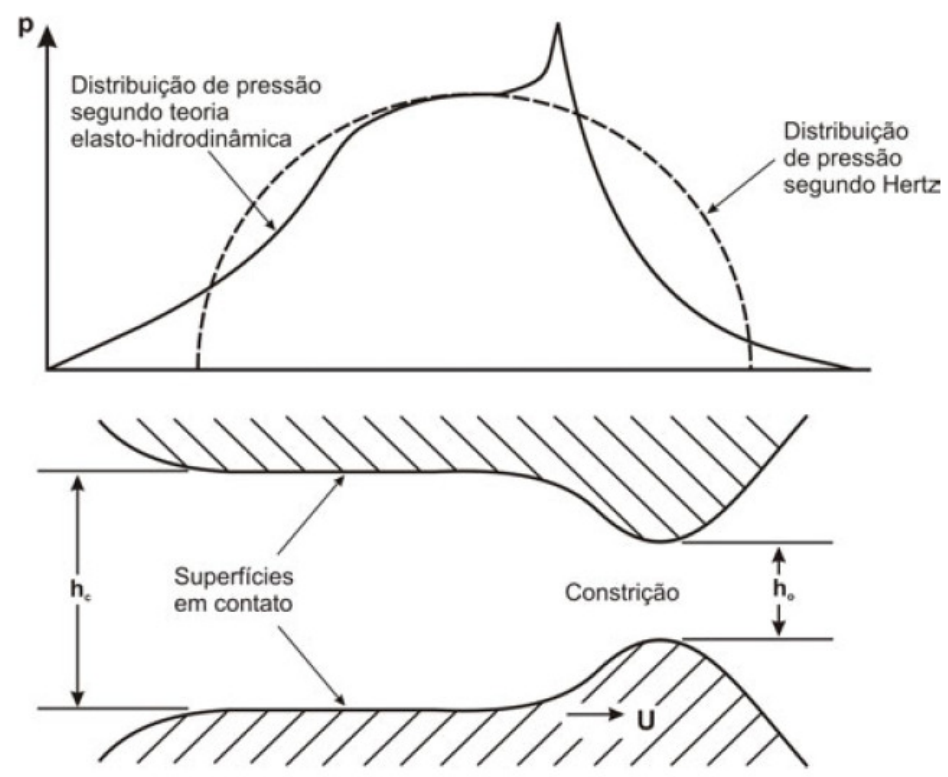

Figura 2.6 - (a) Distribuição esquemática de pressão num contato elastohidrodinâmico; (b) perfil de deformação mostrando a espessura de filme central $\left(h_{c}\right)$ e a espessura minima de filme ( $h_{0}$ ) (STACHOWIAK e BATCHELOR, 2001).

As expressões apresentadas nas equações 13 e 14 que permitem calcular a espessura de filme lubrificante central, e a espessura minima de filme em contatos EHL foram desenvolvidas por Hamrock e Dowson (1981 apud STACHOWIAK e BATCHELOR, 2001). Estas expressões podem ser utilizadas em contatos pontuais, lineares e elípticos, e para diversas combinações de materiais, incluindo aço contra aço com pressões de contato na faixa de $3-4$ GPa (GOHAR, 1981 apud STACHOWIAK e BATCHELOR, 2001). 
$\frac{h_{c}}{R^{\prime}}=2,99\left(\frac{U \eta_{0}}{E^{\prime} R^{\prime}}\right)^{0,67}\left(\alpha E^{\prime}\right)^{0,53}\left(\frac{W}{E^{\prime} R^{\prime 2}}\right)^{-0,067}\left(1-0,61 e^{-0,73 k}\right)$

$\frac{\mathrm{h}_{0}}{\mathrm{R}^{\prime}}=3,63\left(\frac{\mathrm{U} \eta_{0}}{\mathrm{E}^{\prime} \mathrm{R}^{\prime}}\right)^{0,68}\left(\alpha \mathrm{E}^{\prime}\right)^{0,49}\left(\frac{\mathrm{W}}{\mathrm{E}^{\prime} \mathrm{R}^{\prime 2}}\right)^{-0,073}\left(1-\mathrm{e}^{-0,68 \mathrm{k}}\right)$

Onde os termos das equações 13 e 14 são:

U é a velocidade de entrada da superficie $(\mathrm{m} / \mathrm{s})$, que pode ser calculado como, $\mathrm{U}=\left(\mathrm{U}_{\mathrm{A}}+\mathrm{U}_{\mathrm{B}}\right) / 2$; onde os sub-índices referem-se aos corpos A e B;

$\eta_{\mathrm{o}}$ é a viscosidade do lubrificante à pressão atmosférica (Pas);

E' é o módulo elástico reduzido $(\mathrm{Pa})$,

a é o coeficiente de variação da viscosidade com a pressão $\left(\mathrm{m}^{2} / \mathrm{N}\right)$;

W é a carga aplicada $(\mathrm{N})$;

$\mathrm{k}$ é o fator de elipsoidalidade; $\mathrm{k}=1$ para contatos pontuais e $\mathrm{k}=\infty$ para contatos lineares. 


\section{MATERIAIS E MÉTODOS}

Neste capítulo será feita a descrição da metodologia de ensaio empregada e dos materiais utilizados durante os experimentos. Antes de descrever em detalhe os métodos e materiais utilizados, apresenta-se na Figura 3.1 um fluxograma no qual é ilustrada a sequência de procedimentos adotados ao longo deste trabalho. A metodologia é composta de uma primeira etapa na qual foram elaborados os anéis (usinagem e tratamento térmico) onde posteriormente geraram-se as superficies a serem testadas. Após a avaliação do desempenho em fadiga de contato de rolamento das superficies (retificadas e torneadas), foi realizada a caracterização dos principais mecanismos de falha. Vale a pena ressaltar que não existe uma etapa definida para a avaliação da integridade da superfície (IS), já que as técnicas de análise são complementares. As técnicas utilizadas estão presentes em todas as etapas que compõem a metodologia proposta para avaliar o desempenho em fadiga de contato em superficies usinadas (ver Figura 3.1).
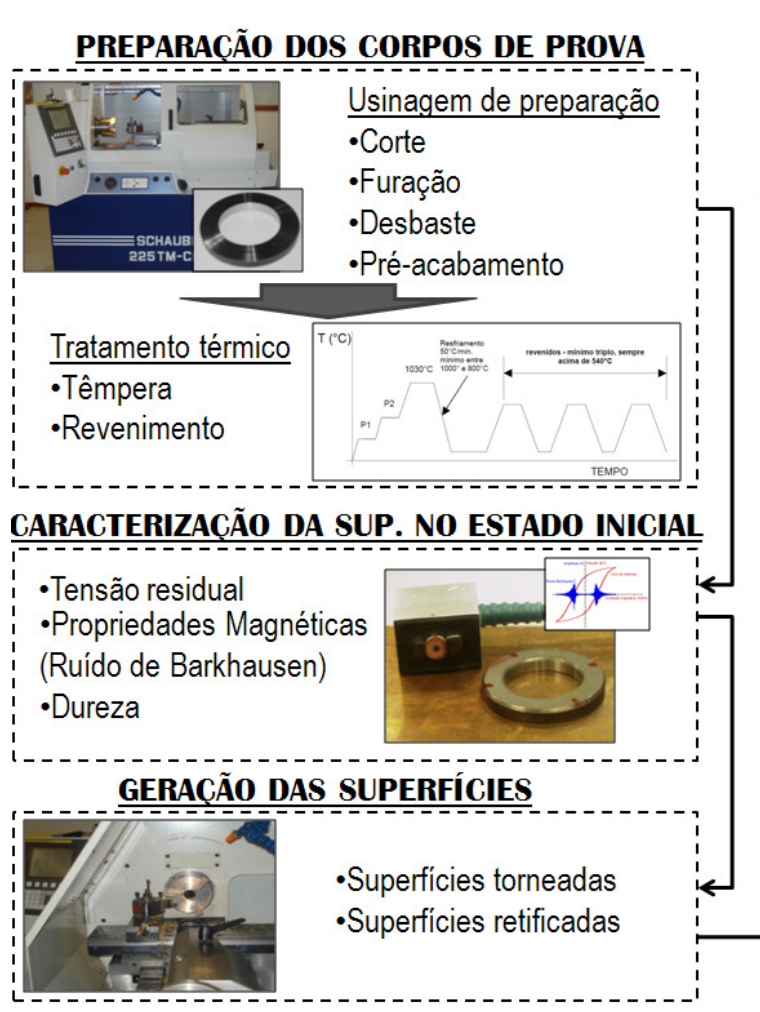

Figura 3.1 - Representação esquemática das etapas que compõem o procedimento experimental para a realização de ensaios de fadiga de contato em superficies usinadas.

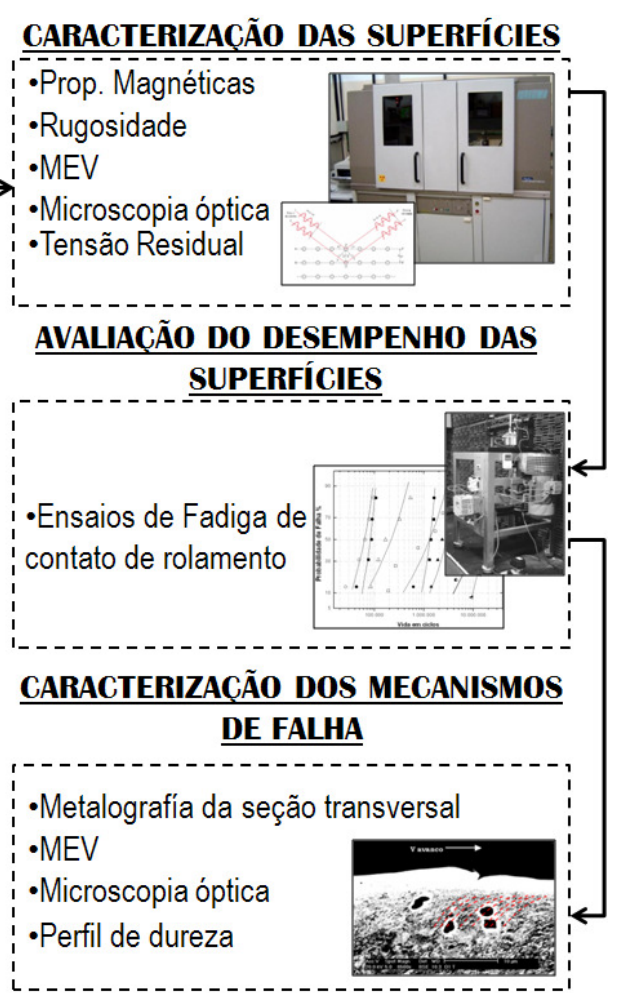




\subsection{Materiais para ensaio}

Os materiais de estudo que foram utilizados são os aços ABNT 52100 e AISI H13. Como contra-corpo usaram-se esferas de aço ABNT 52100, cedidas pela empresa Schaeffler Brasil Ltda. Os corpos de prova foram fabricados a partir de uma barra redonda de aço AISI H13 laminada, levados até o formato de anéis e tratados termicamente por têmpera em óleo seguida de triplo revenimento em forno de atmosfera controlada como detalhado na tabela 3.1. A seguir apresenta-se na tabela 3.2 a composição química do aço AISI H13 obtida do certificado de qualidade emitido pelo fornecedor.

Tabela 3.1. Sequência de tratamento térmico dos corpos de prova (AISI H13).

\begin{tabular}{cccc}
\hline Tratamento térmico & Temperatura & Tempo & Pressão no forno \\
\hline Têmpera & $1030^{\circ} \mathrm{C}$ (austenitização) & & 3,6bar \\
Revenimento 1 & $540^{\circ} \mathrm{C}$ & $2 \mathrm{~h}$ & \\
Revenimento 2 & $540^{\circ} \mathrm{C}$ & $2 \mathrm{~h}$ & \\
Revenimento 3 & $540^{\circ} \mathrm{C}$ & $2 \mathrm{~h}$ & \\
\hline
\end{tabular}

Tabela 3.2. Composição química do aço AISI H13.

\begin{tabular}{ccccccccc}
\hline Elemento & $\mathrm{C}$ & $\mathrm{Si}$ & $\mathrm{Mn}$ & $\mathrm{P}$ & $\mathrm{S}$ & $\mathrm{Cr}$ & $\mathrm{Mo}$ & $\mathrm{V}$ \\
$\%$ & 0,41 & 0,97 & 0,39 & 0,014 & 0,002 & 5,01 & 1,20 & 0,89 \\
\hline
\end{tabular}

\subsection{Máquina-ferramenta e ferramental de corte}

As superficies testadas foram geradas mediante o processo de torneamento e retificação para condições de acabamento. As especificações da máquinaferramenta e ferramental utilizado em cada processo são apresentadas na tabela 3.3. No torneamento de acabamento foram utilizadas pastilhas de metal duro fornecidas pela "Sandvik Coromant", as quais possuem revestimento multicamadas de $\mathrm{Al}_{2} \mathrm{O}_{3}$ sobre uma camada de TiCN, e por último uma camada de TiN. O desgaste da ferramenta não foi objeto do presente estudo, e por isso foi utilizada uma aresta de corte nova para cada superficie gerada. As superficies torneadas foram usinadas com a presença de fluido de corte, e empregando um torno CNC de precisão da marca "Schaublin Machines S.A", modelo 225TM-CNC apresentado na Figura 3.2. As superficies foram 
retificadas em retifica plana tangencial de fabricação FERDIMAT modelo TA63, mediante o uso de rebolo reto de carbeto de silício, especificação RT com as dimensões de dimensões 304,8 x 25,4x 76,2mm. O rebolo utilizado é de grau $\mathrm{R}$ e teve uma velocidade angular de 3400 rotações/min, o avanço longitudinal da mesa foi de $4 \mathrm{~m} / \mathrm{min}$ e a profundidade de remoção de $0,03 \mathrm{~mm}$.

Tabela 3.3. Máquinas ferramenta e ferramental de corte utilizados.

\begin{tabular}{|c|c|c|c|}
\hline \multicolumn{2}{|c|}{ Torneamento } & \multicolumn{2}{|c|}{ Retificação } \\
\hline Item & Especificação & Item & Especificação \\
\hline $\begin{array}{l}\text { Máquina } \\
\text { ferramenta }\end{array}$ & 225TM-CNC & $\begin{array}{l}\text { Máquina } \\
\text { ferramenta }\end{array}$ & Ferdimat TA63 \\
\hline Inserto & VBMT 110304-PF 4015 & Rebolo Reto & C220T11R \\
\hline Porta-ferramenta & Sandvik SVVBN 1616H & Abrasivo & Carbeto de silício \\
\hline
\end{tabular}

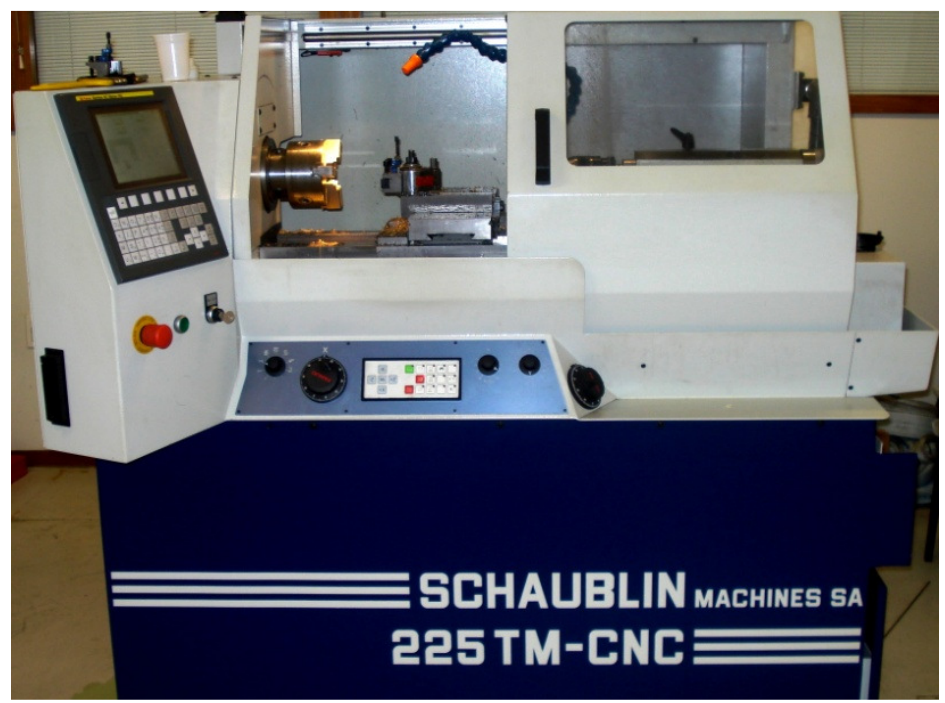

Figura 3.2 - Torno CNC de precisão da marca "Schaublin Machines S.A", modelo 225TM-CNC utilizado para a geração das superficies torneadas.

\subsection{Equipamentos para a caracterização da integridade superficial e das propriedades mecânicas}

As características particulares da IS foram avaliadas com o emprego dos seguintes equipamentos:

i. Análise da camada superficial: As particularidades da subsuperficie foram avaliadas por meio de microscopia óptica (MO) e eletrônica de varredura (MEV). A obtenção das imagens por MO foi realizada no microscópio óptico Olympus BX60M. Características qualitativas particulares da microestrutura foram avaliadas em Microscópio Eletrônico de Varredura modelo Philips XL 30 e microssonda EDAX para análise espectrométrica de Raios X com detector de 
elementos leves. A medição da tensão residual foi realizada no difratômetro de raios -X Rint 2000 do fabricante "Rigaku", e que se encontra instalado no CCTM do IPEN, e uma imagem do equipamento é apresentada na Figura 3.3. Para a medição das propriedades magnéticas foi utilizado o sistema desenvolvido totalmente no Laboratório de Dinâmica e Instrumentação (LADIN) da Universidade de São Paulo (GRIJALBA, 2010), tendo como destaque o desenvolvimento do equipamento "Barktech" e da sonda de medição, que são os principais componentes do sistema apresentado na Figura 3.4.

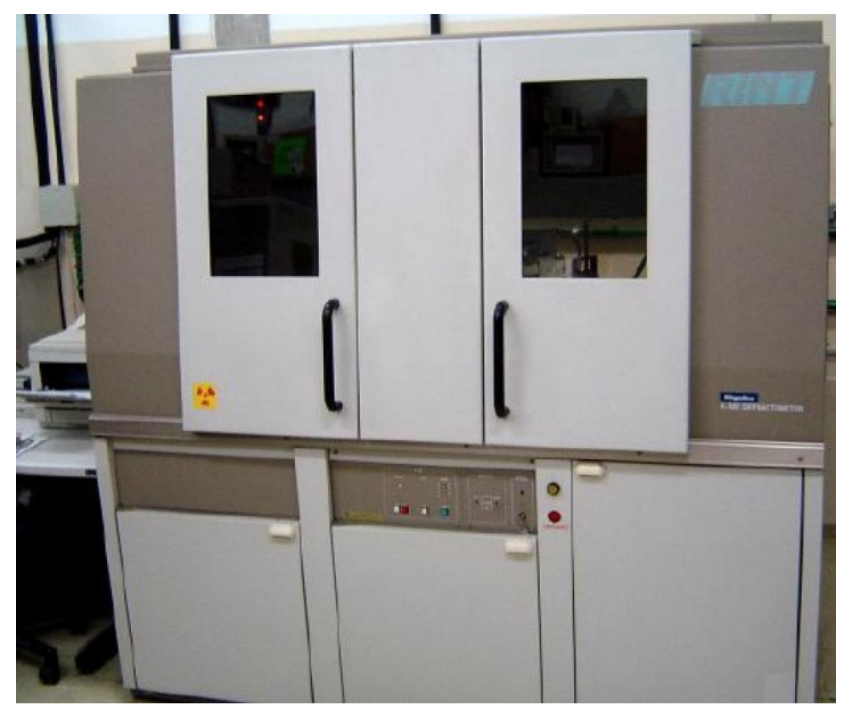

Figura 3.3 - Difratômetro de raios -X Rint 2000 do fabricante "Rigaku" utilizado para a medição da tensão residual.

ii. Análise da topografia das superfícies usinadas: Após os ensaios de usinagem, as características qualitativas tridimensionais da topografia das superficies dos corpos de prova foram observadas mediante a utilização do microscópio eletrônico de varredura, e de microscópio estereoscópio modelo SNV8000 de fabricação Nikon, acoplado a um módulo de aquisição de imagens. As medidas de rugosidade foram feitas em rugosimetro Surfcorder SE1700 $\alpha$ de fabricação Kosaka Lab, que utiliza um microcomputador mediante a interface de transmissão para coleta de dados RS232.

iii. Análise da dureza: A microdureza dos materiais foi determinada por meio de um microdurômetro convencional Vickers - Micromet 2103, que dispõe de um conjunto de lentes que permite aumento de até 1000 vezes. 


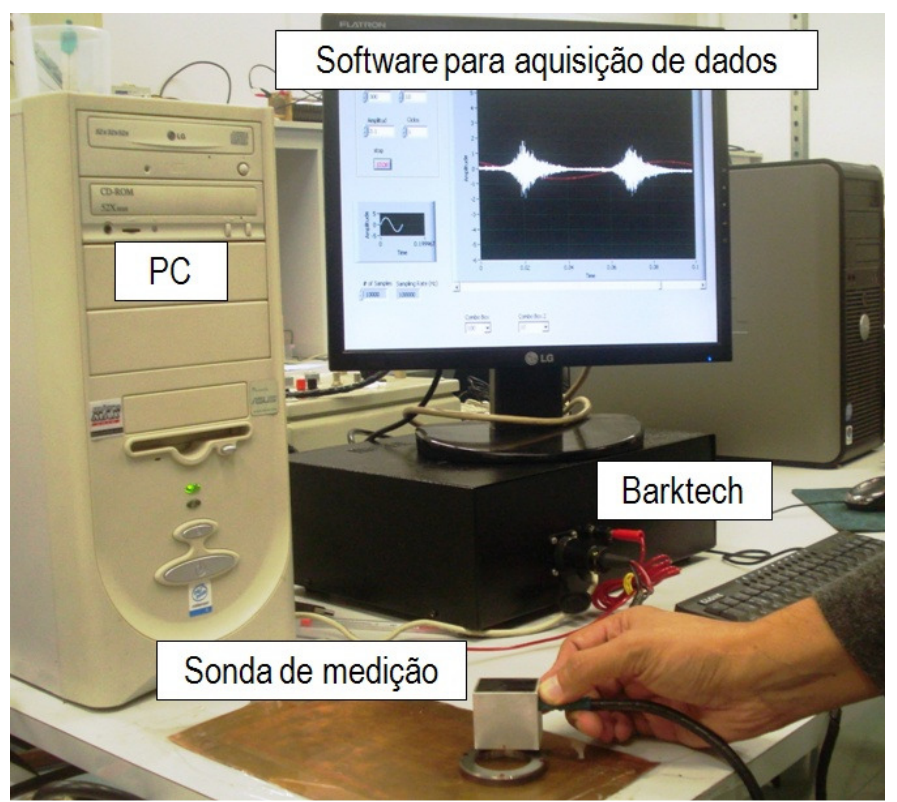

Figura 3.4 - Sistema para medição de propriedades magnéticas desenvolvido no Laboratório de Dinâmica e Instrumentação (LADIN) da Universidade de São Paulo.

\subsection{Equipamento para a avaliação do desempenho tribológico}

O equipamento desenvolvido no LFS - EP/USP (NEVES et al, 2005; NEVES, 2006) utiliza a geometria de contato esfera sobre plano, e permite estudar o efeito da carga, do lubrificante e dos materiais na resistência à vida em fadiga de contato de rolamento. Na Figura 3.5 apresenta-se uma imagem do equipamento onde são ilustrados os principais subconjuntos que compõem o ensaio.

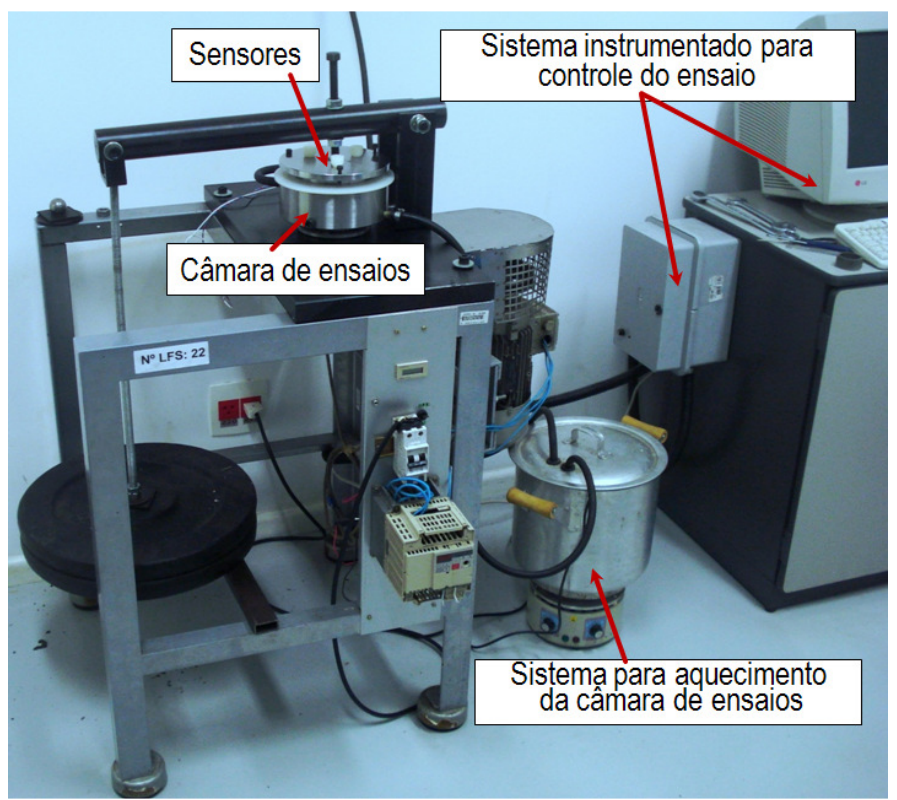

Figura 3.5 - Principais componentes do equipamento de fadiga de contato de rolamento desenvolvido no Laboratório de Fenômenos de Superfícies (LFS) da Universidade de São Paulo. 
O equipamento de FCR baseia-se na substituição da uma das pistas externas de um rolamento axial de duas fileiras de esferas de assentamento esférico (DIN 54206U) por um corpo de prova plano, o qual apresenta a forma de uma arruela. A utilização de um rolamento com assento esférico torna o sistema tolerante a pequenos desalinhamentos entre o eixo da máquina e o assento dos corpos de prova. O rolamento axial se encontra imerso num óleo comercial para caixa de engrenagens. O óleo troca calor com um fluido externo que se encontra a maior temperatura, circulando dentro das paredes da câmera de ensaio. Os ensaios são conduzidos mediante carregamento por peso morto sobre a esfera de carga, a lubrificação é feita com óleo designação SAE 90 API-GL4, e a temperatura de ensaio foi monitorada para ajustá-la numa faixa $\left(49,5\right.$ e $\left.50,5^{\circ} \mathrm{C}\right)$ e assim manter constante a viscosidade do óleo. Como contra corpo são utilizadas três (3) esferas de rolamento fabricadas em aço ABNT 52100. Ilustram-se esquematicamente na Figura 3.6 os detalhes construtivos mais relevantes dos elementos mecânicos que compõem o equipamento de fadiga de contato de rolamento desenvolvido por Neves et al (2005) e Neves (2006).

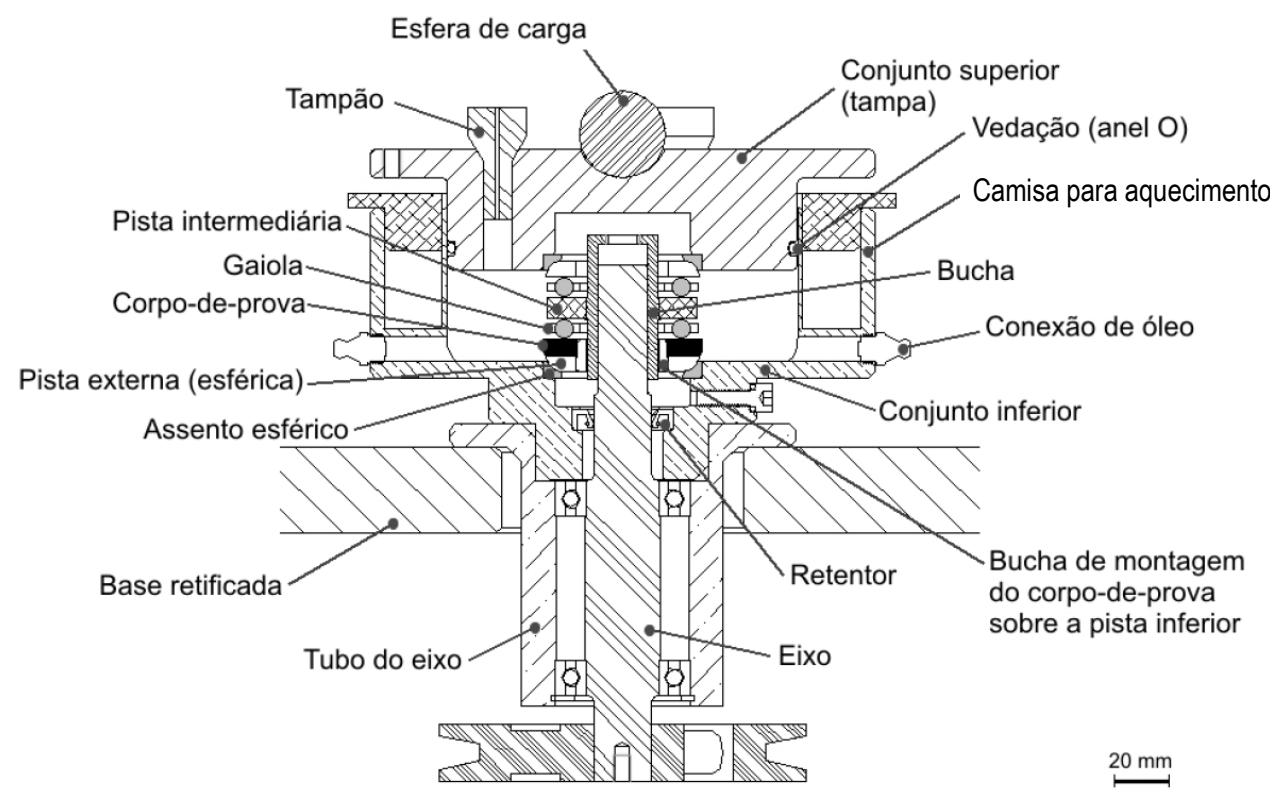

Figura 3.6 - Esquema representativo dos detalhes construtivos do equipamento de fadiga de contato de rolamento (NEVES et al, 2005; NEVES, 2006). 


\section{PROCEDIMENTO EXPERIMENTAL}

Inicialmente foram produzidas as superficies torneadas e retificadas nas quais foi testado o desempenho tribológico do aço ABNT H13, e posteriormente realizaram-se os ensaios de desgaste por rolamento no equipamento que permite reproduzir em laboratório o mecanismo de falha por fadiga de contato (NEVES et al, 2005; NEVES, 2006). A seguir serão detalhados os procedimentos e metodologias empregadas em cada uma das etapas anteriormente enunciadas.

\subsection{Preparação dos corpos de prova}

Os corpos de prova foram cortados a partir de uma barra de aço AISI H13. Após desbastar a barra de aço no diâmetro e realizar o furo no centro da peça, realizou-se o corte de anéis em serra de fita. Foi realizado o desbaste e um préacabamento dos anéis antes de realizar o tratamento térmico (ver tabela 3.1).

\subsection{Ensaios de usinagem}

Após a preparação dos corpos de prova, as operações de torneamento por faceamento foram executadas de acordo com os parâmetros de corte apresentados na tabela 4.1. Durante a etapa de pré-usinagem levou-se em consideração deixar $0,5 \mathrm{~mm}$ de sobre-metal na altura dos corpos de prova para garantir material suficiente a ser removido durante os ensaios. Foram realizados três (3) passes de acabamento consecutivos empregando os mesmos parâmetros de corte da condição que está sendo testada, e empregou-se fluido de corte sintético. O sobre-metal foi retirado da aresta posterior à superficie faceada com o uso de retificadora, garantindo a precisão dimensional na altura do corpo de prova, cujas dimensões nominais são mostradas na Figura 4.1. O estado da aresta de corte das ferramentas foi inspecionado antes e depois de cada ensaio com auxílio de microscópio estereoscópio.

Nas superficies torneadas para cada combinação de parâmetros de corte foram realizadas seis (6) repetições, gerando a matriz de ensaios apresentada na tabela 4.2. As superficies na condição retificada foram geradas empregando-se os mesmos parâmetros para todos os ensaios, para um total de 24 amostras. 
Tabela 4.1. Parâmetros de corte para a condição de torneamento de acabamento.

Parâmetro de corte

$\begin{array}{cc}\text { Velocidade de corte }\left(\mathrm{v}_{\mathrm{c}}\right) & 60-120 \mathrm{~m} / \mathrm{min} \\ \text { Avanço (f) } & 0,05-0,1 \mathrm{~mm} / \mathrm{rev}\end{array}$

Profundidade de corte $\left(a_{\mathrm{p}}\right)$

$0,1 \mathrm{~mm}$

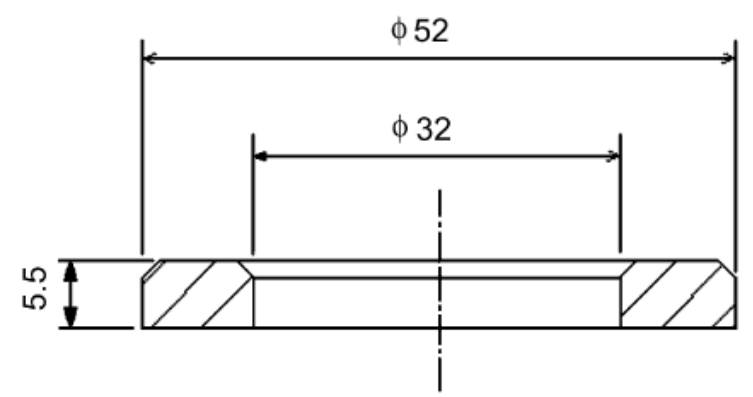

Figura 4.1 - Representação esquemática do corpo de prova de fadiga de contato (todas as dimensões em mm) (NEVES, 2006).

Tabela 4.2. Matriz de ensaios para a condição de torneamento de acabamento.

\begin{tabular}{cccc}
\hline Condição & Vc (m/min) & $\mathrm{f}(\mathrm{mm} / \mathrm{rev})$ & $\mathrm{a}_{\mathrm{p}}(\mathrm{mm})$ \\
\hline S1 & 60 & 0,05 & 0,1 \\
S2 & 60 & 0,1 & 0,1 \\
S3 & 120 & 0,05 & 0,1 \\
S4 & 120 & 0,1 & 0,1 \\
\hline
\end{tabular}

As superficies retificadas foram obtidas em retificadora plana tangencial e utilizou-se fluido de refrigeração, sendo que os parâmetros de corte empregados são apresentados na tabela 4.3.

Tabela 4.3. Parâmetros de corte para as superfícies obtidas pelo processo de retificação.

\begin{tabular}{cc}
\hline Parâmetro de corte & \\
\hline Velocidade de corte $\left(\mathrm{v}_{\mathrm{c}}\right)$ & $54 \mathrm{~m} / \mathrm{s}^{*}$ \\
Avanço longitudinal da mesa $\left(\mathrm{v}_{\mathrm{p}}\right)$ & $4 \mathrm{~m} / \mathrm{min}$ \\
Profundidade de penetração $\left(\mathrm{a}_{\mathrm{e}}\right)$ & $0,03 \mathrm{~mm}$ \\
\hline
\end{tabular}

* A velocidade utilizada está acima do valor de referência do fabricante devido a que o procedimento foi projetado para minimizar o dano na peça, e não em termos de produtividade e vida do rebolo. 


\subsection{Procedimento para a caracterização da integridade superficial}

Após a geração das superficies torneadas e retificadas, iniciou-se o procedimento e as respectivas técnicas necessárias para a avaliação da integridade das superficies.

\subsubsection{Caracterização da superfície usinada}

\subsubsection{Preparação de amostras para caracterização da IS}

As alterações da microestrutura pelo efeito da usinagem e a caracterização dos mecanismos de falha presentes foram avaliados ao longo da profundidade dos corpos de prova. Efetuaram-se cortes transversais no plano perpendicular e paralelo ao sentido de avanço da ferramenta de corte. O corte foi realizado em equipamento de precisão com disco diamantado (ISOMET 4000/Buelher), sempre na presença de fluido de corte sintético e com a seleção dos parâmetros adequados para aço ferramenta, isto com o intuito de minimizar as alterações no material.

Uma vez realizado o corte das amostras passou-se ao processo de preparação metalográfica. As amostras foram embutidas em resina epóxi com carga mineral (Durofast - Struers), produto que melhora a retenção das bordas durante as etapas posteriores de lixamento e polimento. Com a ajuda de politriz automática foi realizado lixamento com lixa de carbeto de silício ( $\mathrm{SiC})$, e posteriormente polimento fino em suspensão de sílica coloidal até $1 \mu \mathrm{m}$.

\subsubsection{Medição da dureza}

Estas medições foram realizadas ao longo da seção transversal dos corpos de prova, cuja superficie foi previamente preparada metalograficamente. O microdurômetro convencional Vickers/Micromet 2103 dispõe de um conjunto de lentes com aumentos de até 1000 vezes, possibilitando medições seletivas em função da posição dos microconstituintes a serem avaliados. Utilizaram-se cargas de 0,49 N (50 gf) e 0,98 N (100 gf) segundo a dureza do material, e foram avaliados 10 campos em diferentes regiões da amostra para cada medição. 


\subsubsection{Análise da topografia}

As características qualitativas tridimensionais da topografia das superficies usinadas foram observadas mediante a utilização do microscópio eletrônico de varredura, e de microscópio estereoscópio.

\subsubsection{Medição da rugosidade}

A medição de rugosidade foi feita em rugosímetro Surfcorder SE1700 $\alpha$ de fabricação "Kosaka lab", acoplado a um microcomputador. Os parâmetros de rugosidade analisados foram a rugosidade média $(\mathrm{Ra})$, a raiz média quadrática de rugosidade ( $\mathrm{Rq})$ e a largura média de um elemento do perfil (Rsm). O espaçamento entre sulcos foi o critério utilizado para escolher o cumprimento de amostragem (tabela 4.4), que por se tratar de superficies periódicas é aproximadamente igual ao avanço da ferramenta.

Tabela 4.4. Comprimento de amostragem (“cut-off") para superficies periódicas (GRIFFITHS, 2001).

\begin{tabular}{ccc}
\hline Distância entre sulcos $(\mathrm{mm})$ & $\lambda \mathrm{c}(\mathrm{mm})$ & $\lambda \mathrm{m}(\mathrm{mm})$ \\
\hline De 0,01 até 0,032 & 0,08 & 0,4 \\
De 0,032 até 0,1 & 0,25 & 1,25 \\
De 0,1 até 0,32 & 0,8 & 4 \\
De 0,32 até 1 & 2,5 & 12,5 \\
De 1 até 3,2 & 8 & 40 \\
\hline
\end{tabular}

Seguindo as recomendações da norma NBR-6405 (1988), foi utilizado um "cut-off" de 0,25mm $\left(\lambda_{c}\right)$ e 5 comprimentos de amostragem para cada medida, totalizando um comprimento de medição de 1,25 $\mathrm{mm}\left(\lambda_{\mathrm{m}}\right)$. Para gerar o perfil de rugosidade empregou-se um filtro Gauss (ASME), e a obtenção dos parâmetros de rugosidade empregando a norma ISO97/JIS2001/ASME95.

\subsubsection{Medição da tensão residual}

Utilizou-se o difratômetro de raios-X Rint 2000 do fabricante "Rigaku". Empregou-se um tubo de Cromo K-alfa de 0,229 nm (2,29 Å). Para as amostras selecionadas avaliou-se uma área onde foram realizadas 13 medições de tensão residual, alterando o ângulo $\psi$ (valores discretos de $10 \mathrm{em}$ 10 graus) de onde é obtida a média e o desvio padrão para a leitura. As medições de tensão residual foram executadas antes do ensaio de desgaste na superficie usinada em dois pontos diferentes a um ângulo de $90^{\circ}$ (P1, P2), e no sentido paralelo e perpendicular às marcas de usinagem (m1, m2) como 
ilustrado na Figura 4.2. Uma medição do estado de tensões foi realizada na superficie de uma amostra antes de ser afetada pelo processo de usinagem.
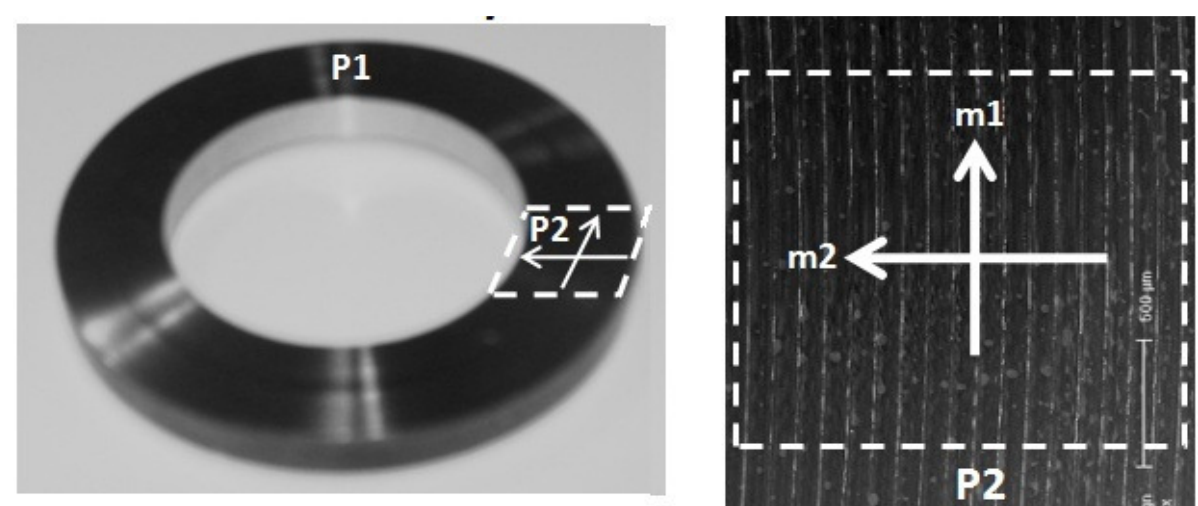

Figura 4.2- Representação esquemática dos pontos (P1, P2) e do sentido de medição $(\mathrm{m} 1, \mathrm{~m} 2)$ da tensão residual na superficie das amostras.

\subsubsection{Medição das propriedades magnéticas - Ruído magnético de Barkhausen (RMB)}

Para a medição de RMB foi utilizado o equipamento "Barktech" desenvolvido totalmente no Laboratório de Dinâmica e Instrumentação (LADIN) da Universidade de São Paulo (GRIJALBA, 2010). O equipamento é responsável tanto pela geração e controle da corrente de excitação, como pela aquisição e filtragem dos sinais de tensão gerados pelo sensor de RMB. Os sinais de RMB foram adquiridos com uma frequência de $200 \mathrm{kHz}$ e amplificados com um ganho de 120. Para cada amostra foram realizadas medições em quatro (4) pontos diferentes a $90^{\circ}$, como apresentado na Figura 4.3.

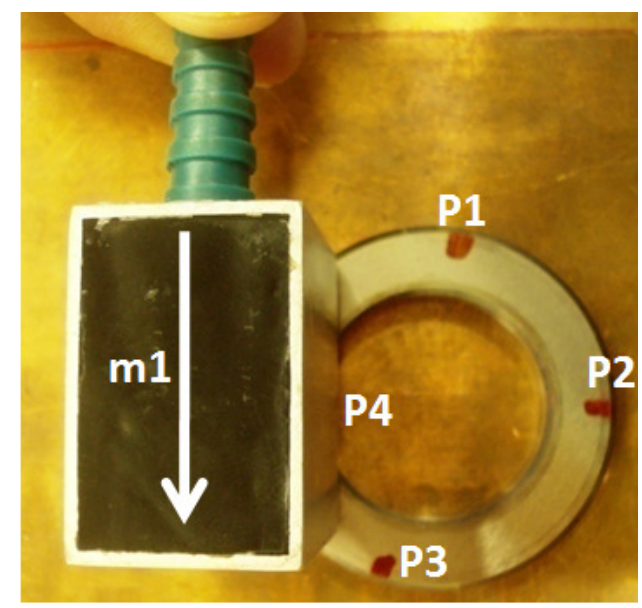

Figura 4.3 Representação esquemática dos pontos de medição (P1, P2, P3, P4) e do sentido de medição do ruído magnético de Barkhausen paralelo às marcas da ferramenta $(\mathrm{m} 1)$. 
O sensor utilizado foi um "Yoke" de ferro-níquel desenvolvido no LADIN (GRIJALBA, 2010). A sonda de RMB tem a função de aplicar o campo magnético de excitação aos materiais e detectar o RMB gerado nos mesmos.

\subsection{Procedimento experimental para ensaios de desgaste}

Os parâmetros de ensaio selecionados para as superficies obtidas por torneamento e retificação foram os mesmos utilizados durante o estudo de aços fundidos e forjados (NEVES et al., 2005; NEVES, 2006), o qual permitirá comparar o desempenho entre as diversas condições ensaiadas. Na tabela 4.5 apresentam-se os parâmetros de ensaio de FCR.

Tabela 4.5. Variáveis de processo empregadas durante o os ensaios de fadiga de contato de rolamento (NEVES, 2006).

\begin{tabular}{cc}
\hline Lubrificante & SAE 90 API-GL4 \\
\hline Temperatura do lubrificante & $500 \mathrm{C}$ \\
\hline Carga total & $2100 \mathrm{~N}$ \\
\hline Número de esferas & 3 \\
\hline Cargas por esfera & $700 \mathrm{~N}$ \\
\hline Diâmetro da esfera & $7,938 \mathrm{~mm}$ \\
\hline Raio de contato (a) & $0,264 \mathrm{~mm}$ \\
\hline Área de contato & $0,216 \mathrm{~mm} 2$ \\
\hline Pressão média de contato $\left(\mathrm{p}_{\mathrm{m}}\right)$ & $3,2 \mathrm{GPa}$ \\
\hline Máxima pressão de contato $\left(\mathrm{p}_{0}\right)$ & $4,8 \mathrm{GPa}$ \\
\hline Frequência de carregamento & $46 \mathrm{HZ}$ (para o eixo rodando a $1900 \mathrm{rpm})$ \\
\hline
\end{tabular}

Empregou-se um sistema instrumentado que foi desenvolvido para controlar as condições do ensaio (ALVAREZ et al., 2008). As tarefas realizadas pelo sistema instrumentado são listadas de maneira resumida a seguir:

- Ligar o equipamento quando a temperatura do óleo utilizado na lubrificação do contato seja a adequada.

- Controlar a temperatura do óleo dentro de uma faixa estável préestabelecida.

- Gerar uma resposta ao surgir o defeito (desligando o equipamento).

- Registrar os sinais de aceleração e temperatura do sistema em tempo real. 
- Comunicar ao usuário a ocorrência do defeito remotamente, (enviar uma mensagem de e-mail mediante o protocolo SMTP "Simple Mail Transfer Protocol').

A configuração do ensaio e os mecanismos de falha que caracterizam o fenômeno se assemelham aos apresentados nas pistas dos rolamentos. Segundo Tandon (1999) os defeitos de um rolamento podem ser categorizados como distribuídos ou localizados. Os defeitos distribuídos estão associados a mudanças de rugosidade e à presença de ondulação nas superfícies de rolamento. Os defeitos localizados são relacionados a trincas, "pites" e lascamentos nas superficies rolantes. Esses defeitos podem ser originados por fadiga, podendo ser acelerados se ocorrer impactos de carga mecânica. Sempre que um defeito localizado em um elemento interage com outro elemento, ocorrem mudanças abruptas nas tensões de contato, o que gera um pulso de curta duração, causando aumento nos níveis de vibração e ruído do componente. Os parâmetros de vibração no domínio do tempo, tais como "overall" RMS, fator de crista e curtose têm um sucesso limitado de detecção de defeitos localizados. O valor de RMS (“Root Mean Square”) considera todo o histórico do sinal de vibração e fornece uma estimativa da energia de vibração (SAAVEDRA, 1988 apud SERRATO, 2006), motivo pelo qual é o parâmetro mais usado para estimar a severidade de vibração de um componente (SERRATO, 2006).

A totalidade dos ensaios foi realizada até o fim de vida dos corpos de prova, adotando como critério para interromper o ensaio a ocorrência do primeiro lascamento na superficie das amostras. Um sensor de aceleração (acelerômetro) é utilizado para captar o surgimento do lascamento, e mediante a análise da amplitude do valor médio eficaz (RMS) do sinal de aceleração é detectada a presença de um defeito na pista de um rolamento. Em um trabalho anterior foi definido o critério de falha a partir da análise da amplitude RMS que caracteriza a severidade da vibração presente no sistema como resultado do surgimento do lascamento, sendo que amplitudes acima de 0,25 gravidades de aceleração $(\mathrm{gP})$ pressupõem a ocorrência da falha na superficie do corpo de prova nas condições de trabalho apresentadas na tabela 4.4 (ALVAREZ et al, 2008). Em condições normais de operação e sem a presença de defeitos no corpo de prova, a amplitude RMS do sinal de aceleração oscila numa faixa de 0,15-0,18 gP. 
Foi utilizado um acelerômetro uniaxial da Kistler, modelo 8702B50M1, com faixa de medição $\pm 50 \mathrm{gP}$, e uma faixa de frequência de 0,5-10.000 Hz. A fixação do sensor na tampa do compartimento do ensaio foi feita mediante parafuso. Os ensaios de FCR até o fim de vida geralmente são de longa duração, de acordo com a resistência do material à fadiga de contato. Uma vez gerado o defeito, o equipamento envia um e-mail via SMTP, notificando o motivo pelo qual se apresentou a parada do ensaio (ocorrência do lascamento ou cancelamento do ensaio pelo usuário). Na Figura 4.4 é apresentada uma representação esquemática do diagrama eletro-eletrônico dos componentes do quadro de controle instalado no sistema instrumentado do equipamento de fadiga de contato de rolamento (ALVAREZ et al, 2008).

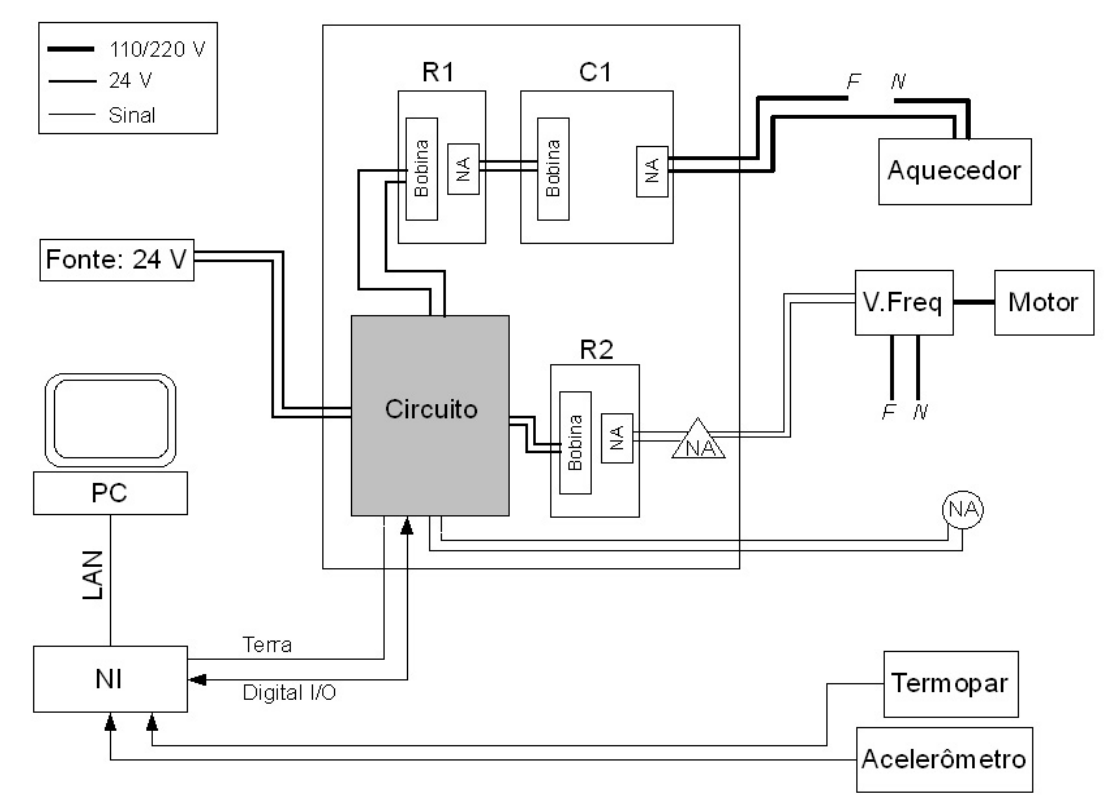

Figura 4.4 Representação esquemática do diagrama eletro-eletrônico dos componentes do quadro de controle instalado no sistema instrumentado do equipamento de fadiga de contato de rolamento (ALVAREZ et al, 2008).

O sistema instrumentado permitiu detectar de maneira eficiente o lascamento das superficies mediante a variação da amplitude RMS do sinal de vibração, e mediante o registro e análise deste valor foi possivel estabelecer claramente um valor de referência (“Set-point") de aceleração a partir do qual o ensaio é interrompido. 


\section{RESULTADOS E DISCUSSÃO}

Hioki (2006) apresentou uma metodologia para estudar a IS em superficies fresadas empregando HSM, e realizou ensaios tribológicos de desgaste por deslizamento para avaliar o desempenho das superficies. Esta metodologia será utilizada como referência para expor os resultados, já que existem semelhanças entre os objetivos dos dois trabalhos. Inicialmente será apresentada uma análise da influência dos parâmetros de corte sobre as características da superficie (. Posteriormente, será estabelecida uma relação entre o efeito destas características e o desempenho da superficie em FCR. Finalmente, será apresentada a relação existente entre os parâmetros de corte e o desempenho da superficie.

\subsection{Caracterização microestrutural dos aços utilizados}

Após a realização do tratamento térmico de têmpera e triplo revenimento nos corpos de prova, obteve-se uma microestrutura composta de matriz martensítica fina, como apresentado na Figura 5.1.

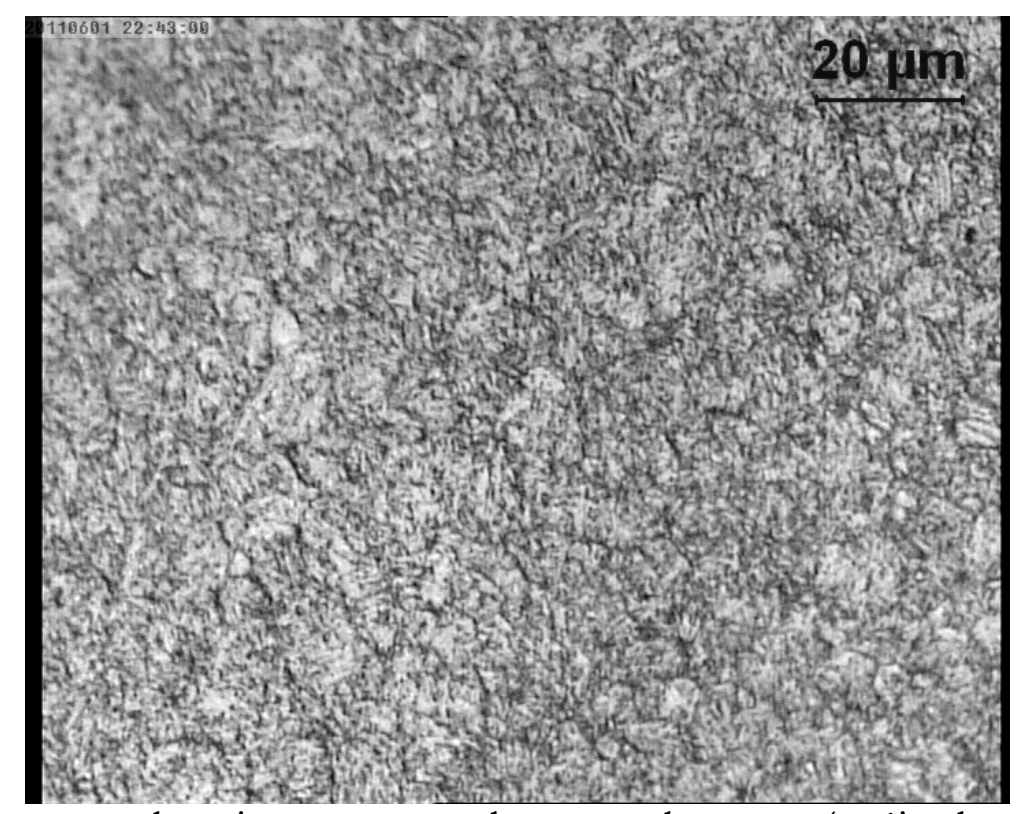

Figura 5.1 - Imagem da microestrutura do corpo de prova (anéis de aço AISI H13) onde se mostra a matriz martensítica fina. Imagem obtida em microscópio óptico (MO). Ataque com Vilella e aumento de 1000 vezes.

Igualmente, observou-se a presença de uma baixa fração de carbonetos finos dispersos na matriz metálica (partículas mais claras na figura) como 
apresentado na Figura 5.2. Após os tratamentos térmicos a dureza média avaliada foi de $668 \pm 15 \mathrm{HV}_{50}$.

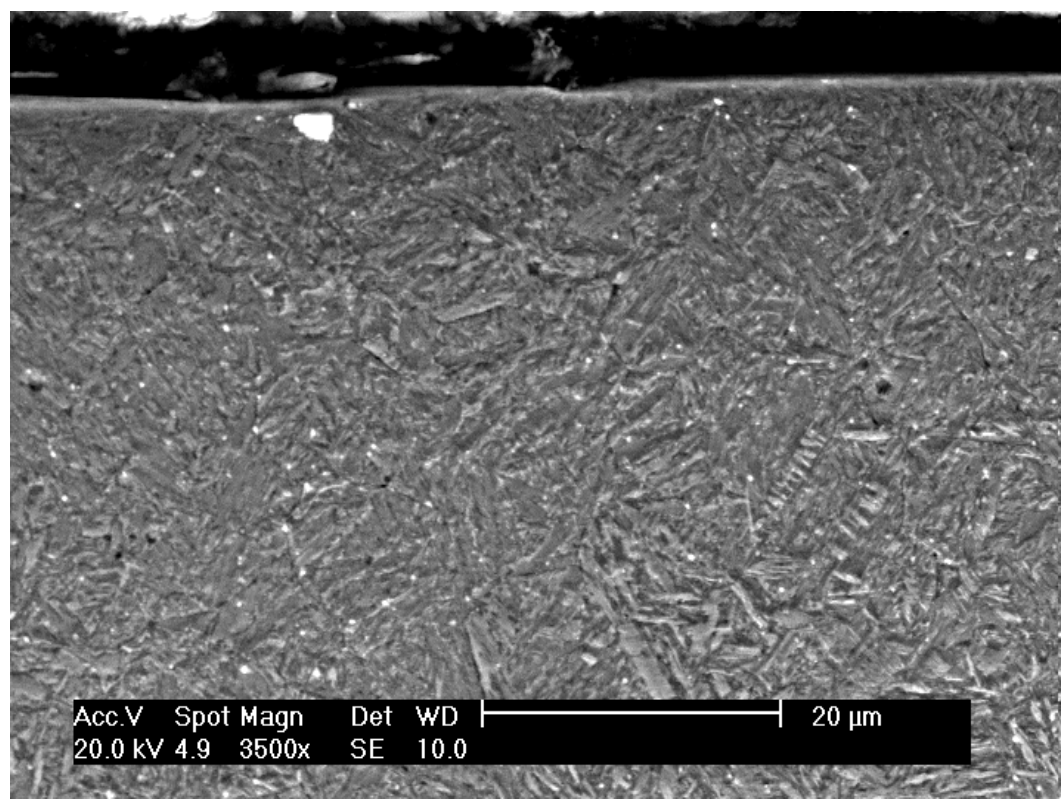

Figura 5.2 - Imagem da microestrutura do corpo de prova (anéis de aço AISI H13) onde se mostra a presença de carbonetos refinados dispersos na matriz metálica. Imagem obtida em microscópio eletrônico de varredura (MEV). Ataque com vilella e aumento de 3500 vezes. Análise de elétrons secundários.

As esferas que atuam como contra-corpo foram adquiridas comercialmente, e uma micrografia é apresentada na Figura 5.3.

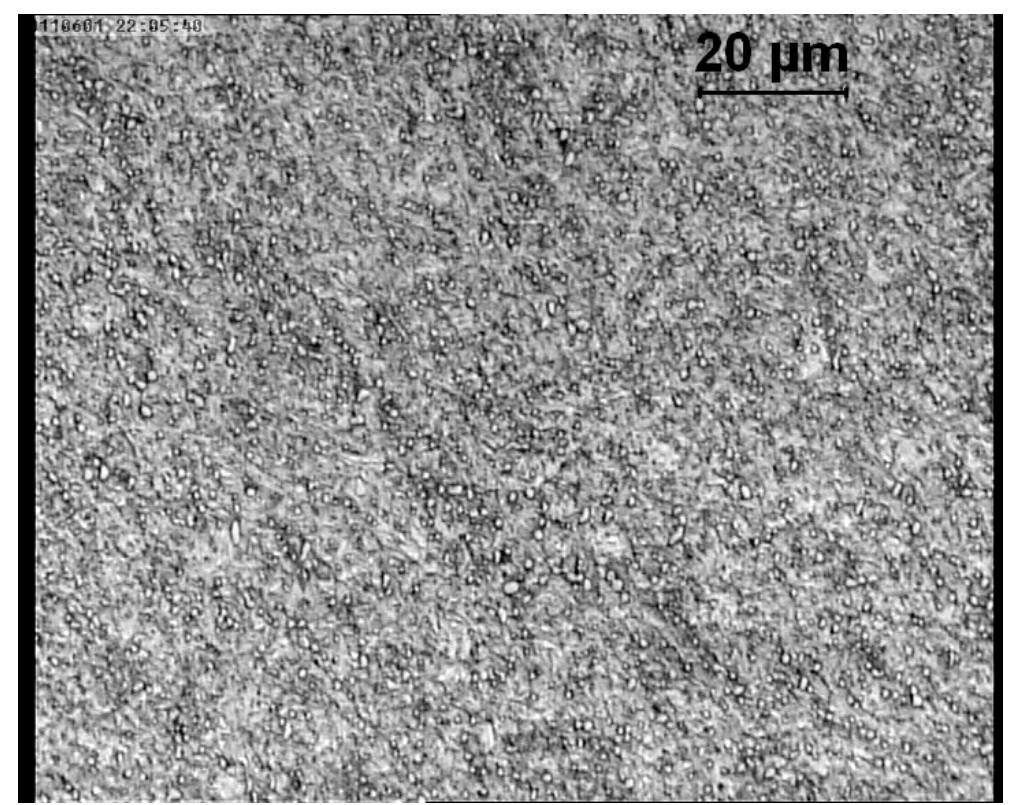

Figura 5.3 - Imagem da microestrutura do contra-corpo (esferas de aço ABNT 52100) onde se mostra a presença de carbonetos espalhados na matriz martensítica. Imagem obtida em microscópio óptico (MO). Ataque com vilella e aumento de 1000 vezes. 
Observa-se na sua microestrutura uma matriz martensitica fina com carbonetos esferoidais refinados e espalhados (fase mais clara) pela matriz metálica como segunda fase. Avaliou-se a dureza em diferentes regiões da seção transversal das esferas, apresentando uma dureza média de 917 $\pm 35 \mathrm{HV}_{100}$.

\subsection{Influência dos parâmetros de corte na integridade de superfície.}

A escolha dos parâmetros de corte objetivou a geração de superficies com propriedades diferentes, mas, sempre utilizando condições de usinagem convencionais. A condição de corte convencional foi garantida pela utilização dos parâmetros de corte adequados. Igualmente, utilizou-se uma aresta de corte para cada ensaio e assim minimizou-se o detrimento da superficie pelo efeito do desgaste da ferramenta. Empregou-se um equipamento de precisão e rigidez adequado aos testes realizados e igualmente, foi feita a escolha de um material com ausência de segundas fases na microestrutura que prejudicassem o aspecto da superficie pelo destacamento dessas partículas de segunda fase. Assim, não houve presença de defeitos e falhas grosseiras na topografia das amostras a serem ensaiadas.

\subsubsection{Influência dos parâmetros de corte na rugosidade}

A seguir serão apresentadas as características dos quatro (4) tipos de superficie (S1, S2, S3, S4) geradas por torneamento e da superficie retificada (SR), sendo que o perfil de rugosidade mostrado corresponde a uma das seis (6) repetições realizadas para cada medida.

Nas Figuras 5.4 a 5.8 será apresentado o perfil de rugosidade das superficies geradas (S1, S2, S3, S4, SR), sendo que, somente será apresentado o perfil avaliado numa das amostras produzidas para cada condição de ensaio. $O$ valor médio dos parâmetros de rugosidade (Ra, Rq, Rsm) avaliados em todas as repetições para cada condição são apresentados na tabela 5.1. 


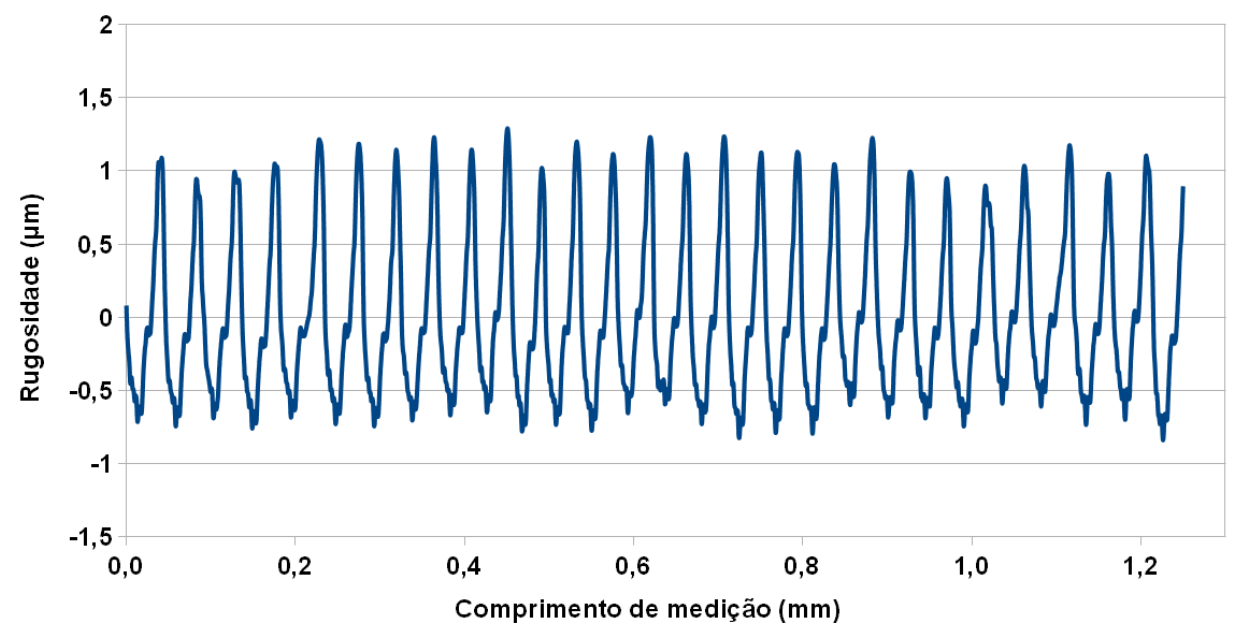

Figura 5.4 - Perfil de rugosidade da superficie do corpo de prova na condição S1 após torneamento com velocidade de corte (Vc) de $60 \mathrm{~m} / \mathrm{min}$, e avanço (f) de 0,05 mm/rot.

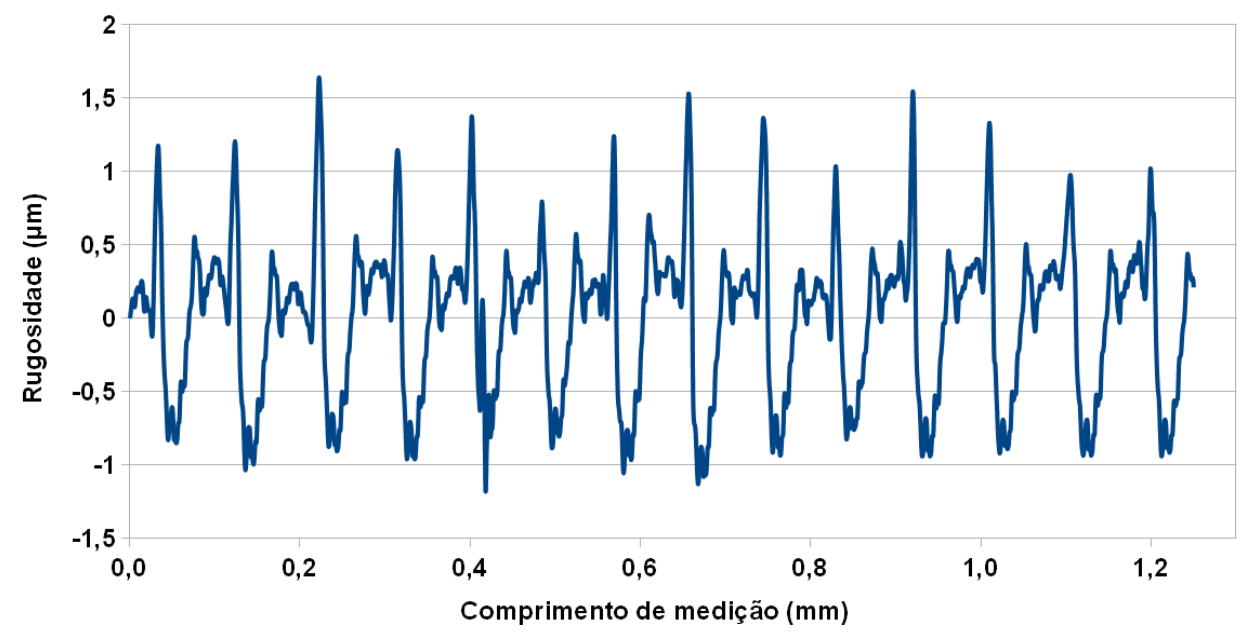

Figura 5.5 - Perfil de rugosidade da superficie do corpo de prova na condição S2 após torneamento com velocidade de corte (Vc) de $60 \mathrm{~m} / \mathrm{min}$, e avanço (f) de $0,1 \mathrm{~mm} / \mathrm{rot}$.

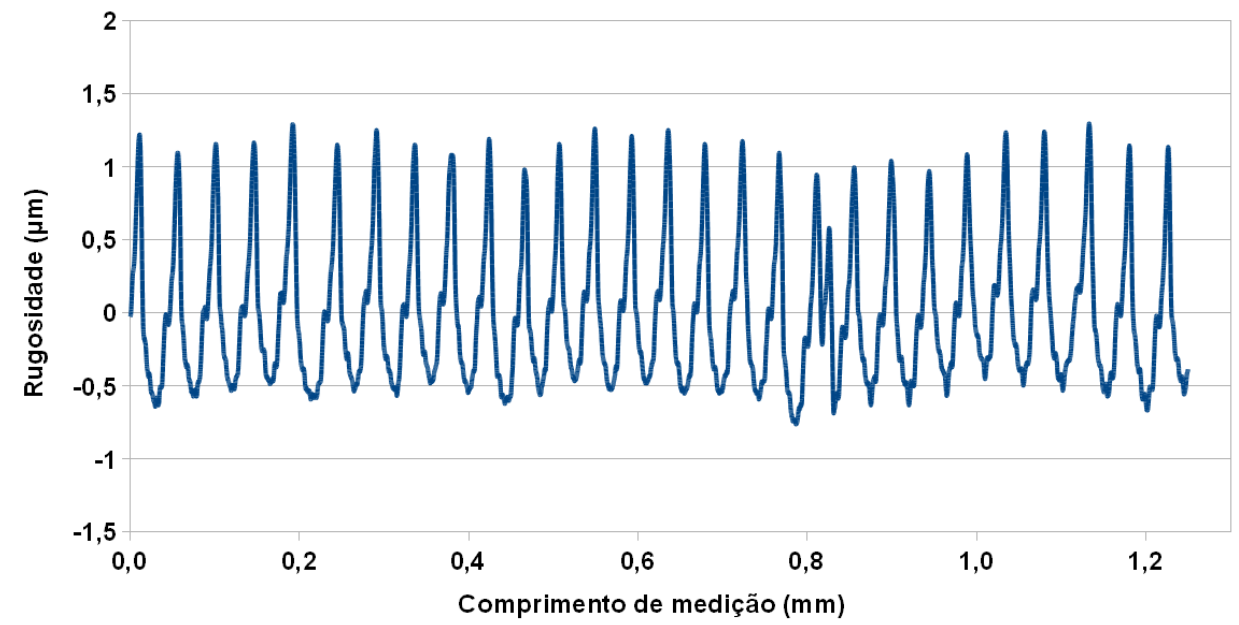

Figura 5.6 - Perfil de rugosidade da superfície do corpo de prova S3 após torneamento com velocidade de corte (Vc) de $120 \mathrm{~m} / \mathrm{min}$, e avanço (f) de 0,05 mm/rot. 


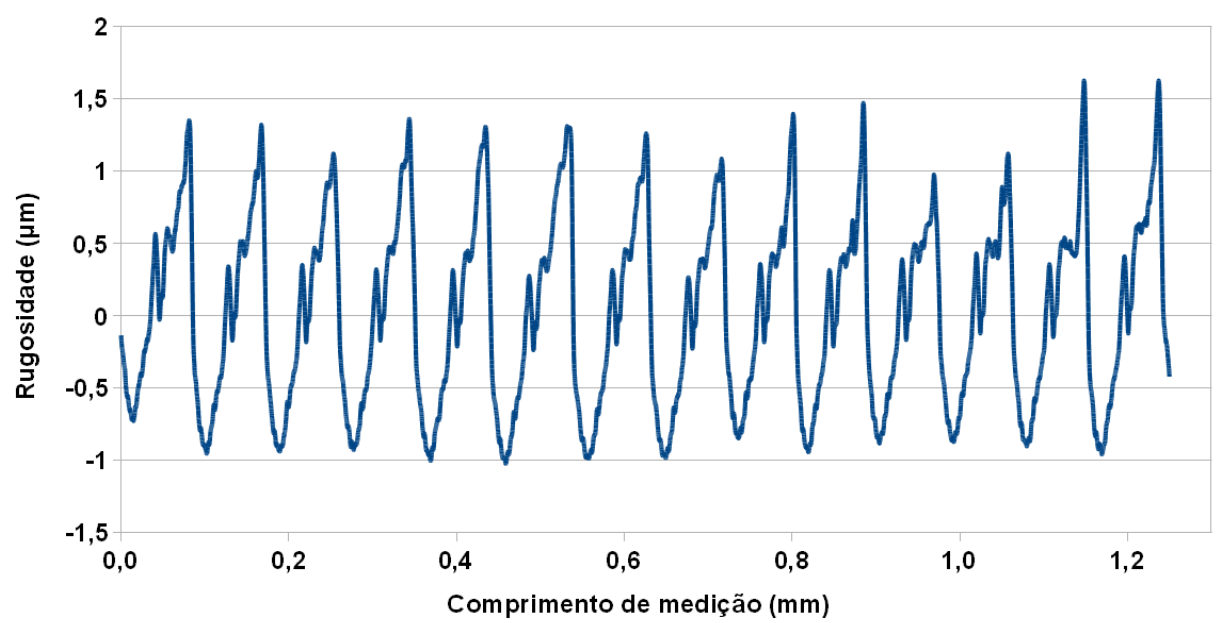

Figura 5.7 - Perfil de rugosidade da superficie do corpo de prova na condição S4 após torneamento com velocidade de corte (Vc) de $120 \mathrm{~m} / \mathrm{min}$, e avanço (f) de 0,1 $\mathrm{mm} / \mathrm{rot}$.

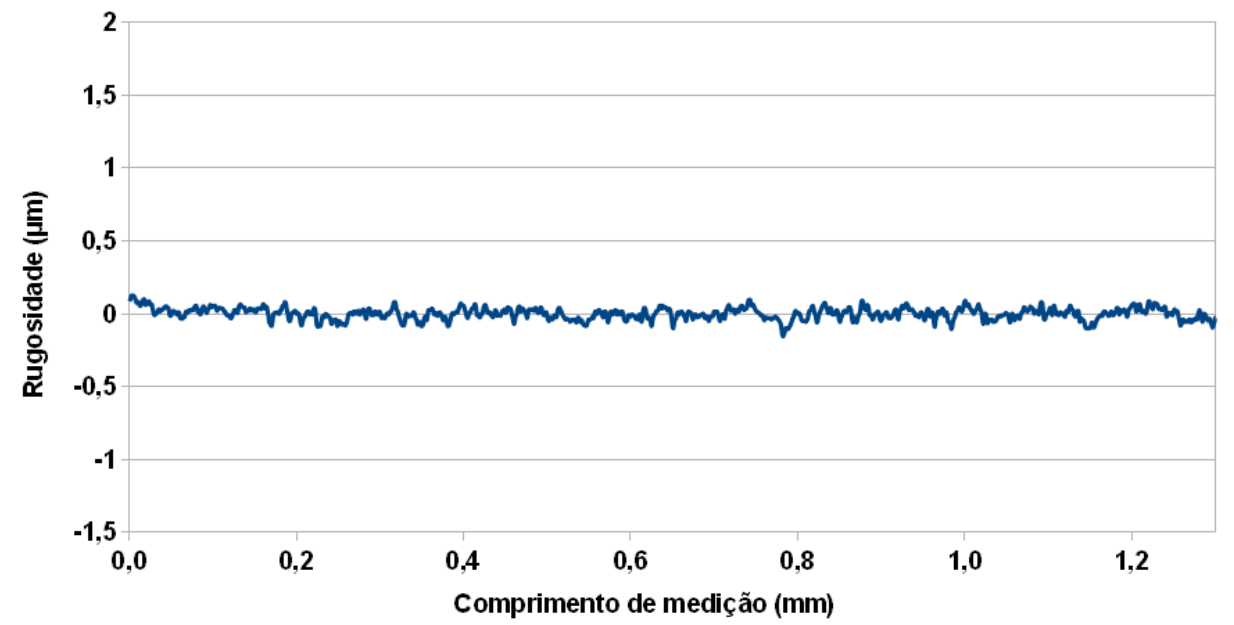

Figura 5.8 - Perfil de rugosidade da superficie do corpo de prova na condição SR após retificação com velocidade de corte $\left(\mathrm{v}_{\mathrm{c}}\right)$ de $54 \mathrm{~m} / \mathrm{s}$, avanço $\left(\mathrm{v}_{\mathrm{p}}\right) 4 \mathrm{~m} / \mathrm{min}$ e profundidade de corte $\left(\mathrm{a}_{\mathrm{e}}\right)$ 0,03 $\mathrm{mm}$.

Tabela 5.1. Valor médio dos parâmetros de rugosidade (Ra, Rq, Rsm) avaliados em todas as repetições para cada condição

\begin{tabular}{cccc}
\hline Condição & Ra $(\mu \mathrm{m})$ & $\operatorname{Rq}(\mu \mathrm{m})$ & $\operatorname{Rsm}(\mu \mathrm{m})$ \\
\hline S1 & $0,486 \pm 0,015$ & $0,582 \pm 0,016$ & $0,439 \pm 0,057$ \\
S2 & $0,462 \pm 0,012$ & $0,581 \pm 0,011$ & $0,765 \pm 0,046$ \\
S3 & $0,446 \pm 0,014$ & $0,520 \pm 0,010$ & $0,453 \pm 0,002$ \\
S4 & $0,557 \pm 0,020$ & $0,645 \pm 0,040$ & $0,937 \pm 0,007$ \\
SR & $0,275 \pm 0,006$ & $0,352 \pm 0,006$ & $0,038 \pm 0,001$ \\
\hline
\end{tabular}

$\mathrm{Na}$ Figura 5.9 é sumarizado de maneira comparativa o valor médio de rugosidade para todas as condições ensaiadas. 


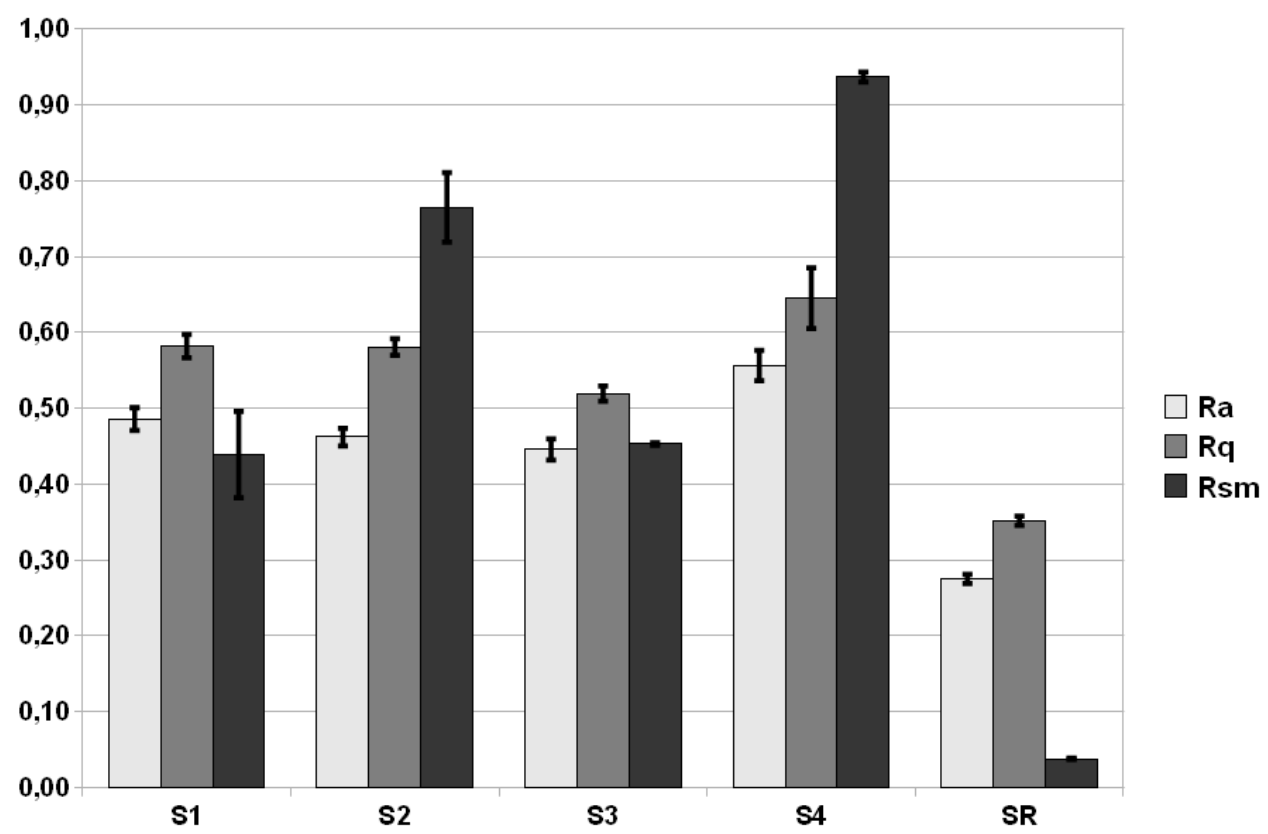

Figura 5.9 - Influencia dos parâmetros de corte no valor médio dos parâmetros de rugosidade $(\mathrm{Ra}, \mathrm{Rq}, \mathrm{Rsm})$ para as superficies geradas.

Para todas as superficies torneadas empregou-se uma profundidade de corte de $\left(a_{p}\right)$ de 0,1 mm. Observa-se que para as superficies torneadas, as condições $\mathrm{S} 1$ e S2 apresentaram um valor semelhante de rugosidade ( $\mathrm{Ra}, \mathrm{Rq}$ ), e que as superfícies na condição S3 possuíram a menor rugosidade. Na Figura 5.9 também é possivel observar que as superficies geradas com maior avanço e maior velocidade de corte (S2, S4) apresentaram maior largura média de um elemento do perfil (Rsm). Isto quer dizer que as superficies geradas pelas condições S2 e S4 tiveram maior espaçamento entre os picos e vales do perfil de rugosidade. Igualmente, pode ser observado que as superficies descritas pela condição S4 apresentaram o maior valor de rugosidade; lembrando-se que estas superficies foram geradas empregando maior avanço e maior velocidade de corte.

Nas condições onde a menor velocidade de corte $(60 \mathrm{~m} / \mathrm{min})$ foi utilizada, o avanço não apresentou influência significativa na altura média dos picos no perfil de rugosidade $(\mathrm{Ra}, \mathrm{Rq})$. O aumento do avanço levou à diminuição do acabamento superficial (aumento do $\mathrm{Ra}$ e Rq).

A combinação de menor avanço aliada à maior velocidade de corte (condição S2) gerou a superficie com melhor acabamento, apresentando um perfil mais regular (menor desvio padrão), com menor valor de rugosidade (Ra e Rq), e baixa largura média de um elemento no perfil (Rsm). Esta melhoria do 
acabamento da superficie (S3) pode ter ocorrido em função do aumento da temperatura de corte ao se aumentar a velocidade de corte, o qual favorece o cisalhamento de material e diminui a quantidade de material deformado plasticamente na superficie da peça (DINIZ et al, 2008). O fato da rugosidade não aumentar sempre que aumentada a velocidade de corte, sugere que o comportamento do sistema máquina/peça/ferramenta/dispositivo de fixação é adequado em termos da resposta em vibração para as condições de trabalho empregadas (SHAW, 2005; DINIZ et al, 2008). Independente da faixa de velocidade de corte empregada, o Rsm sempre cresceu ao aumentar o avanço nas superficies torneadas, isto em função da contribuição geométrica à rugosidade deste parâmetro de corte (TRENT e WRIGHT, 2000).

Já nas superficies retificadas (Figura 5.8), obtiveram-se os menores valores para a rugosidade ( $\mathrm{Ra}$ e $\mathrm{Rq})$ e no Rsm. Isto é devido à ferramenta de corte, onde grãos abrasivos agem como múltiplas arestas de corte espalhadas na ferramenta removendo pequenas quantidades de material, originando espaçamento reduzido entre os sulcos e menor altura dos picos no perfil de rugosidade.

\subsubsection{Influência dos parâmetros de corte no aspecto da superfície}

Um conjunto de imagens das superficies usinadas é apresentado nas Figuras 5.10 a 5.13, nas quais podem ser observadas as diferenças no aspecto das obtidas por torneamento. Observa-se que as marcas da ferramenta seguem o padrão circunferêncial nas superficies obtidas pelo processo de torneamento de faceamento (nas imagens com aumentos de 100 vezes), e padrão unidirecional no caso da retificação plana. 


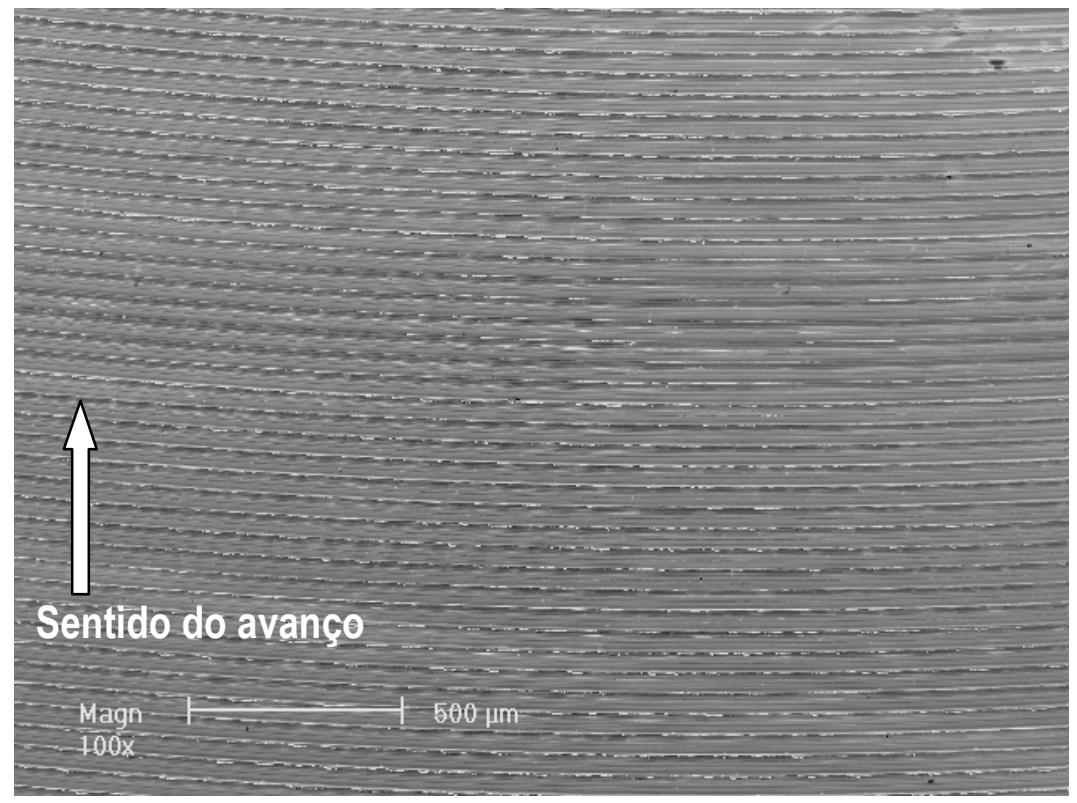

a)

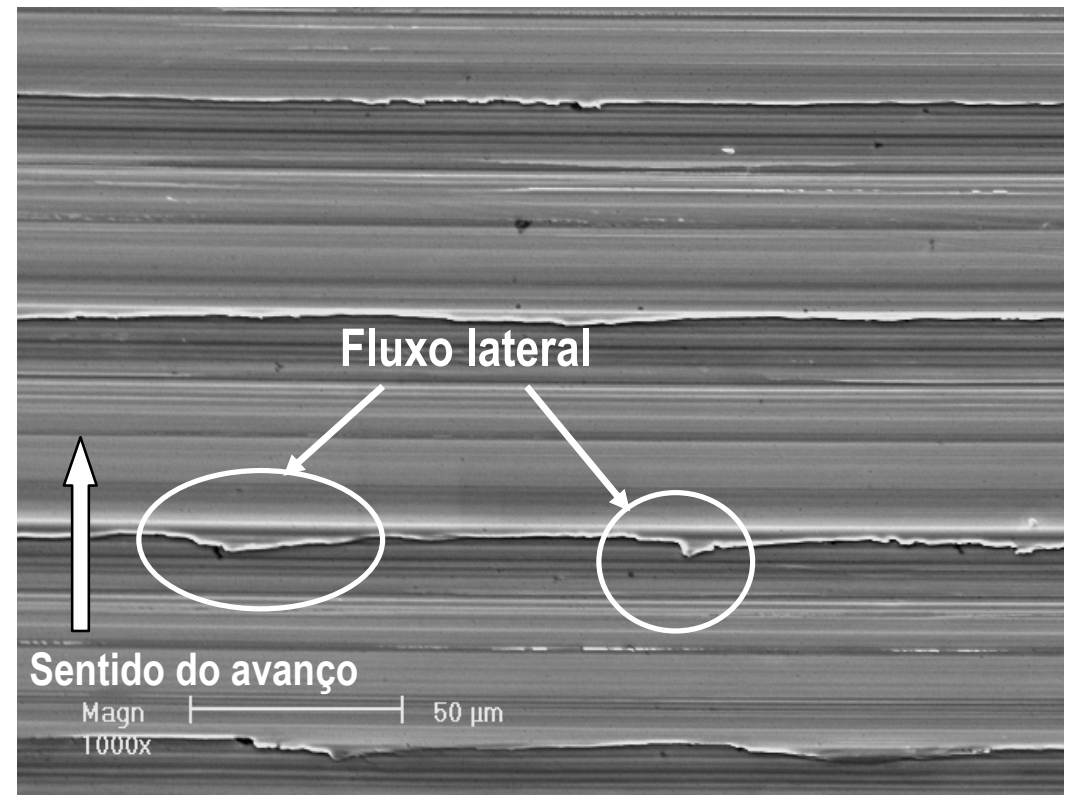

b)

Figura 5.10 - Imagem da superficie do corpo de prova na condição S1 após torneamento com velocidade de corte (Vc) de $60 \mathrm{~m} / \mathrm{min}$, e avanço (f) de $0,05 \mathrm{~mm} / \mathrm{rot}$. Imagens obtidas em MEV com aumento de: a) 100x; b) 1000x.

A superficie da condição S1 apresentou fluxo lateral como indicado pelas setas na Figura 5.10b, que pode ser consequência da baixa velocidade empregada (SHAW, 2005). O fluxo lateral consiste na movimentação de material da peça no sentido contrário ao do avanço. 


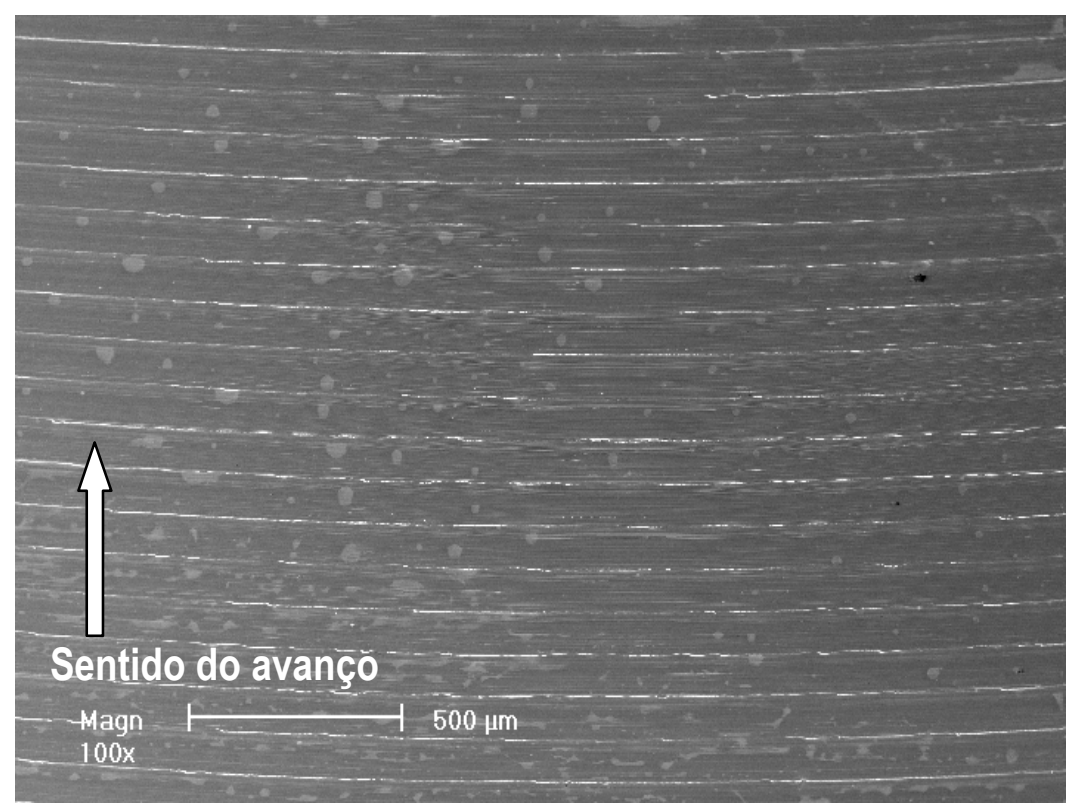

a)

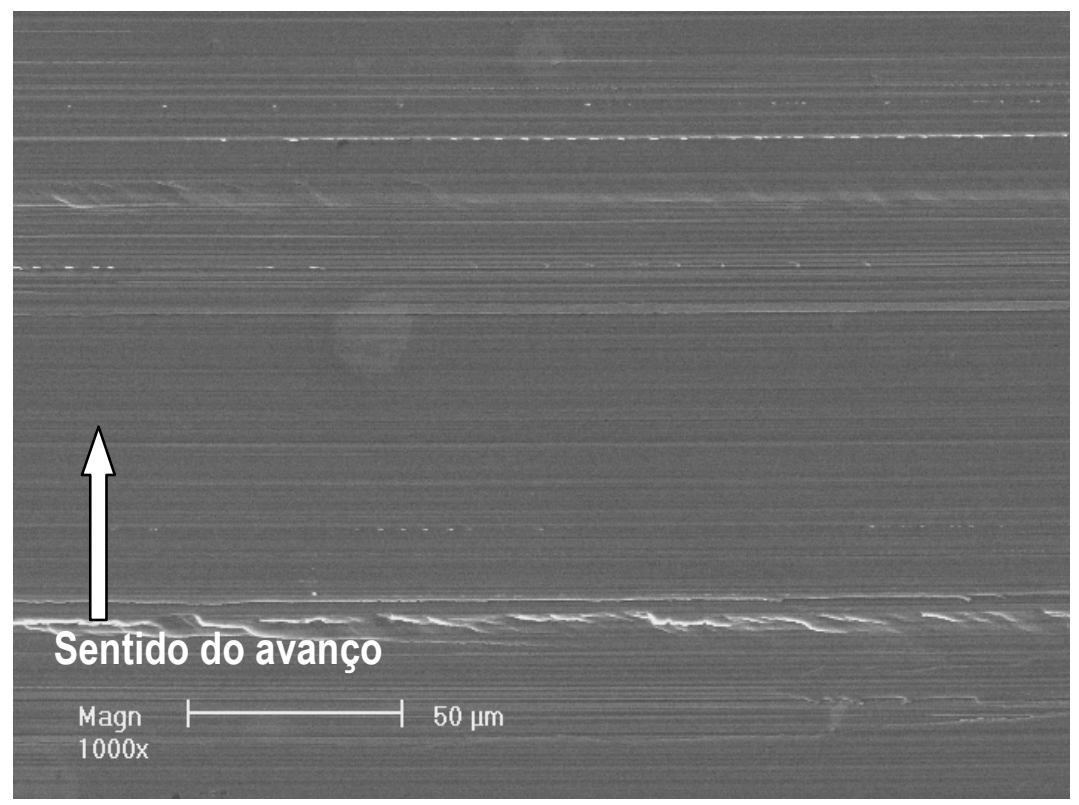

b)

Figura 5.11 - Imagem da superficie do corpo de prova na condição S2 após torneamento com velocidade de corte (Vc) de $60 \mathrm{~m} / \mathrm{min}$, e avanço (f) de $0,1 \mathrm{~mm} / \mathrm{rot}$. Imagens obtidas em MEV com aumento de: a) 100x; b) 1000x.

Na condição S2 (Figura 5.11) não se observam falhas grosseiras na superfície topográfica (crateras, trincas e deformação plástica, entre outros) em termos dos parâmetros de corte empregados. Ao aumentar a velocidade de corte (de 60 pra $120 \mathrm{~m} / \mathrm{s}$ ), geram-se as superficies nas condições S3 e S4 (Figuras 5.12 e 5.13). 


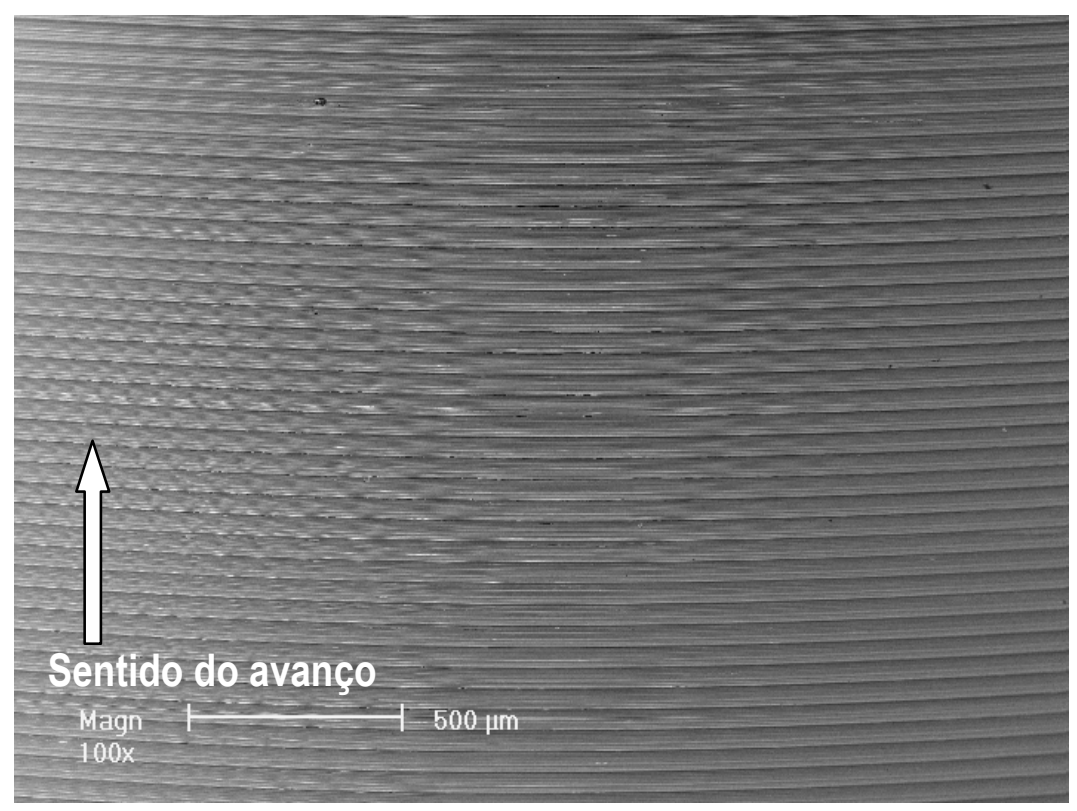

a)

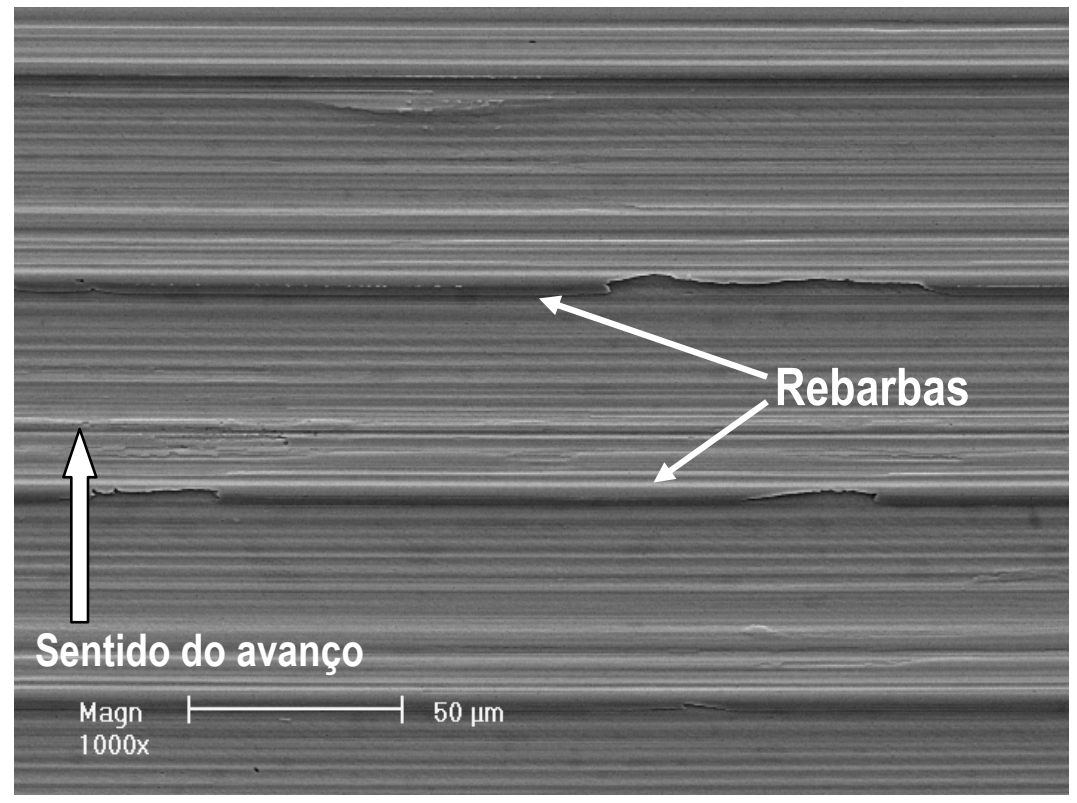

b)

Figura 5.12 - Imagem da superficie do corpo de prova na condição S3 após torneamento com velocidade de corte (Vc) de $120 \mathrm{~m} / \mathrm{min}$, e avanço (f) de $0,05 \mathrm{~mm} / \mathrm{rot}$. Imagens obtidas em MEV com aumento de: a) 100x; b) 1000x.

A partir da análise do aspecto da superficie S3 e das medições de rugosidade, tem-se que é nesta condição onde as superficies torneadas apresentaram o melhor acabamento. Assim, as marcas da ferramenta (Figura 5.12) nesta condição são mais regulares e definidas, condizendo com o aspecto do perfil de rugosidade apresentado na Figura 5.6 e da ilustração comparativa apresentada na Figura 5.8. Porém, como indicado pelas setas brancas na Figura 5.12b, nesta superficie observou-se a presença de rebarbas. 


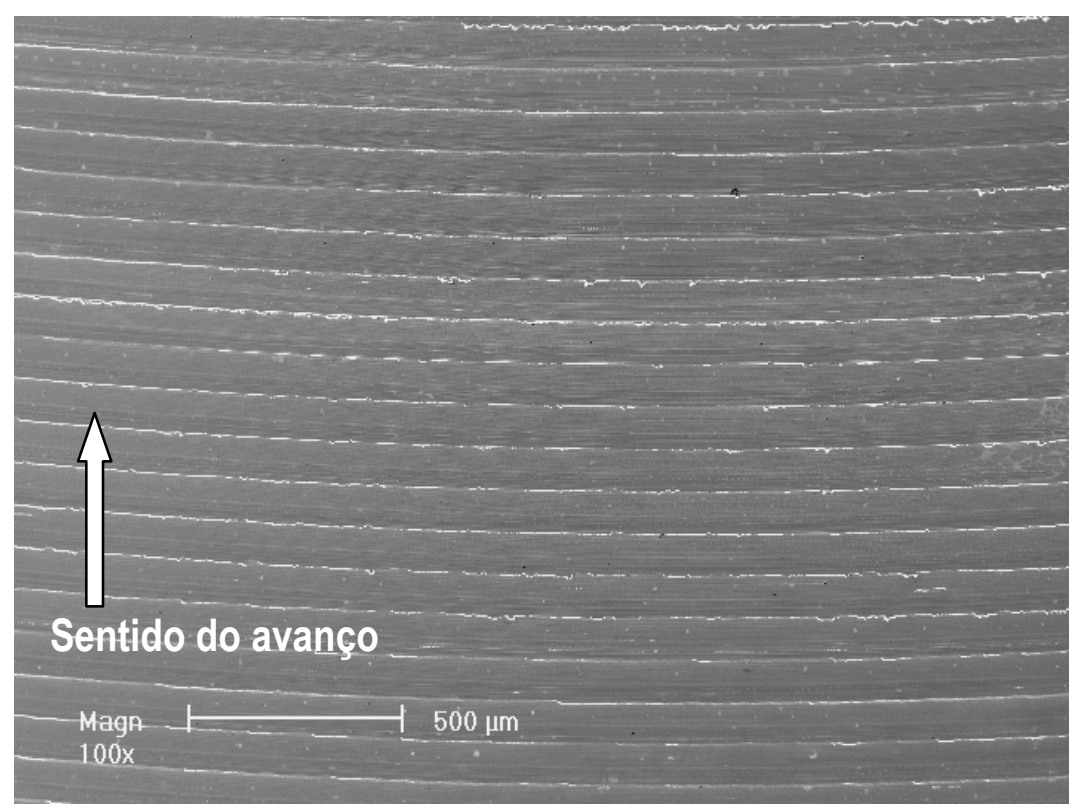

a)

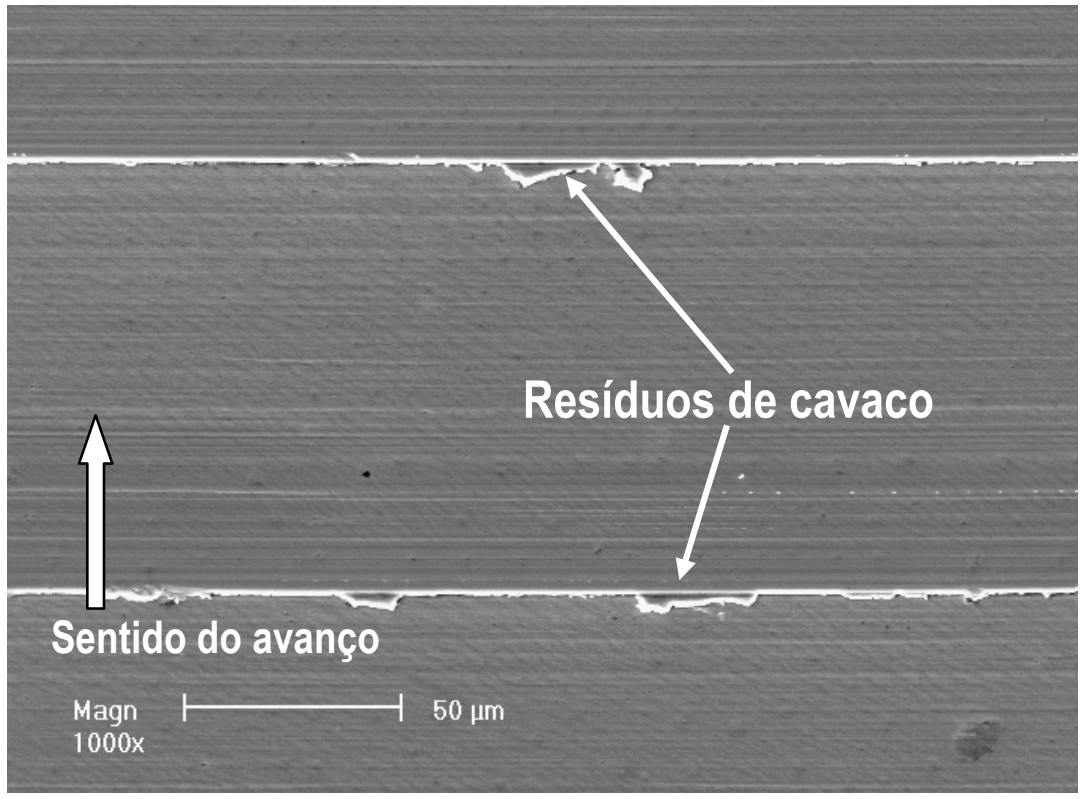

b)

Figura 5.13 - Imagem da superficie do corpo de prova $\mathrm{S} 4$ após torneamento com velocidade de corte (Vc) de $120 \mathrm{~m} / \mathrm{min}$, e avanço (f) de $0,1 \mathrm{~mm} /$ rot. Imagens obtidas em MEV com aumento de: a) 100x; b) 1000x.

Das superficies torneadas, a condição S4 teve o pior aspecto superficial, observando-se a presença de resíduo de cavaco nas cristas das marcas da ferramenta. O avanço foi o parâmetro que mais influenciou no aspecto das superfícies torneadas, porém, não foi possivel observar mediante a técnica de MEV diferenças consideráveis no efeito que a velocidade de corte exerce sobre as características topográficas. 
Na Figura 5.14 apresentam-se imagens da superficie retificada. A pesar de, mediante este processo tenham sido geradas as superficies com os menores valores de rugosidade ( $\mathrm{Ra}, \mathrm{Rq})$ (Figura 5.8), estas superficies não estão isentas de defeitos na superficie topográfica. A quantidade de defeitos é maior, o acabamento superficial é pior, e as marcas na superficie são mais irregulares do que o observado nas superficies geradas mediante processo de torneamento.

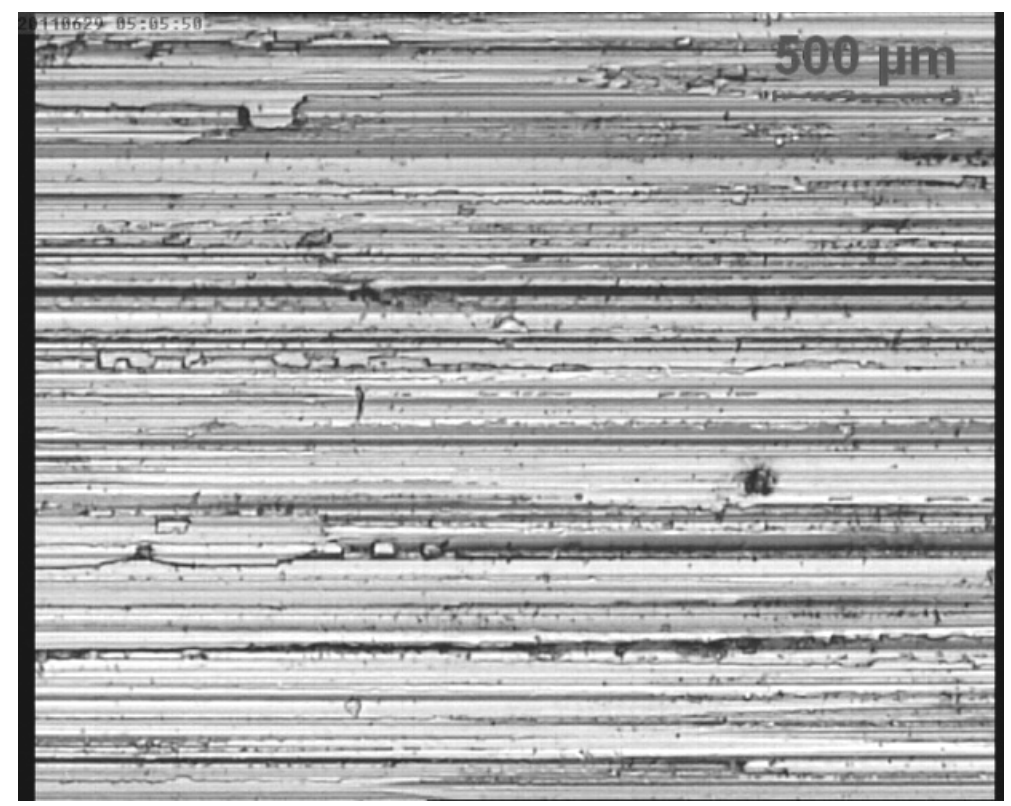

a)

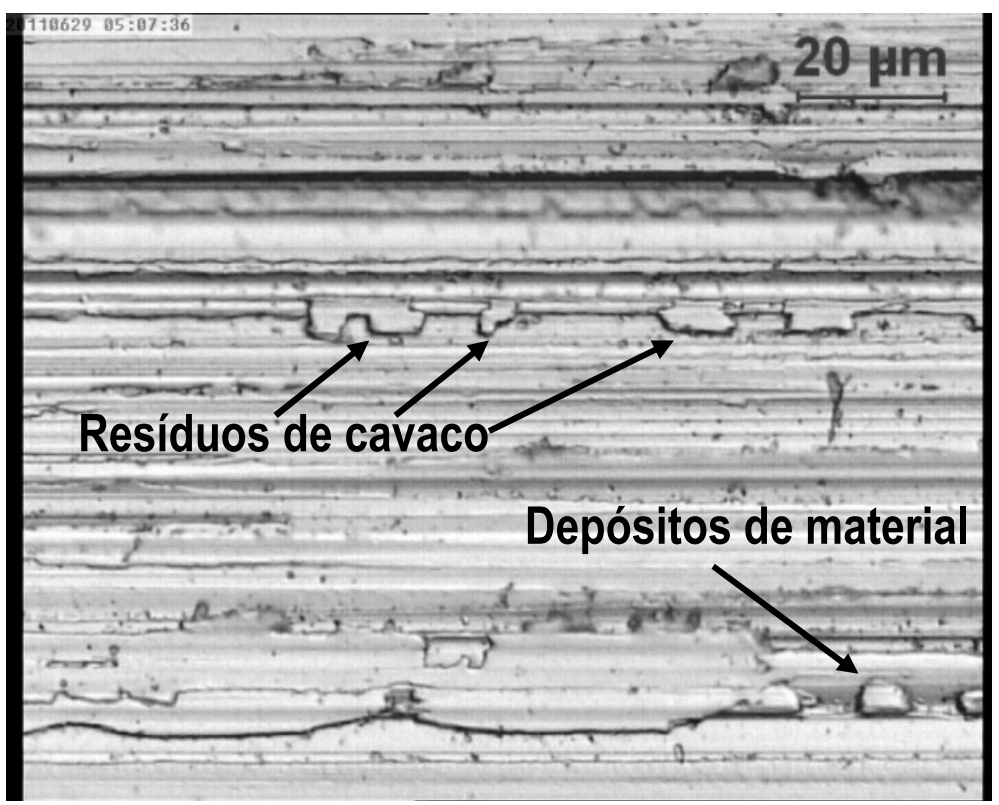

b)

Figura 5.14-Imagem da superfície do corpo de prova SR após retificação com velocidade de corte (Vc) de $\mathrm{m} / \mathrm{min}$, e avanço (f) de $0,1 \mathrm{~mm} /$ rot. Imagens obtidas em MO com aumento de: a) 50x; b) 1000x. 
Deste modo, é possível observar deformação plástica, depósitos de material, resíduo do cavaco e outros defeitos originados como consequência do mecanismo de corte e das elevadas temperaturas a que foi submetido o material durante a retificação.

\subsubsection{Análise da camada superficial}

A seguir será apresentada uma série de imagens onde se mostra o estado da camada superficial como resultado do efeito do processo de geração da superficie. Os planos da amostra nos quais foram extraídas as imagens segue o procedimento ilustrado esquematicamente na Figura 5.15.

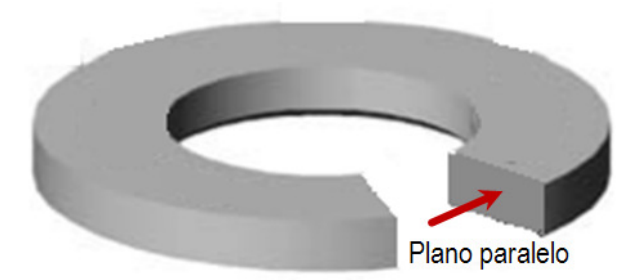

a)

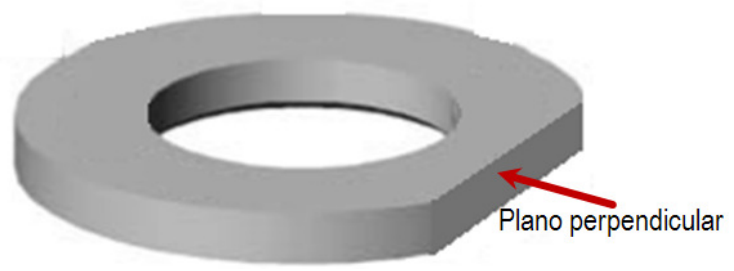

b)

Figura 5.15 - Esquema representativo do corte das amostras para a análise da camada da superficie: a) num plano paralelo ao sentido de avanço da ferramenta; b) num plano perpendicular ao sentido de avanço da ferramenta.

Inicialmente são apresentadas micrografias obtidas em microscópio óptico da seção transversal da amostra na condição S1 (Figura 5.16a), para analisar a presença de camada branca e outros efeitos nos sentidos de corte e avanço da ferramenta. Ao analisar as imagens da camada superficial obtidas nas amostras na condição S1 tem-se que para o aumento com o qual foram geradas (1000 vezes) aparentemente existem poucas alterações microestruturais. Estas alterações são o resultado da combinação dos efeitos induzidos pelas altas taxas de deformação plástica, elevadas temperaturas localizadas, e rápidas taxas de aquecimento que ocorrem na superficie (TOENSHOFF et al., 1995). Observa-se a presença de camadas próximas da borda com deformação plástica em algumas pequenas regiões (como indicado pela seta) geradas durante o processo de remoção de material. A presença de fluxo lateral de material é observada mais claramente nas imagens da superficie da condição S1 apresentadas na Figura 5.10b. Estes defeitos surgem principalmente nas bordas dos sulcos formados pela ferramenta, decorrentes do processo de remoção de cavaco nesta região. Na borda dos sulcos não há mais corte pela ferramenta, sendo atingida uma espessura 
mínima de material nesta região, assim, uma pequena porção de material é apenas deformada plasticamente pela aresta da ferramenta sem ser arrancado na forma de cavaco (GRIFFITHS, 2001).

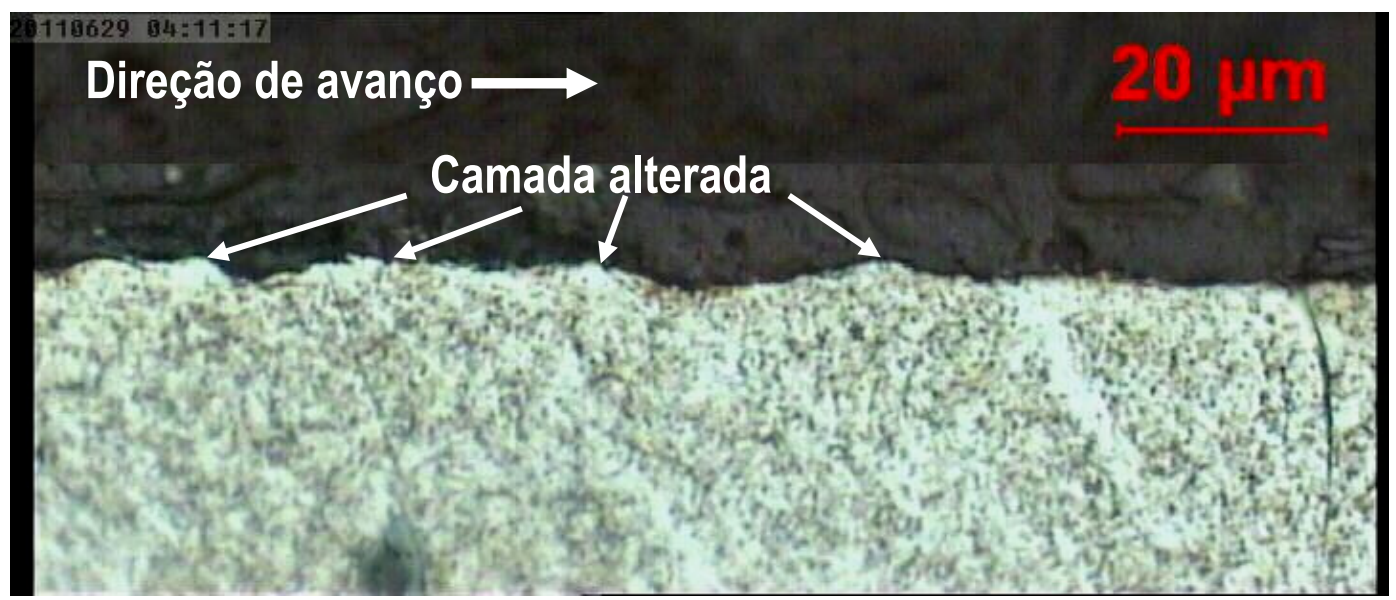

a)

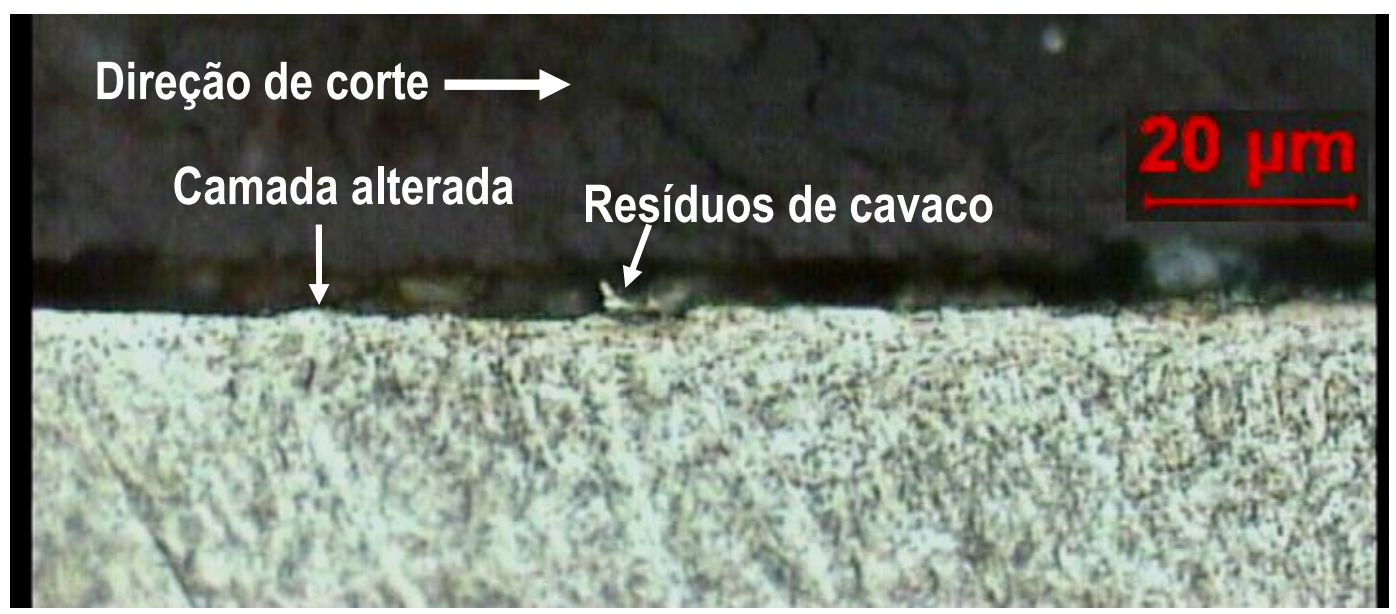

b)

Figura 5.16 - Imagem da subsuperfície do corpo de prova na condição S1. Corte transversal no plano a) perpendicular ao sentido de avanço da ferramenta; b) paralelo ao sentido de avanço da ferramenta. Após torneamento com velocidade de corte (Vc) de $60 \mathrm{~m} / \mathrm{min}$, e avanço (f) de $0,05 \mathrm{~mm} /$ rot. Imagens obtidas em $\mathrm{MO}$ com aumento de 1000x. Ataque com Villela.

Na Figura 5.17 são mostradas imagens obtidas em microscópio eletrônico de varredura da camada superficial (aumento de 10000 vezes) para uma das amostras geradas na condição S1. Na Figura 5.17a é possível diferenciar facilmente duas camadas de material deformado plasticamente até uma profundidade de aproximadamente $5 \mu \mathrm{m}$. Observa-se uma faixa mais estreita de material mais compacto e de cor mais claro, que vai até uma profundidade máxima de $1 \mu \mathrm{m}$ (aproximadamente) a partir da superficie. Nesta camada não é possível observar o padrão dos grãos característicos da microestrutura, os quais se encontram altamente distorcidos. Esta camada é referida na 
literatura como "camada branca por deformação plástica" (GRIFFITHS, 2001; JAVIDI et al, 2008).

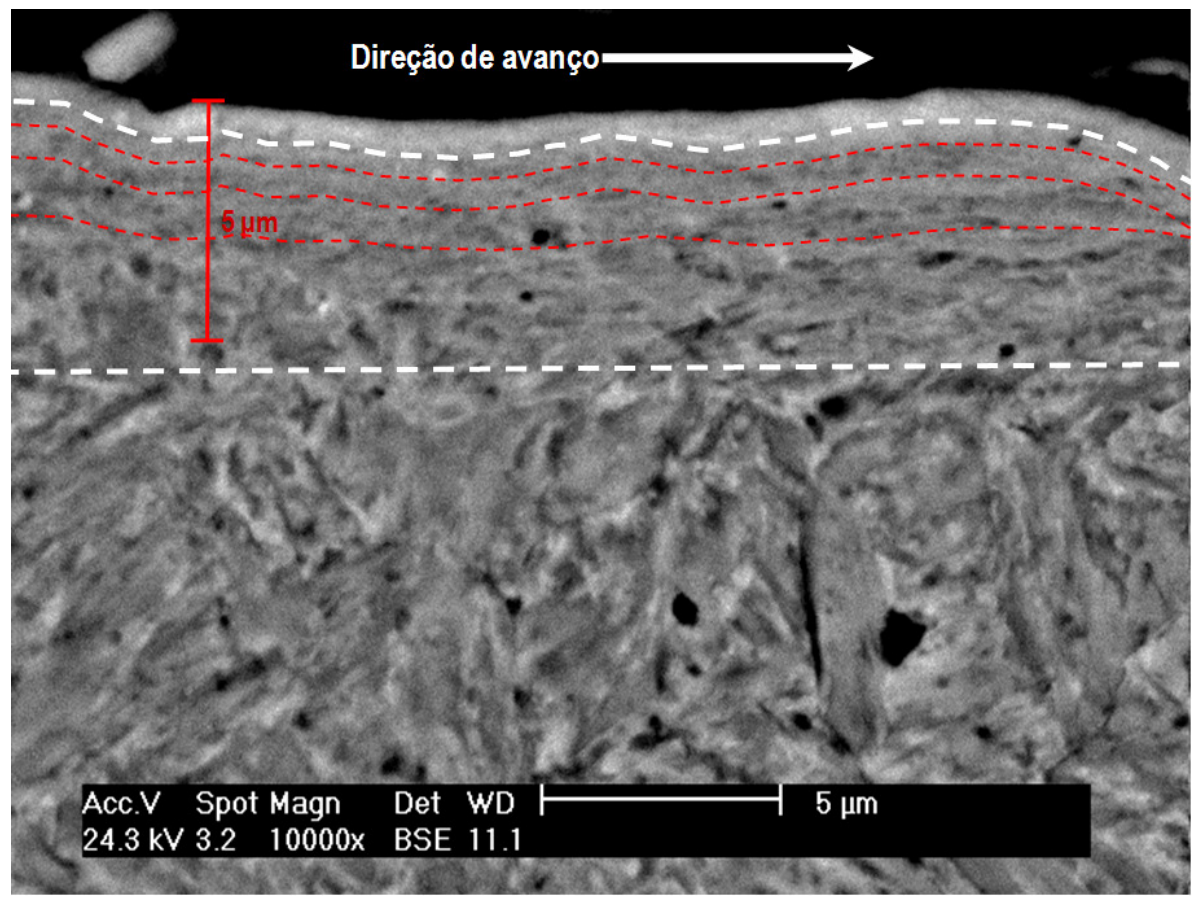

a)

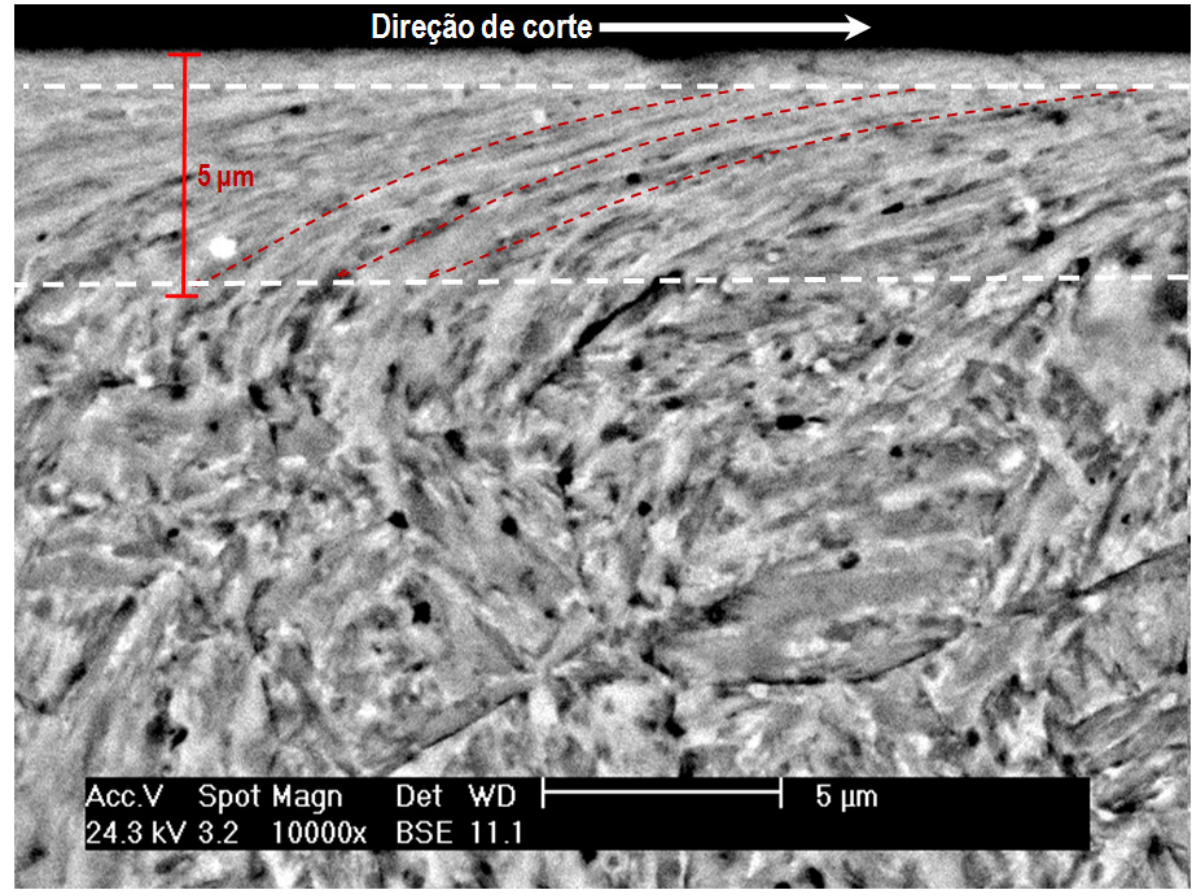

b)

Figura 5.17 - Imagem da subsuperfície do corpo de prova na condição S1. Corte transversal no plano a) perpendicular ao sentido de avanço da ferramenta; b) paralelo ao sentido de avanço da ferramenta. Após torneamento com velocidade de corte (Vc) de $60 \mathrm{~m} / \mathrm{min}$, e avanço (f) de $0,05 \mathrm{~mm} /$ rot. Imagens obtidas em MEV com aumento de 10000x. Ataque com Villela. 
$\mathrm{Na}$ Figura 5.17b observa-se mais claramente esta camada contornando o perfil da superficie. Logo abaixo, se observa um padrão de linhas de deformação plástica dos grãos da matriz que tendem a se orientar desde a subsuperficie no sentido da direção de corte (linhas vermelhas pontilhadas). Estas mudanças nas propriedades do material ocorrem numa camada superficial e geralmente acompanham os padrões de textura da topografia na superficie (GRIFFITHS, 2001).

Apresenta-se a seguir na Figura 5.18 as imagens da seção transversal obtidas numa das amostras gerada na condição S2.

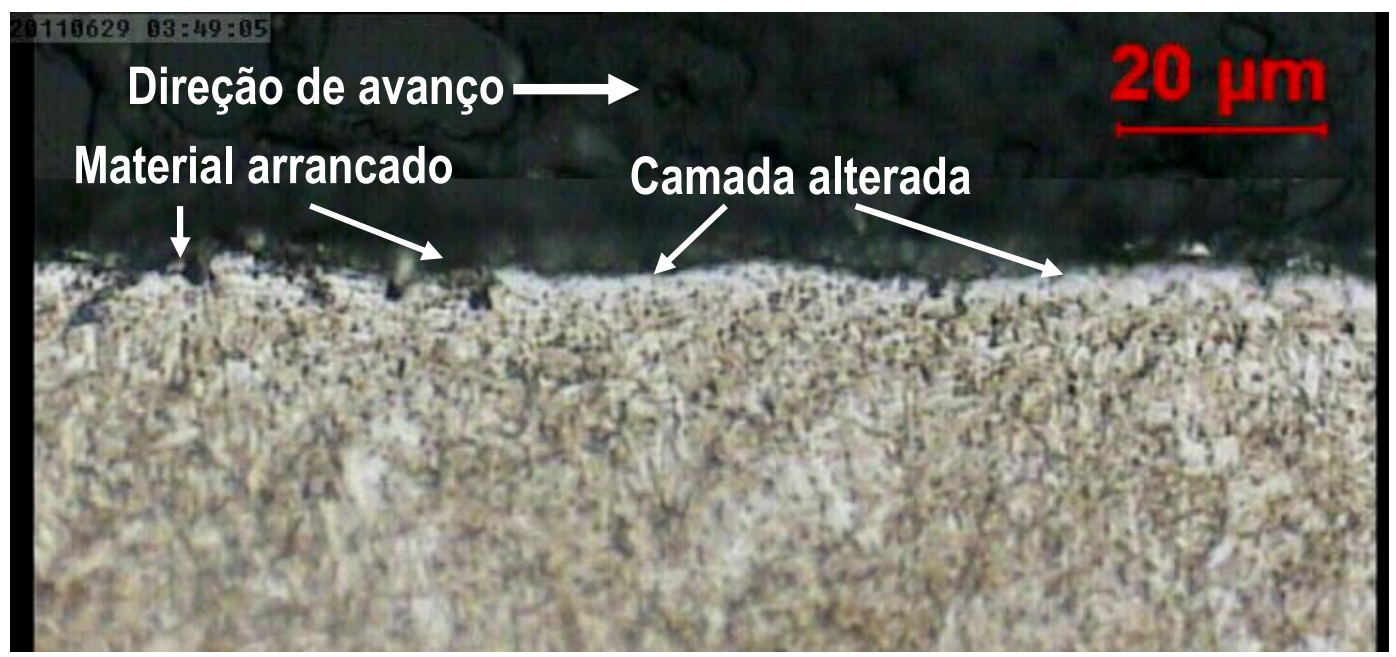

a)

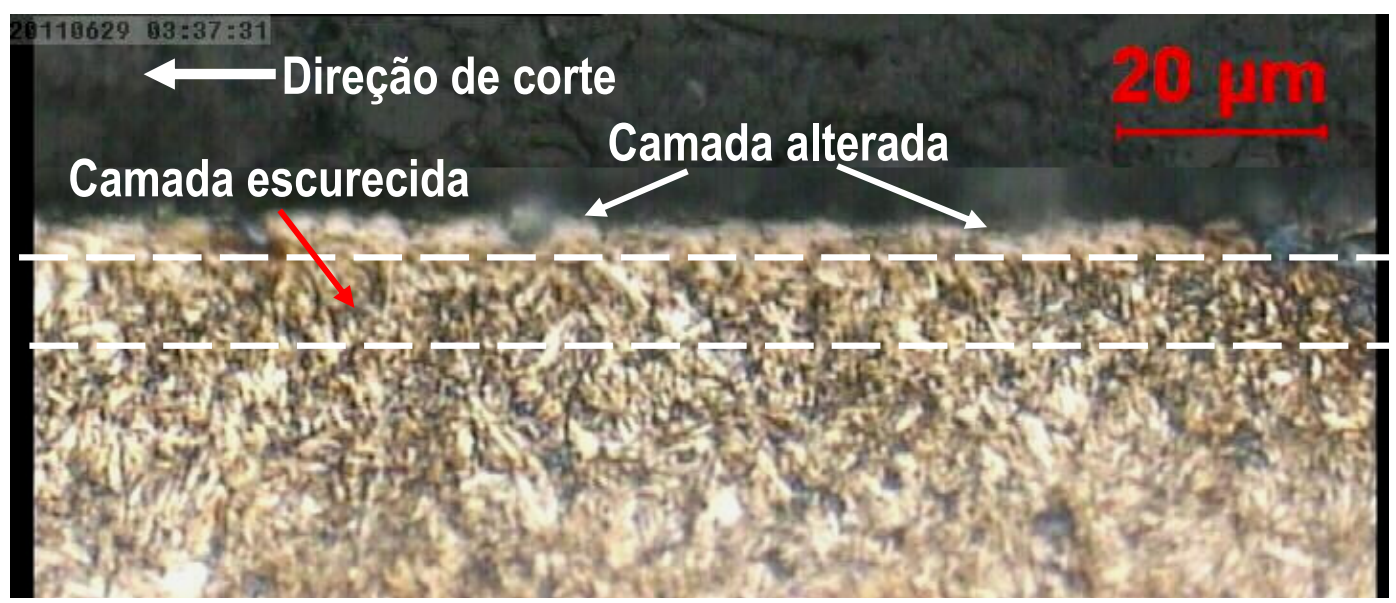

b)

Figura 5.18 - Imagem da subsuperfície do corpo de prova na condição S2. Corte transversal no plano a) perpendicular ao sentido de avanço da ferramenta; b) paralelo ao sentido de avanço da ferramenta. Após torneamento com velocidade de corte (Vc) de $60 \mathrm{~m} / \mathrm{min}$, e avanço (f) de $0,1 \mathrm{~mm} /$ rot. Imagens obtidas em $\mathrm{MO}$ com aumento de 1000x. Ataque com Villela. 
Observam-se diferenças de contraste na cor do material próximo da borda, o que sugere alterações de uma camada do material (Figuras 5.18), alterações que são observadas com maior clareza na Figura 5.18 b na região delimitada pelas linhas pontilhadas. Observa-se camada branca por deformação plástica e camada escurecida, como apontado pelas setas. Esta técnica consiste na análise das imagens obtidas em microscópio óptico da superficie preparada por metalografia e atacada quimicamente (FIELD et al, 1972; MACHINABILITY DATA CENTER, 1980). O anterior se fundamenta no fato do reagente utilizado (Villela) revelar de maneira diferente a microestrutura do material modificado logo abaixo da superficie, contrastando com o resto do material da subsuperficie que permaneceu inalterado. A superficie obtida sob a condição S1 (Figura 5.16) difere da condição S2 com relação ao avanço, o qual aumentou de 0,05 a $0,1 \mathrm{~mm} /$ volta, respectivamente. Isto sugere que 0 aumento no avanço (mantendo constantes os demais parâmetros de corte) para as condições testadas foi o responsável pela geração das alterações no estado da camada superficial. A região de cor mais clara é denominada como camada branca, e sua formação é favorecida pelo aumento do avanço nos processos de corte com ferramentas de geometria definida (GRIFFITHS, 1985; LESCOVAR e KOVAC, 1988; GRIFFITHS, 2001; GUO et al., 2010). Em baixas velocidades de corte, o aumento do avanço acarreta maior deformação plástica (SHAW, 1984; TRENT e WRIGHT; 2000), que pode ter gerado camada branca devido ao material mecanicamente alterado. Igualmente o maior avanço também gera condições de distribuição de temperaturas diferentes, que podem favorecer as alterações na superficie (TRENT e WRIGHT; 2000).

Quando aumentada a velocidade de corte na condição S3 (120m/min), as alterações geradas na camada superficial ficaram bem definidas ao se comparar com S1 e S2 (60m/min), como pode ser observado na Figura 5.19b. Igualmente, logo abaixo da camada branca observa-se outra camada de material, onde é possivel observar as regiões de deformação plástica dos grãos no sentido de corte (como indicado pela seta vermelha). No plano perpendicular ao sentido de avanço da ferramenta não são observadas alterações significativas da microestrutura na camada superficial (Figura 5.19a), exceto no material dos picos localizados na borda, onde é observada camada branca como apontado pelas setas. 


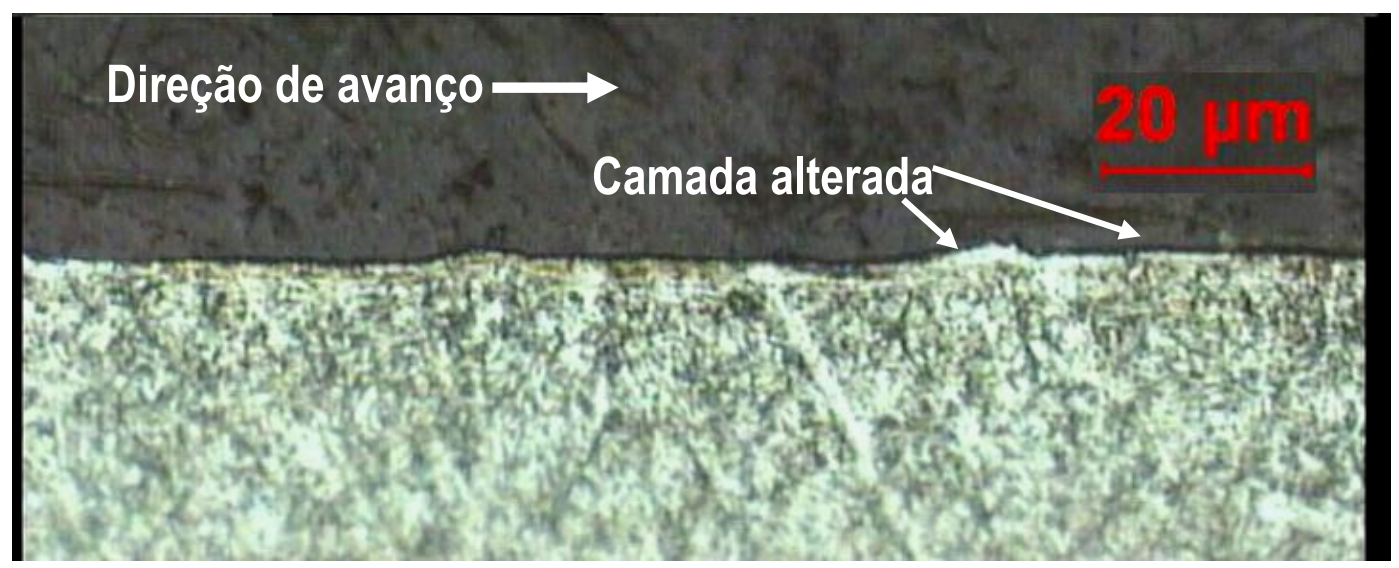

a)

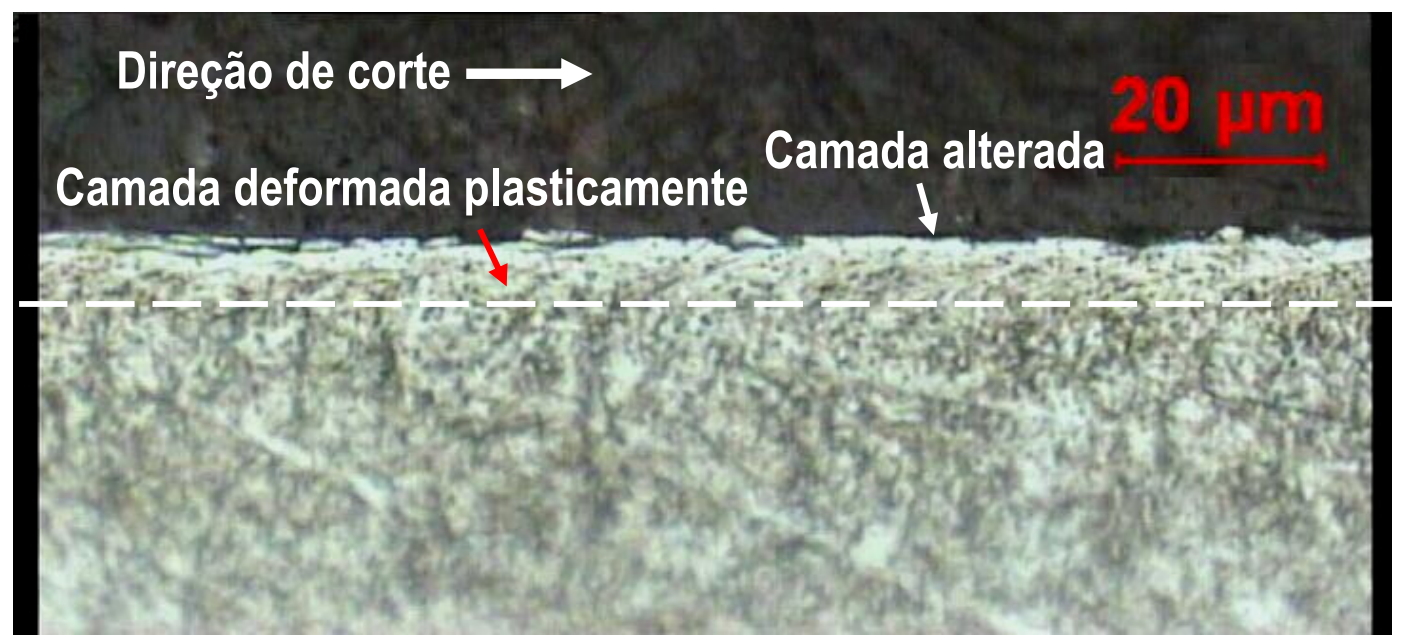

b)

Figura 5.19 - Imagem da subsuperfície do corpo de prova na condição S3. Corte transversal no plano a) perpendicular ao sentido de avanço da ferramenta; b) paralelo ao sentido de avanço da ferramenta. Após torneamento com velocidade de corte (Vc) de $120 \mathrm{~m} / \mathrm{min}$, e avanço (f) de $0,05 \mathrm{~mm} /$ rot. Imagens obtidas em $\mathrm{MO}$ com aumento de 1000x. Ataque com Villela.

A Figura 5.20a corresponde a uma imagem obtida de uma das amostras na condição S3, e observa-se uma fina camada branca pode deformação (menos de $1 \mu \mathrm{m}$ aproximadamente) contornando a borda da amostra, e linhas de deformação nos grãos da matriz (linhas vermelhas pontilhadas) até uma profundidade de aproximadamente $3 \mu \mathrm{m}$ aproximadamente Na Figura 5.20b observa-se que a profundidade da camada afetada é de quase $5 \mu \mathrm{m}$ quando observada no plano paralelo ao sentido de avanço, na direção do movimento de corte. 


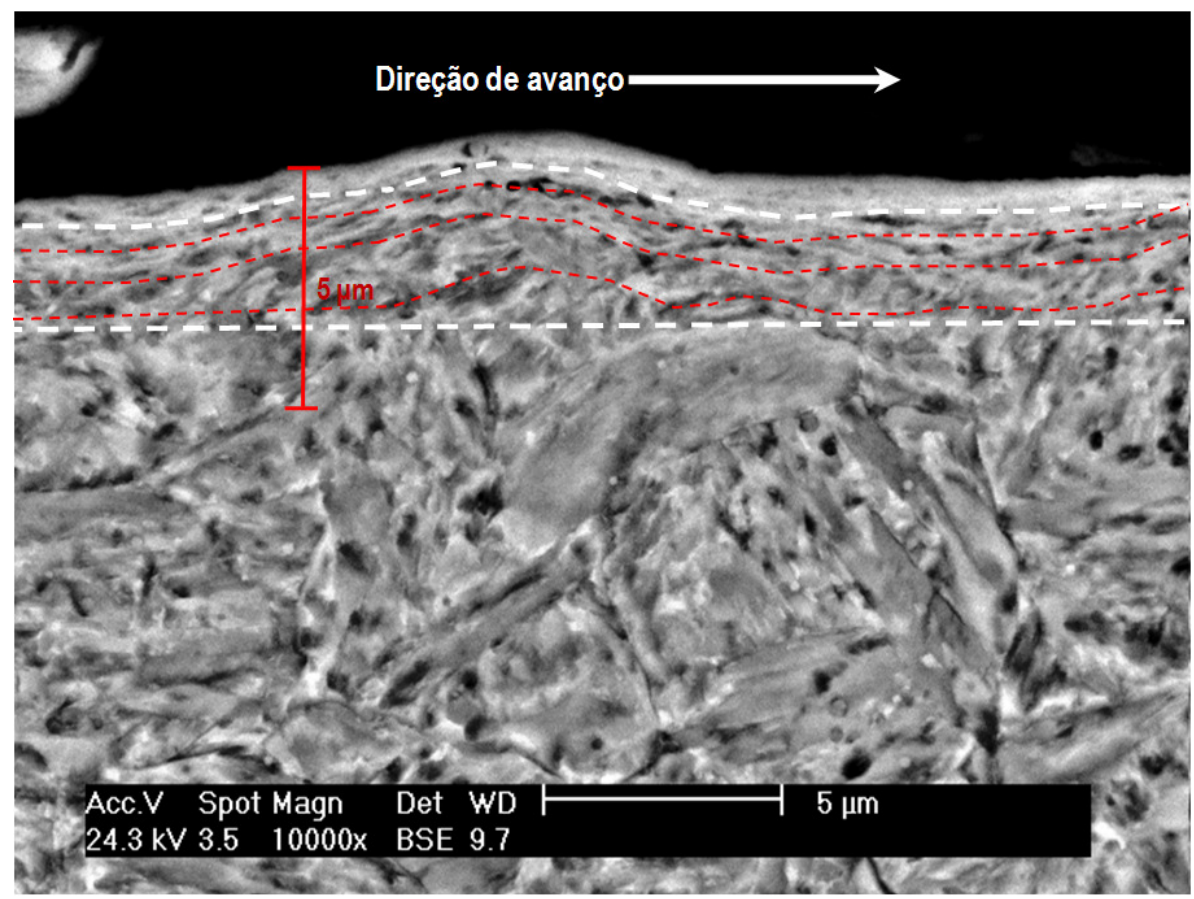

a)

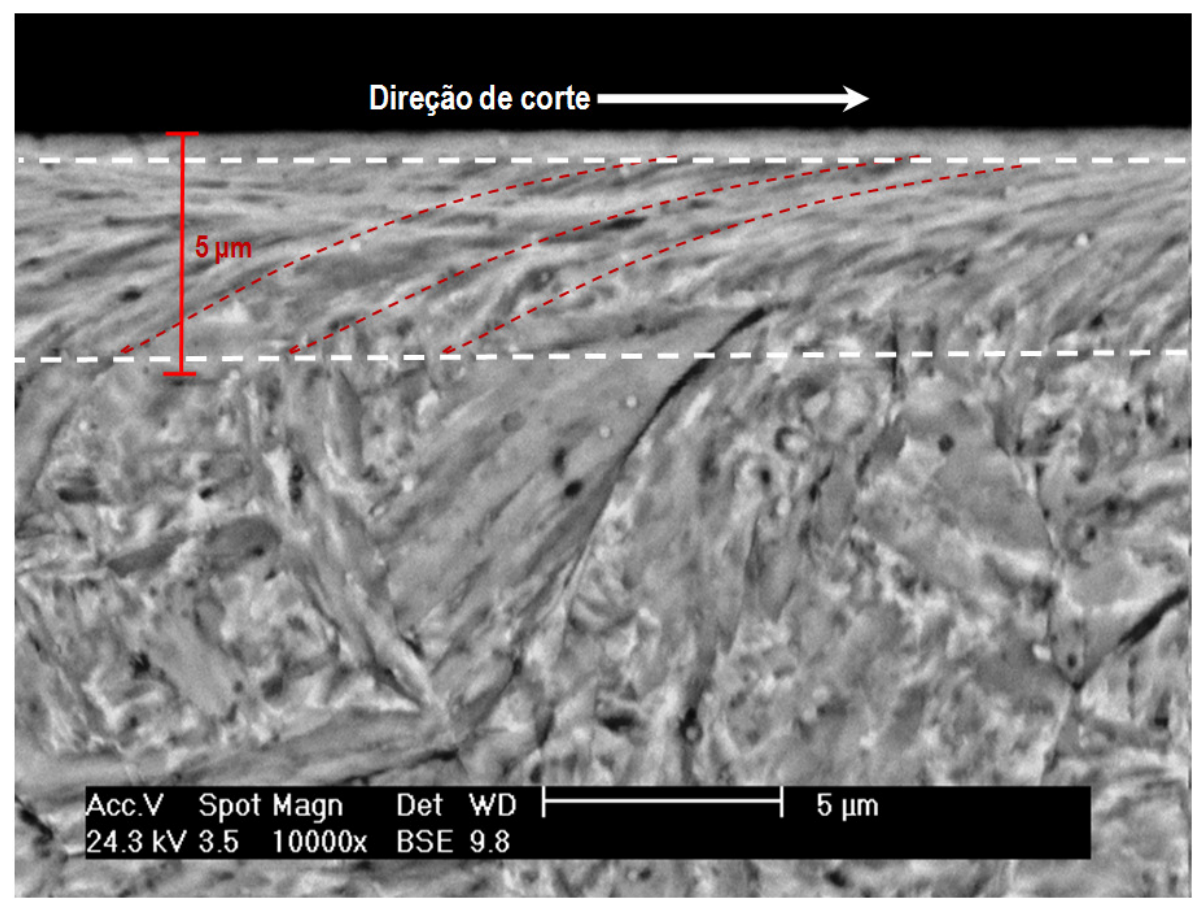

b)

Figura 5.20 - Imagem da subsuperfície do corpo de prova na condição S3. Corte transversal no plano a) perpendicular ao sentido de avanço da ferramenta; b) paralelo ao sentido de avanço da ferramenta. Após torneamento com velocidade de corte (Vc) de $120 \mathrm{~m} / \mathrm{min}$, e avanço (f) de 0,05 mm/rot. Imagens obtidas em MEV com aumento de 10000x. Ataque com Villela.

$\mathrm{Na}$ superficie S4 ocorreram alterações numa camada bem definida nos dois planos de corte do corpo de prova como mostrado na Figura 5.21. 


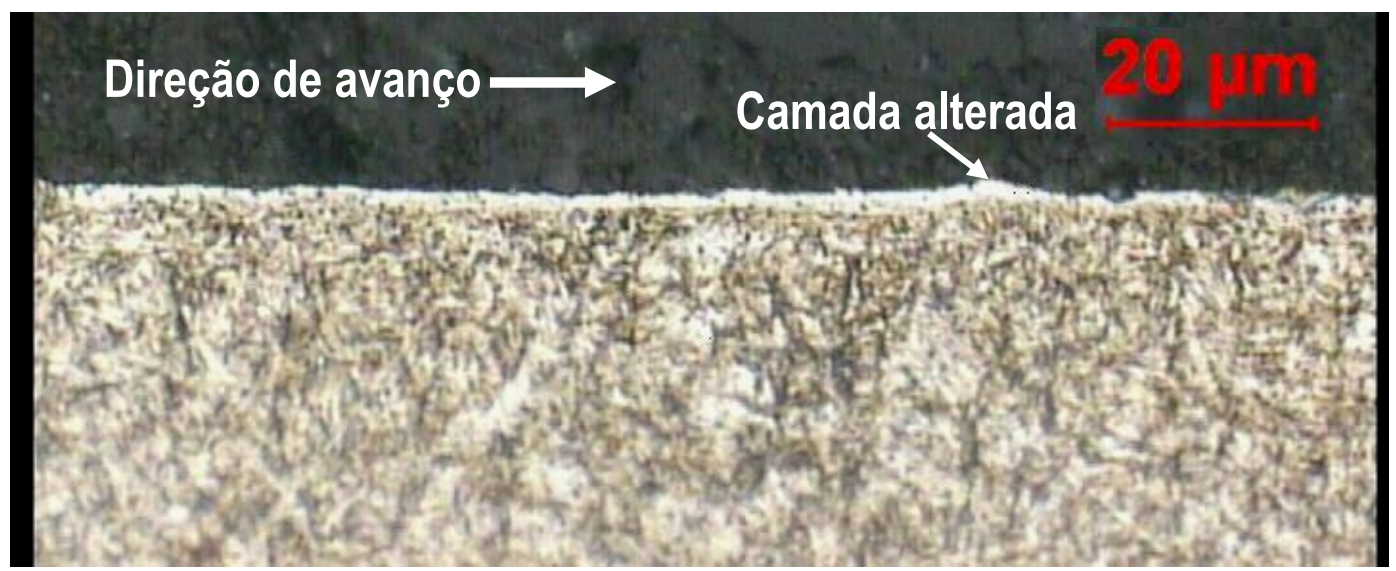

a)

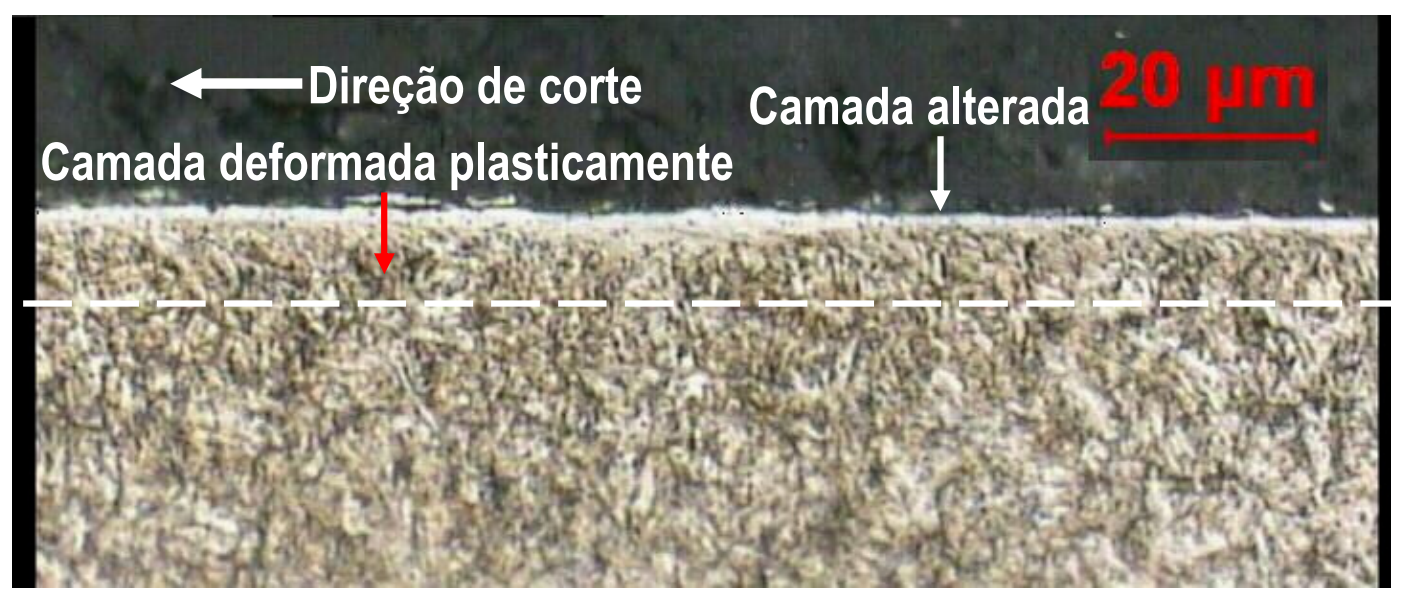

b)

Figura 5.21 - Imagem da subsuperfície do corpo de prova na condição S4. Corte transversal no plano a) perpendicular ao sentido de avanço da ferramenta; b) paralelo ao sentido de avanço da ferramenta. Após torneamento com velocidade de corte (Vc) de $120 \mathrm{~m} / \mathrm{min}$, e avanço (f) de $0,1 \mathrm{~mm} /$ rot. Imagens obtidas em $\mathrm{MO}$ com aumento de 1000x. Ataque com Villela.

Segundo a literatura (MACHINABILITY DATA CENTER, 1980; GUO et al; 2010), a profundidade da camada branca aumenta com a velocidade de corte e com o avanço, mas com relação à profundidade de corte tem-se pouco efeito. Segundo Schwach e Guo (2005) para aperfeiçoar a integridade de uma superficie no processo de torneamento duro deve-se utilizar pequenos avanços e ferramentas pontiagudas, objetivando a melhoria da vida útil do componente evitando a formação da camada branca, que é prejudicial na vida em serviço do mesmo. O desgaste da ferramenta é um fator crítico durante a usinagem de materiais endurecidos, sendo que, a ponta da ferramenta nas operações de torneamento de acabamento deve apresentar raio de ponta pequeno $(0,1-0,4$ $\mathrm{mm}$ ), facilitando assim o desgaste da ponta (SHAW, 1984). 
A Figura 5.22 mostra uma camada branca por deformação bem definida para a amostra S4, na qual foram utilizados a maior velocidade de corte e o maior avanço.

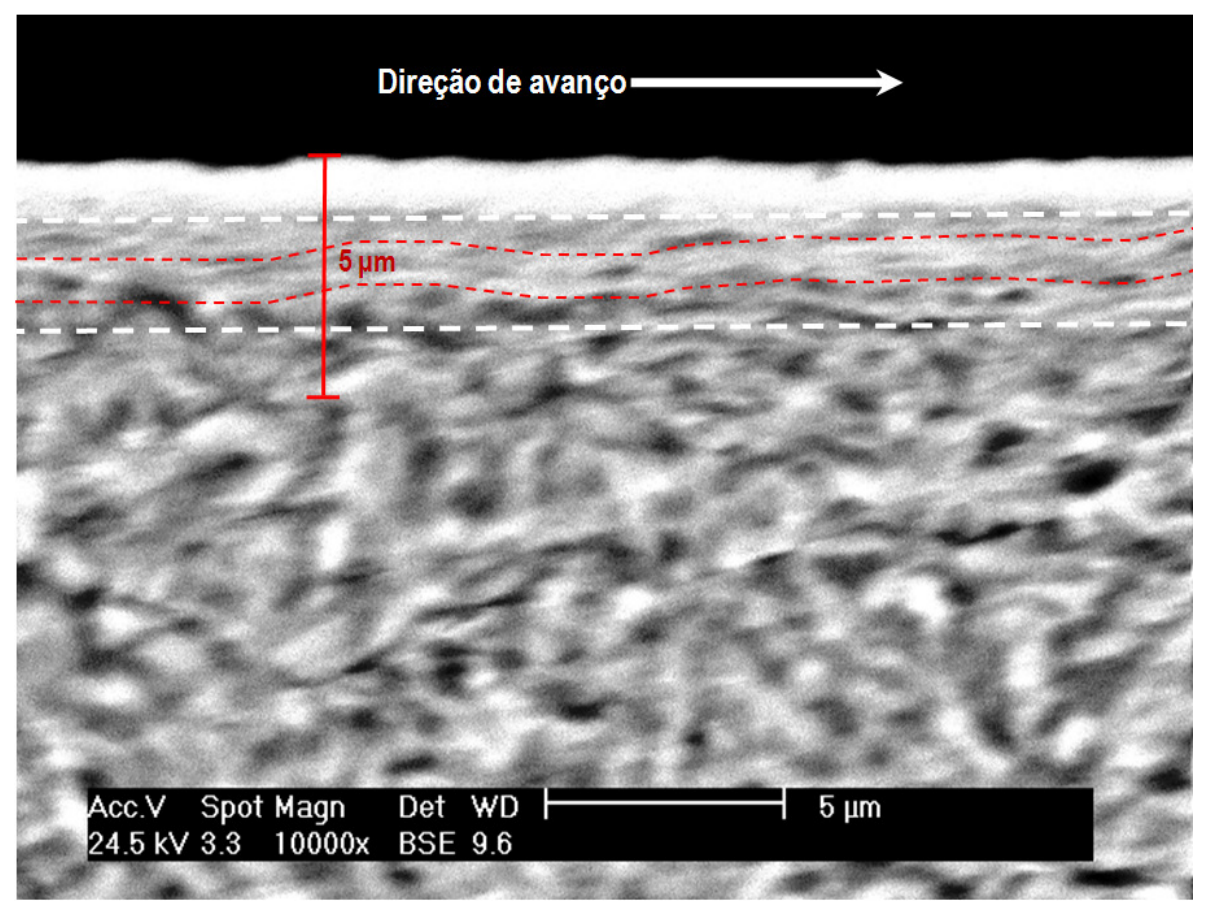

a)

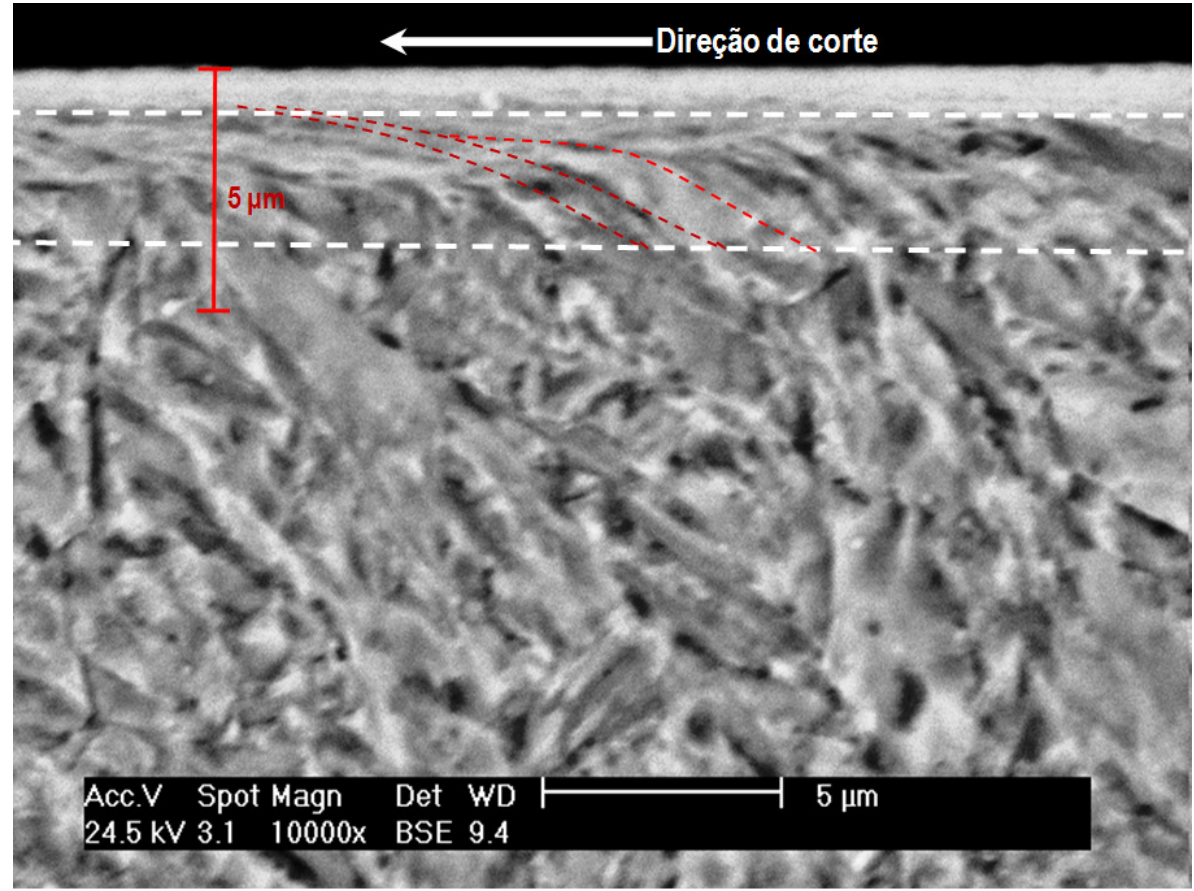

b)

Figura 5.22 - Imagem da subsuperfície do corpo de prova na condição S4. Corte transversal no plano a) perpendicular ao sentido de avanço da ferramenta; b) paralelo ao sentido de avanço da ferramenta. Após torneamento com velocidade de corte (Vc) de $120 \mathrm{~m} / \mathrm{min}$, e avanço (f) de 0,1 mm/rot. Imagens obtidas em MEV com aumento de 10000x. Ataque com Villela. 
Os resultados apresentados anteriormente na Figura 5.22 corroboram os resultados observados na Figura 5.21. Nas Figuras 5.23 e 5.24 apresentam-se micrografias obtidas por $\mathrm{MO}$ e $\mathrm{MEV}$, respectivamente, do corpo de prova retificado. Houve formação de camada branca por deformação e a deformação plástica na camada subsuperficial, como nos corpos de prova torneados. No entanto, a espessuras das camadas geradas foram menores do que as observadas para as superficies geradas com o processo de torneamento.

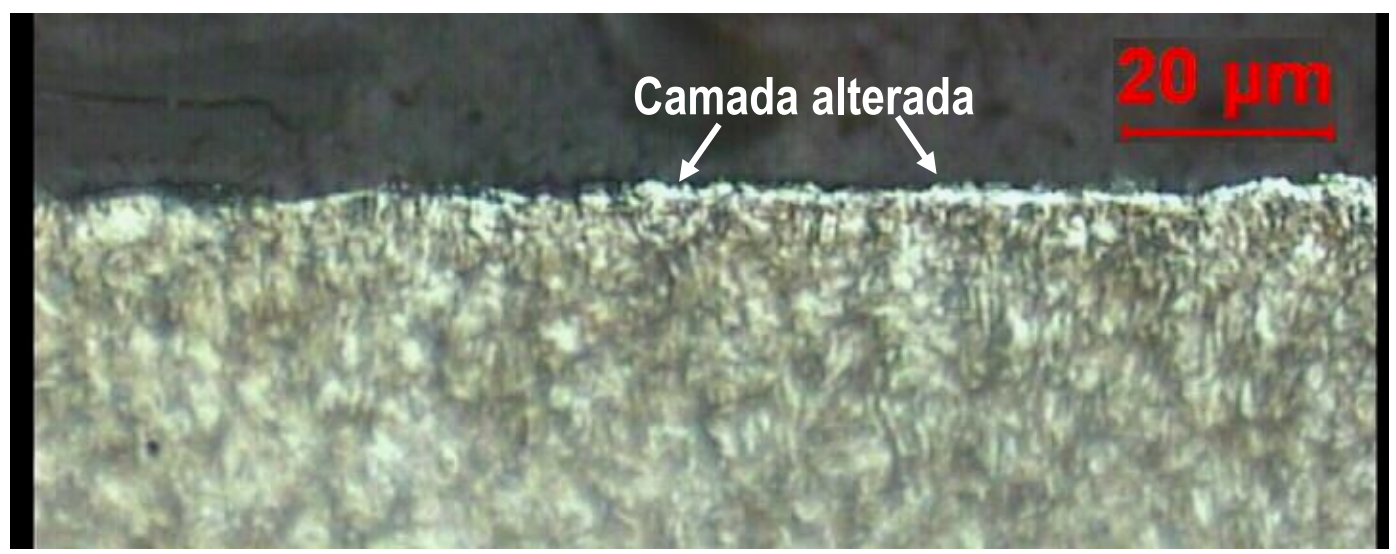

a)

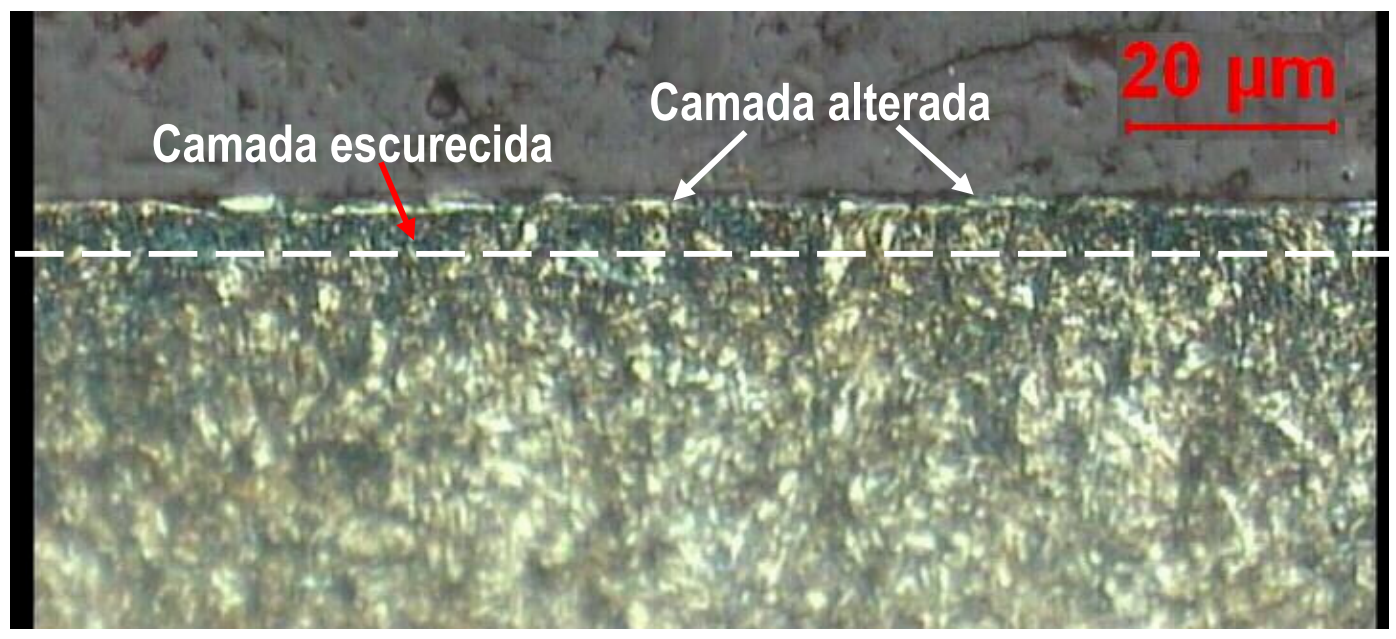

b)

Figura 5.23 - Imagem da subsuperfície do corpo de prova na condição SR. Corte transversal no plano a) perpendicular ao sentido de avanço; b) paralelo ao sentido de avanço. Após retificação com velocidade de corte $\left(\mathrm{v}_{\mathrm{c}}\right)$ de $54 \mathrm{~m} / \mathrm{s}$, avanço $\left(\mathrm{v}_{\mathrm{p}}\right) 4 \mathrm{~m} / \mathrm{min}$ e profundidade de corte $\left(\mathrm{a}_{\mathrm{e}}\right)$ 0,03 $\mathrm{mm}$. Imagens obtidas em MO com aumento de 1000x. Ataque com Villela. 


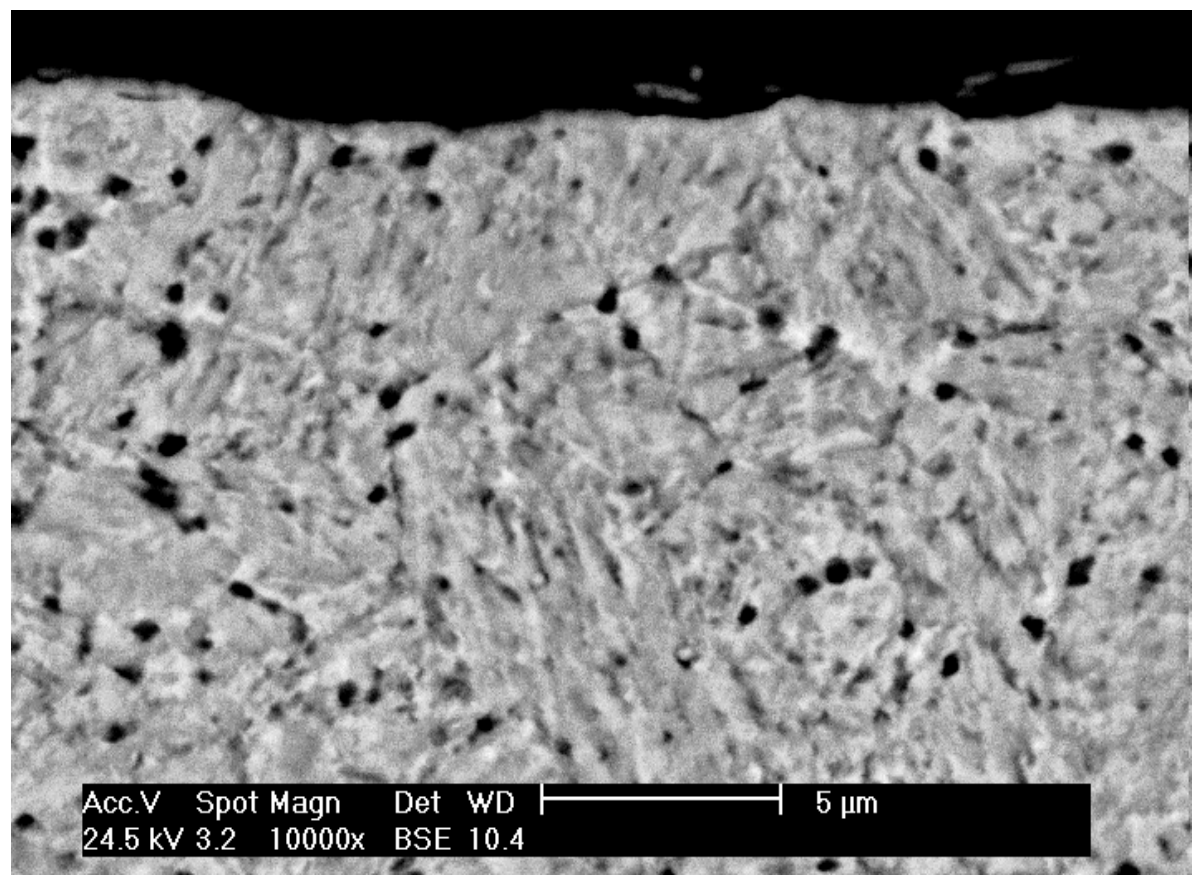

a)

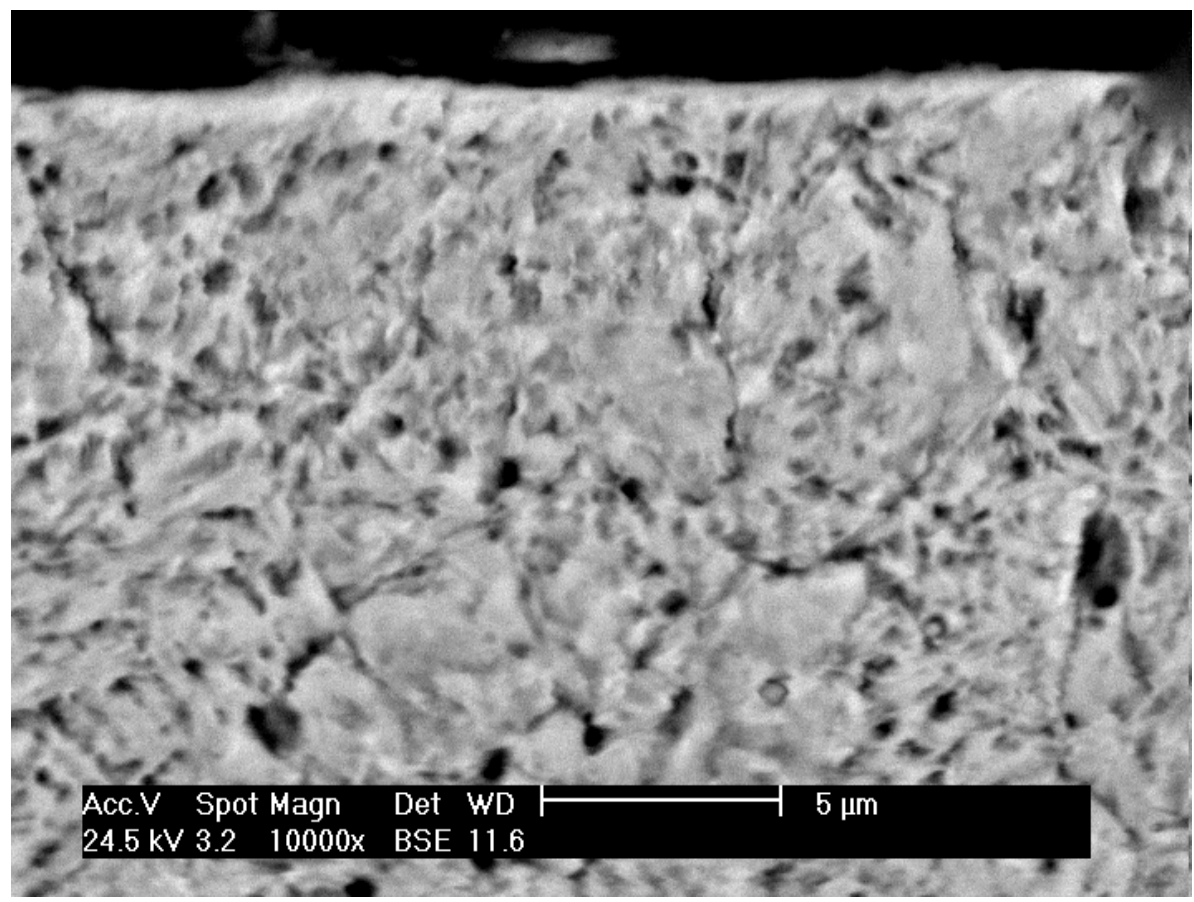

b)

Figura 5.24 - Imagem da subsuperfície do corpo de prova na condição SR. Corte transversal no plano a) perpendicular ao sentido de avanço; b) paralelo ao sentido de avanço. Após retificação com velocidade de corte $\left(\mathrm{v}_{\mathrm{c}}\right)$ de $54 \mathrm{~m} / \mathrm{s}$, avanço $\left(\mathrm{v}_{\mathrm{p}}\right) 4 \mathrm{~m} / \mathrm{min}$ e profundidade de corte $\left(\mathrm{a}_{\mathrm{e}}\right)$ 0,03 $\mathrm{mm}$. Imagens obtidas em $\mathrm{MEV}$ com aumento de 10000x. Ataque com Villela.

\subsubsection{Análise da dureza}

A medição da dureza na seção transversal é uma técnica utilizada como meio de se avaliar as mudanças microestruturais durante o processo de usinagem 
(FIELD et al., 1972; KOSTER et al., 1976; MACHINABILITY DATA CENTER, 1980; HASHIMOTO et al., 2006; HIOKI, 2006). Em função do tipo de material a ser avaliado e das suas características microestruturais, é necessário ajustar a carga ao tipo de equipamento e penetrador utilizado para assim obter um valor adequado de dureza; lembrando que o valor de dureza depende fundamentalmente do material ensaiado, da geometria do penetrador e da força aplicada (TABOR, 1954).

Na seção 5.2.3 apresentaram-se imagens da seção transversal das diferentes condições ensaiadas ao longo deste trabalho. Em geral, observou-se que a profundidade máxima de material da camada superficial que foi afetada pelo processo de torneamento oscila na faixa dos 0,3 a $10 \mu \mathrm{m}$, condizendo com o reportado na literatura, onde para condições de corte convencionais as camadas alteradas ficam próximas dos $2,5 \mu \mathrm{m}$ de profundidade (MACHINABILITY DATA CENTER, 1980; GRIFFITHS, 2001). Para facilitar as medições, a amostra que foi selecionada possuía camada branca contínua e a maior espessura observada do conjunto de amostras analisadas (condição S2, no plano transversal). Na Figura 5.25 apresentam-se diversas indentações na seção transversal, e que foram realizadas utilizando um microdurometro Vickers, com as cargas de 50 e 10gf. O perfil de dureza apresentado na Figura 5.25 foi realizado com a carga de 50gf, carga que gera um tamanho de indentação adequado à visualização.

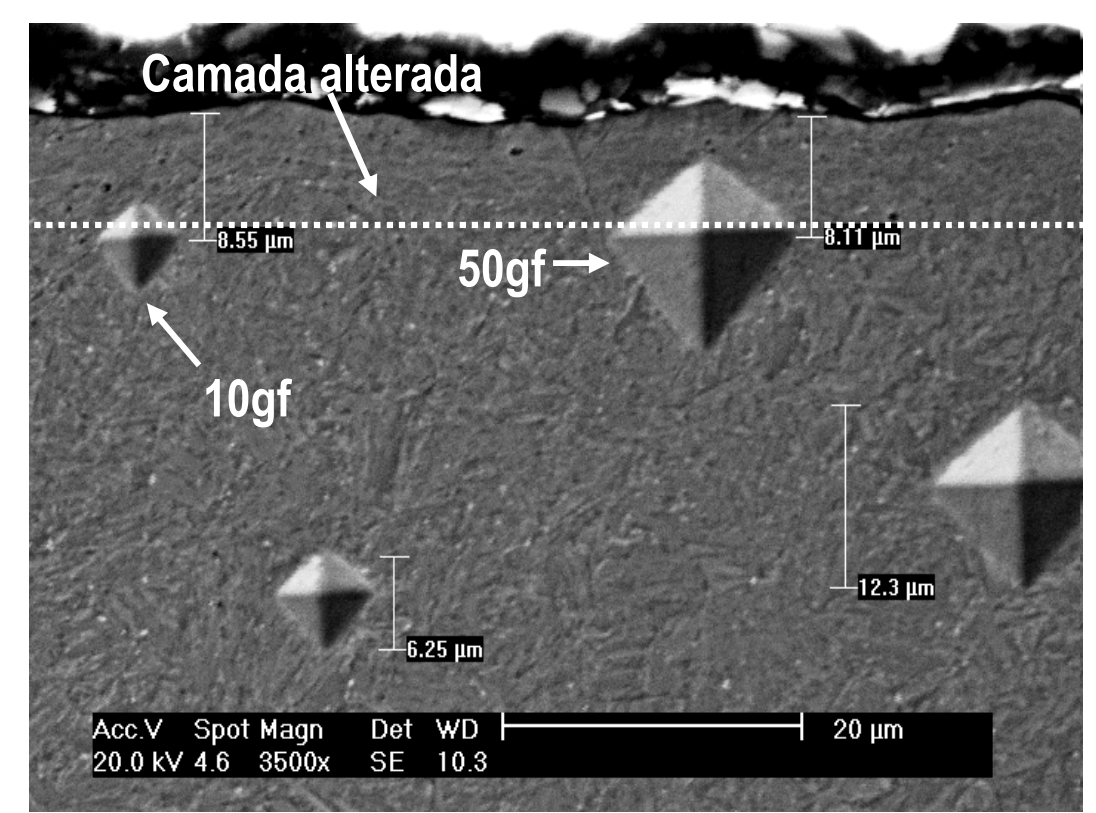

Figura 5.25. Indentações realizadas em microdurômetro Vickers, onde se observa que o tamanho da diagonal das marcas de dureza para as cargas utilizadas de 50 e $10 \mathrm{gf}$. 


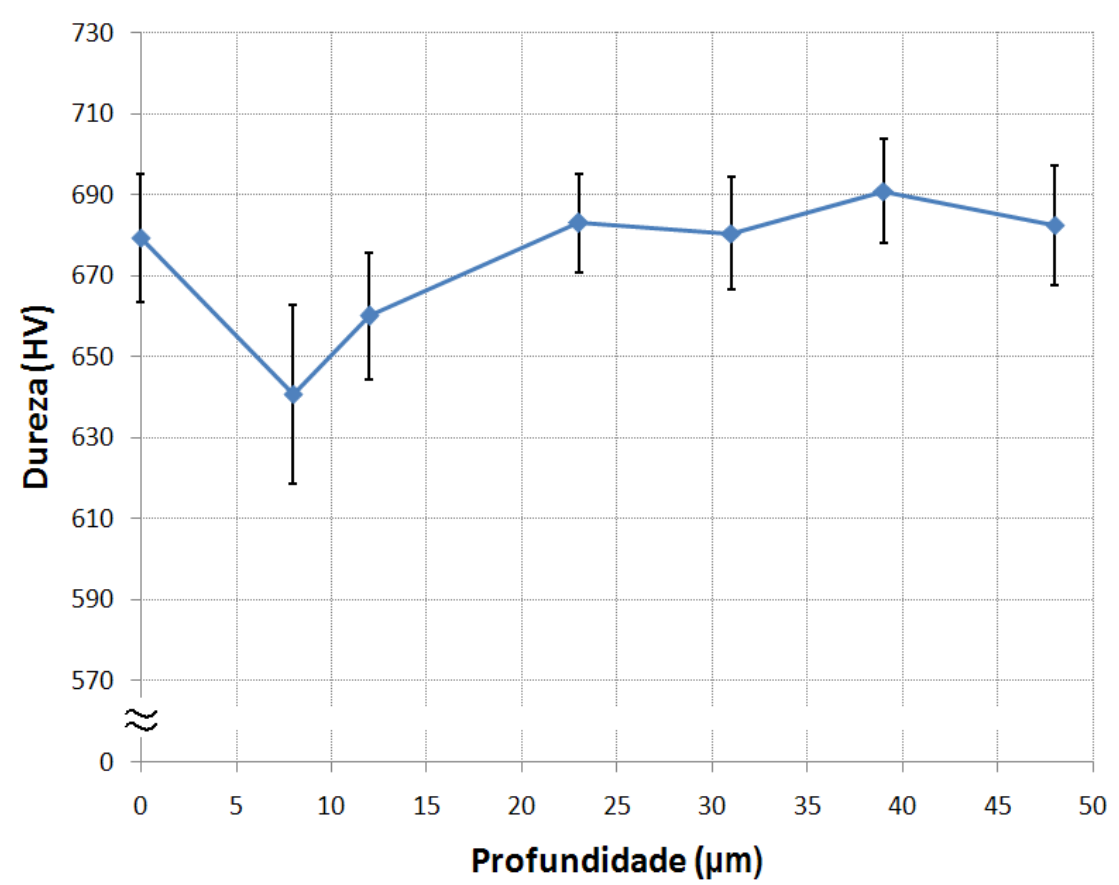

Figura 5.26. Medidas de dureza feitas com microdurometro com indentador Vickers e carga de 50gf, avaliada na seção transversal de uma das amostras torneadas na condição S2. O plano de corte da amostra é perpendicular ao sentido de avanço (na direção de corte).

Observa-se na Figura 5.25 que o tamanho das diagonais das marcas de dureza para a carga de 50 gf (12,3 $\mu \mathrm{m}$ aproximadamente) é maior do que a espessura da camada afetada $(8,5 \mu \mathrm{m}$ aproximadamente). A utilização de cargas na ordem dos 10 gf gera indentações nas quais é dificil a visualização das suas diagonais por parte do usuário empregando a óptica própria do instrumento de medição (Microdurômetro modelo MICROMET 2103, Fabricante Bhuler). Neste instrumento é necessário que o usuário identifique visualmente as diagonais de indentação para poder obter a medida de dureza, e o equipamento permite aumentos somente de até 1000 vezes. Na Figura 5.26 é possível observar que os 2 primeiros pontos abaixo da superficie (8 e $12 \mu \mathrm{m}$ aproximadamente) apresentam menor dureza, mas $20 \mu \mathrm{m}$ abaixo, a dureza é a mesma no material. Além disso, analisando o desvio padrão observa-se que a dureza nos dois primeiros pontos da subsuperficie é mais dispersa com relação ao resto do material. Isto sugere que a diminuição aparente da dureza pode estar relacionada com o "efeito de borda"; observação igualmente realizada por Hashimoto et al (2006) durante o estudo do efeito da integridade superficial na vida em FC de superficies torneadas e retificadas. Em diversos trabalhos é comumente adotado um procedimento conservador ao se realizar as medições de dureza, o "espaçamento mínimo". Este procedimento consiste 
na utilização de uma distância de 3 vezes a diagonal da indentação entre a borda e o ponto de medição (BERNS e FRANCO, 1997; JAKES e DONALD, 2011). Isto evita que as medidas sejam afetadas pelo campo de tensões das indentações vizinhas (FARIAS, 2004; HIOKI; 2006, RECCO et al., 2006; RODRIGUEZ, 2010). A dificuldade no método de medição acima descrito mostra que o tamanho da indentação é um fator crítico ao se avaliar as propriedades do material das superficies torneadas e retificadas sob condições convencionais a partir de ensaios de dureza.

Uma técnica que dispensa a observação da marca de dureza, por parte do usuário, para fornecer o valor da mesma, e que ao mesmo tempo possibilita o uso de cargas menores (produzindo indentações também menores), é a microdureza instrumentada (ou nanoindentação). Não obstante, quando a dureza é avaliada próxima da borda com a técnica de nanoindentação é necessário considerar o "efeito de borda" (GUO e SAHNI, 2004; HASHIMOTO et al., 2006). Para contornar o problema do efeito de borda na nanoindentação são utilizados critérios fundamentados em modelos analíticos e experimentais (RODRIGUEZ, 2010; JAKES e DONALD, 2011), que geralmente são baseados no método para o cálculo de dureza de Oliver e Pahrr (1992).

No durômetro instrumentado marca Fisherscope equipado com penetrador Vickers foram realizadas indentações com cargas de 10 gf nos primeiros $20 \mu \mathrm{m}$ da subsuperfície, numa matriz de $3 \times 10$ como mostrado na Figura 5.27. É possivel observar que algumas marcas de dureza ficaram muito próximas da borda (primeira série de pontos próxima da superfície). Como visto anteriormente, esta série de medidas pode estar influenciada pelo efeito de borda. A terceira série de pontos foi a segunda medida a ser realizada, e finalmente, foi avaliada a dureza na segunda série de pontos. O método empregado para o cálculo de dureza é Oliver e Pharr (1992) usando o fator de correção Beta segundo King (1987). Os cálculos foram realizados segundo o algoritmo inverso de Rodriguez et al (2010), que melhora o procedimento de determinação da dureza, excluindo da análise as curvas dos pontos que estejam fora da faixa de duas vezes o desvio padrão. Esta funcionalidade do algoritmo permite que, por exemplo, pontos de dureza que foram medidos de maneira errada prejudiquem o resultado. 


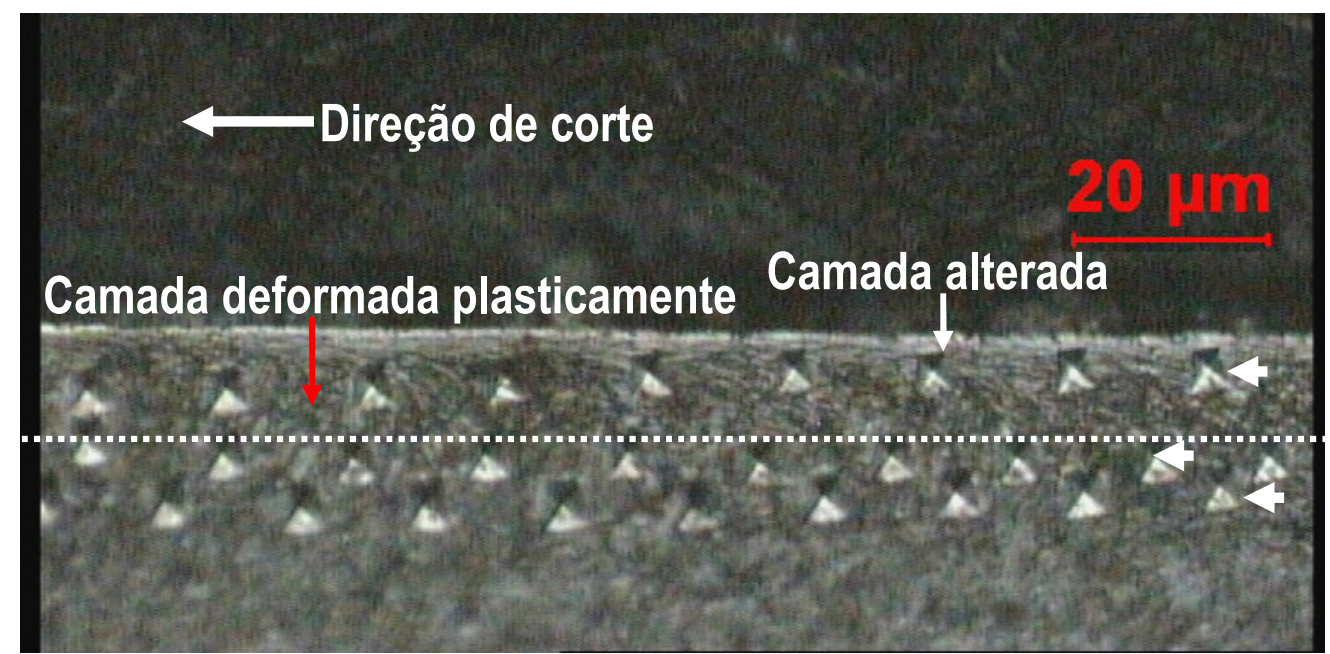

Figura 5.27. Marcas de dureza instrumentada com carga de 10gf, avaliada na seção transversal de uma das amostras torneadas na condição S2. Mostra-se o plano perpendicular ao sentido de avanço (na direção de corte). Imagens obtidas em MO com aumento de 1000x.

Os valores de dureza foram medidos na profundidade de 5, 12 e $20 \mu \mathrm{m}$ como observado na Figura 5.28.

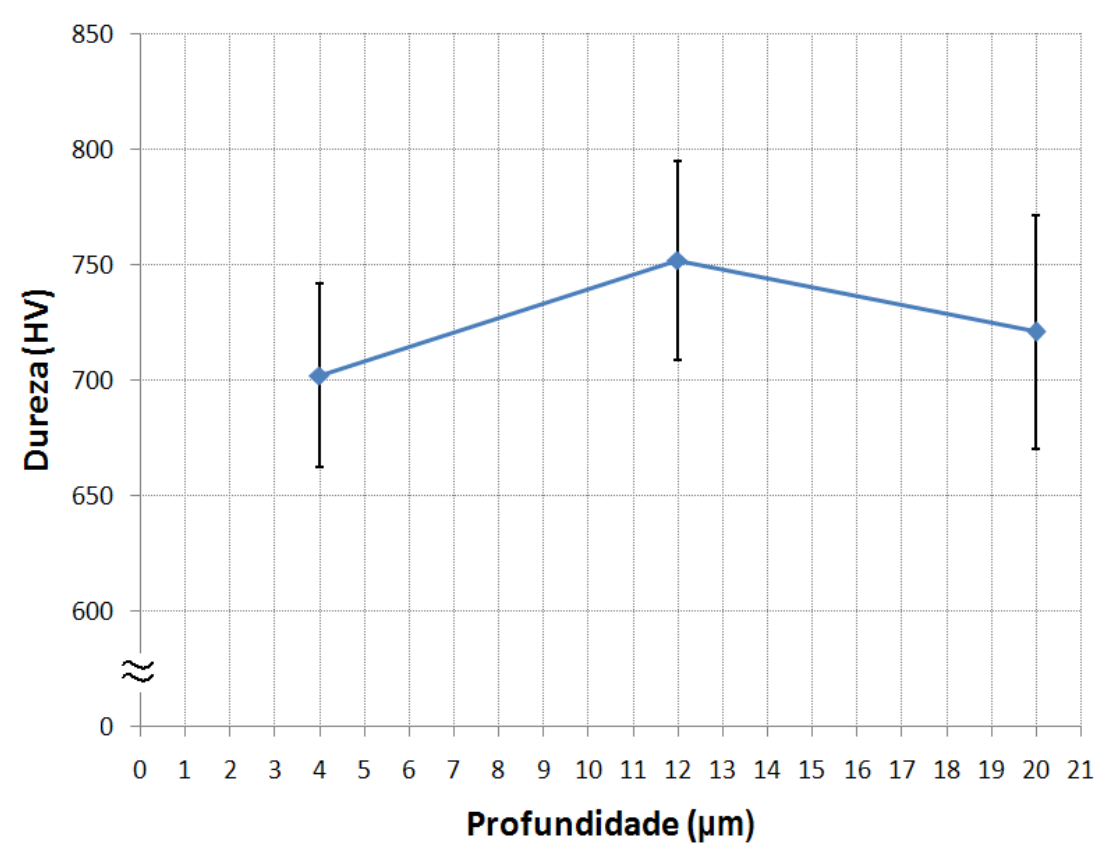

Figura 5.28. Medidas de nanodureza feitas com indentador Vickers e carga de 10gf, avaliada na seção transversal na condição S2. O plano de corte da amostra é perpendicular ao sentido de avanço (na direção de corte).

Observa-se da Figura 5.28 que dureza da região mais próxima da superficie onde foram feitas as medições ( $4 \mu \mathrm{m}$ abaixo da superficie) apresentam a menor dureza quando comparada com o valor médio das outras regiões avaliadas. Contudo, dado o desvio padrão das medidas, pode-se considerar que dureza nos primeiros $20 \mu \mathrm{m}$ de profundidade oscila na faixa dos 690 a $790 \mathrm{HV}$. Isto 
sugere que com o método utilizado não existem diferenças de dureza na região alterada pelo processo ( $8 \mu \mathrm{m}$ aproximadamente), e que o comportamento apresentado pelo perfil de dureza na Figura 5.27 pode ser devido ao efeito de borda. Para conseguir um resultado mais adequado séria necessária a utilização de cargas inferiores aos $10 \mathrm{gf}$ utilizados, mas, não séria possivel com estas cargas a visualização das marcas de dureza com a óptica do microdurometro Fisherscope. Com isso, seria necessária a utilização de outra técnica de microscopia, a qual permita observar a superficie ensaiada com aumentos superiores a 1000 vezes (MEV) uma vez feitas as indentações. Desta maneira, seria possivel identificar a profundidade da região onde foram feitas as medições de dureza.

No presente trabalho não foi adotado o procedimento sugerido anteriormente, dado que as alterações da subsuperficie nas demais amostras são de menor tamanho do que as amostras acima analisadas, o que é característico de superficies geradas com condições convencionais. Também, considerando que para menores cargas, maior é a interação do indentador com os elementos microestruturais (segundas fases, por exemplo) (HASHIMOTO et al., 2006).

Baseado nos resultados encontrados considera-se que, devido ao tamanho das alterações na microestrutura das superficies geradas em condições convencionais e em função do procedimento adotado no presente trabalho, a técnica de dureza não permitiu avaliar as alterações da IS das superficies em termos das diferenças na dureza da camada superficial.

\subsubsection{Caracterização da superfície mediante medição de tensão residual}

A seguir apresentam-se os resultados de tensões residuais obtidos no sentido tangencial e radial da superficie das cinco condições testadas (S1, S2, S3, S4, SR) utilizando a técnica de difração de raios X. Foi selecionado apenas um corpo de prova para medição de tensão residual em cada condição, já que as características topográficas foram semelhantes entre cada condição. A avaliação das características topográficas foi a forma encontrada para verificar a homogeneidade entre as amostras sem alterar ou danificar os corpos de prova antes de se realizar os testes de desempenho. Para cada corpo de prova analisado foi feita uma repetição para cada ponto de medição (P1 e P1', P2 e P2' ). As amostras selecionadas para serem avaliadas por difração de raios $\mathrm{X}$ 
foram: Amostra 13 (S1), 3 (S2), 9 (S3), 6 (S4) e a face retificada da amostra 9 (SR). Os resultados de tensão residual são apresentados na Figura 5.29.

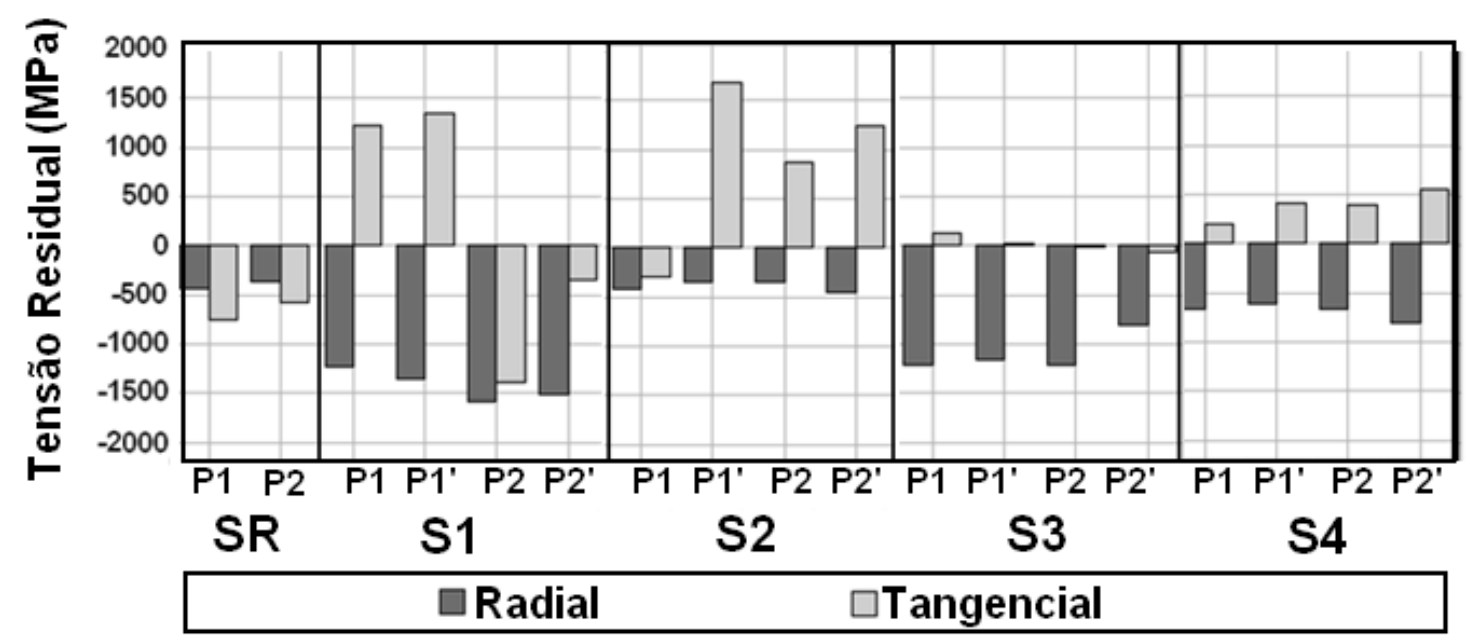

Figura 5.29 - Medidas de tensão residual das superficies ensaiadas adquiridas no sentido de avanço da ferramenta (Radial) e de corte (Tangencial).

Como observado na Figura 5.29, as medidas de tensão residual avaliadas na direção radial (sentido de avanço para torneamento de faceamento), são mais compressivas e consistentes do que as medidas feitas na direção tangencial (sentido de corte). As análises serão baseadas nas tensões medidas na direção de avanço da ferramenta (direção radial), direção de análise mais frequentemente empregada na literatura ao se estudar tensão residual em superficies torneadas (EL-WARDANY et al., 2000b; AXINTE e DENVES, 2002; RECH e MOISAN; 2003; RAMESH et al., 2005; HIOKI, 2006). Por outro lado, para o caso da superficie retificada, a análise será realizada considerando a direção tangencial, já que esta direção coincide com o sentido de avanço do rebolo.

Segundo Matsumoto et al. (1999), a diferença mais significativa na tensão residual induzida pelos processos de torneamento duro e a retificação (empregando ferramentas e rebolos com ausência de desgaste), o qual é devido a que no torneamento duro as tensões compressivas máximas estão localizadas a uma profundidade maior, não entanto, nas superficies retificadas as tensões compressivas são maiores na superficie. A tensão residual foi avaliada na superficie, e lembrando que a profundidade de penetração dos raios $\mathrm{X}$ utilizados nas técnicas para medição da tensão residual é comumente inferior aos $10 \mu \mathrm{m}$ nos aços (MARTINS et al., 2004), profundidade a partir da qual foram observadas as alterações da camada superficial das superficies 
geradas. Com isso, o levantamento do perfil de tensão residual mediante a técnica de remoção de camadas não é estritamente necessária no presente trabalho.

Observa-se da Figura 5.30 que em geral, as amostras torneadas com os menores avanços $(0,05 \mathrm{~mm})$, apresentam a maior tensão residual compressiva no sentido de avanço, comportamento que é observado em outros trabalhos (MATSUMOTO et al, 1999; CAPELLO, 2004; DELIJAICOV, 2004; ABRÃO, 2005, HUA et al., 2006; JADIVI et al. 2008).

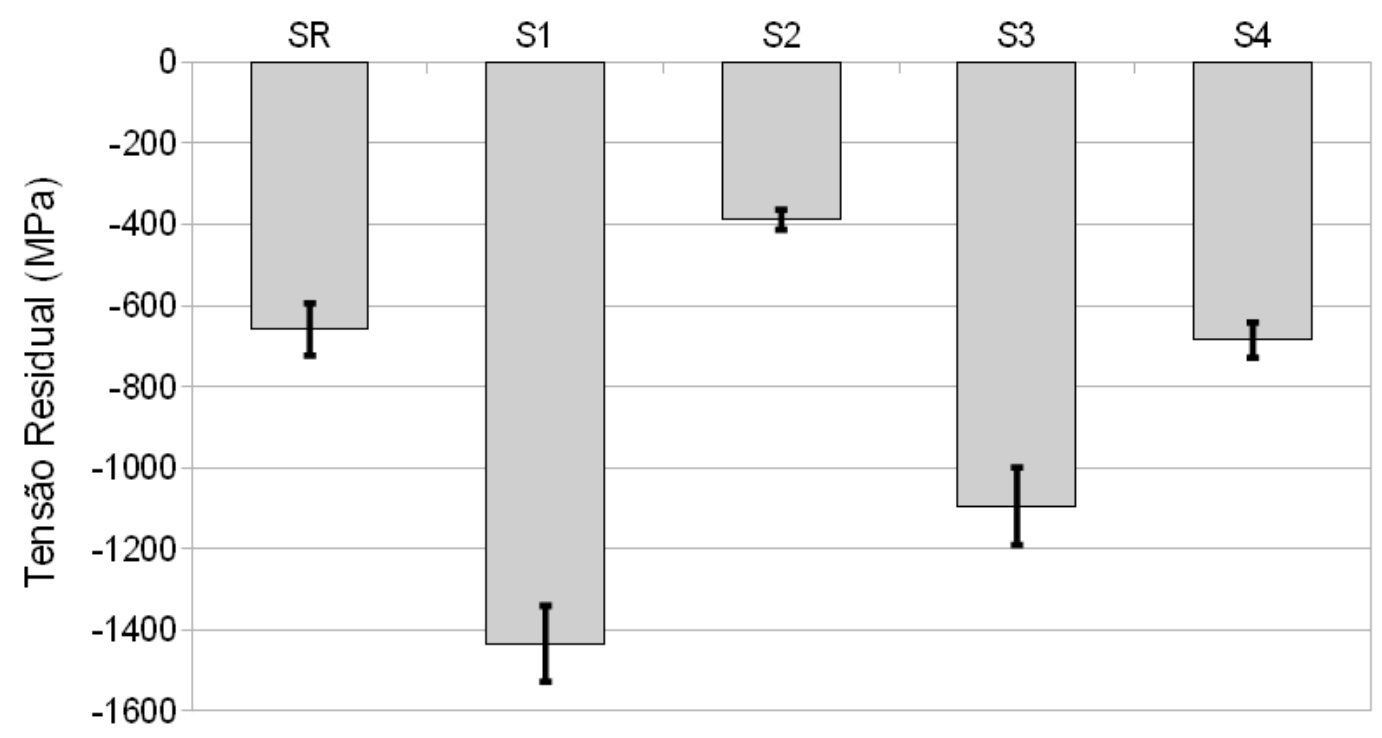

\section{Condição}

Figura 5.30 - Valor médio das medidas de tensão residual das superficies ensaiadas avaliada no sentido de avanço: radial nas superficies torneadas e tangencial nas superficies retificadas.

As superficies que foram geradas com o maior avanço e a mais baixa velocidade de corte tiveram a menor tensão residual, inclusive menor que a observada nas superfícies retificadas. Empregando avanços menores o efeito mecânico será mais acentuado durante o processo de remoção de material, e, por exemplo, a interação da ferramenta com a peça será maior em função da aresta de corte passar mais vezes sobre a mesma região. Igualmente, a influência do avanço pode afetar a temperatura de usinagem, ainda que de forma não tão significativa quanto à velocidade de corte. Portanto, valores mais baixos de avanço seriam responsáveis por temperaturas igualmente mais baixas, minimizando o efeito térmico que induz tensões de tração. Espera-se que nesta condição (S2) a vida desta superfície não seja tão favorecida pelo efeito da tensão residual, como se espera aconteça para as outras condições 
(SR, S1, S3, S4). Em termos gerais, os resultados acima apresentados condizem com as informações encontradas na literatura para o torneamento de materiais endurecidos (MATSUMOTO et al., 1999; GUO e WEN, 2004).

\subsubsection{Caracterização da superfície mediante medição do Ruído Magnético de Barkhausen (RMB)}

Como apresentado na literatura (Capítulo 1), o RMB é fortemente influenciado pelo estado de tensões e pela microestrutura do material (HAUK, 1997; WITHERS E BHADESIA, 2001; STEFANITA et al., 2000; GRIJALBA; 2010). Contudo, por se tratar de um método indireto, é necessária a calibração da técnica com alguma técnica direta ou empregar um padrão de comparação. Isto no intuito de correlacionar os sinais medidos com a variável de interesse (tensão residual, dureza, microestrutura, entre outras). A calibração pode ser baseada nos resultados obtidos a partir de ensaios mecânicos ou de outras técnicas de medição (GRIJALBA; 2010).

No presente trabalho não se objetiva o uso da técnica de RMB como um método de medição de alguma propriedade do material (tensão residual, dureza). O RMB será utilizado como uma técnica complementar na avaliação da IS das diferentes superficies geradas (S1, S2, S3, S4, S5 e SR). Adotou-se uma condição de referência que permita comparar o comportamento do RMB avaliado nas diferentes superficies, e em função disso, medições foram feitas na totalidade dos corpos de prova antes de se produzir as superficies torneadas é retificadas. Esta condição de referência será denominada no presente trabalho como "Superficie no estado inicial - SEI", onde a superficie do material ainda não está afetada pelos efeitos da usinagem, já que os corpos de prova se encontram no estado de tempera e triplo revenido (Capítulo 4).

O sinal de RMB no domínio do tempo obtido em uma das amostras no estado inicial é apresentado na Figura 5.31. Ao se comparar o aspecto do sinal apresentado na Figura 5.31 com sinais de RMB existentes na literatura (GRIJALBA, 2010), pode-se inferir que as condições com as quais foram realizadas as medições de RMB (Capítulo 4) permitem produzir o efeito de ruído magnético de Barkhausen no material da superficie utilizada como referência. 


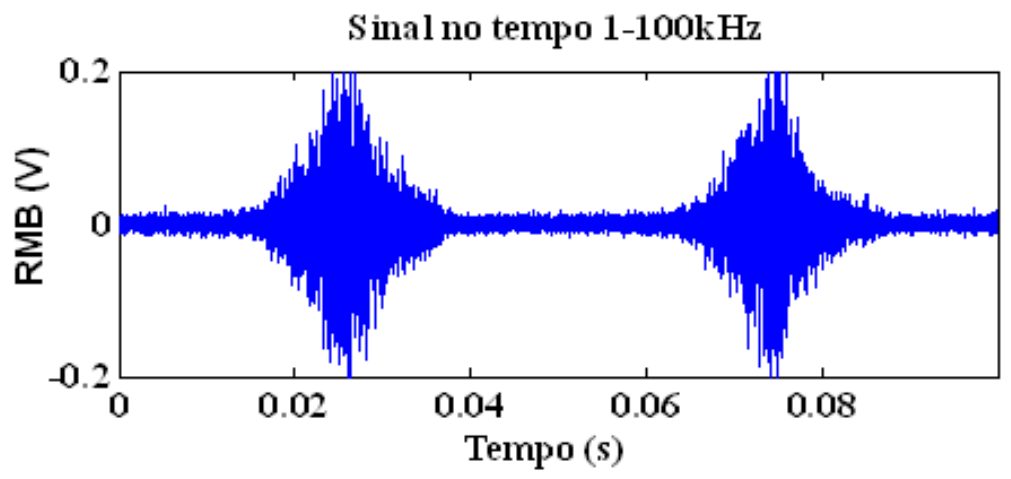

Figura 5.31 - Sinal de RMB no domínio do tempo obtido nas superficies no estado inicial utilizadas como referência.

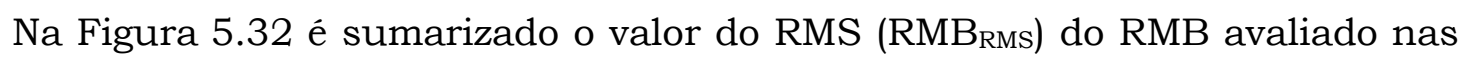
superficies retificadas e no estado inicial. Observa-se que o RMB $B_{R M S}$ do RMB para as superficies no estado inicial é diferente de uma condição para outra. Igualmente, tanto a amplitude como o desvio padrão do valor de RMB $B_{\text {RMS }}$ do RMB das amostras no estado inicial é menor quando comparado com as medidas realizadas nas superficies retificadas.

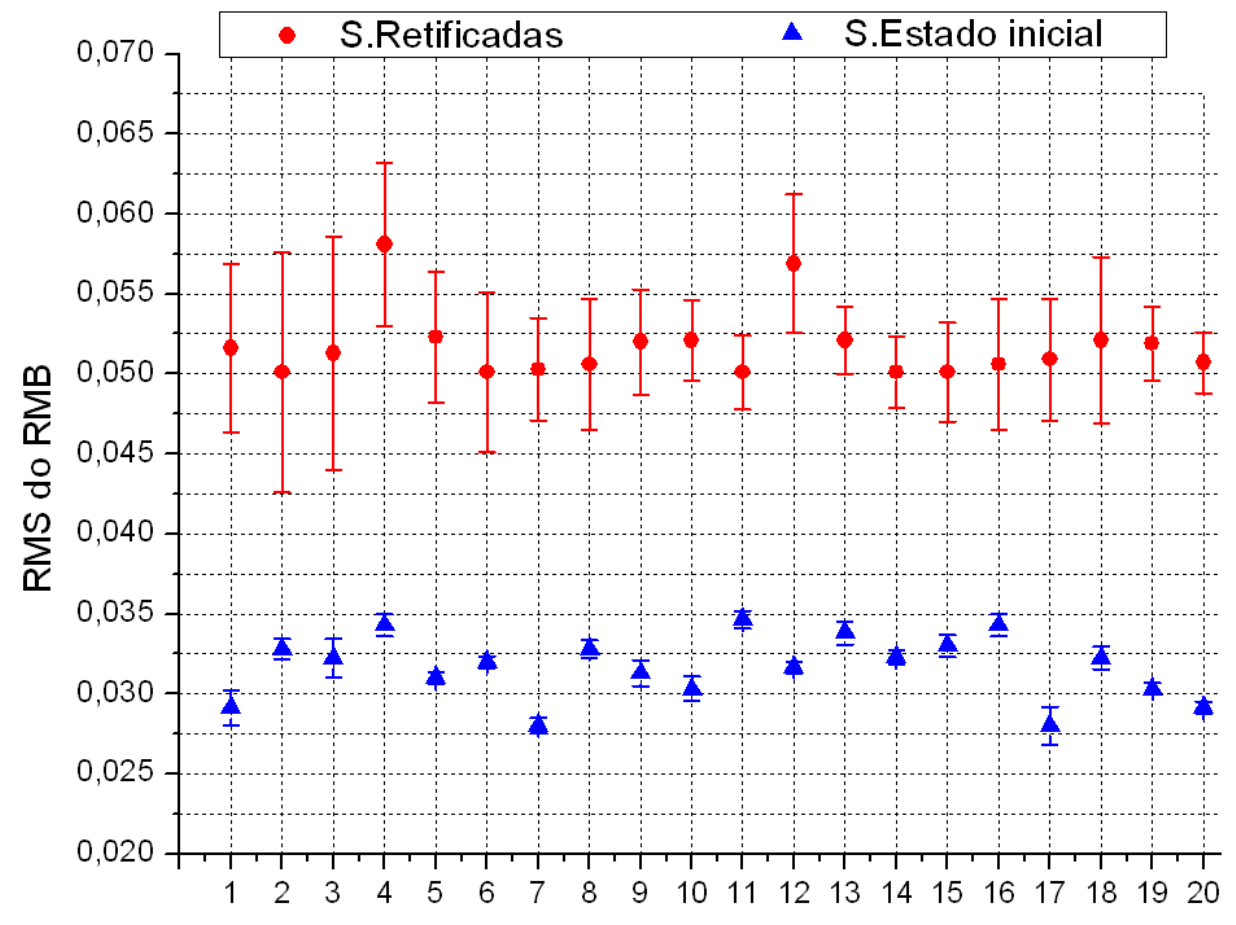

Amostras

Figura 5.32 - RMB $_{\text {RMS }}$ do RMB para as superficies retificadas e no estado inicial.

Na Figura 5.33 apresenta-se um resumo dos valores de $\mathrm{RMB}_{\mathrm{RMS}}$ do RMB agrupados em função da condição da superficie (S1, S2, S3, S4, SR, SEI). Observa-se que as diferenças existentes entre o valor de $\mathrm{RMB}_{\mathrm{RMS}}$ do RMB das superficies retificadas e no estado inicial (Figura 5.31) ficam aparentemente 
"menores" ao serem comparadas com os valores avaliados nas superficies torneadas. Empregando o mesmo tipo de análise, observa-se que o RMB $\mathrm{RMS}_{\text {do }}$ RMB das superficies torneadas possui maior amplitude e dispersão do que o os pontos das medidas observadas nas outras condições (estado inicial e retificação).

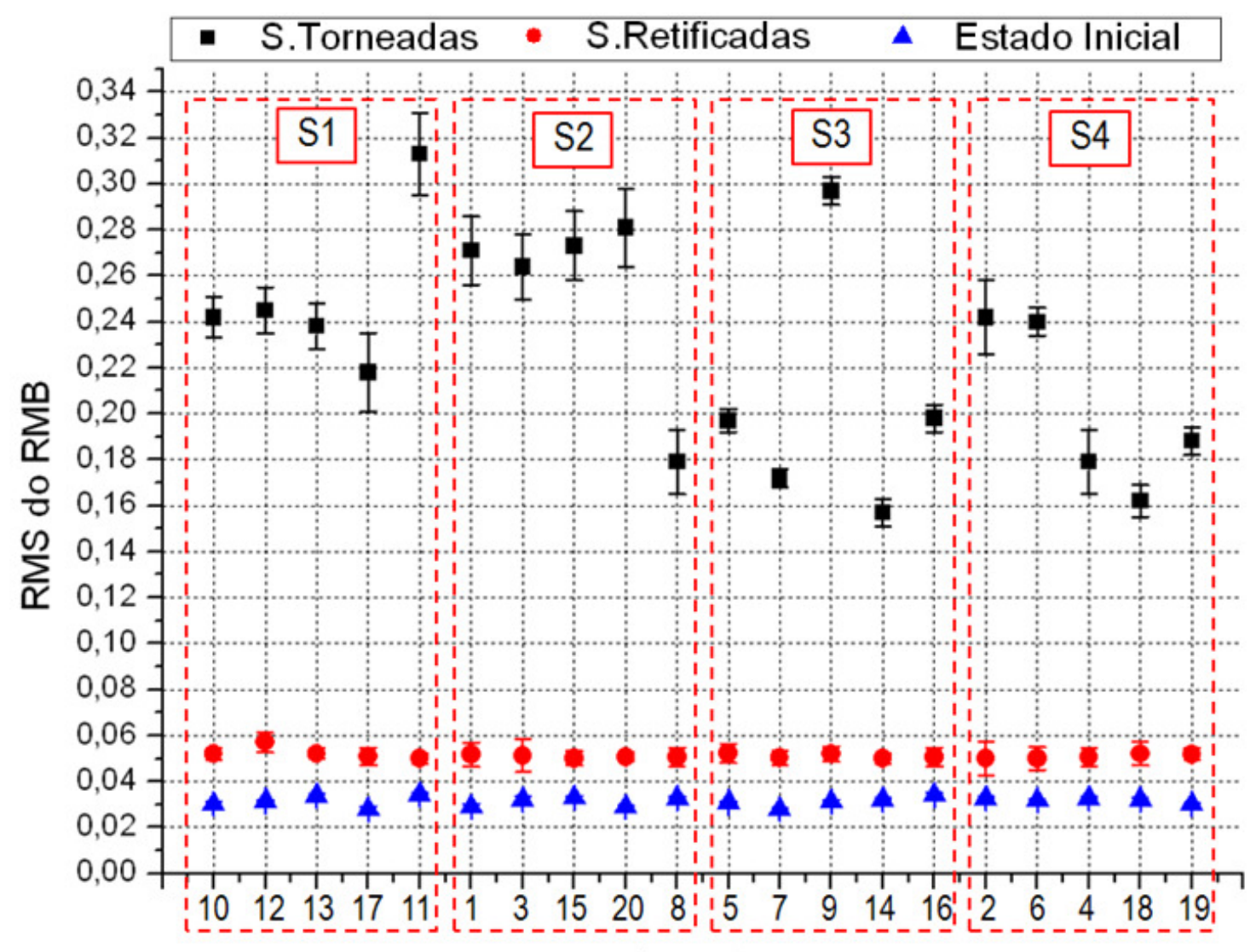

Amostra

Figura 5.33- $\mathrm{RMB}_{\mathrm{RMS}}$ do RMB para as diversas superficies testadas agrupadas de acordo com a condição de geração da superficie. São indicados apenas os corpos de prova torneados. Os corpos de prova retificados e na condição inicial são apresentados como dados de referência para todas as amostras.

$\mathrm{Na}$ Figura 5.33 é possível observar que em função do tipo de processo empregado que existem duas regiões bem diferenciadas onde os pontos de $\mathrm{RMB}_{\mathrm{RMS}}$ do RMB estão localizados. Isto sugere que as diferenças nas alterações da camada superficial, próprias de cada tipo de processo de acabamento utilizado (Retificação, Torneamento), afetam de maneira diferente as emissões de RMB por parte do material. A análise do valor de RMB $B_{\text {RMS }}$ do RMB permite observar estas diferenças nas propriedades magnéticas em função de processo utilizado. 
As superficies geradas mediante o processo de retificação, quando comparadas com as superficies obtidas por torneamento duro, são mais homogêneas em termos de tensão residual e das características geradas na

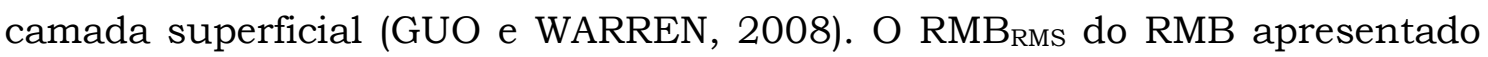
pelas superficies retificadas se aproxima ao valor de $0,005 \mathrm{~V}$, que é próximo ao valor apresentado pela superfície de referência. O menor $\mathrm{RMB}_{\mathrm{RMS}}$ do RMB para as superficies retificadas deve-se a que em aços endurecidos é amplamente aceito que o sinal $\mathrm{RMB}_{\mathrm{RMS}}$ do $\mathrm{RMB}$ aumenta com a presença de tensões trativas e é reduzido para tensões compressivas (MOORTHY, 2006). Por outro lado, a amplitude do RMB aumenta com a deformação plástica, até atingir um valor máximo em certo nível de deformação (HWANG, 1988; MOORTHY et al., 1999; CAMPOS et al.; 2008; GRIJALBA, 2011). Os corpos de prova torneados tiveram maior deformação plástica que as superficies retificadas (seção 5.2.3), o que concorda com as informações da literatura (GRIFFITHS, 2001; GUO E WARREN, 2006) e com o $\mathrm{RMB}_{\mathrm{RMS}}$ de RMB. Esses resultados mostram a potencialidade da técnica de RMB para ser utilizada como método de ensaio não destrutivo (END) e não invasivo no monitoramento das alterações geradas nas superficies obtidas por diferentes processos de fabricação.

\subsection{Efeitos da integridade no desempenho funcional}

A análise realizada a seguir objetiva apresentar os resultados dos testes de desempenho tribológico das superficies. Lembrando do procedimento experimental (Capítulo 4), que todos os ensaios foram realizados até a ocorrência do primeiro lascamento, detectado pelo sistema instrumentado desenvolvido (ALVAREZ et al., 2008) e adaptado ao equipamento de ensaios de FCR também desenvolvido no Laboratório de Fenômenos de Superficies por Neves et al (2005) e Neves (2006).

\subsubsection{Desempenho em fadiga de contato}

Na tabela 5.2 apresentam-se os valores da vida em ciclos das superficies que foram ensaiadas até o lascamento do material. Assumindo-se que estes resultados de vida em fadiga podem ser descritos por uma função de Weibull de dois parâmetros, foi utilizado o procedimento descrito na norma NBR 6742 (ABNT, 1987) para interpretar as informações de falha das superficies. Os valores de vida são apresentados em ordem crescente. 
Tabela 5.2. Valores de vida em ciclos de FC das superficies testadas

\begin{tabular}{|c|c|c|c|c|c|}
\hline Amostra & $\begin{array}{c}\mathrm{S} 1 \\
\text { Vc } 60 \mathrm{~m} / \mathrm{min} \\
\text { f } 0,05 \mathrm{~mm} / \mathrm{rot}\end{array}$ & $\begin{array}{c}\mathrm{s} 2 \\
\text { Vc } 60 \mathrm{~m} / \mathrm{min} \\
\text { f } 0,1 \mathrm{~mm} / \text { rot }\end{array}$ & $\begin{array}{c}\mathrm{S} 3 \\
\text { Vc } 120 \mathrm{~m} / \mathrm{min} \\
\text { f } 0,05 \mathrm{~mm} / \operatorname{rot}\end{array}$ & $\begin{array}{c}\mathrm{S} 4 \\
\mathrm{Vc} 120 \mathrm{~m} / \mathrm{min} \\
\text { f } 0,1 \mathrm{~mm} / \operatorname{rot}\end{array}$ & $\begin{array}{c}\mathrm{SR} \\
\mathrm{v}_{\mathrm{c}} 54 \mathrm{~m} / \mathrm{s} \\
\mathrm{v}_{\mathrm{p}} 4 \mathrm{~m} / \mathrm{min}\end{array}$ \\
\hline 1 & 445.276 & 370.276 & 237.553 & 7.875 .000 & 13.552 .156 \\
\hline 2 & 539.566 & 1.344 .184 & 9.785 .980 & 8.534 .682 & 15.433 .570 \\
\hline 3 & 814.969 & 1.368 .547 & 10.279 .314 & 10.467 .684 & 17.406 .588 \\
\hline 4 & 907.885 & 2.861 .547 & 10.989 .880 & 13.525 .846 & 18.417 .388 \\
\hline 5 & 1.261 .071 & 3.485 .481 & 12.944 .449 & 16.867 .830 & 19.956 .970 \\
\hline 6 & 1.568 .622 & 8.284 .912 & 18.353 .467 & 19.898 .980 & 20.595.297 \\
\hline
\end{tabular}

O método gráfico (ABNT, 1987) permitiu estabelecer a posição de cada ponto, dado que cada valor de vida é associado a uma probabilidade de falha utilizando um papel probabilístico de Weibull. Na tabela 5.3 apresentam-se a inclinação de Weibull (ou coeficiente angular) $(\beta)$ e vida característica $(\theta)$ da distribuição de falha das superficies.

Tabela 5.3. Inclinação de Weibull $(\beta)$ e vida caracteristica $(\theta)$ da distribuição de falha das superficies ensaiadas nas diferentes condições

\begin{tabular}{ccc}
\hline Condição & $\beta$ & $\theta$ \\
\hline S1 & 1,4 & 9.238 .726 \\
S2 & 2,0 & 3.055 .483 \\
S3 & 4,7 & 13.101 .772 \\
S4 & 3,3 & 12.639 .604 \\
SR & 5,0 & 18.132 .429 \\
\hline
\end{tabular}

Valores do parâmetro $\beta$ iguais ou maiores que 4 indicam que a distribuição de probabilidade dos dados se assemelha ao descrito pela distribuição normal (TOLEDO e OVALLE, 2008). A distribuição de Weibull representa um modelo adequado para uma lei de falhas, sempre que o sistema for composto de vários componentes e a falha seja essencialmente devida à "mais grave" imperfeição ou irregularidade dentre um grande número de imperfeições do sistema. Porém, da tabela 5.4 observa-se que condições das superficies S3 e as superficies retificadas (SR) apresentam um comportamento que pode ser descrito pela distribuição normal.

Na Figura 5.34 apresentam-se as curvas de probabilidade de falha em FCR para todas as condições testadas. Os pontos foram ajustados à curva utilizando o método gráfico proposto pela norma NBR 6742 (ABNT, 1987). Observa-se da Figura 5.34 que cada condição foi descrita por uma curva de probabilidade de falha diferente, embora, existam semelhanças no desempenho em função das condições de corte empregadas. De um modo geral, as distribuições de falha das superficies estão divididas em 2 grupos. Em um primeiro grupo estão incluídas as superficies torneadas nas condições $\mathrm{S} 1$ e S2, localizadas mais à esquerda da Figura 5.34, e que foram geradas com 
a menor velocidade de corte $(60 \mathrm{~m} / \mathrm{min})$. Observa-se que o desempenho das superficies torneadas nas condições S3 e S4 (onde foi utilizada a maior velocidade de corte) ficaram mais próximos do apresentado pela superficie retificada (SR). A análise anterior pode ser complementada analisando o comportamento da durabilidade característica das superficies (parâmetro $\theta$ ) da tabela 5.4 .

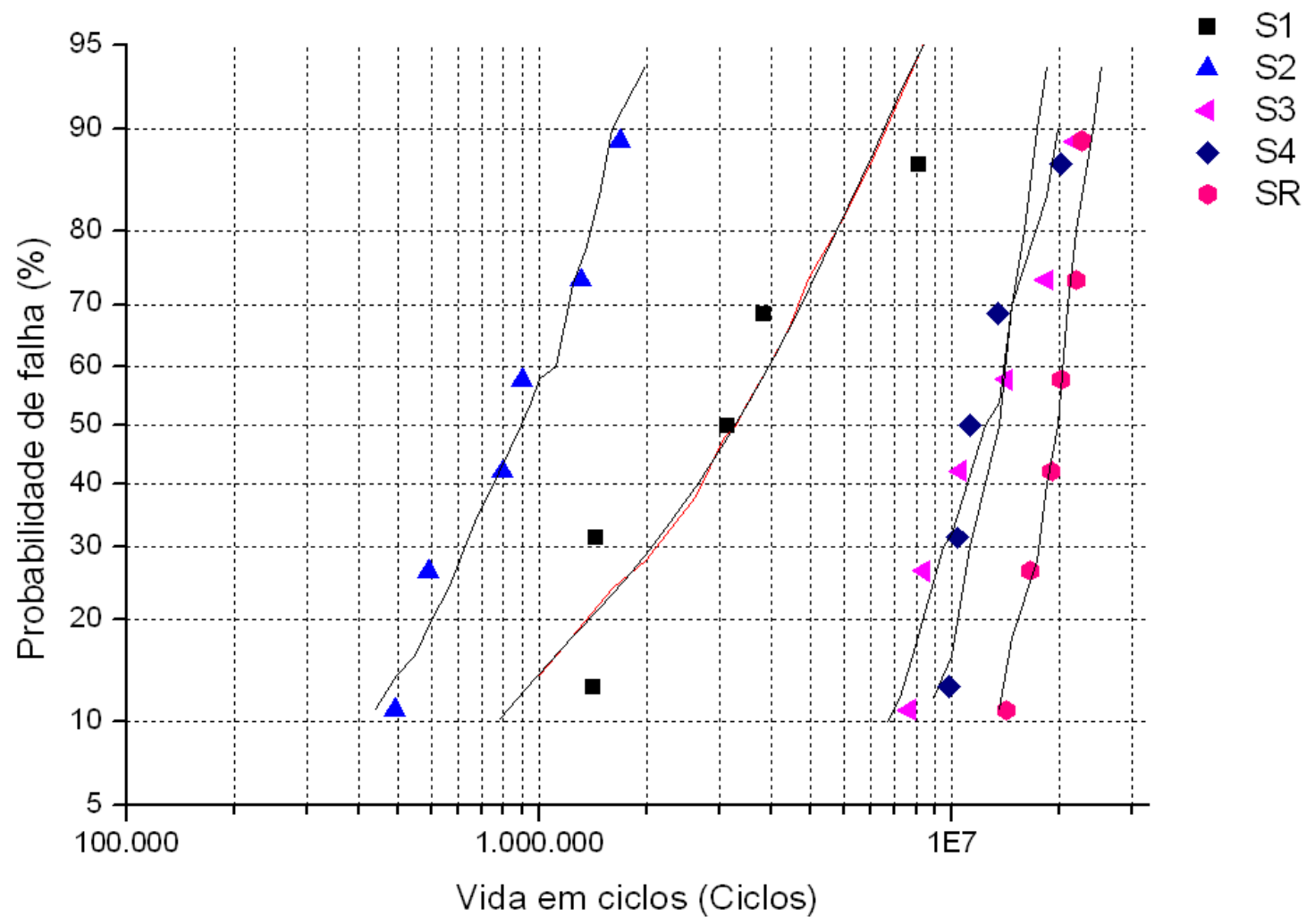

Figura 5.34 - Comparativo da vida em fadiga de contato de rolamento para as superficies torneadas e retificadas.

O valor do parâmetro $\theta$ sempre foi maior nas superficies retificadas do que nas superficies torneadas. Contudo, nas condições S3 e S4, existe uma proximidade do valor deste parâmetro com o $\theta$ observado na condição SR. A durabilidade característica $(\theta)$ é muito diferente nas superficies na condição $\mathrm{S} 1$ e S2 quando comparado com as demais condições (S3, S4, SR). Isto sugere novamente que, a velocidade de corte é o parâmetro de corte que mais influenciou no desempenho das superficies.

Ao analisar o parâmetro de inclinação $(\beta)$ da tabela 5.4 , observa-se que não existe somente uma semelhança na durabilidade das superficies retificadas e aquelas que foram fabricadas empregando uma velocidade de corte maior, mas, também existe semelhança no comportamento da taxa de falha. $O$ 
parâmetro $\beta$ da distribuição Weibull relaciona a forma como a taxa de falha cresce à medida que a vida das amostras torna-se mais longa (ASM, 1996). Assim, considerando a proximidade do valor do parâmetro $\beta$ na superficie gerada com na condição S3 $(4,7)$ e nas superficies retificadas SR $(5,0)$, pode-se supor que nestas superfícies o lascamento obedeceu a padrões semelhantes com relação à distribuição dos tempos de vida até a nucleação dos defeitos, podendo ser descritos pela distribuição normal.

Para as superficies S1 e S2 observando os menores valores do parâmetro $\beta$, a menor inclinação na curva de probabilidade de falha sugere que a taxa de falha é maior para essas condições. Isso pode estar relacionado o surgimento das trincas no início do ensaio, causado por algum fator que facilitou a nucleação dos defeitos próximos da superficie. Os principais fatores concentradores na superficie que facilitam a falha por fadiga de contato de rolamento são os relacionados à topografia (marcas de usinagem, riscos, indentações) e à tensão residual trativa próxima da superficie (ASM, 1996).

Ao observar a tabela 5.4 vale a pena ressaltar que, as condições geradas com maior velocidade de corte (S3, S4) mesmo apresentando os melhores desempenhos das superficies obtidas pelo processo de torneamento, tiveram um desempenho em vida em fadiga mais disperso. Este comportamento é esperado, já que o fenômeno de fadiga de contato está influenciado por uma ampla série de fatores (Figura 1.15). De outro modo, o comportamento em FC apresentado pelas superficies torneadas em baixa velocidade sugere que houve um fator de promoveu a concentração dos lascamentos nestas superficies nas amostras com menos ciclagem de vida.

\subsubsection{Desempenho da superfície em fadiga de contato e ruído magnético de Barkhausen}

A seguir é apresentada uma série de Figuras (5.35 a 5.39) onde será analisado o comportamento do RMB em função do desempenho em FC. No

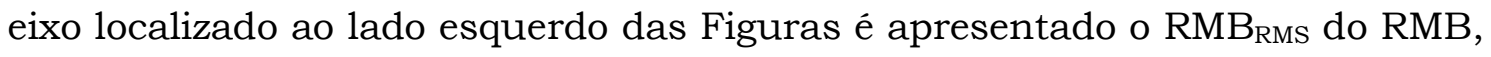
e do lado oposto, apresenta-se a vida em ciclos correspondente. 


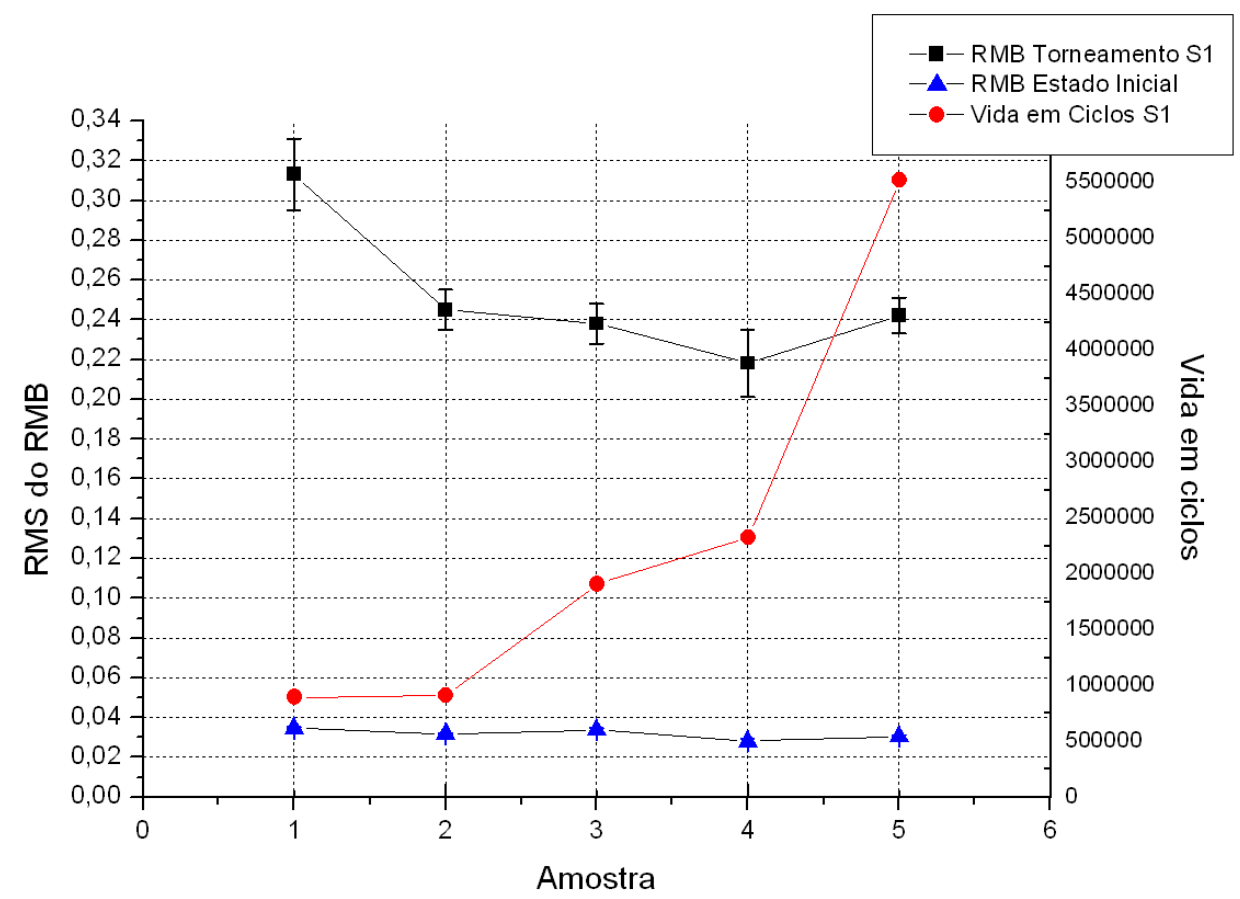

Figura 5.35 - Comparativo da vida em fadiga de contato de rolamento e o RMB $\mathrm{RMS}_{\text {do }}$ RMB para as superficies torneadas na condição S1. As superficies no estado inicial são apresentadas como ponto de referência. As amostras indicadas de 1 a 5 correspondem às 10, 12, 13, 17 e 11 torneadas, respectivamente (Figura 5.33).

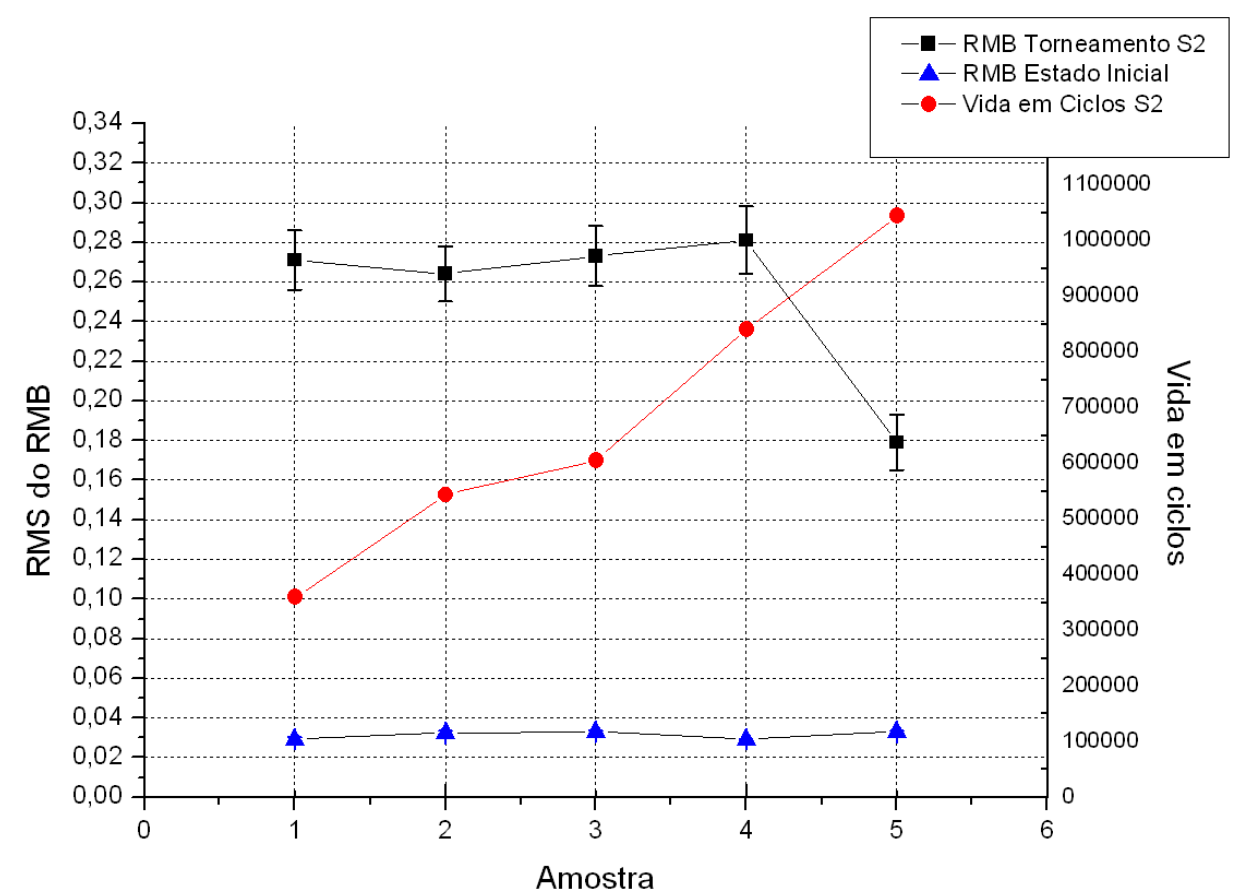

Figura 5.36 - Comparativo da vida em fadiga de contato de rolamento e o RMB $\mathrm{RMS}_{\text {do }}$ RMB para as superficies torneadas na condição S2. . As superficies no estado inicial são apresentadas como ponto de referência. As amostras indicadas de 1 a 5 correspondem às 1, 3, 15, 20 e 8 torneadas, respectivamente (Figura 5.33). 


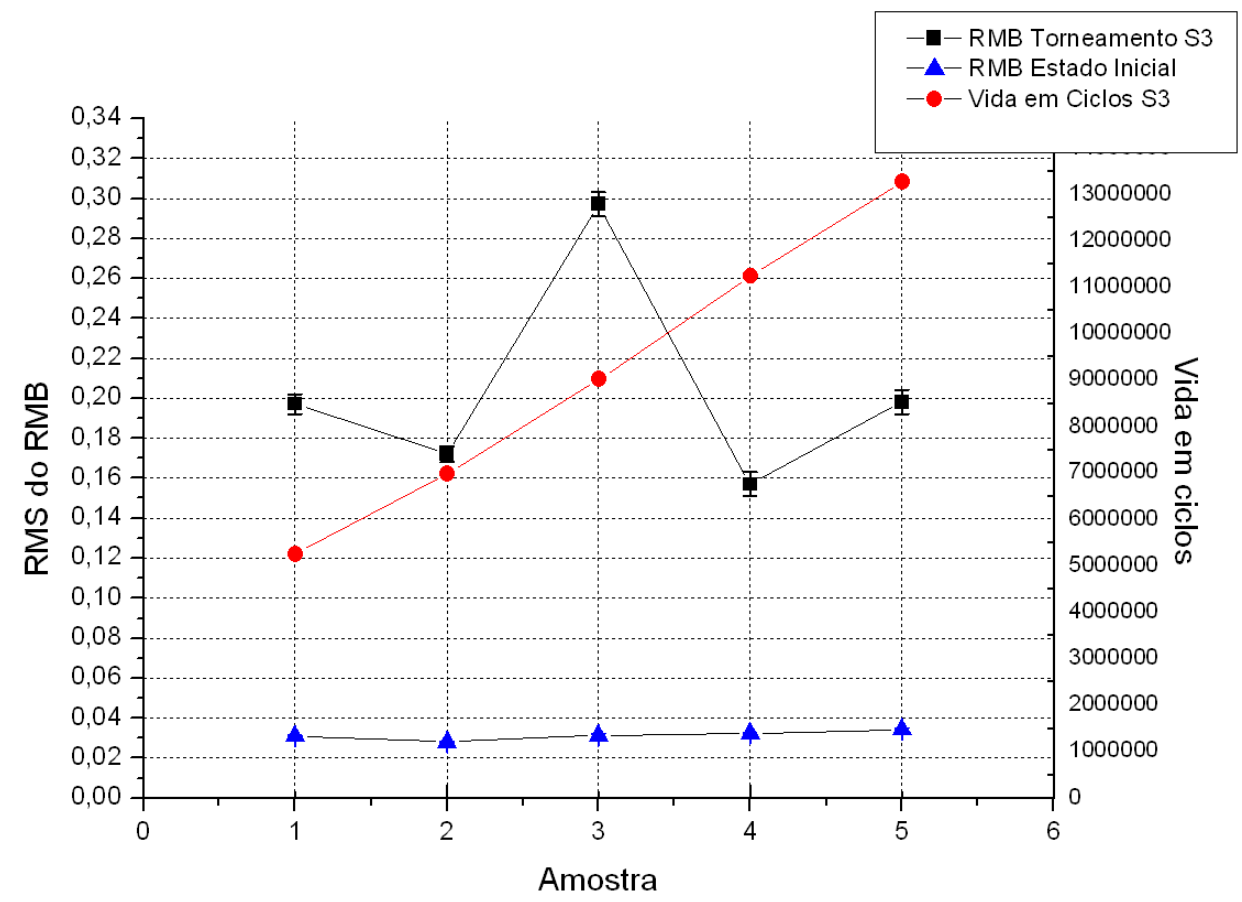

Figura 5.37 - Comparativo da vida em fadiga de contato de rolamento e o RMB $\mathrm{RMS}_{\text {do }}$ RMB para as superficies torneadas na condição S3. . As superficies no estado inicial são apresentadas como ponto de referência. As amostras indicadas de 1 a 5 correspondem às 5, 7, 9, 14 e 16 torneadas, respectivamente (Figura 5.31).

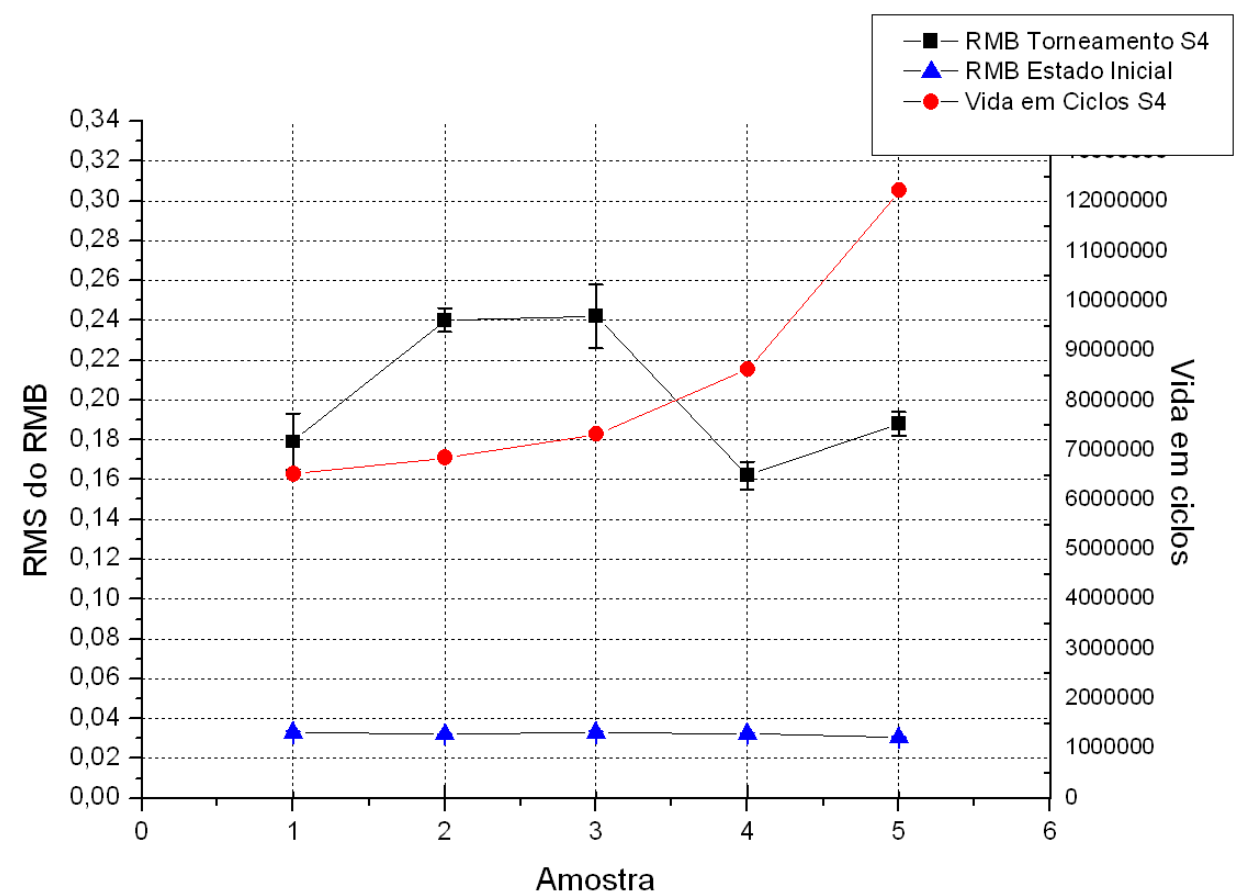

Figura 5.38 - Comparativo da vida em fadiga de contato de rolamento e o RMB $\mathrm{RMS}_{\text {do }}$ RMB para as superficies torneadas na condição S4. As superficies no estado inicial são apresentadas como ponto de referência. As amostras indicadas de 1 a 5 correspondem às 2, 4, 6, 18 e 19 torneadas, respectivamente (Figura 5.33). 


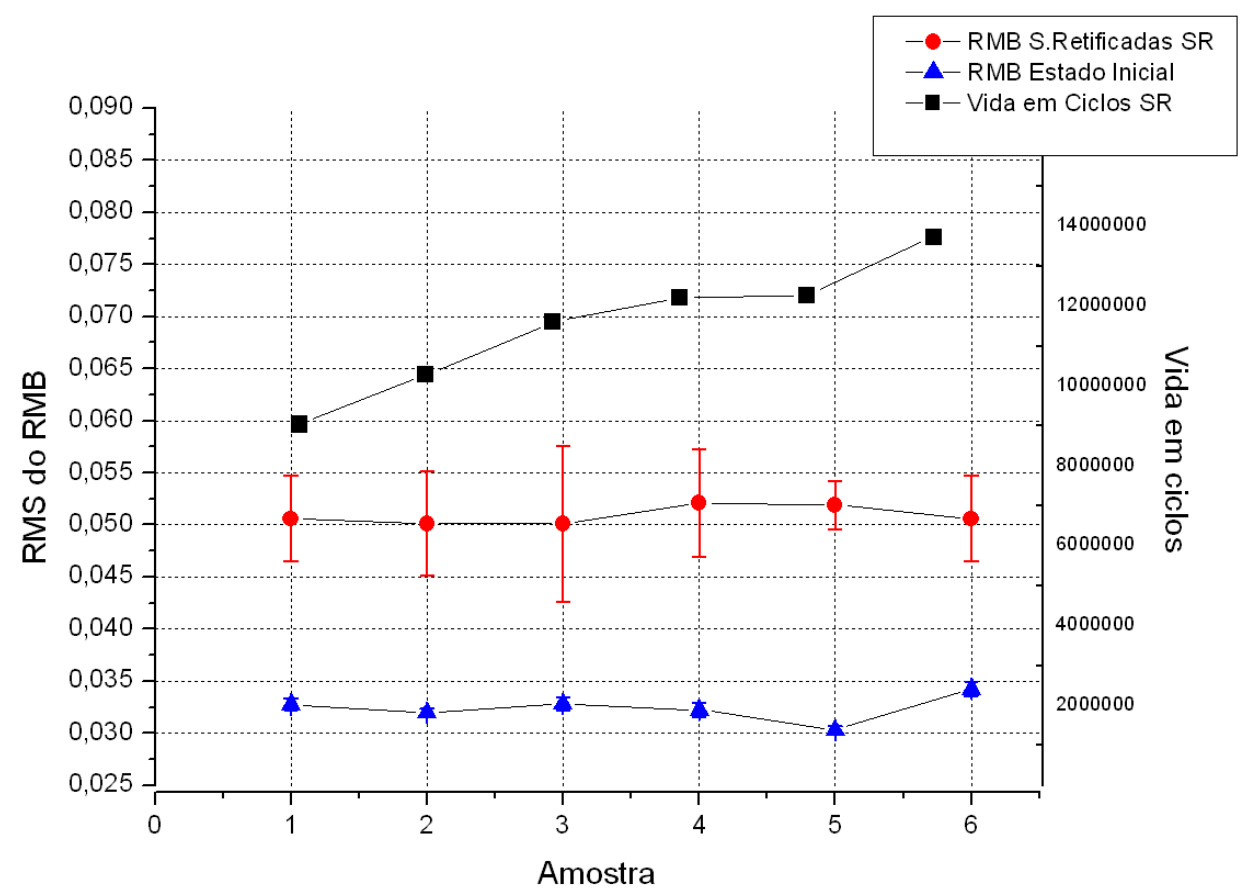

Figura 5.39 - Comparativo da vida em fadiga de contato de rolamento e o RMB $\mathrm{RMS}_{\text {do }}$ RMB para as superficies retificadas na condição SR. As superficies no estado inicial são apresentadas como ponto de referência.

Observa-se no conjunto de Figuras 5.35 a 5.39 que a variação da vida em FC para todas as amostras ensaiadas não apresenta um padrão de variação do $\mathrm{RMB}_{\mathrm{RMS}}$ do RMB nas superficies torneadas. Como apresentado na Figura 5.40, os corpos de prova retificados apresentaram a mesma amplitude $\mathrm{RMB}_{\mathrm{RMS}}$ do RMB quando a vida em FC aumentou nos corpos de prova. Isso sugere que com a técnica de medição e de análise dados empregadas (RMB $B_{R M S}$ do RMB) não existe uma aparente correlação entre o valor $\mathrm{RMB}_{\mathrm{RMS}}$ e a vida em FC para cada uma das superficies estudadas. Contudo, para as amostras retificadas, a amplitude $\mathrm{RMB}_{\mathrm{RMS}}$ do RMB média das amostras oscilou perto de 0,05 V, e a maior parte as amostras apresentaram uma vida media próxima aos 12.000.000 ciclos. Já as superficies torneadas tiveram mais variação do valor do $\mathrm{RMB}_{\mathrm{RMS}}$ com relação à vida em $\mathrm{FC}$, o que também condiz com uma maior aleatoriedade das características da superficie próprias dos componentes gerados a partir do processo de torneamento quando comparados com o processo de retificação (HASHIMOTO et al; 2006; GUO e WARREN, 2008; GUO et al; 2010).

O resumo dos resultados apresentados nas Figuras 5.35 a 5.39 é sumarizado na Figura 5.40., que para efeitos de comparação, os conjuntos de dados serão aproximados à distribuição normal. Observa-se claramente a 
dependência do desempenho da superficie e do nível do nível de RMB com o processo mediante o qual foi gerada a superficie. As superficies com o maior RMB apresentaram o menor desempenho (torneadas utilizando a menor velocidade de corte), e de maneira oposta, as superfícies obtidas pelo processo de retificação tiveram o melhor desempenho e menor RMB com relação ao apresentado pelas superficies torneadas.

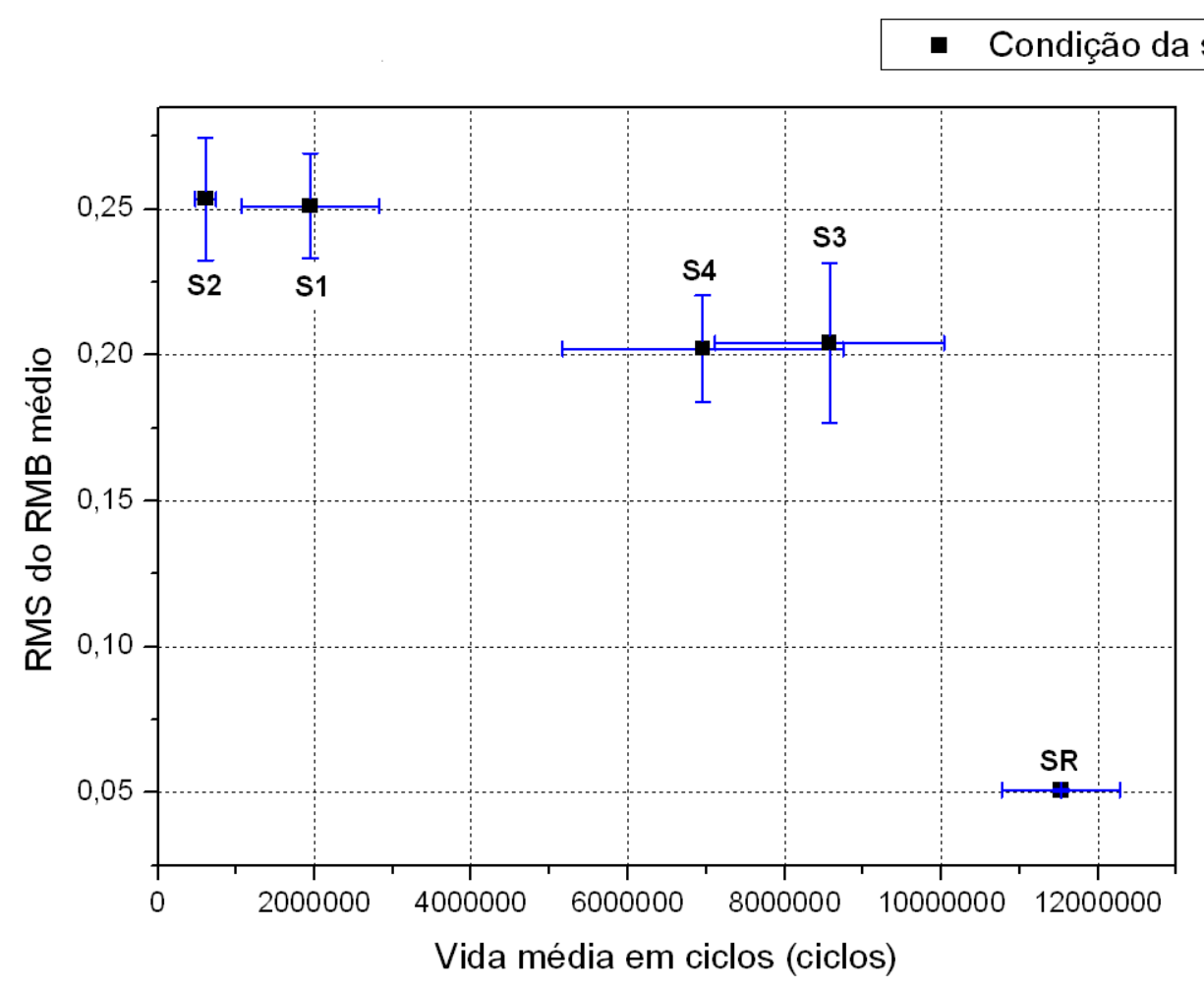

Figura 5.40 - Comparativo da vida média em fadiga de contato de rolamento contra o valor médio do RMB RMS $_{\text {do }}$ RMB para as superficies torneadas e retificadas.

\subsubsection{Caracterização do mecanismo de falha}

A seguir será feita uma descrição do mecanismo de falha de FCR a partir de imagens de MO e MEV obtidas na superficie e na seção transversal dos corpos de prova. Não obstante, como apresentado ao longo do Capitulo 2, o regime de lubrificação é um fator importante a ser considerado ao se avaliar o comportamento das superficies em contato nos sistemas lubrificados (HUTCHINGS, 1992). Por isso, inicialmente será feita uma análise do parâmetro $\lambda$ e assim determinar a condição de lubrificação para cada condição superficial estudada.

$\mathrm{Na}$ tabela 5.4 são apresentados os valores médios do parâmetro de rugosidade media quadrática $\mathrm{Rq}$, que foi avaliado em todas as superficies 
antes de serem ensaiadas. Também será apresentado o valor do parâmetro Rq para as esferas de aço ABNT 52100 que foram usadas como contra corpo no equipamento de FCR.

Tabela 5.4. Valores médios da rugosidade quadrática média Rq antes do ensaio de FCR nos corpos de prova e no contra corpo (esfera de aço AISI 52100). †Tomado de Neves (2006)

\begin{tabular}{cc}
\hline Superficie & Rq $(\mu \mathrm{m})$ \\
\hline S1 & $0,582 \pm 0,016$ \\
S2 & $0,581 \pm 0,011$ \\
S3 & $0,520 \pm 0,010$ \\
S4 & $0,645 \pm 0,040$ \\
SR & $0,352 \pm 0,006$ \\
Esfera $^{\dagger}$ & $0,080 \pm 0,005$ \\
\hline
\end{tabular}

O parâmetro $\lambda$ relaciona a espessura mínima da película lubrificante e a rugosidade superficial composta, informando assim sobre a separação das superficies do sistema lubrificado (HUTCHINGS, 1992). Este parâmetro também está relacionado com o atrito, já que dependendo do regime de lubrificação no qual se encontrem as superficies, a interação das mesmas faz com que o valor do coeficiente de atrito $(\mu)$ mude em função do parâmetro $\lambda$. Utilizando o equacionamento descrito no Capitulo 3 , é calculado o espaçamento mínimo entre superficies $\left(h_{0}\right)$. A estrutura de cálculo e algumas das informações necessárias foi extraída do trabalho de Neves (2006), já que a exceção dos materiais testados e das cargas aplicadas, a metodologia experimental nos ensaios de FC dos ensaios foi a mesma. A seguir apresentase o equacionamento e a sequência de cálculo necessários para determinar a espessura minima de lubrificante $\left(h_{0}\right)$.

$$
\begin{aligned}
& \frac{\mathrm{h}_{0}}{\mathrm{R}^{\prime}}=3,63\left(\frac{\mathrm{U} \eta_{0}}{2 \mathrm{E}^{*} \mathrm{R}^{\prime}}\right)^{0,68}\left(2 \alpha \mathrm{E}^{\prime}\right)^{0,49}\left(\frac{\mathrm{W}}{2 \mathrm{E}^{*} \mathrm{R}^{\prime 2}}\right)^{-0,073}\left(1-\mathrm{e}^{-0,68 \mathrm{k}}\right)=0,28 \mu \mathrm{m} ; \\
& \mathrm{U}=1 \mathrm{~m} / \mathrm{s} \text {, onde: } \mathrm{U}_{\mathrm{A}}=0 \text { e } \mathrm{U}_{\mathrm{B}}=2 \mathrm{~m} / \mathrm{s} ; \\
& \mathrm{R}^{\prime}=1,8495 \times 10^{-3}, \text { onde: } \mathrm{R}_{\mathrm{ax}}=\mathrm{R}_{\mathrm{ay}}=\infty ; \mathrm{R}_{\mathrm{bx}}=\mathrm{R}_{\mathrm{by}}=1 / 2\left(7,398 \times 10^{-3}\right) ; \\
& \mathrm{E}^{*}=101,19 \times 10^{9}, \text { onde: } \mathrm{E}_{\mathrm{A}}=\mathrm{E}_{\mathrm{B}}=210 \mathrm{GPa} ; \\
& \eta_{0}=0,113 \text { Pas; } \mathrm{k}=1 ; \alpha=1,9 \times 10^{-9} \mathrm{~Pa}^{-1} ; \\
& W=700 \mathrm{~N}
\end{aligned}
$$


Com este valor de ho e os valores de rugosidade contidos na tabela 5.5 é possivel determina o parâmetro $\lambda$, mediante uso da equação 12 . Na tabela 5.6 são apresentados os valores do parâmetro $\lambda$ para todas as superficies testadas.

$$
\lambda=\frac{\mathrm{h}_{0}}{\sqrt{\mathrm{R}_{\mathrm{q} 1}^{2}+\mathrm{R}_{\mathrm{q} 2}^{2}}}
$$

Tabela 5.5. Valores do parâmetro $\lambda$ nas diferentes superficies ensaiadas.

\begin{tabular}{cc}
\hline Condição da superficie & $\lambda$ \\
\hline S1 & 0,492 \\
S2 & 0,492 \\
S3 & 0,549 \\
S4 & 0,444 \\
SR & 0,799 \\
\hline
\end{tabular}

O resultado apresentado na tabela 5.5 sugere que todas as superficies ensaiadas trabalharam no regime de lubrificação limítrofe $(\lambda<1)$ (HUTCHINGS, 1992; STACHOWIAK e BATCHELOR, 2001). O valor de $\lambda$ para as superficies torneadas S1, S2 foram iguais, e ao mesmo tempo, apresentaram o menor valor do conjunto de superficies. Consequentemente, nestas superficies $(\mathrm{S} 1, \mathrm{~S} 2)$ se terá a maior interação da superfície do corpo de prova com o contra corpo (esfera de aço). Entretanto, nas superficies retificadas que estão mais próximas da condição de lubrificação mista $(1<\lambda<3)$, esta interação é menos intensa. Como apresentado no capítulo 3, na lubrificação limítrofe existe maior interação entre as superfícies (HUTCHINGS, 1992; STACHOWIAK e BATCHELOR, 2001), isto faz com que as falhas dos materiais submetidos à FCR aconteçam mais próximas da superficie (NEVES, 2006).

Contudo, a rugosidade das superficies tende a diminuir ao longo do ensaio na medida em que como consequência do carregamento cíclico exercido pelo contra corpo, a superficie do material localizado na trilha de rolamento começa a se deformar e desgastar (NEVES, 2006). Este comportamento está relacionado com os resultados das análises do parâmetro de inclinação $\beta$ da distribuição de Weibull feitas no item 5.2.1. Em função disso, espera-se que as superficies que apresentam os menores valores de $\lambda(\mathrm{S} 1, \mathrm{~S} 2, \mathrm{~S} 4)$ também possuam o menor valor de inclinação $\beta$ (S1, S2, S4). Na Tabela 5.6 mostramse os valores do parâmetro $\lambda$ em termos da inclinação de Weibull ( $\beta$ ) para superficies ensaiadas. 
Tabela 5.6. Valores do parâmetro $\lambda$ e da inclinação de Weibull ( $\beta$ ) das superfícies ensaiadas nas diferentes condições

\begin{tabular}{ccc}
\hline Condição & $\lambda$ & $\beta$ \\
\hline S1 & 0,492 & 1,4 \\
S2 & 0,492 & 2,0 \\
S3 & 0,549 & 4,7 \\
S4 & 0,444 & 3,3 \\
SR & 0,799 & 5,0 \\
\hline
\end{tabular}

$\mathrm{Na}$ tabela 5.6 observa-se que o valor do parâmetro $\lambda$ acompanha o comportamento do parâmetro de inclinação de Weibull para todas as superficies. Este resultado reforça a hipótese que nas superfícies S1 e S2 o baixo desempenho em FC foi promovido pelas características da superficie na camada superficial. Já nas outras condições (S3 e SR), o maior valor do parâmetro $\lambda$ indica que nestas superficies uma melhor condição de lubrificação fez com que a superficie trabalhasse em condições de contato mais favoráveis nos primeiros ciclos de vida (devido à presença de uma camada mais espessa de lubrificante no contato). Esta condição se manteve até que, como consequência de um tempo de vida mais longo das superfícies, o desgaste e a deformação da superfície levaram à diminuição gradativa da rugosidade. Nas superficies que tiveram ciclos de vida mais curtos (S1, S2), este comportamento não se apresentou e a taxa de falha foi maior (como informado pelo parâmetro $\beta$ ). Na Figura 5.41 observa-se graficamente a semelhança no comportamento do parâmetro $\lambda$ e da inclinação de Weibull ( $\beta$ ) nas superficies ensaiadas.

Na Figura 5.42 é apresentada uma imagem da superficie do corpo de prova número 15 que corresponde à condição $\mathrm{S} 1$ (Vc $60 \mathrm{~m} / \mathrm{min}$, f 0,05 mm/rev), e onde se mostra o lascamento da superficie gerado após 1.261 .071 ciclos de carregamento (8.400,00 rotações do eixo do equipamento de FCR). Ao observar o aspecto superficial do defeito, e como indicado pelas setas vermelhas, percebe-se que existe uma clara relação entre a topografia da superficie e o padrão de nucleação e propagação da falha. Isto em função das marcas da ferramenta agirem como concentradores de tensão superficial (ASM, 1996; NEVES, 2006). 


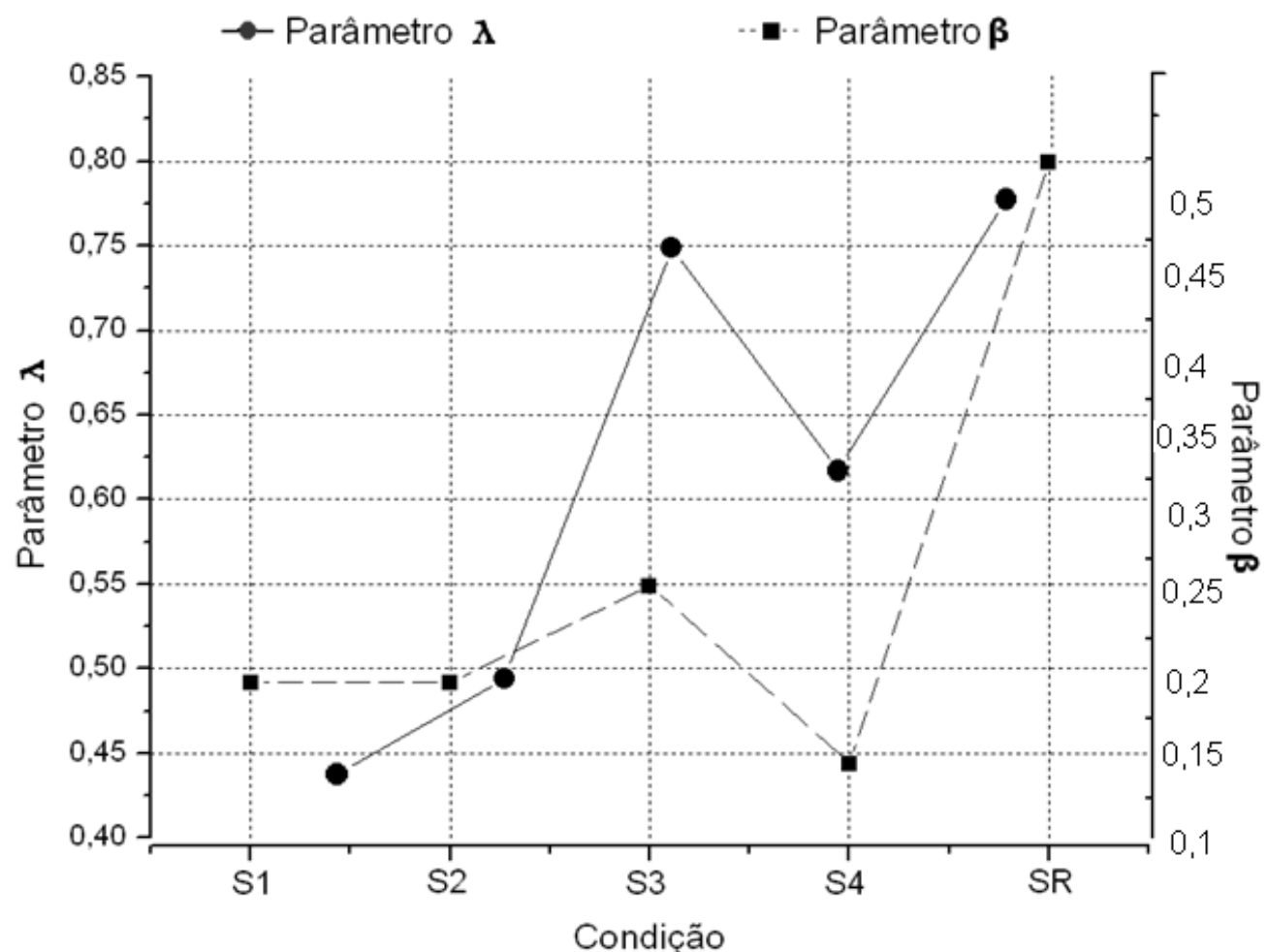

Figura 5.41. Comparação do comportamento do parâmetro $\lambda$ e da inclinação de Weibull ( $\beta$ ) para as superfícies ensaiadas.

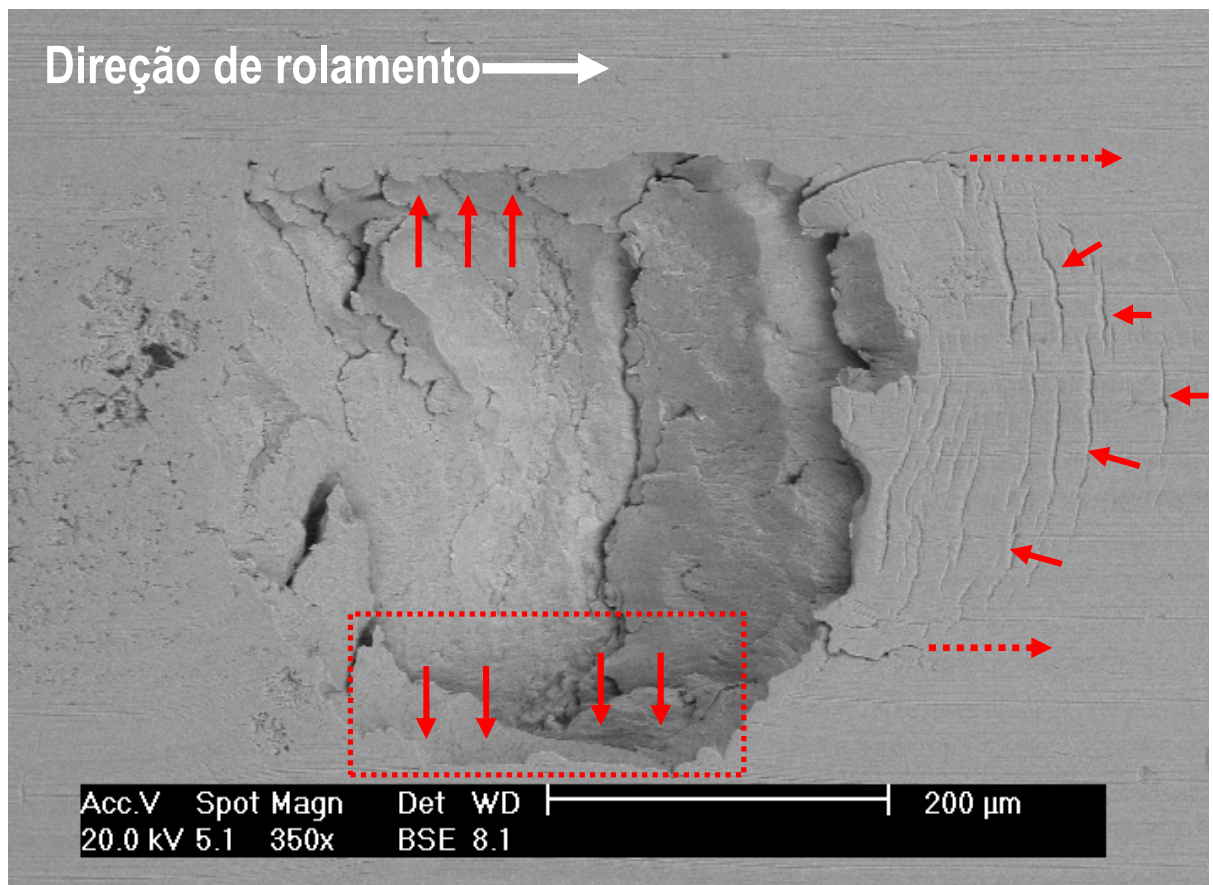

Figura 5.42. Imagem da superficie do corpo de prova No 15 (condição S1) (Vc 60 $\mathrm{m} / \mathrm{min}$, f 0,05 mm/rev). Imagem obtida em MEV com aumento de 350x. Análise de elétrons retroespalhados.

Observam-se uma série de trincas semicirculares na frente do lascamento (linhas vermelhas pontilhadas), as quais estão orientadas perpendicularmente ao sentido de rolamento das esferas (e às marcas de ferramenta). Este padrão 
de trinca é devido à resposta do material ao campo de tensões próprias do contato em FCR, onde altas tensões de cisalhamento cíclicas são geradas durante os movimentos de rolamento e uma parcela de escorregamento do contra corpo, acrescido pela perda de resistência de material já (ver Figura 1.14). Igualmente, observa-se que como indicado pelas setas pontilhadas, existem duas trincas nucleadas desde a borda do defeito. Se o ensaio não tivesse sido interrompido após sistema instrumentado detectar o lascamento, as trincas iam-se propagar como resultado do dano já induzido numa camada de material.

Na Figura 5.43 observa-se uma ampliação de uma região da Figura 5.42 (delimitada pela linha vermelha pontilhada), onde se observa que a fratura do material arrancado durante o lascamento acompanha o padrão da topografia. Salienta-se que mesmo depois da superficie ser submetida a 1.261.071 ciclos de carregamento, alguns detalhes da topografia (marcas de usinagem) decorrentes do processo de torneamento ainda continuam presentes na superficie da trilha de rolamento.

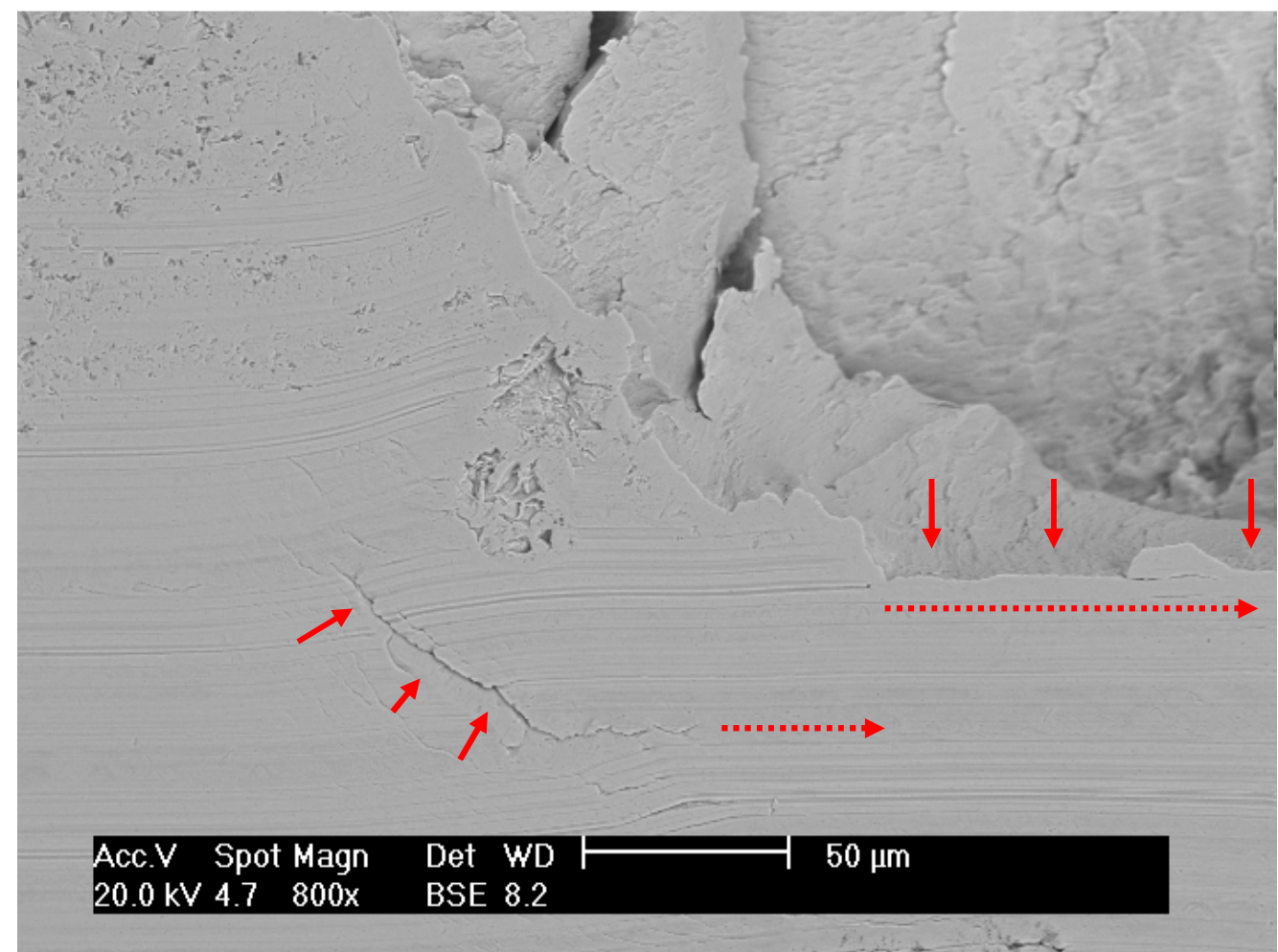

Figura 5.43. Imagem da superficie do corpo de prova No 15 (S1) (Vc $60 \mathrm{~m} / \mathrm{min}$, f 0,05 $\mathrm{mm} / \mathrm{rev}$ ), ampliando um detalhe da Fig. 5.42 onde se mostra o padrão de fratura do defeito seguindo a direção das marcas da ferramenta. Imagem obtida em MEV com aumento de 800x. Análise de elétrons retroespalhados. 
$\mathrm{Na}$ Figura 5.44 é apresentada uma imagem do lascamento originado na superfície do corpo de prova número $11 \mathrm{~T}$, na condição torneada S2. Observase que como indicado pelas setas vermelhas, a fratura em algumas regiões da borda do defeito adota um padrão geométrico regular, seguindo a direção das marcas da ferramenta. O lascamento ocorreu quando tinham decorrido 370.276 ciclos. Em função desta falha acontecer num número reduzido de ciclos com relação às demais amostras, as marcas da ferramenta ainda estão bem definidas na trilha de rolamento.

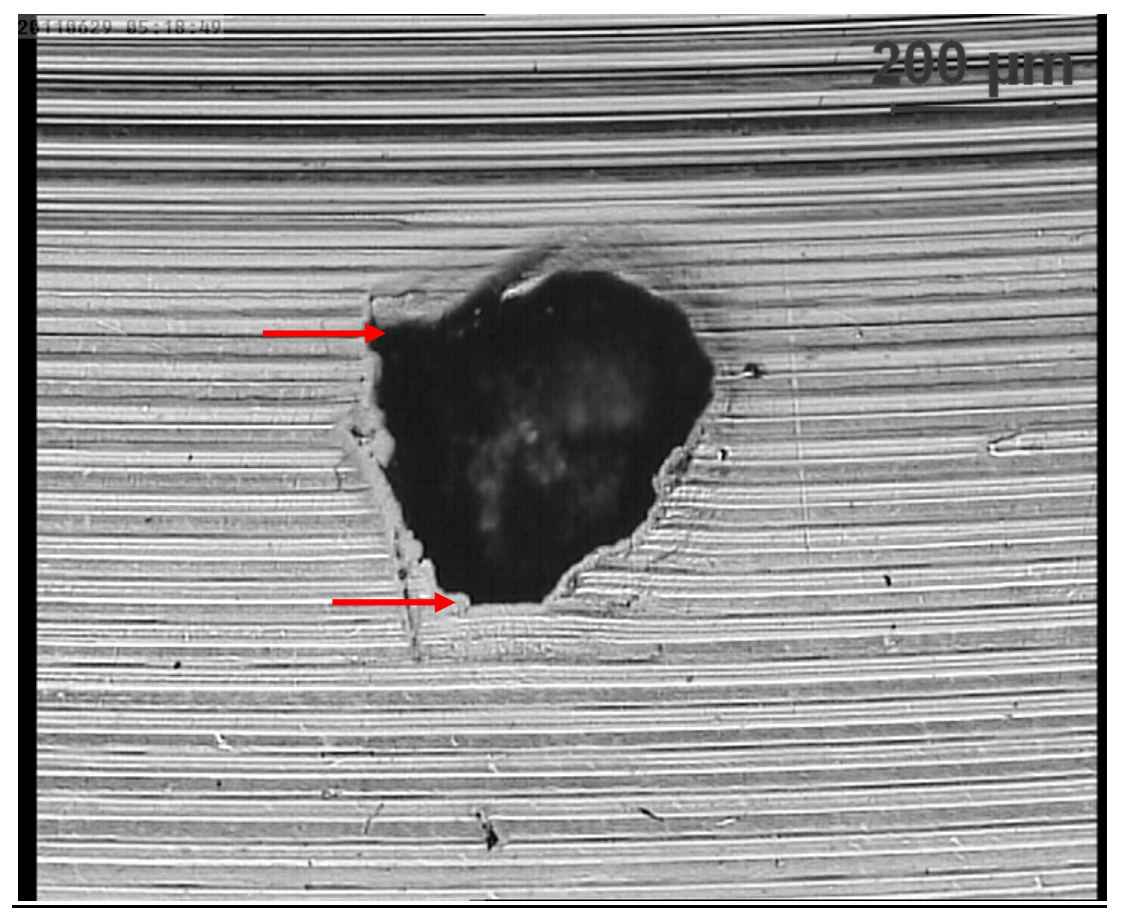

Figura 5.44. Imagem da superficie do corpo de prova No 11 (S1) (Vc $60 \mathrm{~m} / \mathrm{min}, \mathrm{f}$ 0,05 $\mathrm{mm} / \mathrm{rev}$ ). Imagem obtida em MO com aumento de 100x.

Na Figura 5.45 apresenta-se o defeito gerado na amostra 8, que corresponde à condição S3 (Vc $120 \mathrm{~m} / \mathrm{min}$, f 0,05 mm/rev). Esta amostra teve uma vida de 1.0279.314 ciclos, e se observa que a fratura da lasca de material ocorreu em regiões próximas dos sulcos descritos pelas marcas da ferramenta (como indicado pelas linhas pontilhadas). 


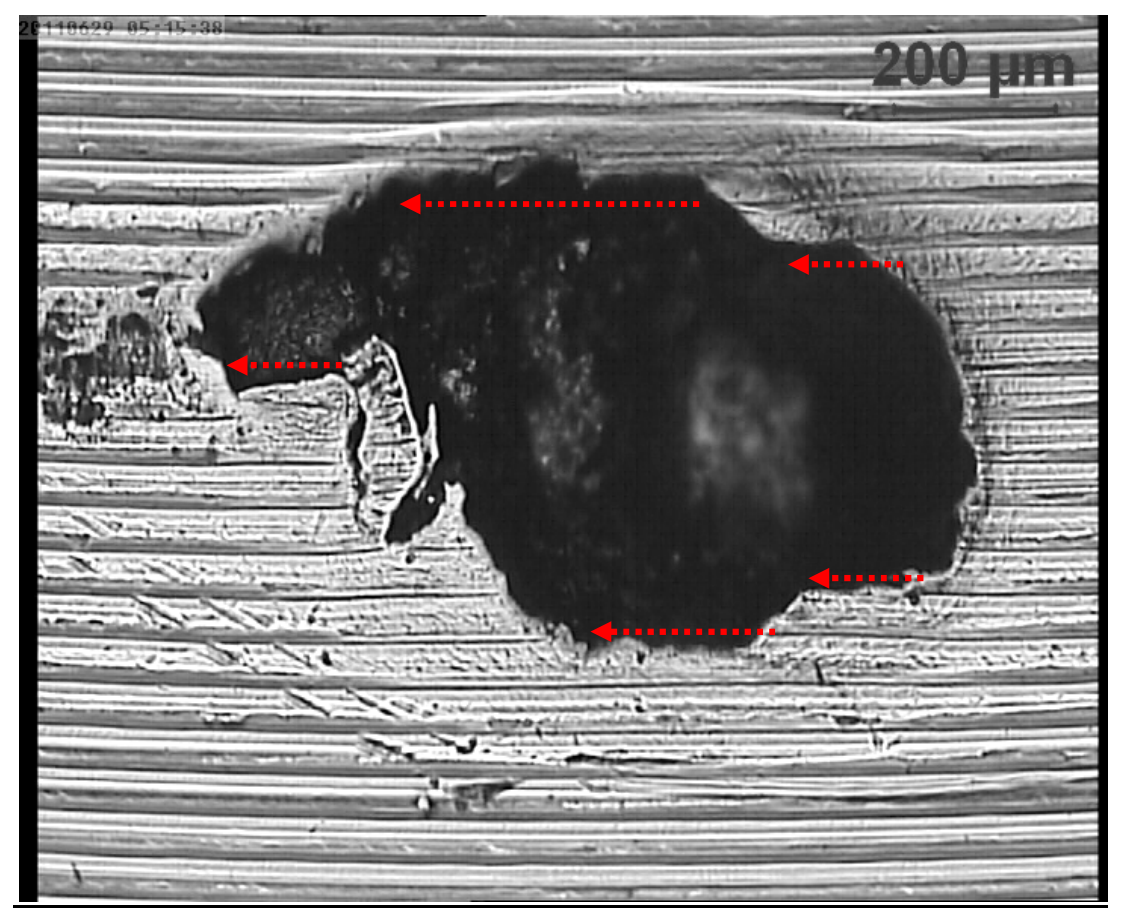

Figura 5.45. Imagem da superficie do corpo de prova No 8 (S3) (Vc $120 \mathrm{~m} / \mathrm{min}$, f 0,05 $\mathrm{mm} / \mathrm{rev}$ ). Imagem obtida em MO com aumento de 100x.

Mostra-se na Figura 5.46 o defeito gerado na amostra 14, que corresponde à condição S3 (Vc $120 \mathrm{~m} / \mathrm{min}$, f 0,05 mm/rev). Esta amostra teve uma vida de 18.353.467 ciclos. As marcas da ferramenta são quase imperceptíveis como resultado do desgaste promovido pelo alto número de ciclos de carregamento. Com isso, a fratura de material não acompanha o padrão descrito pelas marcas da ferramenta, comportamento aparentemente característico das superficies com baixo desempenho tribologico.

Na Figura 5.47 é apresentada uma imagem do lascamento originado na superficie do corpo de prova número 15, na condição retificada (SR). A superficie do corpo de prova teve uma vida em FC de 19'956.970 ciclos. É possivel observar da Figura 5.47 que na trilha de rolamento as marcas decorrentes do processo de retificação estão quase imperceptíveis após o desgaste de rolamento. Contudo, o aspecto da fratura em algumas regiões do defeito parece acompanhar a geometria das marcas deixadas pelos grãos abrasivos durante o processo de retificação. 


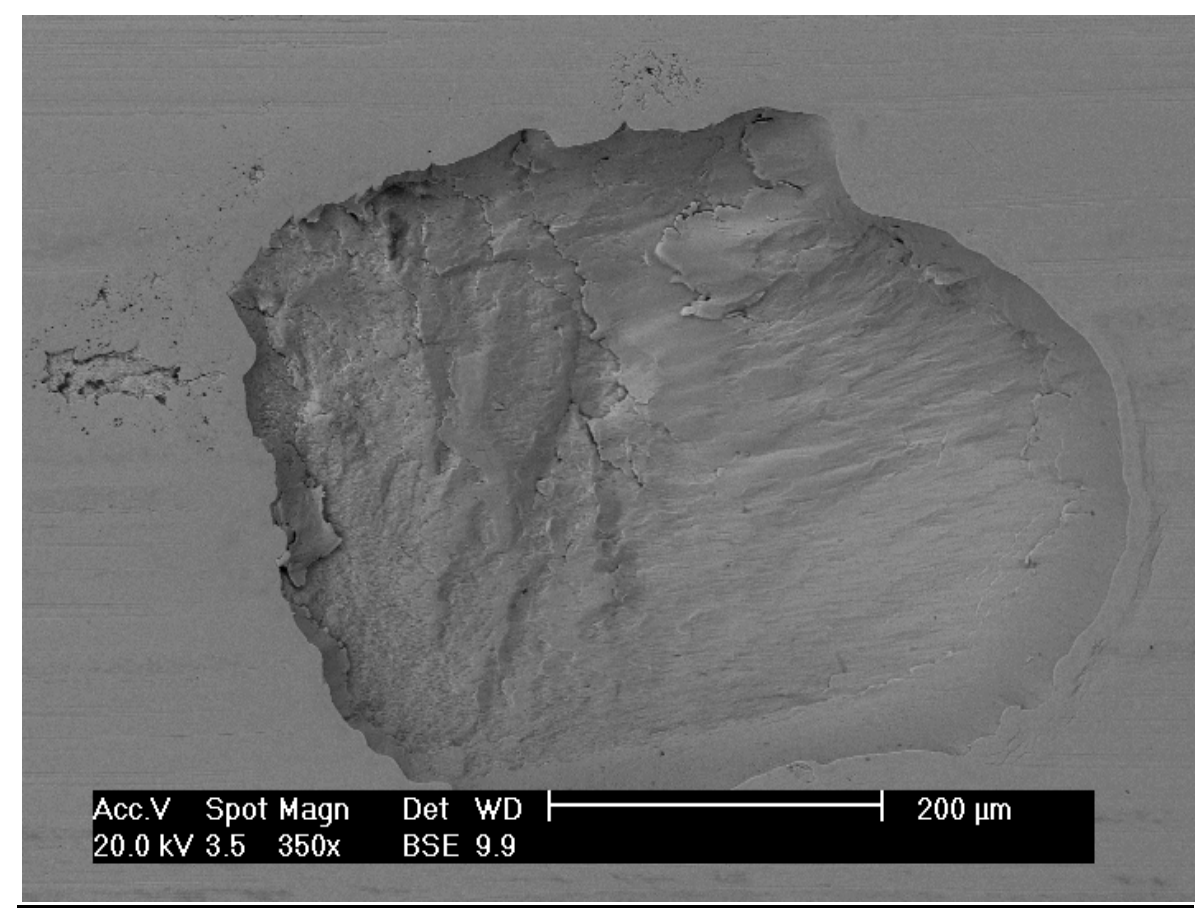

Figura 5.46. Imagem da superficie do corpo de prova No 14 (S3) (Vc $120 \mathrm{~m} / \mathrm{min}$, f 0,05 $\mathrm{mm} / \mathrm{rev}$ ). Imagem obtida em MEV com aumento de 350x. Análise de elétrons retroespalhados.

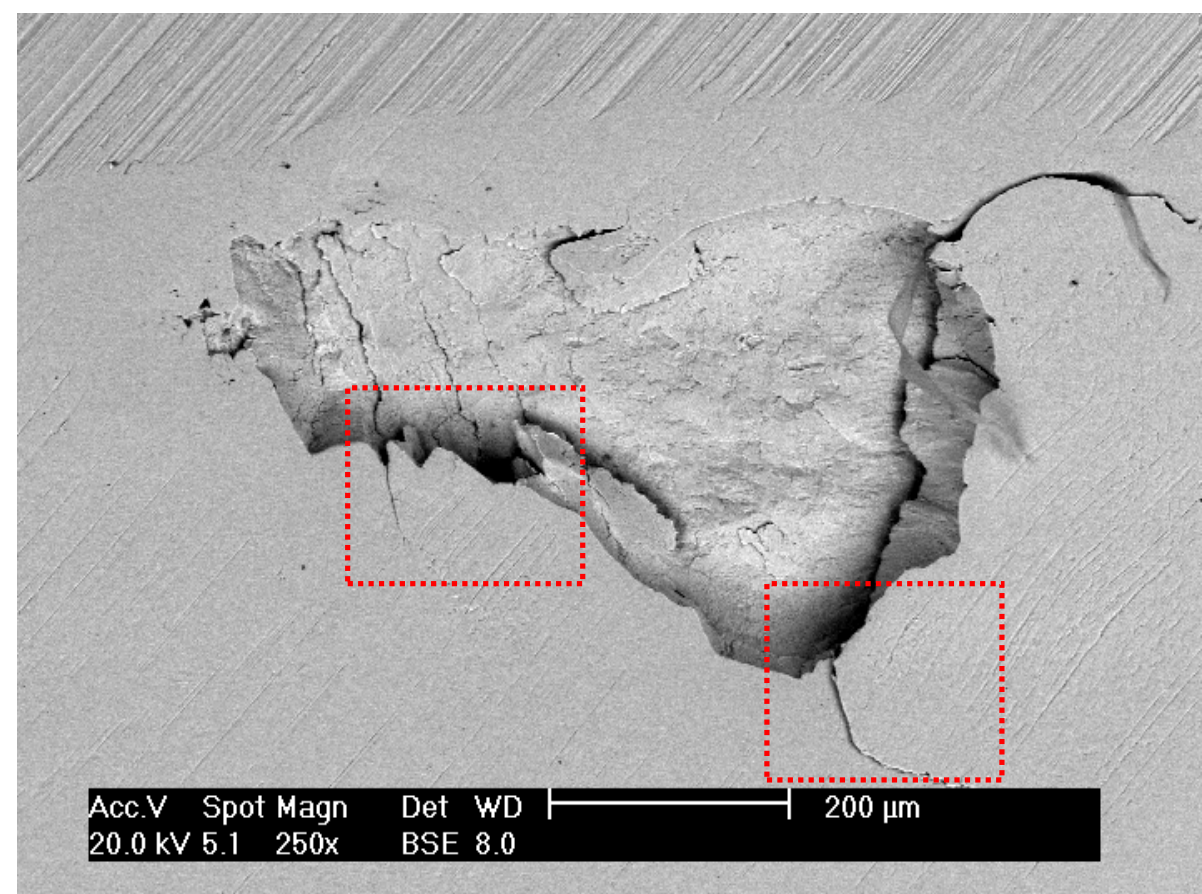

Figura 5.47. Imagem da superficie do corpo de prova No 15, (Condição SR) ( $\mathrm{v}_{\mathrm{c}} 54 \mathrm{~m} / \mathrm{s}$, $\mathrm{v}_{\mathrm{p}} 4 \mathrm{~m} / \mathrm{min}, \mathrm{a}_{\mathrm{e}}$ 0,03 mm). Imagem obtida em MEV com aumento de 250x Análise de elétrons retroespalhados.

Na Figura 5.48 apresenta-se um detalhe ressaltado no quadro inferior de cor vermelho da Figura 5.47, onde se observa que a borda do defeito se encontra direcionada no sentido das marcas do processo de usinagem. 


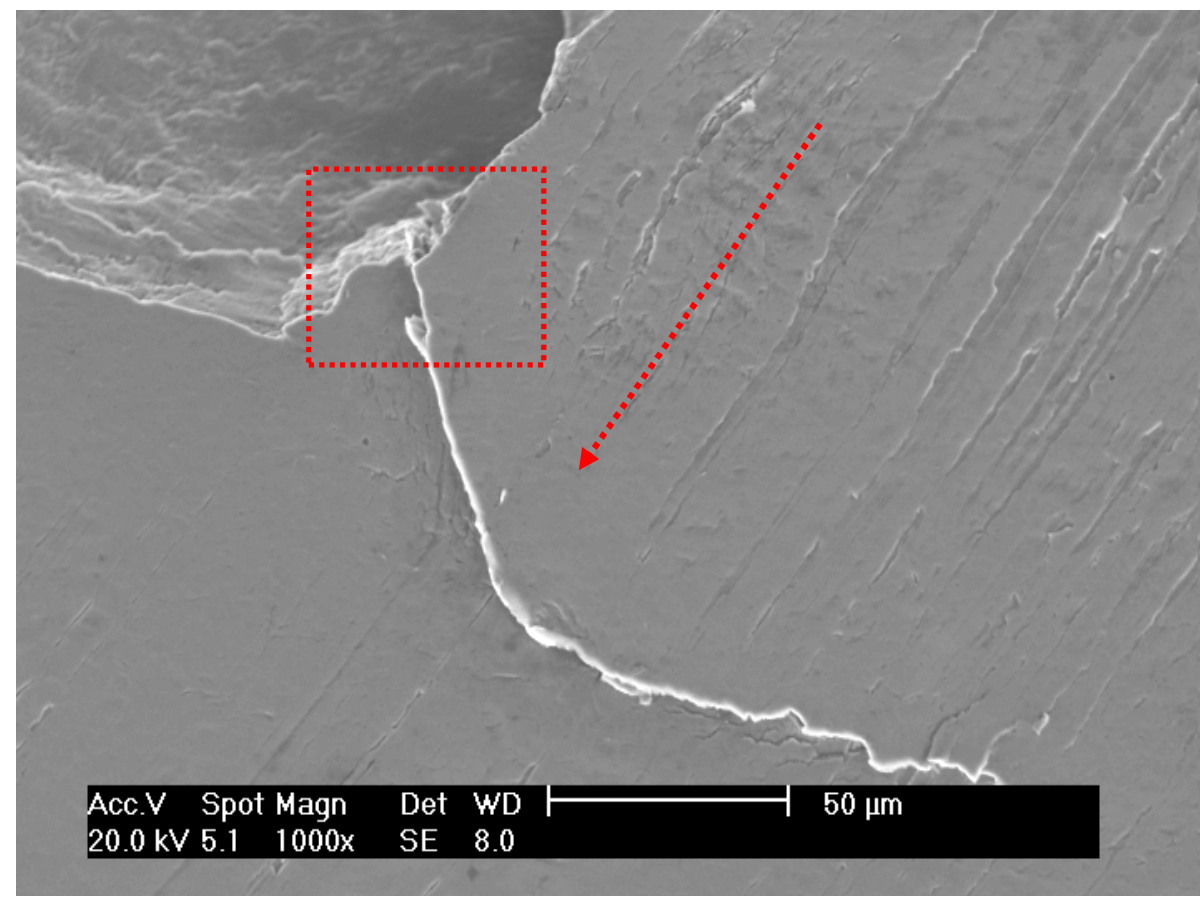

Figura 5.48. Imagem da superficie do corpo de prova No 15 (SR), ampliando um detalhe da Fig. 5.47. Imagem obtida em MEV com aumento de 1000x. Análise de elétrons secundários

Na Figura 5.49 apresenta-se um detalhe ressaltado no requadro indicado na Figura 5.48, onde se observa com mais detalhamento o padrão descrito pelo arrancamento do material.

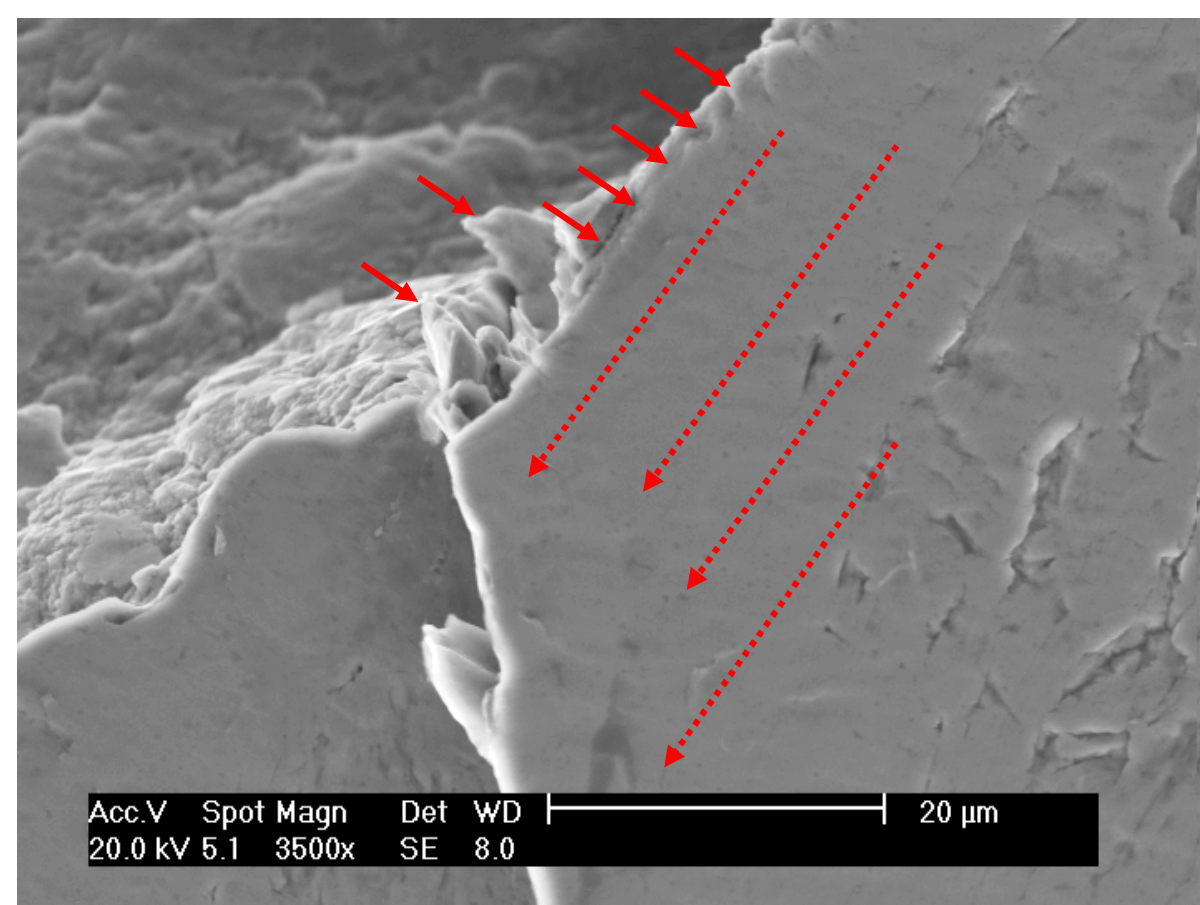

Figura 5.49. Imagem da superficie do corpo de prova No 15 (SR), ampliando um detalhe da Fig. 5.48. Imagem obtida em MEV com aumento de 3500x. Análise de elétrons secundários 
Como apontado pelas setas vermelhas de linha continua, observam-se alguns pontos na borda do defeito onde ocorreu o cisalhamento do material.

Na Figura 5.50 apresenta-se um detalhe ressaltado no requadro vermelho superior indicado na Figura 5.47. Observa-se que como indicado pela linha vermelha, ainda com o elevado numero de ciclos de carregamento ao qual foi submetido a superficie, a fratura tende a acompanhar os padrões da topografia.

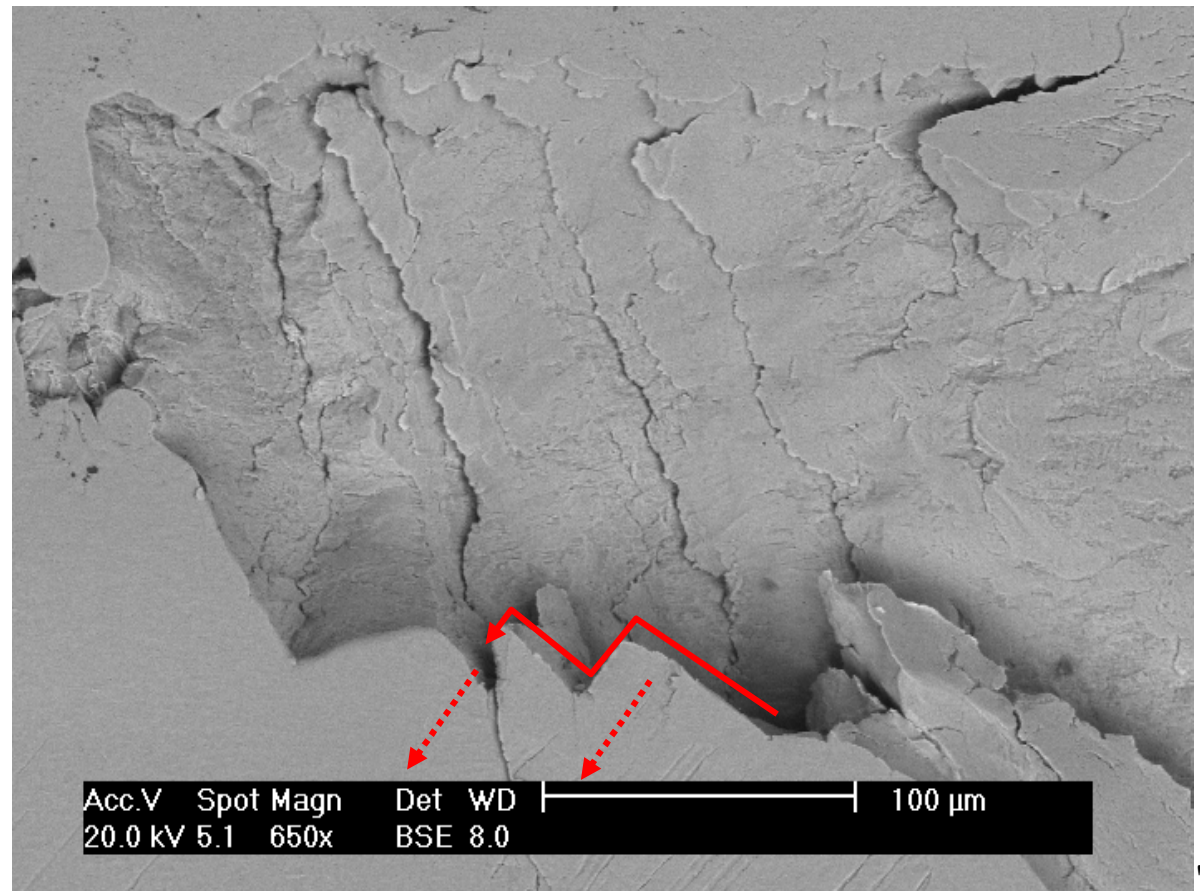

Figura 5.50. Imagem da superficie do corpo de prova No 15 (SR), ampliando um detalhe da Fig. 5.47. Imagem obtida em MEV com aumento de 650x. Análise de elétrons retroespalhados.

Nas Figuras 5.51 e 5.52 observa-se o aspecto da falha gerada na superficie dos corpos de prova 2 e 6 , que foram gerados na condição de retificação (SR). A amostra 2 teve uma vida de 13.552.156 ciclos, e a amostra $17,15.433 .570$ ciclos. Nestas Figuras pode-se observar que as marcas deixadas pelo processo de retificação ainda estão bem definidas em algumas regiões da trilha de rolamento. Observa-se claramente que a fratura acompanha os sulcos decorrentes da retificação. 


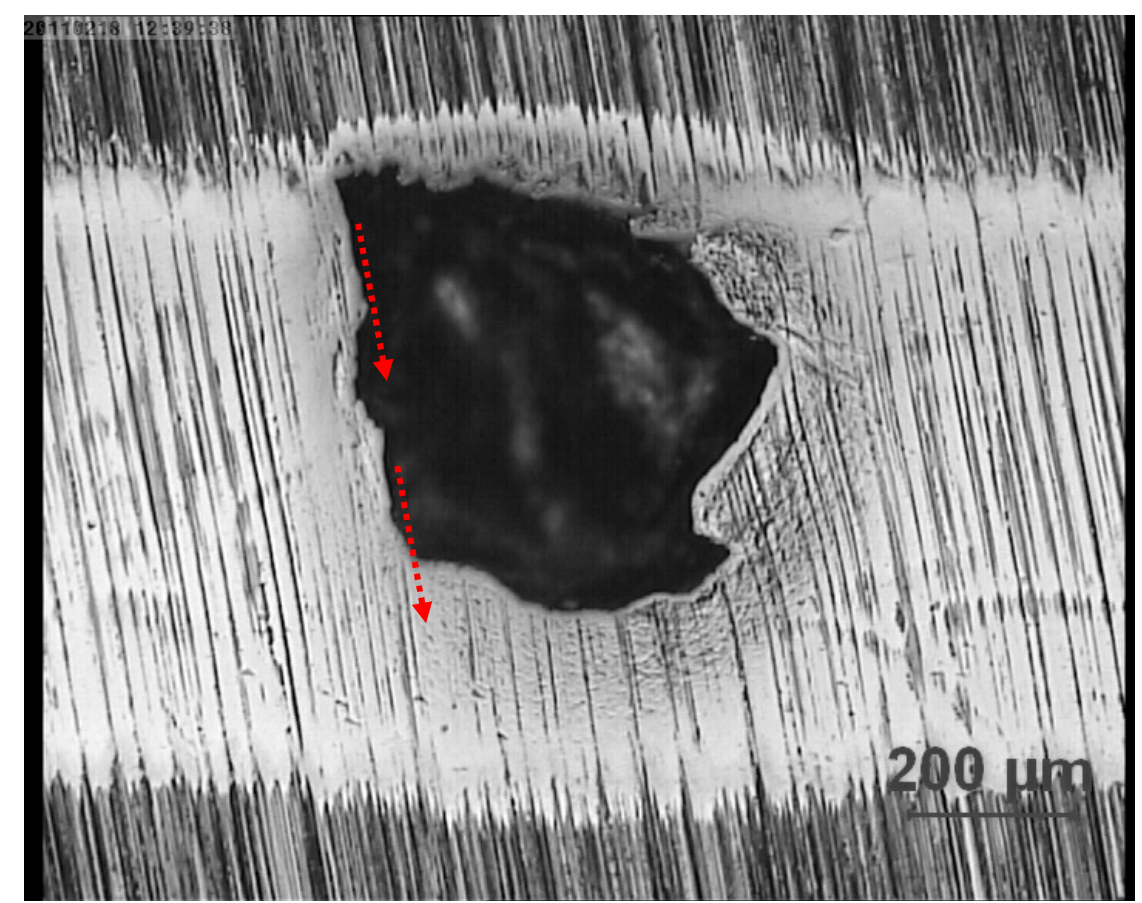

Figura 5.51. Imagem da superficie do corpo de prova No 2 (SR) $\mathrm{v}_{\mathrm{c}} 54 \mathrm{~m} / \mathrm{s}, \mathrm{v}_{\mathrm{p}} 4 \mathrm{~m} / \mathrm{min}$, $\mathrm{a}_{\mathrm{e}}$ 0,03 $\mathrm{mm}$ ). Imagem obtida em MO com aumento de 100x.

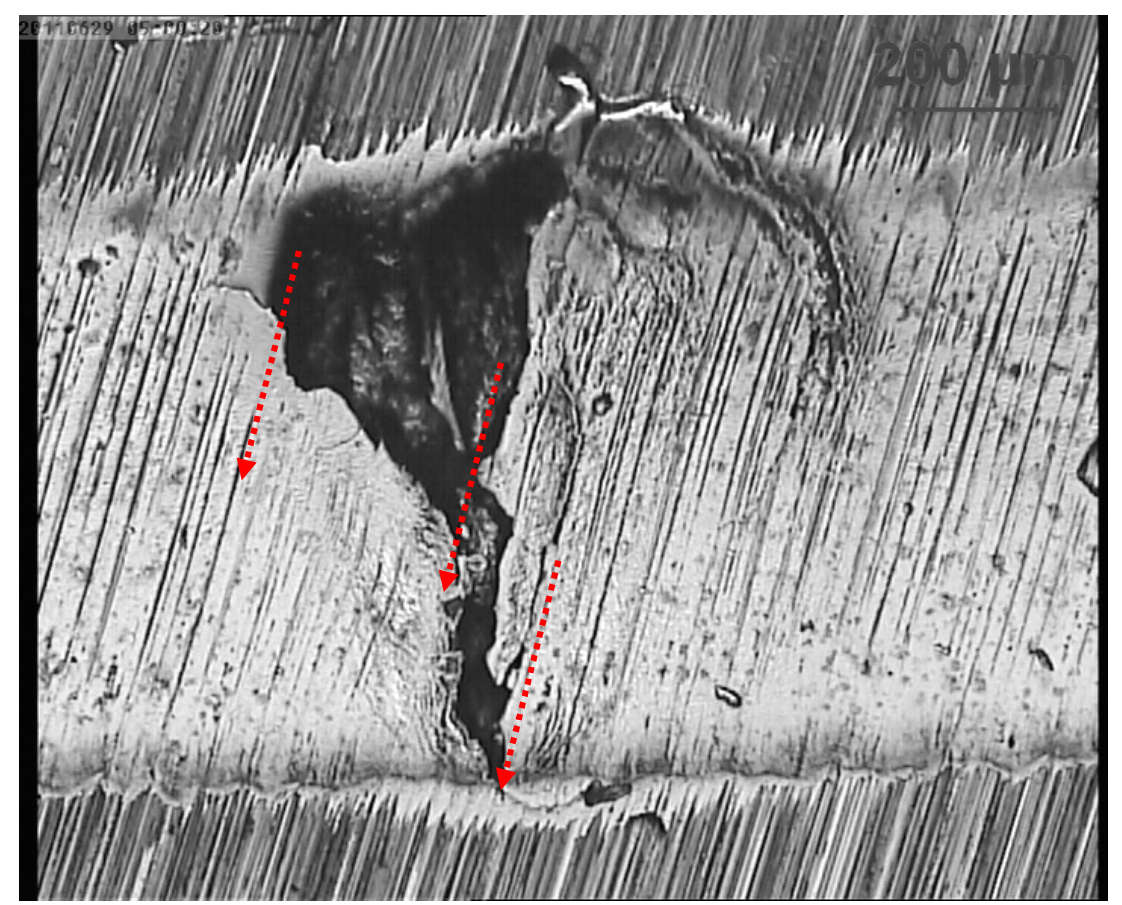

Figura 5.52. Imagem da superficie do corpo de prova No 6 (SR) $\mathrm{v}_{\mathrm{c}} 54 \mathrm{~m} / \mathrm{s}, \mathrm{v}_{\mathrm{p}} 4 \mathrm{~m} / \mathrm{min}$, $\mathrm{a}_{\mathrm{e}}$ 0,03 mm). Imagem obtida em MO com aumento de $100 \mathrm{x}$.

Na Figura 5.53 é apresentada a seção transversal de um lascamento que foi gerado na amostra 19, da condição S4, após 19.956 .970 ciclos. Observam-se algumas trincas que partem da superficie da cratera para a subsuperfície. Igualmente, observa-se na Figura 5.54 uma trinca (como indicado pelo quadro vermelho) que provavelmente se originou na superficie e se propagou na 
subsuperficie em direção de uma partícula de segunda-fase, que esta indicada pela seta.

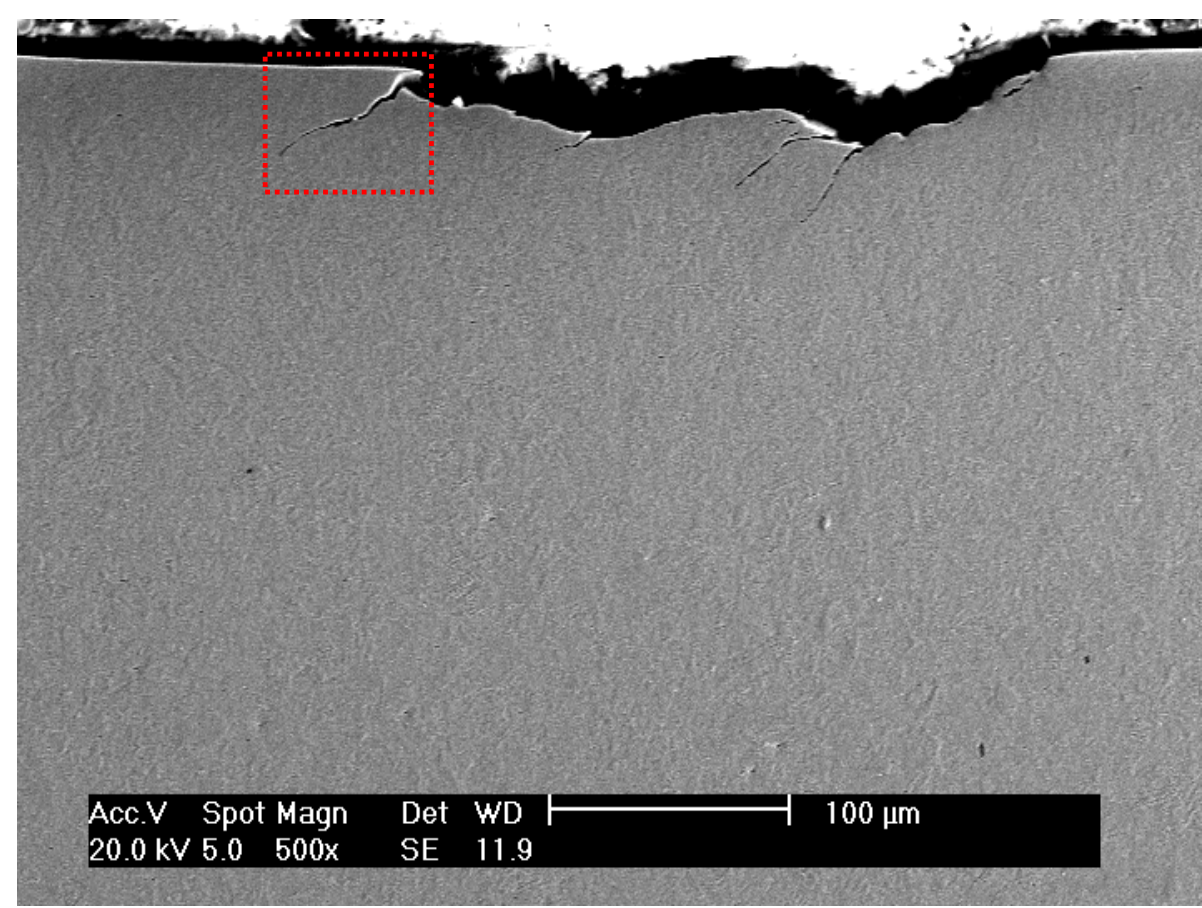

Figura 5.53. Imagem da seção transversal do corpo de prova No 19 , onde se mostra a seção transversal do Lascamento. Imagem obtida em MEV com aumento de 500x. Análise de elétrons secundários
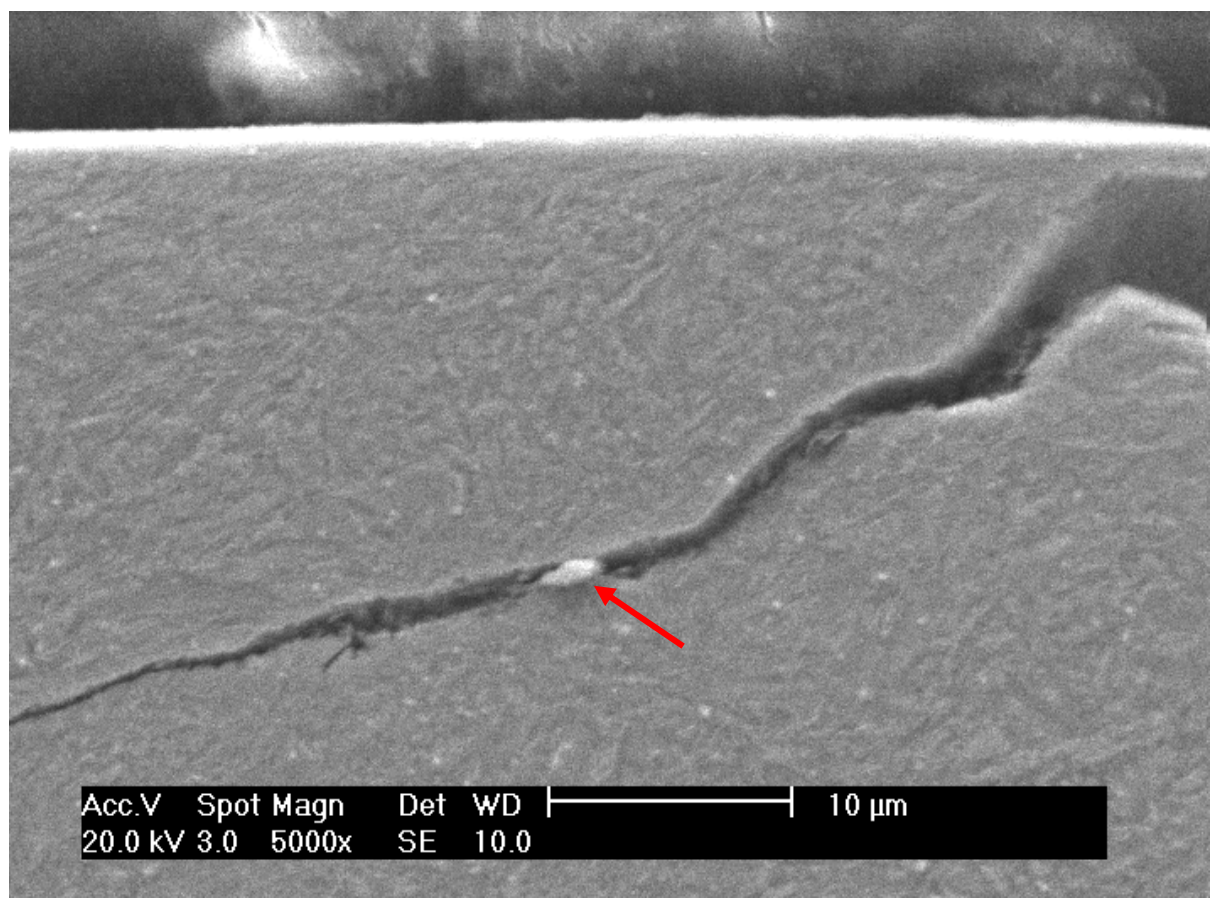

Figura 5.54. Imagem da superfície do corpo de prova No 19T, ampliando um detalhe da Fig. 5.53 onde se mostra nucleação da trinca passando por uma segunda fase. Imagem obtida em MEV com aumento de 5000x. Análise de elétrons secundários

Na Figura 5.55 observa-se a presença de duas trincas localizadas na seção transversal da trilha de rolamento da amostra 19. 


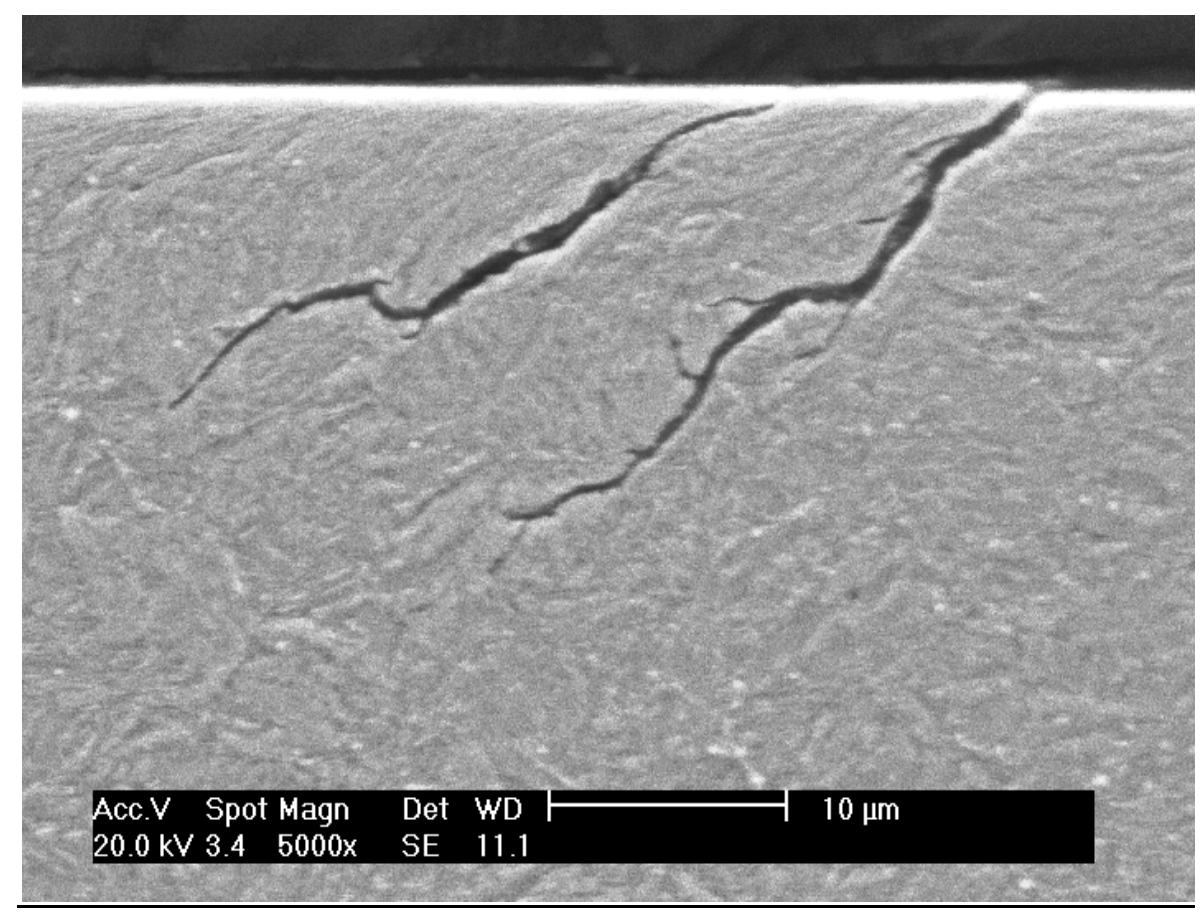

Figura 5.55. Imagem da superficie do corpo de prova No 19 onde se mostra nucleação de duas trincas na seção transversal. Imagem obtida em MEV com aumento de 5000x. Análise de elétrons secundários

Estas trincas estão orientadas no sentido dos contornos gerados pelo rolamento da esfera e movimento de corte da ferramenta. Estas trincas originaram-se próximas da superfície, e se o ensaio de FC tivesse continuado, iam se propagar ainda mais na subsuperficie, desprendendo uma lasca de material alguns ciclos de carregamento depois. 


\section{CONCLUSÕES.}

O estudo realizado permite realizar as seguintes observações com relação ao método adotado e as técnicas utilizadas para a avaliação da integridade superficial em superficies torneadas e retificadas em condições convencionais:

\section{Sobre a topografia:}

- A avaliação da topografia é um primeiro método para conhecer a IS, mas, torna-se limitado quando são geradas mudanças na camada superficial e mesmo sendo uma técnica amplamente difundida e utilizada em diversas aplicações, é uma parte da análise em IS e pouco informa sobre a IS.

- A diminuição gradativa da rugosidade das superficies obtidas pelo processo de torneamento e retificação, durante o carregamento em ensaios de fadiga de contato de rolamento, favorece o desempenho das superficies que possuem uma melhor integridade superficial. Nas superfícies com baixo desempenho tribológico, a topografia acelera a taxa de falha agindo como concentradora de tensão superficial.

\section{Sobre a análise da seção transversal:}

- Nas superficies retificadas em condições convencionais as alterações que ocorrem na superficie não comprometem o desempenho em fadiga de contato de rolamento.

- Com as técnicas empregadas, não foi observado um padrão entre a falha das superficies e as alterações microestruturais das superficies torneadas.

\section{Sobre a dureza:}

- As técnicas para avaliar a dureza são de difícil aplicação ao estudar a IS das superficies torneadas e retificadas em condições convencionais, já que em função da camada superficial apresentar tamanho inferior aos $10 \mu \mathrm{m}$, as indentações nesta região com as técnicas de microdureza são maiores que a camada alterada

- Com a técnica de dureza instrumentada é possivel conseguir cargas menores que geram marcas de indentação na ordem de grandeza dos 
defeitos. Contudo, estas marcas são de dificil observação e precisam ser apoiadas com outras técnicas auxiliares ao equipamento de dureza (MEV) e algoritmos de análise dos dados, que permitam identificar a região onde foi feita a indentação.

\section{Sobre a tensão residual:}

- Reflete os resultados observados na literatura (o avanço é o parâmetro mais importante). Foi observado que quanto maior o avanço gera-se um estado de tensões mais compressivas. Não obstante, as medições realizadas não foram suficientes para inferir sobre o desempenho na totalidade das amostras ensaiadas.

\section{Sobre o ruido magnético de Barkhausen:}

- A técnica permite diferenciar entre superficies geradas por diferentes processos em condições convencionais (torneamento e retificação)

- A técnica é sensivel às diferenças de Integridade de superficies geradas por um mesmo processo (torneamento) com diferentes parâmetros de corte (Velocidade de corte e avanço).

- A técnica de RMB se mostra como um método que possibilita estabelecer relações entre o desempenho de um componente e os parâmetros de processo.

\section{Sobre o teste de desempenho:}

- O mecanismo de falha em FC para as superficies torneadas e retificadas em condições convencionais foi lascamento, produzindo-se cinco tipos diferentes de curvas de desempenho em FC para cada condição testada.

- Para as condições ensaiadas, a velocidade de corte maior favorece o desempenho em fadiga de contato para superficies obtidas por torneamento em condições convencionais.

- Para condições de processo convencionais, as características da topografia e da integridade das superficies geradas pelo processo de retificação favorecem o desempenho em fadiga de contato quando comparado com o comportamento apresentado pelas superficies torneadas. 
Como comentário final, uma das conclusões importantes desse trabalho é que a avaliação da IS dever ser feita utilizando técnicas complementares. Dependendo das características da superficie uma ou outra técnica torna-se mais relevante na análise. Portanto, o trabalho desenvolvido mostrou uma metodologia, utilizando técnicas complementares e a importância de cada uma na análise feita. A técnica de RMB, que tem sido utilizada desde um passado recente foi importante na avaliação das superficies. 


\section{SUGESTÕES PARA NOVOS TRABALHOS.}

- Comparar os dois métodos de processo (retificação e torneamento) empregando ferramentas de CBN nas superficies torneadas.

- Comparar os dois métodos de processo usando HSM nas superfícies torneadas.

- Estender o estudo para outros processos de geometria definida (fresamento)

- Calibrar a técnica de Barkhausen com medições feitas por difratômetria de raios $\mathrm{X}$ para avaliar tensão residual em superficies usinadas a partir de RMB.

- Utilizar outras técnicas de processamento dos sinais de ruído magnético de Barkhausen que permitam melhorar as análises dos dados experimentais.

- Realizar um planejamento estatístico completo para realizar um modelo experimental que correlacione os dados de processo com o RMB. 


\section{REFERÊNCIAS BIBLIOGRÁFICAS}

ABNT, Associação Brasileira de Normas Técnicas. NBR 6162, "Movimentos e Relações Geométricas na Usinagem dos Metais Terminologia”. 1989.

ABNT, Associação Brasileira de Normas Técnicas. NBR 6742, "Utilização da distribuição de Weibull para interpretação de ensaios de durabilidade por fadiga - Procedimento". 1987.

AGHA, S.R.; LIU, R. Experimental study on the performance of superfinish hard turned surfaces in rolling contact. Wear, v244, p. 5259, 2000.

ALTINTAS, Y. Manufacturing automation: metal cutting mechanics, machine tool vibrations and CNC design. Cambridge University Press. 2000, 283p.

ALVAREZ, J.F. Avaliação da integridade da superficie no torneamento de um ferro fundido nodular com carboneto. Dissertação (Mestrado) Escola Politécnica da Universidade de São Paulo. Departamento de Engenharia Mecânica. São Paulo, 2006. 138p.

ALVAREZ, J.F.; FRANCO, E.E; MACHADO, I.F; SINATORA, A. Instrumentação do equipamento para ensaios de fadiga de contato de rolamento do laboratório de fenômenos de superfície da EPUSP. In: V Congresso Nacional de Engenharia Mecânica - CONEM, 2008, Salvador - BA. Anais do V Congresso Nacional de Engenharia Mecânica, 2008. p. 1400 .

ANSI B.46.1-1978. "Surface Texture". 1978.

ASM. ASM Handbook Volume 19: Fatigue and fracture, ASM International, 1996. 1057p.

ASTAKHOV, V.P. Surface Integrity - Definition and Importance in Functional Performance. Surface Integrity in Machining. SpringerVerlag London Limited, 2009.

ASTHANA, P. Micro-and Nano-Scale Experimental Approach to Surface Engineering Metals, in Mechanical Engineering. 2006, Texas A\&M University: College Station, TX. 131p.

BAYER, R.G. MECHANICAL WEAR PREDICTION AND PREVENTION. New York: Marcel Dekker, 1994, 657 p.

BERNS, H; FRANCO, S.D. Caracterização in SITU de propriedades mecânicas de materiais resistentes ao desgaste abrasivo usando o método da indentação. Cerâmica Vol 43, No. 2, p81-282. 1997 
BHUSHAN, B. INTRODUCTION TO TRIBOLOGY. New York: John Wiley \& Sons, 2002. 732p.

BOOTHROYD, G.; KNIGHT, W.A. Fundamentals of machining and machine tools, New York: Marcel Dekker, 1989.

BRINKSMEIER, E. State-of-the-art of non-destructive measurement of sub-surface material properties and damages Precision Engineering, v.11, n 4; p. 211-224, 1989.

CHOI, Y; LIU, C.R. Rolling contact fatigue life of finish hard machined surfaces Part1. Model develompent. Wear 261. 485-491p. 2006.

CHOI, Y; LIU, C.R. Rolling contact fatigue life of finish hard machined surfaces Part2. Experimental verification. Wear 261. 492-499p. 2006.

CHOU, Y.K.; EVANS, C.J. White layers and thermal modelling of hard turned surfaces. International Journal of Machine Tools and Manufacture, v.39, p. 1863-1881. 1999

DEGARMO, E.P.; BLACK, J.T.; KOSHER, R.A. Materials and Processes in Manufacturing. Wiley Edition. 10th Edition. 2003. 1032p.

DELIJAICOV, S. Modelagem das tensões residuais no processo de torneamento duro de um aço $100 \mathrm{CrMn} 6$ e suas correlações com os esforços de corte, 183 p., Tese (Doutorado), Departamento de engenharia Mecânica, Escola Politécnica da USP, Universidade de São Paulo, São Paulo, 2004.

DINIZ, A.E.; MARCONDES, F.C.; LEMOS, N.C. TECNOLOGIA DA USINAGEM DOS MATERIAIS, 6.ed. São Paulo: Editora Artliber Editora ltda., 2008. 262p.

DOWSON, D., HIGGINSON, G. R. Elasto-hydrodynamic lubrication (SI edition). Oxford: Pergamon Press Ltd., 1977. 235p.

FARIAS, A.D. Análise da tensão residual e integridade superficial no processo de torneamento em material endurecido do aço ABNT 8620 cementado, 191 p., Dissertação (Mestrado), Departamento de engenharia Mecâtronica e de Sistemas Mecânicos, Escola Politécnica da USP, Universidade de São Paulo, São Paulo, 2009.

FARÍAS, M.C. Influência da velocidade de deslizamento, da carga normal e da transformação martensitica induzida por deformação plástica na resistência ao desgaste por deslizamento dos aços inoxidáveis austeníticos. Tese (Doutorado), Universidade de São Paulo, São Paulo, 173 p. 2004

FERRARESI, D. FUNDAMENTOS DA USINAGEM DOS METAIS. São Paulo: Editora Edgar Blücher. 1970. 751p. 
FIELD, M.; KAHLES, J. F.; KOSTER, W. P. Surface finish and surface integrity. In: ASM Handbook. Machining. v.16. p. 19-36, 1989.

FIELD, M.; KAHLES, J.F. Review of surface integrity of machined components, Annals of the CIRP, v. 20/2, p. 153 - 163, 1971.

FIELD, M.; KAHLES, J.F. The surface integrity of machined and ground high strength steels. Defense Metals Formation Centre Report, DIMC. p. 210. 1964.

FIELD, M.; KAHLES, J.F.; CAMMETT, J. T. A review of measuring methods for surface integrity, Annals of the CIRP, v. 21/2, p. 219-238, 1972.

GAHR, K.-H.Z. MICROSTRUCTURE AND WEAR OF MATERIALS. Amsterdam: Elsevier Scientific Publishing Company, 1987. 560p.

GOCH, G.; SMITH, B.; KARPUSCHEWSKI, B.; GEERKENS, J.; REIGL, M.; SPRONGL, P.; RITTER, R. Review of non-destructive measuring methods for the assessment of surface integrity: a survey of new measuring methods for coatings, layered structures and processed surfaces. Precision Engineering, v.23, n 1, p. 9-33, 1999.

GOHAR, R. ELASTOHYDRODYNAMICS. Ellis Horwood Limited. 1998.

GRIFFITHS, B. Manufacturing surface technology: Surface integrity \& functional performance. London: Penton Press, 237p, 2001.

GRIFFITHS, B. White layer formations at machined surfaces and their relationship to white layer formations at worn surfaces. Transactions of the ASME, Journal Tribology, vol. 7, p. 165-171. 1985.

GRIJALBA, F.A.F. Desenvolvimento de ensaio não destrutivo baseado no ruído magnético de barkhausen para caracterização de tensões elásticas e deformações plásticas em aços / F.A.F. Grijalba. - São Paulo, 2010. 161 p. Tese (Doutorado) - Escola Politécnica da Universidade de São Paulo. Departamento de Engenharia Mecânica.

GUO, Y.B.; WARREN, A.W. The impact of surface integrity by hard turning vs. grinding on fatigue damage mechanism in rolling contact. Surface \& Coatings Technology. 2008.

GUO, Y.B.; WARREN, A.W.; HASHIMOTO, F. The basic relationships between residual stress, white layer, and fatigue life of hard turned and ground surfaces in rolling contact. CIRP journal of manufacturing science and technology 2. 129-134p. 2010

HASHIMOTO, F.; GUO, Y.B.; WARREN, A.W. Surface integrity diferrence between hard turned and ground surfaces and its impact ond fatigue life. Annals of the CIRP, Vol. 55. 2006. 
HIOKI, D. Influência dos parâmetros de corte do fresamento HSM sobre o desempenho tribológico do aço ABNT H13 endurecido. São Paulo, 2006. Tese (Doutorado) - Escola Politécnica da Universidade de São Paulo. Departamento de Engenharia Mecânica.

HORNBOGEN, E. On the microstructure of alloys. Acta Metall, vol. 32, No 5, p. 615-627. 1984

HUTCHINGS, I.M. TRIBOLOGY: FRICTION AND WEAR OF ENGINEERING MATERIALS. London: Edward Arnold, 1992. 273p.

JAKES, J.E.; STONE, D.S. The edge effect in nanoindentation. Philosophical Magazine. Vol. 91, No 7-9. p. 1387-1399. 2011.

JAVIDI, A.; RIEGER, U.; EICHLSEDER, W. The effect of machining on the surface integrity and fatigue life. International Journal of fatigue, 30. p. 2050-2055. 2008.

JOHNSON, K. L. Contact mechanics, 2nd ed. New York: Cambridge University Press, 1985.

JUNEJA, B.L.; SWKHON, G.S. FUNDAMENTALS OF METAL CUTTING AND MACHINE TOOLS. John Wiley \& Sons. New Delhi: Índia, 1987. $462 \mathrm{p}$.

KALPAKJIAN, S.; SCHMID, S.R. Manufacturing Engineering and Technology. $4^{\text {th }}$. edition ed, New Jersey: Prentice-Hall. 2001.

KING, R.B. Elastic analysis of some punch problems for a layered medium. International Journal of Solids and Structures 23, $1987 \mathrm{p}$. $1657-1664$

KOENIG, W. Tecnologia da fabricação: tornear, fresar e furar, v.1, Achen: 1981.

KOENIG, W.; KLOCKE, F. Fertigungsverfahren: Drehen, Frasen, Bohren. Springer - Verlag Berlin Heidelberg. 5. Edição revisada. Band 1. 471 p. 1997

KOENIG, W; BERKTOLD, A; KOCK, K.F. Turning versus grinding: A comparison of surface integrity aspects and attainable accuracies. Annals of the CIRP, v.42, p 39-43. 1993.

KOSTER, W.P. et al. Manufacturing methods for surface integrity of machined structural components. U.S. Air Force Technical Report AFML-TR-71-258. Metcut Research Associates Inc., Cincinnatti, OH. 1972

KRUTH, P.; STEVENS, L.; FROYEN, L.; LAUWERS, B. Study of the white layer af a surface machined by die-sinking electro-discharge machining. Annals of the CIRP, vol. 44, No 1, p. 169-172. 1995. 
KUNDRAK, J.; BANA, V. Microgeometry of bore holes after hard machining. 7hㅡInt. Res. Confer. TMT, Barcelona, Spain. 2003.

LESKOVAR, P.; KOVAC, M. Surface integrity as a quality criterion for fabrication processes, Robotics and computer-integrated manufacturing, v. 4, No. 1/2, p. $253-257,1988$.

LINDGREN, M.; LEPISTO, T. Relation between residual stress and Barkhausen noise in a duplex steel. NDT\&E International, v. 36, p. 279-288. 2003.

LONARDO, P.; LUCCA, D.A.; DE CHIFFRE, L. Emerging trends in surface metrology. Annals of the CIRP, v. 51/2, p.701-723. 2002.

LUCCA, D.A.; BRINKSMEIER, E.; GOCH, G. Progress in Assessing Surface and Subsurface Integrity CIRP Annals - Manufacturing Technology, v.47, n 2, p 669-693, 1998.

LUI, C.R.; MITTAL, S. Optimal pre-stressing the surface of a component by super finish hard turning for maximum fatigue life in rolling contact. Wear, v.219, p. 128-140. 1998.

LUI, C.R.; MITTAL, S. Single step superfinishing hard machining feasibility and feasible cutting conditions. . Robotics and computer integrated manufacturing. v.12, 15-27p. 1996.

MACHINABILITY DATA CENTER. Machining data handbook, Machining data center, v. 2, p. 18-39/18-136, 1980.

MARTINS, C.O.D.; STROHAECKER, T.R.; ROCHA, A.S.; HIRSCH, T.K. Comparação entre técnicas de tensões residuais em anéis de rolamento do aço ABNT 52100. Revista Máteria, v.9, No 1, p. 23-31. 2004.

MATSUMOTO, Y.; BARASH, M.M; LIU, C.R. Effect of hardness on the surface integrity of AISI 4340 steel. Journal of Engineering for Industry, v. 108 , p. 169-175. 1986

MOORTHY V.; SHAW B. A.; HOPKINS P. Surface and subsurface stress evaluation in case-carburised steel using high and low frequency magnetic Barkhausen emission measurements, J. Magn. Magn. Mater. v. 299, 362-375p, 2006.

MORTON, R.K. Topography of surfaces. In: ASM Handbook. Surface engineering. v.5. p. 136-138, 1991.

NEVES, J.C.K. Desenvolvimento de um equipamento para ensaio de fadiga de contato esfera sobre plano e sua aplicação na caracterização de ferros fundidos com matrizes de elevada dureza. Tese Escola Politécnica da Universidade de São Paulo, São Paulo, 2006. 138p. 
NEVES, J.C.K.; LEITE, M.V; SILVA., F.C; SANTOS, C.E.R.; CARVALHO, M.A.; SINTORA, A. Development of an apparatus for rolling contact fatigue tests. Proceedings of International Conference: Abrasion 2005 - Abrasion Wear Resistant Alloyed Cast Iron for Rolling and Pulverizing Mills. Department of Mechanical Engineering, University of São Paulo and Institute for Technological Research - IPT, São Paulo, Brazil, 2005. P. 129-141.

OLIVER, W.C.; PHARR, G.M. An improved technique for determining hardness and elastic modulus using load and sensing indentation experiments. Journal of Materials Research 7, p1564-1583. 1992

OLIVER, W.C.; PHARR, G.M. Measurement of hardness and elastic modulus by instrumented indentation: Advances in understanding and refinements to methodology. Journal of Materials Research 19. p3-20.

PANASYUK, V.V.; DATSYSHYN, O. P.; MARCHENKO, H. P. The crack propagation theory under rolling contact. Engineering Fracture Mechanics Vol. 52, No. 1, pp. 179-191. 1995

POPINCEANU, N.G; DIACONESCU, E; CRETU, S. Critical stresses in rolling contact fatigue, Wear 71.265-282p. 1981.

RABINOWICZ, E. FRICTION AND WEAR OF MATERIALS. Second Edition. New York: John Wiley \& Sons Inc., 1995. p.128.

RECCO, A.; TSCHIPTSCHIN, A. P.; OLIVEIRA, I. C.; MASSI, M.; MACIEL, H. S. Influência da razão entre a dureza e o módulo de elasticidade (H/E) na aderência de revestimentos de $\mathrm{TiN}$ e TiC depositados sobre aço AISI H13. 17 Congresso Brasileiro de Engenharia e Ciência dos Materiais, Foz do Iguaçu. 2006.

RODRIGUEZ, S.A. Modelamento do ensaio de indentação instrumentada usando elementos finitos e análise dimensional - Análise de unicidade, variações experimentais, atrito e geometria e deformações do indentador. 2010. $171 \mathrm{p}$ Tese (Doutorado) - Escola Politécnica da Universidade de São Paulo. Departamento de Engenharia Mecânica. São Paulo. 2010.

RODRÍGUEZ, S.A.; FARIAS, M.C., SOUZA, R.M., Mechanical properties extraction of bulk materials and thin films based on Vickers instrumented indentation tests, Coatings Technology, 205, p.13861392. 2010

SAAVEDRA, P. Análisis de vibraciones de máquinas rotatorias Nivel I. Universidad de Concepción, Chile. 1998

SCHMALTZ, G. TECHNISCHE OBERFLÄCHENKUNDE. Berlin: Springer Verlag, 1936. 
SCHWACH, D.W.; GUO, Y.B. A fundamental study on the impact of surface integrity by hard turning on rolling contact fatigue. Transactions of NAMRI/RI/SME, 33. 541-548p.

SERRATO, R. Análise da Assinatura Mecânica em Mancais de Rolamento de Rolo Cilindrico - Efeitos da viscosidade e da contaminação do óleo lubrificante. Dissertação (Mestrado) - Escola Politécnica da Universidade de São Paulo. Departamento de Engenharia Mecânica. São Paulo. 2006.

SHAW. Metal Cutting Principles. Clarendon, Great Britain. 590 p., 1984.

SOCIETY OF MANUFACTURING ENGINEERS. Tool And Manufacturing Engineers Handbook. 4.ed. Dearborn: SME 1983. v.1.

STACHOWIAK, G. W., BATCHELOR, A. W. Engineering tribology. Boston: Butterworth Heinemann, 2001. 744p.

SURESH, S. Fatigue of Materials. Cambridge: Cambridge University Press, 2nd ed. 1998.

TANDON, N.; CHOUDHURY, A. A review of vibration and acoustic measurement methods for the detection of defects in rolling element bearings. Tribology International, Vol. 32, pp.469-480. 1999

TOENSHOFF, H.K.; ARENDT, C; AMOR, R. Cutting of hardened steel. Annals of the CIRP 49/2. 2000, p. 547-566.

TOENSHOFF, H.K.; WOBKER, H.G.; BRANDT, D. Hard TurningInfluences on the Workpiece Propierties. NAMRI/SME, 23. p. 215-220. 1995.

TORRANCE, A.A. The metalography of worn surfaces and some theories of wear. Wear, vol. 50, p. 169-182. 1978

TOLEDO, G. L., OVAllE, I. J. Estatística Básica. 7. Ed. São Paulo: Atlas, 2008.

TRENT, E.M.; WRIGHT, P.K. Metal cutting, 4.ed., ButterworthHeinemann, 2000.

UEHARA, S. Influência do acabamento superficial no desempenho de bronzinas. Dissertação (Mestrado) - Escola Politécnica da Universidade de São Paulo. Departamento de Engenharia Mecânica. São Paulo, 2005. $143 p$.

VANEGAS, M., ALVAREZ, J.F., DE SOUZA, G.F.M. Teoria da confiabilidade aplicada na avaliação da vida em fadiga de contato. Ingeniare. Revista chilena de ingeniería, v. 17, p. 423-431, 2009. 
WHITEHOUSE, D.J. Surface texture. In: Handbook of surface metrology. v.18. p. 184-190, 1994.

WHITEHOUSE, D.J. Surfaces and their measurement. Hermes Penton Science, London. 394 p., 2004. 